\title{
SISTER ARE YOU OUT OF PLACE ON TOP? INDIGENOUS PERSPECTIVES ON WOMEN IN TOP- MANAGEMENT FROM NEW ZEALAND AND SOUTH AFRICA
}

By

\section{ZANELE THEODORAH NDABA}

\begin{abstract}
A thesis
submitted to the Victoria University of Wellington in fulfilment of the requirements for the degree of Doctor of Philosophy in Management
\end{abstract}

Victoria University of Wellington

2012 


\begin{abstract}
This thesis examines the interactions between issues of race and gender as they affect top-management positions. Specifically, it asks how these issues affect access to top jobs and experiences in those positions for ethnic 'minority' women. In response to this question, I conducted empirical research with Māori and Black indigenous women in two former British settler States, New Zealand and the Republic of South Africa. I investigated issues, lessons and strategies for indigenous women entering top-management roles. I investigated the experiences and perceptions of these women within their own historical and political contexts to interpret my findings.
\end{abstract}

I drew on the management literature which theorises issues of race and gender for women in top-management positions. In the broad context of theorising the interactions of race and gender in top-management, I focused in particular on studies which developed the metaphor of the 'concrete ceiling' to explore the issues facing ethnic 'minority' women trying to reach top-management roles and to succeed in them. To carry out this research in a way that was culturally appropriate, I developed a combination of methodologies, which drew on Māori and African cultural protocols, as well as western paradigms. I explored the experiences of 15 Māori women (10 in the public sector and 5 in the private sector) in New Zealand, and 12 Black women in the private sector in South Africa through qualitative interviews.

My findings added new perspectives to the 'concrete-ceiling' literature, while also confirming some familiar themes. The 'concrete-ceiling' theory focuses on barriers to accessing top positions, but, by contrast, the women in my study were actively recruited. In my findings I discuss how my participants used strategies, such as mentoring, which are familiar in the literature, from new perspectives based on their cultural and political backgrounds. The lives of the women I interviewed were part of a historical and political moment of change in both countries, where political struggles led to new opportunities for indigenous women. These changes included the post-apartheid Broad-Based Economic Programmes (BEE) in South Africa and the ratification of the Treaty of Waitangi 
as well as Government sponsored Equal Employment Opportunities (EEO) programmes in New Zealand. The effects of these policies were that my participants were 'head-hunted' in South Africa and 'shoulder-tapped' in New Zealand without actively seeking new roles. My participants entered their initial top-management roles through these initiatives and they believed that they were perceived as tokens by their organisations, upon initial entry. They encountered familiar 'concrete-ceiling' challenges based on negative stereotyping in terms of 'racialised-gender'. But in most cases my participants were able to go beyond token positions to become genuinely influential as top managers.

My project contributes primarily to studies focusing on ethnic 'minority' women in top-management. The existing literature is based mainly on studies conducted in the United States of America and Europe. These studies therefore embed historical and political contexts of issues such as slavery and migration, present in these countries. In contrast, by studying indigenous women in Settler States, my project provides different perspectives and also highlights the importance of local context for any such research. 
To my research participants 


\section{Acknowledgements}

This project has been a good learning process for me at both personal and professional levels. I could not have achieved this learning without people who assisted me throughout the journey.

To start, I would like to thank God, my spiritual guides and ancestors for guiding, protecting, and giving me the strength to complete this thesis. I thank you Mwelase for making contact and communicating with me in dreams and through myself.

I would like to say thank you to my supervisors. I am very grateful to my primary supervisor, Assoc Prof Deborah Jones, for inspiring and helping me to complete this project. I would also like to thank my secondary supervisor, Dr Todd Bridgman, for guiding me. I have learnt a lot from both of you. I appreciate your knowledge and wisdom.

I am very grateful to my parents and siblings for supporting me throughout this journey. I thank my parents for their prayers.

I would also like to a big thank you to all my participants for their stories. This project would not have been possible without their involvement. Thank you for welcoming me into your homes and sharing your time with me.

Thank you to the staff at Victoria University of Wellington for assisting me to finish this thesis. In particular, I would like to thank the Victoria Management School (VMS) staff, Sophia Lum, Tricia Lapham, Megan Key, Estela Agudelo, Tania Loughlin and Garry Tansley. Your administrative support made my experience pleasant and welcoming at VMS. Kamy Ooi, thank you for your patience. I would also like to thank Student Learning Support Service. Ms Aroha Mead, I appreciate your words of encouragement. Also, thank you to Dr Sarah Proctor-Thomson for your advice at the initial stages of this project. 
I am grateful to my friends in the Wellington community. I would like to thank John (pseudonym), Jane (pseudonym), and Jo-anne (pseudonym) in the Māori community for providing me with support. Thanks for helping me find my research participants. I appreciate your guidance about the Māori culture. I would also like to thank James (pseudonym), John (pseudonym), Peter (pseudonym), and Mary (pseudonym) in the African community. Thanks for your humour, support, and 'hammering common sense into my head'.

I thank my $\mathrm{PhD}$ colleagues for their support. Best wishes to Lois Parkes, June Longjit, Jorge Velez, Wayne Pihema, Garoon Pongsart, Guillaume Rosquin, Heike Schänzel, Dung Tran, Marian Evans, Huong Nguyen, Cesar Guala, Rebecca Bednarek, Maree Foley, Mary Ashby, Ainie Aluwi, Saurabh Jain, Dimu Ehalaiye, Bruce Edman, Suze Wilson, Terry Bowe, Nam Le, and Simon Scott. Thanks for providing a positive social environment. 


\section{TABLE OF CONTENTS}

\section{CHAPTER ONE}

\section{INTRODUCTION}

Definition of 'Minority' in my study 2

Numerical statistical minority 2

Socio-economic minority 2

Minority in the women in management literature 3

Background 4

$\begin{array}{ll}\text { Locating myself in the research } & 7\end{array}$

Definition of terms 10

Theorising race, gender and management 11

$\begin{array}{ll}\text { Research methodology } & 14\end{array}$

$\begin{array}{ll}\text { Summary of findings } & 17\end{array}$

$\begin{array}{ll}\text { Research contribution } & 19\end{array}$

$\begin{array}{ll}\text { Structure of the document } & 20\end{array}$ 


\section{CHAPTER TWO}

HISTORICAL-POLITICAL BACKGROUND: NEW ZEALAND AND SOUTH AFRICA

'Indigenous' status in New Zealand/Aotearoa and the Republic of 26

South Africa/uMzansi Afrika

Context of New Zealand/Aotearoa and the Republic of South

Africa/uMzansi Afrika

The British colonisation period

The Republic of South Africa/uMzansi Afrika

New Zealand/Aotearoa

The political activism period

The Republic of South Africa/uMzansi Afrika 32

New Zealand/Aotearoa 34

The positive changes period 36

The Republic of South Africa/uMzansi Afrika 36

New Zealand/Aotearoa 38

Labour Legislation: Comparison of New Zealand/Aotearoa and the

Republic of South Africa/uMzansi Afrika

African women and the current legislation in the workplace

Màori women and the current labour legislation in the workplace

EEO Policy - New Zealand/Aotearoa

Private and public sector differences for indigenous women

Overview of Māori women statistics

The status of Māori women in the public and private sectors

Overview statistics of African women

The status of African women in the public and private sectors 


\section{CHAPTER THREE}

\section{THEORISING ETHNIC MINORITY WOMEN IN TOP-MANAGEMENT: 'RACIALISED-GENDER' AND THE 'CONCRETE-CEILING'}

$\begin{array}{ll}\text { The 'concrete-ceiling' concept } & 79\end{array}$

International literature on the social, organisational and attitudinal $\quad 84$

'barriers' for women entering top-management

Social 'barriers' 85

Organisational 'barriers'

Race and gender attitudinal 'barriers' 87

Self-selection 'barriers' 91

'Barriers' focusing on studies in New Zealand/Aotearoa and the 91

Republic of South Africa/uMzansi Afrika

'Strategies' for top-management entry $\quad 94$

The development of people skills $\quad 94$

Mentors 95

'Biculturalism' 98

$\begin{array}{ll}\text { Conclusion } & 100\end{array}$ 


\section{CHAPTER FOUR}

\section{INDIGENOUS AND WESTERN PERSPECTIVES}

Reasons for choosing a combination of methodologies 103

$\begin{array}{ll}\text { Research questions } & 106\end{array}$

$\begin{array}{ll}\text { Indigenous and cross-cultural methodologies } & 109\end{array}$

Insider/outsider perspectives in my research 109

Cross-cultural research 111

Māori and non-Māori research 112

Research in a Kaupapa Māori framework $\quad 114$

Ethics of researching across cultures $\quad 116$

Research in an Afrocentric framework $\quad 119$

$\begin{array}{ll}\text { Interpretive approaches } & 121\end{array}$

My role as a researcher $\quad 124$

$\begin{array}{ll}\text { Philosophical assumptions } & 125\end{array}$

$\begin{array}{ll}\text { What I did } & 128\end{array}$

A Pilot study 128

$\begin{array}{ll}\text { Interviews } & 129\end{array}$

My experiences of the interviews 132

Sample identification: Snowball sampling 134

Characteristics of sample $\quad 138$

Data analysis 141

Accuracy and truthfulness of data 142

Data coding 144

$\begin{array}{ll}\text { Conclusion } & 154\end{array}$ 


\section{CHAPTER 5}

POSITIVE POLICIES FOR INDIGENOUS WOMEN FACILITATING TOP-MANAGEMENT ENTRY

Government policies to enhance opportunities for Indigenous women 157

Māori Women 158

African Women 159

Shoulder-tapping / Head-hunting activities for the participants 160

Māori women 161

African women 163

$\begin{array}{ll}\text { Initial appointments } & 165\end{array}$

Visible projects facilitating entry into top roles 167

Pioneering work 169

$\begin{array}{ll}\text { First face of change } & 171\end{array}$

$\begin{array}{ll}\text { Conclusion } & 173\end{array}$ 


\section{CHAPTER 6}

\section{MENTORSHIP AS A COLLECTIVE STRATEGY}

Cultural issues in informal mentoring 176

$\begin{array}{ll}\text { Informal group peer mentoring } & 179\end{array}$

$\begin{array}{ll}\text { One-on-one informal mentoring } & 184\end{array}$

$\begin{array}{ll}\text { Cross gender in one-on-one informal mentoring } & 187\end{array}$

$\begin{array}{ll}\text { Same gender in one-on-one mentoring } & 189\end{array}$

Indigenous women in one-on-one informal mentoring 190

Participants reciprocating mentoring support to other

Indigenous people 192

Participants as outsiders and insiders of their organisations 195

$\begin{array}{ll}\text { Conclusion } & 197\end{array}$ 


\section{CHAPTER SEVEN}

\section{PAYING INDIGENOUS WOMEN'S TAX}

'Racialised-gender' 200

Individual strategy to work harder than the $\begin{array}{ll}\text { majority group } & 208\end{array}$

Downplaying race and gender to address 'racialised-gender' as an individual strategy

Alignment with white women as an individual strategy to address 'racialised-gender'

Alignment with indigenous men as an individual strategy to address 'racialised-gender' 216

Paying Indigenous women's tax

'Biculturalism' as an individual strategy to

address 'racialised-gender'

En/gendered 'biculturalism' 


\section{CHAPTER EIGHT}

\section{CONCLUSION}

Methodology 229

A historical-political approach 229

Combination of indigenous and western methodologies 231

Unique data sets 232

Theoretical contribution 233

Theories of race and gender in management 234

Access to top-management jobs 234

Support to succeed in top-management 238

Lessons for other indigenous women 241

Research implications to theory 243

Scope and transferability of the study 246

$\begin{array}{ll}\text { Future research } & 248\end{array}$

$\begin{array}{ll}\text { My personal reflection } & 249\end{array}$

REFERENCES 253

\section{APPENDICES}

APPENDIX A: History and labour law chronologies ii

APPENDIX B: Interview questions xiv

APPENDIX C: $\quad$ Research information sheets $\quad$ xviii

APPENDIX D: Research agreement xxiv

APPENDIX E: $\quad$ Confidentiality agreement (typist) xxvi 


\section{TABLES AND FIGURES}

\section{LIST OF TABLES}

Table 2.1 Racial group as a percentage of the total population in 2006 - New Zealand

Table 2.2 Gender group as a percentage of the total population in 2006 - New Zealand

Table 2.3a The labour force participation rate in September 2011 by race and gender - New Zealand

Table 2.3b Historical labour force participation rate from 2008 to 2010 - New Zealand

Table 2.3c Labour force participation rate per racial group for 2008, 2009 and 2010

Table 2.4a Unemployment rate in September 2011 by race and gender - New Zealand

Table 2.4b Historical unemployment rate per race and gender for the years 2008, 2009, and 2010 - New Zealand

Table 2.4c Unemployment rate per racial group for 2008, 2009 and 2010 - New Zealand

Table 2.5 Representation of the EEO groups (Māori and women) in senior (top three tiers) management over the years in the public sector

Table 2.6 National population distribution percentage (Census 2011) - South Africa

Table 2.7a Labour force participation rate per race and gender in June 2011 - South Africa

Table 2.7b Labour force participation rates from 2002 to 2007 per race and gender - South Africa

Table 2.8a National unemployment rate per gender and race (Census 2011) - South Africa

Table 2.8b Historical unemployment rate per gender and and race - South Africa 
Table 2.9a Changes in employment by occupational group

and gender - South Africa

Table 2.9b Percentage of women in the public sector in 2010 and 2011 - South Africa

Table 2.9c Women of all races combined in the public sector across different levels - South Africa

Table 2.9d Progress on the gender composition in top-management in the public sector (all races included) - South Africa

Table 2.9e Workforce population distribution for top-management for all employers - South Africa

Table 2.9f Women in top-management by race in the private sector (JSE and SOE only) - South Africa

Table $4.1 \quad$ Summary profile of participants

\section{LIST OF FIGURES}

$\begin{array}{lll}\text { Figure 3.1 } & \text { My study focus } & 78\end{array}$

$\begin{array}{lll}\text { Figure 4.1 My analytical steps } & 146\end{array}$

Figure 4.2 An example of a coded interview transcript 147

Figure 4.3 Naming of themes 152

Figure 4.4 An example of analytical steps from data to a theme 153 


\section{CHAPTER ONE}

\section{INTRODUCTION}

In this thesis, I examine the interaction between race and gender in topmanagement. I ask the question: how do gender and race impact on topmanagement ${ }^{1}$ roles? In response to this question, I conducted cross-cultural qualitative research with indigenous women, Māori in New Zealand/Aotearoa and Black in the Republic of South Africa/uMzansi Afrika in these two different countries, which were former British settler States. The individual accounts of these indigenous women in top-management roles, which present their experiences and perceptions, provide my core data. I was interested in studying ethnic minority women, defined later in this chapter, who are in organisations that I believed were the most difficult environments for them because they were a numerical minority in top-management. My political background and identity influenced the design of this study as well as my sample choice, because I wanted to study my own group - Black women. The concept of the 'concreteceiling', which I define later in this chapter and in Chapter Three, has been widely used to theorise race and gender in the management literature. I use the idea to conceptualise my study. This thesis argues that for ethnic minority women in my study, specific historical and political factors show some important differences to the ways that the 'concrete-ceiling' worked in their settings. In addition, culturally specific factors affected how my participants carried out familiar strategies, such as mentorship.

In this chapter, I start by defining the terms 'minority' and 'ethnic minority women'. Thereafter, I state the background to the problem that first interested me, and I introduce the context for my empirical research. I then describe my own location as a researcher, further connecting with my own interests and knowledge of the research problem, and my personal as well as political connections with interviewees. Subsequently, I define key descriptive terms to familiarise the reader with their meanings, and how I use those terms in the

\footnotetext{
${ }^{1}$ I hyphenate the term 'top-management' throughout this thesis because I use it repeatedly in a specific way (see p. 10).
} 
thesis. Thereafter, I provide an overview of my conceptual framework, and discuss how my study developed from it. I then provide a personal discussion of what led to my research approach, and I introduce my insider/outsider perspective, my methodology, and what I did to collect and analyse data. Afterwards, I discuss how I view my thesis as contributing to the literature. I end the chapter by outlining the chapters of this thesis and what I discuss in them.

\section{Definition of 'Minority' in the study}

I define the term 'minority' and how I use this concept in the thesis. I use the term 'minority' in three different ways. Firstly, I refer to a numerical statistical minority. Secondly, I mean a socio-economic position of disadvantage. Thirdly, I use 'minority' in the phrase 'ethnic minority women in management' to refer to the literature guiding my study, termed the 'concrete-ceiling'. In this thesis, I use the term 'minority' to mean the first, or the second, or the third definitions, making it clear throughout the thesis, which is relevant in a given context. I define the first, second and third definitions below.

\section{Numerical statistical minority}

Firstly, I use the term 'minority' to mean a numerical statistical minority. This definition includes racial / and ethnic minorities in terms of demographic statistical numbers. I use this term to mean those groups of individuals who are statistically small in terms of numbers in their communities, countries, organisations and positions of influence, particularly in top-management roles and to discuss issues that they face as numeric minorities. In this thesis document, I use the phrase 'statistical minority' or 'minority in terms of numbers' to refer to this definition of being a numerical statistical minority.

\section{Socio-economic minority}

Secondly, I use the term 'minority' to refer to power differences and social as well as economic positions amongst different groups and social structures in a society and organisations. Minorities under the second definition shall mean individuals, who are positioned as minorities because they are economically and historically disadvantaged, due to the positions that they occupy, which are largely not influential, despite their population numbers in their countries. Other 
researchers (Mukherjee, Mukherjee, \& Godard, 2006) use the term 'minoritised' to discuss this socio-economic position of disadvantage. In this document, I use the term 'ethnic minority' to mean the ethnic groups who are positioned in a socio-economic disadvantage - minoritised - in their countries, despite their population numbers. The phrase 'ethnic minority' without reference to 'statistical minority', 'minority in terms of numbers' or 'numeric minority' shall refer to the second definition of the term 'minority'.

This second definition of 'minority' includes my research subjects, who are indigenous women from the Republic of South Africa/uMzansi Afrika and New Zealand/Aotearoa in top-management roles of predominantly white organisations. African women in the Republic of South Africa/uMzansi Afrika are the majority group in terms of national demographic numbers; however, they largely do not occupy positions of influence, such as top-management roles, as I will explain in Chapter Two of the thesis. They are in a position of a minority (second definition) group - are minoritised - because African women in the Republic of South Africa/uMzansi Afrika largely do not have economic influence (refer to Chapter Two). In addition, I also use the term 'minority' to include Māori women, who largely do not occupy top-management roles, as examples of influential positions (second definition), in New Zealand/Aotearoa. In the thesis, I make it clear which definition of 'minority' refers to my sample, as per definitions one and two of the term 'minority'.

\section{'Minority' in the women in management literature}

Thirdly, in this document, I use the term 'minority' in the phrase 'ethnic minority women in management' to focus on the studies that discuss the metaphor of the 'concrete-ceiling'. This thesis focuses on women whose ethnic groups are in a position of being minoritised (second definition) and tend to be a statistical minority (first definition) in top-management roles of predominately white organisations. I draw my research sample from African women in the Republic of South Africa/uMzansi Afrika and Māori women in New Zealand/Aotearoa, as women who are not represented in large numbers in top-management roles. I explain further in Chapters Two and Three. 


\section{Background}

As I mentioned earlier, I was interested in understanding the practical problem of a limited number of ethnic minority women in top jobs of predominately white organisations, who were in organisations that had major influences. I was curious about those organisations that drove policy issues, were the biggest employers, and had the capacity to implement changes within, as well as having an effect on, the economies of each country. Within such organisations, I studied the perceptions and experiences of women in top-management. I identified the 'strategies' that ethnic minority women, who were already in top-management, had implemented to enhance their opportunities. In addition, I wanted to know what lessons the ethnic minority women in top-management would impart to other ethnic minority women wishing to occupy top-management roles. I also wanted to know what issues ethnic minority women face when trying to access top-management roles. The research findings provide an insight into how ethnic minority women move into top-management positions in influential organisations in New Zealand/Aotearoa and the Republic of South Africa/uMzansi Afrika, highlight issues these women face in these organisations, and describe some of the enablers that facilitate their success.

In New Zealand/Aotearoa and the Republic of South Africa/uMzansi Afrika, the organisations that have influence, capacity to implement changes, and are of interest are in different sectors. In New Zealand/Aotearoa, the public sector is predominantly white in top-management; while in the Republic of South Africa/uMzansi Afrika it is largely Black. In the Republic of South Africa/uMzansi Afrika, the current ruling party is the African National Congress (ANC), which comprises mostly Black members, who constitute the majority members of Government. The private sector in the Republic of South Africa/uMzansi Afrika is largely white in top-management roles, which makes it similar to the public sector in New Zealand/Aotearoa in terms of racial composition. I give statistics in Chapter Two that explain the context and situation of ethnic minority women in these two countries in both public and private sectors because they are the sites from which I mainly draw my samples. 
Women, particularly white women in western countries, have been entering management levels for several decades (Duehr \& Bono, 2006). This change has been facilitated by the historical moments of introducing Equal Employment Opportunities (EEO) or similar policies for women in different parts of the world. However, top-management entry has been a challenge, particularly for ethnic minority women. The lack of access to top-managerial roles for ethnic minority women leads to inequalities in a broader societal context (Gatrell \& Swan, 2008). Their presence in top roles, in my view, is an indication of the economic and social changes for ethnic minority women. This study contributes to the question: how do women get into top-management? It has a particular focus on ethnic minority women from countries that have had a history of a presence of former British rulers, as minority women, in terms of numbers, in top-management roles of predominantly white organisations. To date, there are very few studies that focus on the experiences of indigenous women entering top-management levels.

In my study, I use the term 'indigeneity' to describe my research sample and background to the study. As I started to conceptualise about my study, the concept of indigeneity became important to understand my sample. The understanding of the concept of indigeneity was important because my original and continual interests were two groups of women from countries with a particular history of colonisation of being former British colonial states. Of significance to me is a shared history of colonisation and decolonising processes from New Zealand/Aotearoa and in the Republic of South Africa/uMzansi Afrika, which led to new opportunities for contemporary indigenous women. By indigenous people, I define them using guidelines from the United Nations, to mean those communities, groups of people, or groups of families who were occupants of the land and depended on the land for survival prior to the historical periods of the British colonisers (UN, 2004). In Chapter Two, I elaborate on my definition of indigenous people. These people tended to have their own distinct languages and cultural beliefs. Historically, these groups were disadvantaged in comparison to the dominant group. This study locates my subjects, who are Māori in New Zealand/Aotearoa and Black in the Republic of South 
Africa/uMzansi Afrika women within the local contexts of these countries, which I explain in Chapter Two.

In New Zealand/Aotearoa, the Treaty of Waitangi of 1840 (refer to Chapter Two) positions Māori as the tangata whenua (people of the land). The Treaty of Waitangi is an agreement between the British Crown and Māori chiefs. As tangata whenua, the Treaty asserts the group rights of Māori as indigenous people of New Zealand/Aotearoa. The indigenous people of the Republic of South Africa/uMzansi Afrika are also a group of people who existed in the land before the arrival of the former British rulers and Dutch colonisers. In both countries, indigenous people were colonised by the former British settlers. In the Republic of South Africa/uMzansi Afrika, other European rulers, such as the Dutch, also colonised indigenous people.

In the Republic of South Africa/uMzansi Afrika context, when I use the term indigenous, I define the term to mean people of African descent who were marginalised historically (refer to Chapter Two). These people have African ancestry, cultural practices and languages that are different from those of the former Dutch and British settlers. In the Republic of South Africa/uMzansi Afrika, indigenous people may also be identified as 'Black'. This research will focus on all Black people who are the indigenous group in the Republic of South Africa/uMzansi Afrika. I use the terms 'Black' or 'Africans' interchangeably to refer to people from indigenous groups of the Republic of South Africa/uMzansi Afrika. I discuss African people in the Republic of South Africa/uMzansi Afrika in context and relation to other groups, such as white South Africans. I discuss the interaction of African women in top-management roles in relation to other groups that dominate these roles, such as white males. I discuss and 'unpack' issues that affect the race and gender relationships in top-management structures for Black women who are economically marginalised in the Republic of South Africa/uMzansi Afrika.

In a New Zealand/Aotearoa context, when I use the term 'indigenous', I mean the Māori people. I discuss Māori individuals in relation to other groups in New Zealand/Aotearoa. I use the term 'Māori' to mean any individual who considers 
himself or herself as Māori from the different indigenous communities and descended from the indigenous nations or tribes of New Zealand/Aotearoa. The term Māori denotes the indigenous people of New Zealand/Aotearoa, who bear distinct notions, identities, culture and practices (Ruwhiu \& Wolfgramm, 2005). I discuss the interaction of Māori in relation to Pākehā (white New Zealanders), particularly in top-management-levels.

\section{Locating myself in the research}

At a personal level, gaining knowledge of the issues affecting indigenous women in top-management roles was important for me for several reasons. Growing up as a Black girl in the Republic of South Africa/uMzansi Afrika during the 1970s and 1980s has shaped my understanding of the world in a unique manner. I remember an incident when I was a young girl. My aunt and I were in one of the streets of Johannesburg city. As a five-year-old child, I was innocently jumping up and down and carefree. We were about to cross a traffic light. My aunt gently held my hand and was teaching me how to safely cross at the traffic lights. She pointed out a white man who was standing not too far from us. She then advised me to follow a white man when crossing at a traffic light because cars will not hit him, they will wait for him to pass. So I had to keep pace with him to cross safely. That was one of the first defining moments for me in grappling to understand race and gender realities, or perceived realities, in South African society.

I have been socialised as a Black woman with traditional roles in an African society regarding what constitutes an African woman. These traditional roles were influenced by the Christian religion that I was exposed to from an early age. Concepts such as such as humility, collectivity, looking after others before self, and the different roles between men and women were inculcated in me from a very early age. I was taught how to be a 'good African woman' and 'good wife' to a man. As I grew up, I struggled with some of the concepts that define an African woman within the African and Biblical contexts. Because of my internal conflicts and struggles, from an early age, I wanted to break free from some of my internal conflicts. Conducting the Doctor of Philosophy research study with a focus on interrogating the intersection of both race and gender in management 
was a way for me to question some of the norms, beliefs, practices and traditions regarding both gender and race issues for ethnic minority women in management.

When I first entered the work environment, somehow I expected to practise those African values and ways of doing things. I assumed that there was space for those cultural practices and norms in the workplace in the Republic of South Africa/uMzansi Afrika. I also expected men in the working environment to appreciate those 'good' qualities of being a 'good African woman' I had been prepared for throughout my life. However, the reality was different for me; to function effectively, I had to learn quickly the European norms of performing business in the Republic of South Africa/uMzansi Afrika and abandon my African ways of executing tasks. Obviously, I had not anticipated that, but I managed to adapt to the working culture of the business in that context. At the early stages of my professional life, my career progressed well. Promotion to higher levels was relatively successful and straightforward. As my career progressed, I got to a stage in my career where I felt that my next promotion was not coming as quickly as comments such as 'you are doing great'. I also realised that many of my friends who were also African women were leaving their jobs, either to start their own businesses or to be unemployed. What I never realised was: is the socialisation of African women in the Republic of South Africa/uMzansi Afrika not preparing them for top-management jobs in predominately white organisations, or do these organisations not have space for these women in top-management roles? The answer to this question extends beyond the scope of this project, but the question encouraged me to do my $\mathrm{PhD}$ studies on indigenous women in top-management of predominately white organisations.

I worked for both the public and private sectors. I worked as both a line employee and as a management consultant. During my career as a management consultant, I got an opportunity to work with different organisations, as my clients. I noticed different individuals using different tactics and skills to get ahead in different organisations. As a management consultant and outsider of organisations, I found that different individuals from the respective organisations 
felt comfortable to express their challenges and experiences of their organisations to me. Although their stories were different, they had similar themes. Most of their issues centred around gender, race, power and class. Then I thought and decided that was a good opportunity for me to conduct my $\mathrm{PhD}$ studies and write about issues that I wanted to question for a long time; that is, intersection of gender and race. Based on my working experience and my own observations, some people tended to move to top-management quicker than others. I wanted to understand the experiences of those individuals, particularly indigenous women, and to share their stories.

I came to New Zealand/Aotearoa from the Republic of South Africa/uMzansi Afrika to carry out my $\mathrm{PhD}$ for four reasons. Firstly, I wanted to be supervised by someone who did not have the 'political baggage' of the Republic of South Africa/uMzansi Afrika. I preferred someone who could assist me to examine my research with different eyes, which would hopefully give me a broader framework to examine my research. Secondly, I came to New Zealand/Aotearoa because I wanted to learn from another group of indigenous people, economically and historically disadvantaged women, about how they address the issues raised by my research. This, I hoped, would create a dialogue between the Republic of South Africa/uMzansi Afrika and New Zealand/Aotearoa that would later be a platform for discussion for other researchers interested in this topic in other countries. Thirdly, I wanted to do my $\mathrm{PhD}$ in a country that was able to create space for me to address some of my issues at a practical level. From my eyes in the Republic of South Africa/uMzansi Afrika, New Zealand/Aotearoa was making progress on gender issues; at the time I was deciding on the country in which to conduct my studies, New Zealand/Aotearoa had a woman Prime Minister, Helen Clark. Fourthly, I came to New Zealand/Aotearoa because, like the Republic of South Africa/uMzansi Afrika, it had been colonised by the British. This, I thought, gave it some similarity in history with the Republic of South Africa/uMzansi Afrika. I thought both countries could learn from each other's experiences. For these reasons, I thought New Zealand/Aotearoa would be a good space for my $\mathrm{PhD}$ studies. 


\section{Definition of terms}

This section explains some of the key terms that I use in this document. I introduce them to help the reader follow the discussions in the introduction and later chapters of the thesis.

I use the phrase 'top-management'. I will use it to mean those individuals or structures that are part of the highest decision making body in an organisation. I define 'top-management' as the roles at the Executive Committee (EXCO) level of an organisation. They have titles such as Chief Executive Officer (CEO), Managing Director (MD), Country Director, General Manager, and Senior Manager. They are above the middle management structure, as defined by their organisations. In this thesis, the terms 'top manager', 'top-management' or 'topmanagement roles' refer to someone who occupies one of these levels at EXCO level in an organisation. I use the term 'top-management' to mean those individuals with power to control resources and the strategic direction of the organisation. In this document, I compare the situation of indigenous women in top-management with other individuals, particularly white males, who dominate these roles and tend to control resources of organisations. I engage with the issues of being a top manager while also belonging to an indigenous group.

My research sample in the Republic of South African/uMzansi Afrika is drawn from the private sector (12 participants). 'Private sector' in this document shall mean an organisation that is profit-based and is a company that employs more than 50 people. In New Zealand/Aotearoa, it will include both national and overseas companies that are based there. In the Republic of South Africa/uMzansi Afrika, it will include both the Republic of South African/uMzansi Afrika and overseas corporations based in the Republic of South Africa/uMzansi Afrika that are mainly white owned and managed. In Chapter Two, I will discuss the effects of different organisations, such as the private sector, on the number of indigenous women in top-management roles.

In New Zealand/Aotearoa my research sample is drawn mainly from the public sector (10 participants from the public sector and 5 participants from the private sector). 'Public sector' in this document means the different organs of the State. 
It will mean the different entities that are designed to give service to its citizens. 'Public sector' and the different tiers of government are those organisations that report to the political head, who is a Minister and who, in turn, reports to the Head of State. I use 'public sector' to mean different initiatives that are initiated and/ funded by Governments in either New Zealand/Aotearoa or the Republic of South Africa/uMzansi Afrika.

I also use the term 'race' in this document. I use the term 'race' to mean the social construction and production of performances and behaviours that are created by society and associated with different 'races'. The term 'race' has political, social and ideological connotations and meanings. These connotations and meanings affect attitudes, behaviours and experiences towards the victim. The term 'race' tends to define individuals in a society in terms of the dominant race. The different races are usually defined as the rainbow colours such as Black, yellow, Brown, white, etc. The colours that are associated with the term tend to have salient stereotypical information. I acknowledge the different usage of the terms 'race' and 'ethnicity' in New Zealand/Aotearoa and the Republic of South Africa/uMzansi Afrika. In the Republic of South Africa/uMzansi Afrika, race has been particularly important because of the historical racial classification under the Apartheid system (see Chapter Two for definition). Generally, Black women from the Republic of South Africa/uMzansi Afrika would refer to 'race' instead of 'ethnicity'. On the other hand, in New Zealand/Aotearoa, the maintenance of Māori culture has been one of the issues of political activism. Māori women would use the term 'ethnicity' or 'culture' instead of 'race'. In this document, I use the term 'race' to discuss the social construction of stereotypes towards indigenous and ethnic minority women in management. I take the stand that race is socially constructed, and that it produces different practices and behaviours according to the stereotypes and norms.

\section{Theorising race, gender and management}

In this section, I introduce the theoretical concepts that I use to design my study and to interpret the results. This introduction frames the key ideas used when theorising the intersection between race and gender in top-management. I draw my discussions from the women in management literature and my findings 
contribute to this literature. I discuss the literature in more detail in Chapter Three.

In order to understand the experiences of women in top-management roles, I draw from literature that addresses broad issues affecting women in management. In this literature, it is difficult to separate studies focusing on women entering top-management roles from other levels (such as senior and middle management) because levels of management are defined differently by each study. This literature largely focuses on two types of debates impacting on women entering management roles: 'barriers' and 'strategies' and these guided my study. In this thesis, I use the term 'concrete-ceiling' to mean studies focusing on ethnic minority women within the women in management literature.

To explain the 'barriers' faced by women entering management roles, the women in management literature uses the concept of the 'glass-ceiling'. The idea behind the 'ceiling' is that women reach a certain level, a 'ceiling', in the organisational ladder where they start to face 'barriers' hindering them to progress to upper levels of management. Women start to face challenges because of inequities based on belonging to the female gender (Doherty \& Manfredi, 2010). The idea behind the 'glass-ceiling' is that 'barriers' are 'unseen' and not easily identifiable. The 'glass-ceiling' concept is specific to management roles and relates to women in regard to, how they access these roles and succeed in them. The 'glass-ceiling' concept is primarily based on the research conclusions of studies that draw research samples of white women (Maume, 2004).

Later in my readings, the term 'concrete-ceiling' shaped my understanding of studies focusing on ethnic minority women in management. For ethnic minority women, the 'ceiling' is visible and thick metaphorically because they can often observe their limitations of career progress in organisations. This is because ethnic minority women are often not represented in large numbers in topmanagement of organisations. Studies (Bell \& Nkomo, 2001; Holvino, 2010) within this literature, argue that ethnic minority women in management face 'barriers' that are compounded by race. Because ethnic minority women belong to both race and gender that is lower in status, social position, and economic 
power than white males, their experiences in management are compounded in a complex manner. Their experiences are complex because race and gender are not independent analytical categories that can be simply added together, argues King (1989). Race is 'gendered', and gender is 'racialised' in such a manner that they fuse together to create distinctive experiences and opportunities for all groups (Browne \& Misra, 2003; Essed, 1991). For ethnic minority women, their experiences of gender are rooted in the meaning of their racial and ethnic groups and create a particular experience that is unique (Browne \& Misra, 2003).

Bell and Nkomo (2001) argue that ethnic minority women in management face negative stereotypes that result from feminine traits of their ethnic group. Brigham (1971) defines an ethnic stereotype as a "generalisation made about an ethnic group, concerning a trait attribution, which is considered to be unjustified by an observer" (p. 31). McCauley (1980) contends that a negative stereotype is a source or excuse for social injustice, including racial prejudice and sexism. The challenge with stereotypes is that they imply that traits are inborn for large groups and contain not only description, but evaluation (Brown, 1965). Stereotypes also tamper with women's performance, because stereotypes position groups within their social circumstances, and women respond by being self-protective of their selves and social groups (Steele \& Brown, 1999). In topmanagement, ethnic minority women face stereotypes that are 'locked' in the feminine traits of their ethnic groups; this is termed 'racialised-sexism', according to Bell and Nkomo (2001), and it disadvantages them in performing and succeeding in their roles. The idea behind the metaphor of the 'concreteceiling' is that ethnic minority women in management face negative biases and stereotypes resulting from both race and gender that are interlocked in a unique manner. Within this literature, there are also suggestions on 'strategies' to overcome 'barriers'.

Both the 'glass-ceiling' and 'concrete-ceiling' concepts as they are presented in the women in management literature tend to put the responsibility of achieving success, that is 'strategies' for entering top-management roles, on the individual woman. This literature tends to focus on the idea of a woman having the personal characteristics, and to have her own skills and abilities, to attain top- 
management roles. Her success is largely attributed to her sole ability to manoeuvre in top-management in breaking through the 'concrete-ceiling'. As an individual she breaks through the 'concrete-ceiling' and is solely accountable for her own achievement. This literature ignores the role of political and social influences to assist the individual woman in achieving top-management roles.

\section{Research methodology}

My overall research question for this project is: how do gender and race impact on top-management roles? The research sub-questions are: what issues do indigenous women face when they move into top-management roles? What strategies do indigenous women implement to enhance the opportunities to advance into top-management roles? What do indigenous women believe are the lessons for other indigenous women entering or wishing to enter topmanagement roles? I discuss the origin of my research questions, research design, and methodology in Chapter Four, Methodology Chapter.

My research questions changed after I had started the research interviews. As per 'concrete-ceiling' studies, there are 'barriers' for ethnic minority women in management positions. At the initial stages of my project, I expected my participants to indicate many challenges in entering top-management roles. My initial research sub-question was: what barriers do indigenous women face when they move into top-management roles? During the interviews, the participants emphasised successes rather than barriers. This was contrary to what I had expected. I then realised that my participants had been actively recruited to occupy their current roles. Their skills were in demand in the job markets in both New Zealand/Aotearoa and the Republic of South Africa/uMzansi Afrika. I then changed my sub-question to: what issues do indigenous women face when they move into top-management roles? This wider question did not assume 'barriers', but opened up to a wider set of issues, impacting on them in top-management roles.

This study is cross-cultural in nature, but I do not intend to make cultural differences a focus of this research. It investigates two groups of indigenous women in top-management located in two different countries: New 
Zealand/Aotearoa and the Republic of South Africa/uMzansi Afrika. There are hardly any studies that focus on two groups of indigenous women in management from different countries, in the women in management literature. My study is also cross-cultural because I am conducting research on a group that is different, yet similar to my own - indigenous, but not Māori, in a different country. A lot of cross-cultural research tends to be based on American research samples and interests, as well as being published in American journals (Jack \& Westwood, 2009). The extent of generalisation to other countries becomes questionable, according to Adler (1983). This is because most cross-cultural research tends to promote western values, mostly American, argues Adler (1983). This study also applies the master narratives of the 'concrete-ceiling' theoretical metaphor, which are largely based on research conclusions from samples drawn from the USA and UK, and apply the concept in a different context (ethnic minority women in New Zealand/Aotearoa and the Republic of South Africa/uMzansi Afrika). However, my study affirms indigenous women by conceptualising the understanding and perceptions of their experiences within their own sense making of the world, that is, indigenous methodologies.

I am both an insider and outsider to my participants and research. In the Republic of South Africa/uMzansi Afrika, I am an insider to my participants because I study my own group, indigenous women. In New Zealand/Aotearoa, I am both an insider and outsider to my participants. My indigenous identity makes me an insider to Māori. However, my country of origin makes me an outsider to Māori and New Zealand/Aotearoa. In this research, I am both an insider and outsider negotiating my space as an indigenous woman and academic researcher to an insider community discussing western concepts, values and principles. I am an insider in studies focusing on women in management as an academic writer focusing in this area. On the other hand, I am an outsider because I do not fully subscribe to the western values and principles present in this literature. In this study, I negotiate my insider and outsider status at different levels and manage the complexities thereof.

In this study, I use a combination of western and indigenous worldviews of understanding the world. I make my research accountable to indigenous women 
in top-management by incorporating the manner in which they live their lives and make sense of their worlds in both their white and indigenous worlds. The participants understood their experiences through their socialisation as a collective in their communities as indigenous women. However, in the corporate setting, they also made sense of their lives by articulating western values that promoted individualism. One research approach would not be sufficient to fully capture, articulate and understand as well as interpret their experiences, as they make sense of their lives in both communal and individualistic values. My participants' understanding of the world moved between western and indigenous perspectives. Their understanding of the world was in two different paradigms: western and indigenous. Failure to include indigenous epistemologies that are embedded in the way of life of indigenous people would be to perpetuate the exclusion of majority indigenous people and to reinforce the knowledge only to the few - white western scholars and the paradigms thereof. This position would encourage the majority of indigenous women to remain the 'other women' in management studies focusing on women in a management position.

My thesis also contributes to research methodology in management studies by combining western and indigenous methodologies. Most research studies focus only on western methodological paradigms. Contrary to these studies, my research design integrates both western and indigenous values. I use an interpretive approach drawn from western methodological traditions. The indigenous epistemologies were the Kaupapa Māori in New Zealand/Aotearoa and Afrocentric paradigm in the Republic of South Africa/uMzansi Afrika. The Kaupapa Māori framework is the concept of Māori people finding space for themselves within the research arena, argues Smith (2005). This concept was originally brought to light in dissuading mainly white researchers from continuing to use Māori as research objects and Māori not benefiting from the research studies. The Kaupapa Māori framework empowers Māori to improve their lives. In Chapter Four, I will explain the Kaupapa Māori framework for my study. The Afrocentric framework is rooted in the cultural lives of people of African descent (Karenga, 1988). It also addresses the needs of African people (Alkebulan, 2007). I also discuss in Chapter Four the details of my indigenous and western methodologies. These indigenous epistemologies encourage 
indigenous people to take proactive steps in improving their lives. It also persuades researchers to be socially responsible with their research and be accountable to the indigenous people. As part of my responsibility to improve the status of indigenous women in both these countries, in Chapter Eight I will suggest some lessons to impart to other indigenous women to improve their positions in management based on my findings. My research supports both the Māori and African aspirations of bringing forth knowledge about Māori and African women in top-management positions.

\section{Summary of findings}

My participants were in a paradoxical situation of achieving success in entering and moving up in top-management roles, while also encountering challenges once they reached these levels.

My findings place the importance of introducing a political strategy as a mechanism or 'ladder' to uplift ethnic minority women entering top-management roles. My participants reached top-management roles through Governments' initiatives to enhance the opportunities for indigenous women. In New Zealand/Aotearoa, one of the initiatives that enhanced the opportunities for my participants for success was the Waitangi Tribunal. It was set up to address breaches to the Treaty of Waitangi and wrongs to the Māori people (Jones, 2006). The Waitangi Tribunal makes recommendations to the New Zealand/Aotearoa Government on resolving Māori claims (Stokes, 1992). In addition, another initiative that also helped to enhance the opportunities for success for my participants, was the implementation of the Equal Employment Opportunities (EEO) policies applicable in the public sector. The EEO policies were introduced to enhance access to organisational entry, including management roles, for groups such as Māori women. I explain in Chapters Two and Five about these initiatives in New Zealand/Aotearoa. In the Republic of South Africa/uMzansi Afrika, the Government promulgated a series of legislation under the Broad-Based Black Economic Empowerment Act No.53 of 2003 to improve access for indigenous women into organisations, including topmanagement roles. I explain in Chapters Two and Five the exact initiatives of the Republic of South Africa/uMzansi Afrika. The new opportunities were 
created because of liberation struggles of indigenous people in these countries. Although Governments played a role to promote indigenous women, my participants had to have individual skills to take the opportunities presented by their Governments. However, indigenous women in top-management roles of predominantly white organisations are still not many, and I will discuss this in Chapter Two.

As I have explained, I initially expected my participants to articulate lots of barriers impeding them from entering top-management roles. However, my findings indicate that they were in demand for top-management entry in both New Zealand/Aotearoa and the Republic of South Africa/uMzansi Afrika. They were largely encouraged to occupy their current roles. They were not in the job market seeking the roles. They had to be convinced to occupy their current positions in top-management. They were the first wave of indigenous women occupying top-management roles in predominantly white organisations. They were at a point in history where organisations sought their skills for strategic reasons. They were shaping history in their organisations and countries. This was possible because these Governments were adopting positive policies to correct the wrongs to indigenous women at this period in politics. These changes by Governments resulted from the activism of mostly Māori and Africans in these countries. My participants were writing a new chapter in the histories of these countries.

The politics and history of both New Zealand/Aotearoa and the Republic of South Africa/uMzansi Afrika became important to my study. There were similarities and differences between these countries regarding approaches to redress the historical injustices to indigenous people, particularly for women (see Chapter Two). I do not intend to compare New Zealand/Aotearoa and the Republic of South Africa/uMzansi Afrika, as the main objective of my study. However, in examining the experiences and perceptions of indigenous women in top-management roles, I use the local content, that is, the history and politics of these countries, to theorise about my study. I argue that history and politics affect the experiences of women in management in specific ways. 
Once my participants were in top-management roles, they faced similar challenges as per 'concrete-ceiling' where they face 'racialised-sexism' as ethnic minority women (Bell \& Nkomo, 2001), who do not have access to power and resources in their countries. My participants encountered challenges that were based on the unique combination of belonging to two groups (indigenous and female) that are socially and economically disadvantaged compared to white males in their societies. I use the term 'racialised-gender' to discuss this concept. My participants used familiar themes of success, such as mentorship, drawing from their cultural backgrounds.

\section{Research contribution}

This study contributes to the women in management literature, and in particular to studies that focus on ethnic minority women in management. Through my working experience of being a woman in a management position, I had notions of the issues affecting a woman in a management position. As a Master's student in western universities, I became aware of relevant studies focusing on a woman in a management position. My concern with these studies was the absence of indigenous women's voices in shaping this literature. We were, and are still, invisible in these studies (Collins, 1986). This research contributes to the emerging presence of experiences of indigenous women in the top-management discussions, particularly those from countries that have had a presence of British rulers, in the literature concentrating on women in management.

Because of the problems in assuming an undifferentiated and universal category of 'woman', researchers make calls for the inter-sectionality of race and gender effects (Forson, 2006; Gatrell \& Swan, 2008). Research on the combination of both race and gender as dual aspects of identity in organisations has been limited (Holvino, 2010). Most studies in organisations have focused on gender, class or racial inequalities, but rarely as a combination of categories (Acker, 2006). The research arguments between men and women are often 'proposed as binary opposition of identity characteristics and preferences' (Gunew, 1990, p.39). Part of the reason that the experiences of ethnic minority women are not well investigated is that researchers treat this subject as an 'ethnic minority issue that is a matter relevant only to ethnic minority group members' (Cox, 2004, p. 
127). Faculty members of universities cite different reasons to discourage doctoral students from researching issues of race (Cox, 2004). Ethnic minority women are often considered under other headings, that is, women or ethnic minority. Few studies have addressed the combination of race and gender in organisations (Combs, 2003). Those that do address the intersection of race and gender largely ignore indigenous women in management as their research samples.

Many studies focusing on women in management draw their samples from white women (Hite, 2007) in western societies. The term 'woman' is often taken to mean 'white, heterosexual, healthy, and middle class' (Bell, Denton, \& Nkomo, 1993, p. 106). On the other hand, there are a few studies, for example Turner and Shuter (2004), in this literature that draw their samples from ethnic minority women in management. The challenge with these studies that focus on ethnic minority women in management is that they are dominated by African-American women from the USA (Combs, 2003) and Black women from the UK (Forson, 2006). Embedded within these studies are historical contexts reflecting the histories present in these countries. These histories are of being a slave in the USA and a migrant in the UK, which shape current debates and experiences of ethnic minority women in management. There are scant studies that draw research samples from indigenous women in the USA (Muller, 1998). These studies also have an American historical perspective.

Contrary to these studies, my project contributes to ethnic minority women with a different history, outside the USA and UK. This study draws samples from women who have the status of indigeneity in former British settler states. It provides an insight into the way in which the interaction of issues between gender and race are experienced or lived by an indigenous woman in this context. Further, this study focuses on what it means to be an indigenous woman in topmanagement levels of predominantly white organisations.

\section{Structure of the document}

My thesis has eight chapters. In Chapter Two, I discuss the historical and political contexts of the thesis in the Republic of South Africa/uMzansi Afrika 
and New Zealand/Aotearoa as contexts for the study. I argue that the improved status of indigenous women is attributed to the mobilisation of indigenous people, particularly the role of women in political activism. I also contest that history and politics are important to explain the experiences of women in management. I focus on the history, labour law environment, and the status of indigenous women in both the public and the private sectors, in these countries. Chapter Two is also the background to my study and puts the problem of a low number of indigenous women in top-management roles in context of the labour market statistics of different social groups. This chapter shows that my sample represents an elite group in the wider context of ethnic minority women in these countries. I discuss the importance of history, politics and legislation in promoting the current status of indigenous women in top-management roles. Chapter Two locates the experiences of indigenous women in the historical contexts of these countries and explains the reasons for their recently improved status through positive legislation.

In Chapter Three, I explain the conceptual design and theory for my study. In the chapter, I discuss the gaps in the women in management literature. In addition, I elaborate on how this study fills those theoretical gaps in the literature. I also address the problems with assumptions and current theorisation of women in management within this literature. In so doing, I explain the theoretical concepts that I used to answer my research questions, which are both the 'glass-ceiling' and 'concrete-ceiling' metaphors as the ideas guiding my project. I discuss both 'barriers' (for example, organisational practices) and 'strategies' (for example, mentorship) present in these studies of women in management. In this chapter, I discuss concepts in women in management shaping my understanding of the issues faced by ethnic minority women in management.

In Chapter Four, I discuss the research methodology. I outline the methods for my research, along with my reasoning for my methodological choices and decisions. For example, I address issues such as cross-cultural research, the complexities of being an insider/outsider, and my research paradigms. I combine western and Indigenous methodologies. I tease out my reasoning for thematic 
content analysis, and other analysis issues, such as the interpretation of my data. This chapter addresses the research methodological decisions guiding this study in answering my research question.

Chapter Five is the first chapter that presents my findings. It responds to the question: what issues did indigenous women experience when they moved into top-management roles? I will explain that the issues my participants faced were that they were head-hunted in the Republic of South Africa/uMzansi Afrika and shoulder-tapped in New Zealand/Aotearoa. Organisations recruited them for various strategic reasons. Their first role was a token within their organisations. Subsequent roles were those of influence. This chapter discusses how my participants reached top-management roles in these countries.

Chapter Six is the second chapter of my data analysis. It responds to the question: what strategies have indigenous women implemented to enhance the opportunities to advance into top-management roles? Chapter Six discusses how my participants supported themselves in succeeding, once they achieved topmanagement roles. The participants used strategies that were reflective of both the indigenous and western cultures in both countries. The main strategy was to have a mentor in different forms (one-on-one and group). The strength that my participants had in supporting themselves was using mentors in a manner that reflected reciprocity and collectivity, embedded in their cultural values. Drawing from the indigenous cultures in supporting themselves became a strength for my participants.

Chapter Seven is the last chapter of my data analysis. It responds to the question: what do indigenous women believe are the lessons for other indigenous women entering top-management roles? The principal lesson for other indigenous women is to be conscious of their behaviours. They may have to avoid behaviours that reinforce stereotypes, particularly in front of those who tend to be in power, white males. They have to be aware of the challenges of having the identity that is interlocked in both gender and race of being economically marginalised. Chapter Seven discusses the 'concrete-ceiling' challenges that my participants faced in their roles as top-managers in their organisations. 
Chapter Eight is my concluding chapter. I synthesize my findings. I discuss how I have contributed to the women in management literature. I have contributed to the literature by explaining the historical-political context for the women in my study and its wider relevance to studying the experiences of ethnic minority women in management. This approach, I argue, is transferable to other empirical studies. In using indigenous women as my research sample, the findings provided a new perspective from what is understood regarding the 'concreteceiling' concept. My findings affirmed the challenges facing ethnic minority women in top-management resulting from 'racialised-gender'; that is, negative stereotypes that are complex and unique because of belonging to two groups (indigenous and female) that are marginalised in both New Zealand/Aotearoa and the Republic of South Africa/uMzansi Afrika and largely not represented in topmanagement roles. My findings also provided new perspectives on how my participants accessed top-management roles; that is, the role of Government in taking the responsibility to promulgate historical redress legislation and implement policies that provide a 'ladder' for my participants to access top jobs. Also, my participants used familiar themes, such as strategies for success found in the 'concrete-ceiling' studies, differently, drawing from their cultural backgrounds. In Chapter Eight, I also discuss my research methodology as a contribution to management studies, which includes my development of the combination of western and indigenous methodologies as well as cross-cultural research. 


\section{CHAPTER TWO}

\section{HISTORICAL-POLITICAL BACKGROUND: NEW ZEALAND AND SOUTH AFRICA}

In this chapter, I argue that political activism was important in both New Zealand/Aotearoa and the Republic of South Africa/uMzansi Afrika to promote the current status of indigenous women in top-management. I do this by discussing the position of indigenous people and women prior to the arrival of British colonisers and how the economic position of these groups changed soon after the British settlers occupied land in these countries. In New Zealand/Aotearoa, Māori engaged in political activities to re-claim their resources from the British Crown based on their indigenous status and struggled to revive Māori culture and language. In the Republic of South Africa/uMzansi Afrika, political activism was focused on achieving democracy for all those who live in it. It was part of the liberation struggles of indigenous people from the oppressive policies. In both these countries, women played a very important role to improve the conditions of women by influencing policies and legislation.

In this chapter, I discuss the effects of colonisation and de-colonisation processes on both New Zealand/Aotearoa and the Republic of South Africa/uMzansi Afrika. I argue that the political and social contexts of my study are important. This is because the indigenous status is important in the histories and politics of both New Zealand/Aotearoa and the Republic of South Africa/uMzansi Afrika to understand the contexts from which I draw my participants. Indigenous status is noteworthy because it contextualises the perceptions and experiences of my participants in top-management roles of organisations within the histories and politics of these countries. The histories and politics of these countries are also important because they inform the current policies of both New Zealand/Aotearoa and the Republic of South Africa/uMzansi Afrika regarding the status of indigenous women. They also explain and have relevance to the current situation of indigenous women in both New Zealand/Aotearoa and the Republic of South Africa/uMzansi Afrika. 
In this chapter, I also elaborate on the current status of indigenous women in both countries through the illustration of statistics to show their current position in top-management roles. However, there is still a problem in the structural economies of both the Republic of South Africa/uMzansi Afrika and New Zealand/Aotearoa because the statistics that I present later in this chapter demonstrate that indigenous women are concentrated in lower positions and limited in top-management roles, despite pro-active policies to promote them. The objective of this chapter is to understand the perceptions and experiences of my participants in top-management roles within the histories and politics of New Zealand/Aotearoa and the Republic of South Africa/uMzansi Afrika. It also provides a background to my study.

I came to New Zealand/Aotearoa to study a historically and socially disadvantaged group that is an ethnic minority - Māori women in topmanagement - hoping to understand how being an ethnic minority intersected with gender into top-management roles. Being a Black woman from the Republic of South Africa/uMzansi Afrika, I understood the Government strategy in addressing issues affecting historically and socially disadvantaged women in top-management. However, I wanted to understand the situation of being an ethnic minority that is historically and socially disadvantaged in another country that has some similar characteristics to the Republic of South Africa/uMzansi Afrika to understand different issues facing ethnic minority women in different countries.

In the next section, I discuss indigenous status in both New Zealand/Aotearoa and the Republic of South Africa/uMzansi Afrika. I follow this with a section that discusses New Zealand/Aotearoa and the Republic of South Africa/uMzansi Afrika on a variety of factors, such as history and labour laws. Then I present the differences in both the public and private sectors for indigenous women in both New Zealand/Aotearoa and the Republic of South Africa/uMzansi Afrika. 


\section{'Indigenous' status in New Zealand/Aotearoa and the Republic of South}

Africa/uMzansi Afrika

Indigenous status in my study became important in understanding perceptions and experiences of my participants in top-management roles as indigenous women at this current historical moment in these countries. It also became important because indigenous women played an important role in different historical periods in these countries to advance their economic conditions as indigenous women. I define the concept of indigeneity as I use it in this study.

My definition of indigeneity draws from international guidelines. The United Nations (UN) provides guidelines for nation states on the definition of indigenous people. No definition of indigeneity has been agreed internationally at inter-government level. This is because of the controversy around the construct of indigeneity. The controversy is that in liberal thought, individual rights such as free association and speech are important, rather than group membership serving as a determinant of rights (Roach \& Egan, 2008). Article I of the International Labour Organisation (ILO) Convention No.169 contains a statement of coverage for indigenous people rather than a definition and covers...

...tribal peoples in independent countries whose social, cultural, and economic conditions distinguish them from other sections of the national community and whose status is regulated wholly or partially by their own customs or traditions or by special laws or regulations; peoples in independent countries who are regarded as 'indigenous' on account of their descent from the populations which inhabited the country, or a geographical region to which the country belongs, at the time of conquest or colonisation or the establishment of present state boundaries and who irrespective of their legal status, retain some or all of their own social, economic, cultural and political institutions (UN, 2004). 
Currently at a global level, 'indigenous' largely means those groups of people who were colonised and are still disadvantaged in their own societies, identify with a specific place or region, and whose cultural traditions reflect an inherent environmental orientation (Royal, 2002). Indigeneity is linked to socioeconomic disadvantage, post-colonial marginalisation and cultural difference from the dominant group (Durie, 2008). It is a term applied to a group of people who are facing struggles for political rights, for land, and for a place and space within their societies (Guenther, 2006). Other research contends that the ideology of indigenous people is based on culture and identity (Kuper, 2003). Indigenous people face issues such as cultural and linguistic preservation, land rights, ownership and exploitation of natural resources, political determination and autonomy, environmental degradation and inclusion, poverty, health and discrimination. Each nation state has adopted a different approach to address issues regarding indigenous communities in their own countries (Johnson, 2008) to compensate for their status and economic marginalisation in their countries. These individuals had their own systems of law, culture, relationship with nature and of interaction before they were disrupted by the European colonisation events. These events led them to be disturbed in their living arrangements and marginalised in their countries as well as societies. This history forms the base for most indigenous claims (UN, 2004). The indigenous claims are for the recognition of 'collective' or 'group' rights (Roach \& Egan, 2008). The collective rights are defined through being based on the natural needs and cultural differences (Nair, 2006) of indigenous groups.

I define the concept of indigeneity to refer to the special circumstances of the position of being the 'first' or 'last' occupants of the land prior to the European colonisers in a nation. In both New Zealand/Aotearoa and the Republic of South Africa/uMzansi Afrika, the definition of indigeneity is important because it is associated with claims to 'collective rights'. In the Republic of South Africa/uMzansi Afrika, I define indigeneity as a concept that focuses on the identity of indigenous people with rights and land claims based on the 'first people's' (and 'last people's') status and standing, prior to the arrival of the European colonisers, after generations of oppression by the Apartheid State (Guenther, 2006). In New Zealand/Aotearoa, it is about Māori claiming their 
land and resources' rights emanating from the Treaty of Waitangi agreement (see explanation later in this chapter). The current international definition of indigeneity, which is the centre of my definition, is based on collective rights allowing indigenous people to make claims to their governments.

In the next section, I explain histories and politics of New Zealand/Aotearoa and the Republic of South Africa/uMzansi Afrika.

\section{Context of New Zealand/Aotearoa and the Republic of South Africa/uMzansi Afrika}

In this section, I provide a historical context of what it means to be indigenous as an identity in different historical-political moments in both New Zealand/Aotearoa and the Republic of South Africa/uMzansi Afrika. I also discuss the influence of women in the different historical-political moments in these countries to improve economic legislation and policies to advance themselves in the labour market.

I locate the context of the perceptions and experiences of my participants as being influenced by three significant historical and political moments of New Zealand/Aotearoa and the Republic of South Africa/uMzansi Afrika. I group the historical moments into 'British colonisation', 'political activism' and 'positive changes'. In Appendix A, I include key events of the histories and politics of these countries. Within these three historical moments, the roles and status of indigenous women change because of the politics and policies targeting women and indigenous people within those periods in both New Zealand/Aotearoa and the Republic of South Africa/uMzansi Afrika. In addition, the economic position of indigenous women changes during these historical periods because of the change in Government policies implemented by a political party in power occupying a political office.

In the next section, I discuss the historical periods of British colonisation, political activism, and positive changes of both New Zealand/Aotearoa and the Republic of South Africa/uMzansi Afrika to put context to the perceptions and experiences of indigenous women in top-management. 


\section{The British colonisation period}

The British colonisation period is important in this thesis because it underlies the current reconciliatory politics present in these countries. It signified the beginning of the relationships between the British colonisers and indigenous communities in these countries. In both New Zealand/Aotearoa and the Republic of South Africa/uMzansi Afrika, the British colonisation period is marked as the initial contact with European colonisers. This period was marked by the expansion of the British (and other Europeans in the Republic of South Africa/uMzansi Afrika) nationals who started colonising these countries. It is during this period that indigenous people in both New Zealand/Aotearoa and the Republic of South Africa/uMzansi Afrika were 'disturbed' by the European colonisers in their living arrangements. There were different approaches in which European colonisers migrated into New Zealand/Aotearoa and the Republic of South Africa/uMzansi Afrika to occupy the land, which I explain under New Zealand/Aotearoa and the Republic of South Africa/uMzansi Afrika.

\section{The Republic of South Africa/uMzansi Afrika}

In the Republic of South Africa/uMzansi Afrika, the arrival of European colonisers took place from 1795 to around 1905 (see Appendix A). The influx of European colonisers in the Republic of South Africa/uMzansi Afrika was earlier than in New Zealand/Aotearoa (see British colonisation period for New Zealand/Aotearoa in this chapter). Bartholomeu Dias, a Portuguese navigator, was one of the first Europeans to travel into the Southern part of the Republic of South Africa/uMzansi Afrika. He was followed by the arrival of the Dutch and British migrants. The European colonisers took land forcefully from the 'Bantu' (African) group through a series of wars, such as the battle at Ulundi, during the war between the British and the Zulus (indigenous group) in 1879 (Guy, 1971). There were several other battles fought by the European colonisers with different indigenous groups in the Republic of South Africa/uMzansi Afrika to seize resources from them. This led to many deaths and persecutions of indigenous people, including women. In addition to the British settlers, the Dutch descendants also arrived in the Republic of South Africa/uMzansi Afrika and 
introduced brutal forms of colonisation processes when occupying the land (see the period of political activism in this chapter).

\section{New Zealand/Aotearoa}

The distinctive feature of colonisation of New Zealand/Aotearoa was the central position taken by the Treaty. The British Government mediated the signing of the Treaty. In 1840, Māori chiefs signed an agreement, the Treaty of Waitangi, with the British colonisers, and the contents thereof later became a major focus of disputes (Bess, 2010; Gibbs, 2005; Stokes, 1992). After signing of the Treaty, the British settlers seized land from Māori communities, which resulted in New Zealand/Aotearoa Wars (Statistics New Zealand, 2006). The arrival of the former British settlers was from 1769 to 1852 . One of the first British people to encounter indigenous people was Captain James Cook, a British explorer, while visiting New Zealand/Aotearoa for the first time in 1769 (see Appendix A). This was followed by the arrival of a series of British nationals.

The Treaty of Waitangi is important to Māori as indigenous people, and it acknowledges Māori as 'tangata whenua' (people of the land) (Fitzgerald, 2003, p. 17) and was regarded as a contract between both sovereigns (Māori and the British Crown) (Johnson, 2008). Indigenous people through Māori chiefs signed this agreement (Treaty of Waitangi) to guide the relationship with the British colonisers. The Treaty then and now is contested for various reasons, but is still being used. For example, under the Treaty, Article I addresses issues of sovereignty and there is no consistency between the English and Māori versions of what Māori gave up on control and governance, according to Jones (2006). Generally, the agreement provided the British Government sovereignty over New Zealand/Aotearoa, under the English version (Gibbs, 2005; Stokes, 1992). It grants right of governorship to the Crown and reserves the right to selfdetermination to Māori, that is Māori chiefs, over their land, peoples, and treasured resources (Johnson, 2008). However, the details of governorship and sovereignty are debatable and contestable (Seuffert, 2002; Stokes, 1992). This is because the Treaty document is grammatically clumsy and the words chosen to translate important terms in the Māori and English versions have different meanings (Bess, 2010). The Māori words are more generalised and less precise 
than the English version (Bess, 2010). The Treaty of Waitangi is a document under continual negotiation in modern New Zealand/Aotearoa and continues to guide the relationship between Māori iwi (tribes) and the British Crown. The existence of the Treaty led to later reconciliatory process and compensation that I discuss later in this chapter.

In New Zealand/Aotearoa, British colonisation led to loss of power for Māori women. Prior to the period of British colonisation, there were Māori women who were chiefs and had status for managing a community. Researchers indicate that chiefly Māori women, during this period, exercised political rights and power that were much greater than later in history (Metge, 1990; Ralston, 1993). After the period of British colonisation, Māori women became marginalised economically and politically, as a result of the effects of colonisation.

In summarising the British colonisation period, the key difference between the Republic of South Africa/uMzansi Afrika and New Zealand/Aotearoa was the approach by which the British colonisers occupied the land in these two countries. In the Republic of South Africa/uMzansi Afrika, it was by force through wars and in New Zealand/Aotearoa it was initially by agreement and later, the New Zealand/Aotearoa Wars.

\section{The political activism period}

After the British colonisers arrived in New Zealand/Aotearoa and the Republic of South Africa/uMzansi Afrika, indigenous people in both these countries became disadvantaged culturally, socially and economically. This period is important in these countries because political activism put pressure on Governments to improve economic conditions through legislation for indigenous women. Indigenous people organised and revolted against the colonisers through political activism. The peak of political activism occurred from the mid to late twentieth century in both countries. The influence and structure of political activism was different in both these countries. During this period, the indigenous people in these countries became economically marginalised as the British colonisers were expanding their influence and taking advantage of resources in these countries. 
The Republic of South Africa/uMzansi Afrika

In the Republic of South Africa/uMzansi Afrika, political activism occurred from 1905-1993. In the Republic of South Africa/uMzansi Afrika, the political activism was against resistance of separate development policies called 'Apartheid'. This policy was effective from 1949 to 1990 (Meintjes, 2005).

In the Republic of South Africa/uMzansi Afrika, during this period, Apartheid policies were implemented by the National Government that won the elections in 1948. This was a key influence on the Republic of South African/uMzansi Afrika political and economic histories and had an impact on both race and gender. Apartheid was a policy of separate development for different races Whites, Indians, Coloureds (Mixed-Race) and Africans (Hart \& Padayachee, 2000; Schutte, 2000). Through the Population Registration Act of 1950, No 30, every individual in the Republic of South African/uMzansi Afrika society was classified into these four racial groups (Wing \& Carvalho, 1995). Every aspect of living was racially codified, including the education system, social relationships, income, status, political participation, housing and mobility (Carr \& Human, 1989). Race was also associated with career and economic opportunities (Carr \& Human, 1989) favouring white males. The Apartheid policy created structural changes, favouring white males, for the economy of the country.

Under Apartheid policies, indigenous culture was manipulated to justify inequality and segregation in all areas of life (Enslin, 2001). For example, the Christian National Education Policy of 1948, provided justification for separate and inferior schooling for Blacks, known as 'Bantu' Education (Enslin, 2001) and was later translated into the Black Education Act of 1953, No 47 (Wing \& Carvalho, 1995). There were great disparities in the standards of education provided for white and Black students (Wing \& Carvalho, 1995), which favoured white students. Under this education policy, schooling preserved the cultural identity of the Black community, under the trusteeship of whites because of the 'cultural infancy' of the Africans (Enslin, 2001). 
White South Africans were relatively wealthy, politically powerful, and were associated with the upper class, while the majority of Africans were poor and, working class, with limited political power and economic opportunities (Carr \& Human, 1989). White males occupied skilled, professional and managerial jobs while the majority of Africans were consigned to unskilled, menial tasks (Littrell \& Nkomo, 2005). Another factor affecting women, especially in occupations, was the patriarchal society; females were subordinate to males (Littrell \& Nkomo, 2005), under the Apartheid system. Under this policy, women were considered to be minors (Littrell \& Nkomo, 2005) in terms of the law. Once married, they had to give up full-time employment, and this system also legalised lower rates of remuneration for women (Bezuidenhout, Bischoff, Buhlungu, \& Lewins, 2008). Apartheid was a system of both racial and gender construction. African women experienced their identities as a combination of race and gender in a society that was both patriarchal and racially unjust.

The introduction of Apartheid policies led to the legal discrimination and marginalisation of indigenous people, particularly women. Indigenous people revolted because of the implementation of Apartheid policies. In the Republic of South Africa/uMzansi Afrika, the core argument led by the African National Congress (ANC) movement, a majority liberation political party, was for democratic freedom and equality for all those who lived in the country (ANC, 2011). There were also other political activists and parties such as the Azanian People's Organisation (AZAPO) that promoted philosophies of Black consciousness and liberation, as well as the Pan Africanist Congress (PAC) that promoted the return of the land to the indigenous people (South African History Online, 2012).

In the Republic of South Africa/uMzansi Afrika, the role of women became important during the liberating struggles. They organised to oppose Apartheid policies. As early as 1913, Black women in Bloemfontein protested against the pass laws that restricted their movements in white residential areas (Meintjes, 1996). In addition, on 9 August 1956, about 20,000 women marched to the Union Building in Pretoria, an official seat of the Government that also houses the Office of the President, to oppose the pass laws (Andrews, 2001) and inferior 
'Bantu' education, targeting Africans (Meintjes, 2005). As part of women organising, in 1953, the Federation of South African Women was formed comprising women across trade unions, and political organisations (Goetz, 1998). They drafted a Women's Charter in 1954 and participated in drawing up the Freedom Charter in 1955 (Goetz, 1998). Women played an important role to fight Apartheid policies.

Also, during the national negotiations into democracy and drafting of a new Constitution of the Republic of South Africa/uMzansi Afrika, women's organisations played an important role to ensure that their interests were incorporated into debates about rights into a modern democratic State. For example, a Women's National Coalition (WNC), which comprised more than two million women, was formed across racial and ideological divides to influence the constitution-making process (Meintjes, 2005). They produced a Charter for Women's Effective Equality to integrate the interests of women, which became a blue-print for gender policy direction for a new State (Goetz, 1998; Meintjes, 2005; Wing \& Carvalho, 1995). The Charter has twelve articles that aim to improve the lives of women in different economical, political, social, traditional, and health sectors. The objective of WNC was to participate in national negotiations to include women's interest in democracy, during the transition process into democracy of the country. The organising work of women led to the success of women in the ANC, which was the majority political party leading the democratic processes, to have an agreement of $30 \%$ self-administered women quota on the party list for the 1994 first democratic national elections (Goetz, 1998). After the 1994 national election, a cross-party women's caucus was formed to co-ordinate women's agenda, which was one of the outcomes of the WNC work (Meintjes, 2005). The imperative to change legislation to incorporate women's needs and interests was the work of women mobilising in the ANC.

\section{New Zealand/Aotearoa}

In New Zealand/Aotearoa, I define the peak of political activism from 1853 to 1992. Political activism focused on the Crown's failure to honour the Treaty. During this period, being Māori in New Zealand/Aotearoa was associated with 
cultural, social and economic disadvantage. This was because the Treaty of Waitangi was neglected and not readily acknowledged by the Crown. In addition, the concepts of 'biculturalism' embedded in the Treaty were not promoted. The principles of 'biculturalism' are a partnership between Māori communities and the British Crown (Seuffert, 2002). Māori became marginalised in the economy through failure by the Crown to acknowledge the 'power-sharing' between Māori and the Crown contained in the Treaty. This led to Māori being dissatisfied and led to political activism. They started questioning the Crown about returning resources to Māori. During this period, discourses of 'biculturalism' gained momentum (Seuffert, 2002). Indigenous people wanted the British Crown to embrace principles of 'biculturalism' in Government services. Political activism in New Zealand/Aotearoa focused on achieving recognition of the Treaty, and on maintaining the Māori culture and ensuring its survival.

The role of Māori women was important during the period of 1970 to 1985. Māori women were involved in political activities to influence policies to improve the conditions of women (Walker, 1987). They also organised themselves into groups to promote interests of Māori women and sometimes led political activities (Seuffert, 2002). For example, in the 1950s the Māori Women's Welfare League organisation was formed (Walker, 1984). One of its main initial objectives was to influence Government policy to improve Māori health, child-care and pre-school education (Walker, 1984).

There was a general shift in the position of women in New Zealand/Aotearoa, in general, which was also reflected in politics. Amongst other initiatives to improve the status of women, in 1960s and 1970s, the women's liberation movements assisted to energise a Labour Party by mobilising many women to join the political organisation and demanded that the Party committed to an identifiable presence of women (Curtin, 2008). These women assisted in the formation of the New Zealand/Aotearoa Labour Women's Council, which lobbies on women's policy issues and development within the party (Curtin, 2008). My discussions of these initiatives are not exhaustive, but I provide a picture of the type of activities occurring to promote the position of women, particularly indigenous women. 


\section{The positive changes period}

The latest historical-political phase is that of positive changes. Because of both African and Māori political activism, Governments were beginning to address compensation to indigenous people during this period to redress historical injustices. These Government solutions in both countries created access and opportunities for indigenous women to attain positions of influence. My participants entered top-management roles during this period. It was the historical point of correcting the wrongs of the past resulting from their collective rights as occupants of the land prior to the arrival of the British colonisers. They were the first wave of indigenous women entering top-management roles of predominantly white organisations because of changes in Government policies resulting from political struggles. My participants were at a point in history that began to address the historical injustices for indigenous women.

\section{The Republic of South Africa/uMzansi Afrika}

In the Republic of South Africa/uMzansi Afrika, the beginning of this period of positive changes is marked by the first democratic elections in 1994 where all racial groups, including indigenous people, were eligible to vote.

As a result of resistance movements and women organising, a National Gender Machinery was formed. In the Republic of South Africa/uMzansi Afrika context, National Gender Machinery means the structures within Government and civil society that promote gender equality (Office on the Status of Women, 2006) and improve the social, welfare, and economic conditions of women. It is an institution of the state that promotes women's interests (Goetz, 1998) through policies. These institutional bodies are established to monitor, investigate, review and advise on gender-related practices (Denton \& Vloeberghs, 2002). As part of a National Gender Machinery, amongst others, a Commission of Gender Equality was established in 1997, as an independent body and constituted as one of six state institutions listed in Chapter Nine of the South African Constitution (Geisler, Mokgope, \& Svanemyr, 2009). Its role was to protect, and promote gender equality in the Republic of South African/uMzansi Afrika society (Meintjes, 2005) to ensure that Government and non-statutory bodies implement 
policies that promote the status of women. It also ensures that both the private and public sectors eradicate practices to discriminate against women and promote equality between the female and male genders (Denton \& Vloeberghs, 2002). These institutions create an opportunity through which women may shape the policies that affect them (Seidman, 1999).

The Office of the Status of Women in the Office of the Presidency and in the Office of the Premiers at Provincial levels, under former President Mbeki was established (Geisler, et al., 2009), as part of a National Gender Machinery. Its main objective was to lead the gender mainstreaming activities for women (Meintjes, 2005). In May 2009, a Ministry of Women, Children, Youth and the Disabled was established (Geisler, et al., 2009). In addition, there is a Parliamentary Joint Monitoring Committee on the Improvement of the Quality of Life and Status of Women (Geisler, et al., 2009). There is also a 'women's budget process' which aims to analyse the Government budgets from a gender perspective to ensure that money is allocated to activities, policies and programmes that empower women (Myakayaka-Manzini, 1998). It audits the impact of public spending on women and their programmes (Goetz, 1998). This idea and process has been adopted by the Commonwealth as a pilot study (Myakayaka-Manzini, 1998). In addition to the establishment of the new National Gender Machinery institutions, other existing Government departments were tasked with establishing policies and legislation that promote the status of indigenous women within the respective areas. The challenge with these structures is that they lack 'teeth'. They were largely established for policy advisory and monitoring purposes and do not have mandates to sanction organisations.

The above institutional bodies and political processes that target gender equality and other progressive processes aiming to advance the position of indigenous women, led to the legislative changes during the period of positive changes. An example of positive legislation to correct the historical wrongs of the Apartheid policies is the promulgation of a series of legislation under the Broad-Based Black Economic Empowerment (BEE) Act No.53 of 2003. After the 1994 elections, there were subsequent positive changes towards indigenous people. 
The new legislation began to redress the social, educational and economic inequities experienced by indigenous people under the Apartheid system.

\section{New Zealand/Aotearoa}

In New Zealand/Aotearoa, the period of positive changes started from 1992. The Machinery of Government, which I define as a system or a State funded body that promotes the position of Māori women, was for women the Ministry of Women's Affairs, and for Māori there were the Ministry of Māori Development and the Waitangi Tribunal. The year 1992 marks the period of positive changes because the Ministry of Māori Development (TPK) replacing the Ministry of Māori Affairs and Te Tira Ahu Iwi (the Transition Agency), was established in that year (Bess, 2010). TPK was mandated to advise the Government on how the Government could comply with its obligations under the Treaty and to provide guidance on Treaty claim settlements (Bess, 2010). This Department advises and monitors Māori economic and social developments relating to Māori, particularly Māori women. In addition, Cabinet approved the establishment of the Ministry of Women's Affairs as a separate State Department in 1984 and it became operational in 1986 (Curtin, 2008). The establishment of these Government Departments is attributed to the political mobilisation of women and Māori.

The period of positive changes was also manifested by the first decision of the Crown to return land to Māori iwi (tribe). Because of the breaches to the Treaty of Waitangi by the Crown, the Waitangi Tribunal was established, as part of Government Machinery for Māori, to address issues of debate emanating from breaches of the Treaty. It was formed because of the disappointment of Māori with the failure of the Crown to honour its obligations under the Treaty of Waitangi, according to Jones (2006). The Waitangi Tribunal is a permanent Commission of Inquiry charged with making recommendations in respect of Māori claims against the Crown based on their rights, as indigenous people, under the Treaty of Waitangi. It investigates Māori grievances and makes recommendations to the New Zealand/Aotearoa Government on resolving Māori claims (Stokes, 1992). Māori have been actively making claims to land and resources as well as the assertion of kaitiaki (guardianship) through the Waitangi Tribunal (Johnson, 2008). The Tribunal was empowered to make 
recommendations to the Government with regards to redress to the claims and not to order redress binding on the Government (Seuffert, 2002). Māori claims are many and varied, but work on the principle on redress for loss of language, culture and resources (Stokes, 1992). Through the iwi (Māori tribes) claims and Waitangi Treaty settlements, Māori assets and wealth have been growing. For example, in 2005, Māori assets grew by 83\% (Ministry of Māori Development, 2008). The growth of wealth through the Waitangi Treaty settlements encouraged the establishment of organisations owned by Māori.

\section{Labour Legislation: Comparison of New Zealand/Aotearoa and the Republic of South Africa/uMzansi Afrika}

The National Gender Machineries in both New Zealand/Aotearoa and the Republic of South Africa/uMzansi Afrika, amongst others, created an environment where policies and legislation could be created to advance the position of indigenous women. Changes to the employment laws and policies assisted my participants to penetrate top-management roles. An understanding of the labour laws is important to understanding the legislative and policy frameworks that affected my participants in the workplace. The employment laws and policies impact on my participants' ability to penetrate top-management roles.

\section{African women and the current labour legislation in the workplace}

In the Republic of South Africa/uMzansi Afrika, as a reconciliatory measure of the injustices of the past, several Government-supported initiatives aim to promote the economic status of indigenous women. Recent legislation has been passed to advance the economic status of African women. The Broad-Based Black Economic Empowerment (BEE) Act No.53 of 2003 is an example of the legislation that empowers African women to improve their own economic standing (Republic of South Africa, 2004). It focuses on the change of ownership and management structures of existing and new enterprises (Republic of South Africa, 2004). The Act also has an objective to increase the extent to which Black women own and manage current and new organisations (Republic of South Africa, 2004) by encouraging them to occupy top-management positions in existing organisations. The different tiers of provincial governments 
also have their own BEE strategies and procurement compliance policies. For example, the Gauteng Provincial Government targeted $15 \%$ of their procurement suppliers to be companies that are owned by African females (Big Media South Africa, 2008). It also targeted a representation of $40 \%$ of African women in topmanagement by 2009 (Big Media South Africa, 2008).

I use the Employment Equity Act (EEA) no55 of 1998 and its amendments as an example of part of the BEE legislation that promotes indigenous women to occupy top-management roles. This Act is applicable to all employers and all sectors, except the South African National Defence Force (Department of Labour Republic of South Africa, 1998). Section Six of the EEA prohibits unfair discrimination and section 6 (1) forbids direct and indirect unfair discrimination against individuals on the basis of race, gender, sex, pregnancy, marital status, family responsibility, ethnic or social origin, colour, sexual orientation, age, disability, religion, HIV status, conscience, belief, political opinion, culture, language and birth (Bezuidenhout, et al., 2008). Discrimination is fair only when Affirmative Action measures are taken and consistent with the purpose of this Act' or where a person is excluded or preferred based on 'on an inherent requirement of a job' (Bezuidenhout, et al., 2008, p. 16). The Act focuses on preferential treatment for the previously disadvantaged groups (Department of Labour Republic of South Africa, 1998). It also attempts to eliminate the historical unfair practices in the workplace by advancing the disadvantaged groups (females of all races, Black people, and disability groups) through Affirmative Action (Denton \& Vloeberghs, 2002). This includes removal of barriers for previously disadvantaged individuals entering organisations (Denton \& Vloeberghs, 2002). Removal of barriers includes processes such as guidelines on psychometric assessments, language, interview process, recruitment barriers and an evaluation process (Denton \& Vloeberghs, 2002). Cater (1995) argues that there comes a point where one is responsible for the advancement of one's career. Fischer (1996) debates that Affirmative Action in the Republic of South Africa/uMzansi Afrika empowers all the groups for the development and growth of the country. He further argues that the 'potential' of the previously disadvantaged groups should be a criterion at the selection stage because of the lack of formal education opportunities for African employees. 
Although the Republic of South Africa/uMzansi Afrika Government has introduced positive changes for indigenous women, there are still problems with the implementation of the improved legislation. For example, in the survey conducted by the Commission on Gender Equality (1999), 47\% of the corporations in the private sector did not have a gender policy (Commission on Gender Equality, 1999). This is despite the Employment Equity Act requirements that organisations should include gender equality initiatives as part of the employment equity planning (Commission on Gender Equality, 1999). Those that had a gender policy stated that the overall cultural views of a man and woman (36\%) and racist stereotypes about Black women (24\%) were major internal barriers to implementing the policy (Commission on Gender Equality, 1999). Most organisations in the Republic of South Africa/uMzansi Afrika face attitudinal biases and negative stereotypes towards African women employees. Although Government has extensive bodies and initiatives to improve the status of African women in the workplace, organisations continue to conduct business without addressing issues that may improve the experiences of African women. In the Republic of South Africa/uMzansi Afrika, the Government has been the major driver to promote the economic status of indigenous women, and 1994 was the official end of Apartheid separate race policies. However, effective implementation of these policies and legislation has been a challenge to advance a large number of indigenous women in top-management, as I show by statistics later in this chapter.

\section{Mâori women and the current legislation in the workplace}

The labour laws in New Zealand/Aotearoa affect the working environment for indigenous women and their progression through the ranks in organisations. Over the years, there have been positive changes in the workplace to address issues affecting women and indigenous people.

In New Zealand/Aotearoa, there is no specific law that targets the labour conditions of indigenous women. However, equality in the workplace is addressed by two main pieces of legislation; the Human Rights Act of 1993 and Equal Pay Act of 1972, both are applicable to both the private and public sectors 
(McGregor, Still, \& Dewe, 1996). Article III of the Treaty of Waitangi addresses equality between the Māori people and the former British colonisers, argues Jones (2006). To address Article III, the Human Rights Act of 1983 deals with equality in the workplace amongst all groups and individuals (Pringle \& Olsson, 2002). The Equal Pay Act of 1972 addresses issues of equal remuneration for jobs of equal value amongst individuals. In addition, the Equal Employment Opportunity (EEO) policy in the workplace targets women, Māori, other ethnic minorities and people with disabilities. It is applicable only to the public sector.

\section{EEO Policy - New Zealand/Aotearoa}

The (EEO) issues in the public service are addressed through the State Owned Enterprises Act of 1986 under the 'good employer' principle and the State Sector Act of 1988 (McGregor, et al., 1996). As part of being a 'good employer' all Chief Executives Officers (CEO) in the public service should maintain EEO programmes that are designed to eliminate 'barriers' in employment for ethnic minority groups, women in general, people with disabilities and Māori (Mintrom $\&$ True, 2004). In the private sector, the Government has adopted an approach of non-interference and has not legislated on the EEO concept (Edgar, 2001). The private sector does not have the EEO legislative requirement, and the EEO policies are voluntary. The decision to implement EEO issues is at managerial discretion in the private sector.

The anti-discrimination approach embedded in EEO policy in New Zealand/Aotearoa attempts to incorporate previously excluded or underrepresented groups (including Māori women) into organisations. The antidiscrimination policy encourages equal treatment of both men and women (French, 2001). Under this policy, women, ethnic minorities, Māori and people with disabilities have the right to access employment. This policy focuses on discrimination at the entry of organisations. Once the individual has entered the organisation she/he may encounter subtle organisational barriers.

Researchers argue that equal treatment in the workplace is not sufficient to facilitate access for women entering management roles (Bachi, 2000). Women may encounter 'barriers' to access managerial roles within an organisation, after 
having gained access. They continue to be concentrated in lower-levels in organisations with limited access to management (Still, 1993). Critics of the anti-discrimination approach argue that this approach has limited ability to redress the discriminatory practices in organisations and is universal in its approach (French, 2001). It integrates the previously excluded groups and works on the assumptions that equality of treatment through procedurally fair process ensures equal opportunity of access to benefits within the workplace. The policies ensure equal opportunity of access regardless of the identity differences (French, 2001). This could be problematic because it ignores the different experiences and social advantages that exist in societies and amongst individuals. Equal treatment may disadvantage individuals who are different from the standard or norm. The anti-discrimination policies narrowly focus on specific groups, such as women, indigenous people and people with disabilities, these groups 'fixing' themselves by integrating these people within the dominant patriarchal modes of organisations (Ely \& Meyerson, 2000) to be equal to the 'norm'. The 'norm' tends to be non-gender, non-racist, able-bodied solutions for these groups. Studies suggest that organisations that have not only EEO policies but also proactive measures to remove organisational systematic barriers that have higher numbers of women in management than those with just EEO policies (French, 2001).

However, there are several challenges with the principles embedded in antidiscrimination policies. The EEO policies only redress individual cases of discrimination after they occur (Strachan, Burgess, \& Sullivan, 2004). There are no explicit national standards and penalties for discrimination. One of the challenges is that it places the onus on an individual to lodge a complaint in regard to being discriminated against (Mintrom \& True, 2004). The difficulty with that is that not every individual would lodge a complaint. In addition, organisations tend to have more resources than individuals do. The combination of individuals' lack of resources and red-tape that is associated with the process means that most people would not lodge a formal complaint due to the lack of sufficient resources. Also, it takes courage for a person to lodge a formal complaint, particularly against an organisation. 
Another challenge with the legislation is that there are no Government incentives for organisations for pro-active behaviours, such as monitoring mechanisms, and having an EEO plan as well as policies. Therefore, it is easier for organisations to stick to the businesses of the day than to demonstrate the pro-active behaviours that promote Māori women into top-management levels. There is an extensive literature that addresses the cost and benefit of having EEO initiatives. However, for the scope of this study, I shall not address that literature because it is not central to the focus of this study. The details of the arguments for these approaches are outside the scope of my project. In summary, the business case approach for EEO is based on economics, and organisational and competitive success (Cassell, 1997) to maximise diverse skills in an organisation and retain high quality staff, including women and ethnic minorities. Theoretically, it is debatable whether EEO always makes business sense, as most EEO policies are based on a justice and fairness approach. In New Zealand/Aotearoa, the EEO policies have been actively implemented by the public sector to promote economically disadvantaged groups, such as, women and Māori.

\section{Private and public sector differences for indigenous women}

The objective of this section is to provide overall data on indigenous women in the workforce. The labour force data from each country gives information and background about the proportion of indigenous women able to penetrate topmanagement roles within the historical-political environment. It also provides a comprehensive picture of those indigenous women who are in top-management roles in relation to other social groups in both the public and private sectors. It is important to note that Māori women in New Zealand/Aotearoa are not one of the majority groups. On the other hand, African women from the Republic of South Africa/uMzansi Afrika are the largest group in relation to other social categories. However, both groups are mostly disadvantaged and are minorities, in terms of numbers, in predominantly white organisations, particularly in top-management roles.

In New Zealand/Aotearoa, my participants were from mainly the public sector (10 from the public sector and 5 from the private sector), and in the Republic of South Africa/uMzansi Afrika they were all from the private sector (12 
participants). Being located in Wellington city, the capital of New Zealand/Aotearoa with a presence of Government departments, had advantages for my study. Over the period of my stay in Wellington, I developed a network of Māori women in top-management roles in Government. Therefore, it was convenient for me to locate my participants in the public sector where they were mostly present in top-management and in close proximity to my physical location at Victoria University of Wellington. It also made it easier to locate other indigenous women across the country in the public sector because of connections with my public sector contacts in Wellington. This, in turn, influenced my selection of the participants for this study to be largely from the public sector.

Although I interviewed participants from different sectors contrasting New Zealand/Aotearoa and the Republic of South Africa/uMzansi Afrika, these two sectors have some commonalities in these two countries. In New Zealand/Aotearoa, the public sector is predominantly white in top-management; while in the Republic of South Africa/uMzansi Afrika it is largely Black. In the Republic of South Africa/uMzansi Afrika, the current ruling party is the African National Congress (ANC), which comprises mostly Black members, who constitute the majority members of Government. The private sector in the Republic of South Africa/uMzansi Afrika is largely white in top-management roles, which makes it similar to the public sector in New Zealand/Aotearoa in terms of racial composition. In addition, in New Zealand/Aotearoa, EEO policy is applicable in the public sector under the principle of being a 'good employer' and encourages State departments to have programmes to implement EEO initiatives. In contrast, the BEE legislation in the Republic of South Africa/uMzansi Afrika is applicable in the private sector, which is similar to the application of the EEO policies to the public sector in New Zealand/Aotearoa. These similarities do not make these sectors alike, but they have common elements. Although these sectors (public in New Zealand/Aotearoa and private in the Republic of South Africa/uMzansi Afrika) are different, they have some characteristics that are similar in these two countries. 


\section{Overview of Māori women statistics}

It is important that the statistical data for Māori women in top-management roles are understood in relation to their population percentage and labour force participation rate. My analysis of statistics highlights this group because it is part of my research interest and focus for my study. The challenge with most statistics presented by the Government in New Zealand/Aotearoa is that they are largely represented in relation to gender or race, and not an intersection of both.

Tables 2.1 and 2.2. represent both race and gender of the population proportion in New Zealand/Aotearoa.

Table 2.1

Racial group as a percentage of the total population in 2006

\begin{tabular}{|l|l|}
\hline Race & Percentage \\
\hline White/European & $67.6 \%$ \\
\hline Māori & $\mathbf{1 4 . 6 \%}$ \\
\hline Pacific peoples & $6.9 \%$ \\
\hline
\end{tabular}

Statistics New Zealand (2006). QuickStats about culture and identity 2006

Census. Wellington: Statistics New Zealand.

People can choose to identify with more than one racial group; therefore, percentages do not add up to $100 \%$. The above population groupings are the largest in New Zealand/Aotearoa. Māori is the second largest ethnic group, after the European group. As a percentage of the total Māori population, Māori who were under 15 years of age were $35.4 \%$ and those over the age 65 years were 4.1\%, in 2006 (Statistics New Zealand, 2007). This means that Māori as a group has a high number of young individuals who are generally not available to work because they are still under the minimum age of employment (16 years). 
Table 2.2

Gender group as a percentage of the total population in 2006

\begin{tabular}{|l|l|}
\hline Gender & Percentage \\
\hline Male & $48.8 \%$ \\
\hline Female & $\mathbf{5 1 . 2 \%}$ \\
\hline
\end{tabular}

Statistics New Zealand (2006). QuickStats about culture and identity 2006

Census. Wellington: Statistics New Zealand.

About $15 \%$ of women in New Zealand/Aotearoa identify as belonging to Māori (Ministry of Women's Affairs, 2009).

Labour force participation rate

The labour force participation rate is important in understanding the composition of the workforce in New Zealand/Aotearoa. In this study, the labour force participation rate helps in understanding the proportion of Māori women who are available for employment. In New Zealand/Aotearoa, the labour force participation rate is the proportion of people aged 15 years and older who are employed for at least one hour per week or unemployed, but available for work (Statistics New Zealand, 2011a). In New Zealand/Aotearoa, people over 65 years and older are counted in the participation rate statistics, but this is not the case in the Republic of South Africa/uMzansi Afrika. 
Table 2.3.a shows the labour force participation rate of different social groups in New Zealand/Aotearoa in September 2011.

Table 2.3.a

The labour force participation rate in September 2011 by race and gender

\begin{tabular}{|l|l|l|l|}
\hline \multirow{2}{*}{ Race } & \multicolumn{2}{|c|}{ Gender } & \\
\hline White / European & $75.5 \%$ & Females & Total \\
\hline Māori & $73 \%$ & $63.8 \%$ & $69.5 \%$ \\
\hline Pacific peoples & $68.8 \%$ & $\mathbf{5 9 . 6 \%}$ & $63.6 \%$ \\
\hline Total & $\mathbf{7 4 . 8 \%}$ & $53.9 \%$ & $59.1 \%$ \\
\hline
\end{tabular}

Statistics New Zealand. (2011b). Household Labour Force Survey: September 2011 quarter - tables. Wellington: Statistics New Zealand.

In New Zealand/Aotearoa, the national labour force participation rate was $68.4 \%$ in September 2011 (Statistics New Zealand, 2011b). This means that people who are employed and available for employment at different levels of various organisations are $68.4 \%$ of the national population of New Zealand/Aotearoa above the age of 15 years. Based on the September 2011 data, Māori women have a labour force participation rate of 59.6\%. Māori have a lower labour force participation rate $(63.6 \%)$, than the white/Pākehā group $(69.5 \%)$ and are above Pacific peoples (59.1\%) (refer to Table 2.3.a). The labour force participation rate is lower for women of all ethnic groups than their male counterparts. Research in New Zealand/Aotearoa, shows that women with children had a lower participation rate, whereas women with no children had a similar labour force participation rate to that of men, based on the 2001 census (Johnstone, 2005). This may be because women with children may be not available for employment as they may be raising their children. 
The table below (table 2.3.b) shows the gender and race labour force participation rate from the years 2008 to 2010 .

Table 2.3.b

Historical labour force participation rate from 2008 to 2010

\begin{tabular}{|l|l|l|l|l|l|l|l|}
\hline & \multicolumn{3}{|c|}{ Male } & \multicolumn{3}{c|}{ Female } & $\begin{array}{l}\text { National } \\
\text { Total }\end{array}$ \\
\hline & Māori & $\begin{array}{l}\text { White/ } \\
\text { European }\end{array}$ & $\begin{array}{l}\text { Pacific } \\
\text { peoples }\end{array}$ & Māori & $\begin{array}{l}\text { White/ } \\
\text { European }\end{array}$ & $\begin{array}{l}\text { Pacific } \\
\text { peoples }\end{array}$ & \\
\hline $\mathbf{2 0 0 8}$ & $72.7 \%$ & $75.8 \%$ & $72.1 \%$ & $\mathbf{5 7 . 7 \%}$ & $63.4 \%$ & $54.9 \%$ & $68.5 \%$ \\
\hline $\mathbf{2 0 0 9}$ & $70.8 \%$ & $75.5 \%$ & $70.6 \%$ & $\mathbf{5 8 . 4 \%}$ & $63.6 \%$ & $50.3 \%$ & $68.2 \%$ \\
\hline $\mathbf{2 0 1 0}$ & $70.7 \%$ & $75.3 \%$ & $68.9 \%$ & $\mathbf{5 7 . 9 \%}$ & $63.6 \%$ & $51.2 \%$ & $68.1 \%$ \\
\hline
\end{tabular}

Statistics New Zealand. (2011c). Household Labour Force Survey: Table Labour

Force Status by Sex by Sing/Comb Ethnic Group (Annual-Dec).

The table below (table 2.3.c) shows the labour force participation rate from the years 2008 to 2010 for different racial groups.

Table 2.3.c

Labour force participation rate per racial group for 2008, 2009 and 2010

\begin{tabular}{|l|l|l|l|}
\hline & $\mathbf{2 0 0 8}$ & $\mathbf{2 0 0 9}$ & $\mathbf{2 0 1 0}$ \\
\hline Māori & $\mathbf{6 4 . 9 \%}$ & $\mathbf{6 4 . 4 \%}$ & $\mathbf{6 4 . 0 \%}$ \\
\hline Pacific peoples & $63.1 \%$ & $59.7 \%$ & $59.6 \%$ \\
\hline $\begin{array}{l}\text { White/ } \\
\text { European }\end{array}$ & $69.4 \%$ & $69.4 \%$ & $69.3 \%$ \\
\hline
\end{tabular}

Statistics New Zealand. (2011c). Household Labour Force Survey: Table Labour Force Status by Sex by Sing/Comb Ethnic Group (Annual-Dec).

The labour force participation rate for the years 2008-2010 show a similar picture to that of September 2011. Women have lower participation rates in all racial groups compared to their male counterparts for the years 2008-2010 (refer to table 2.3.b). Māori women have a lower labour force participation rate than the national one for each year from the years 2008 to 2010 (refer to table 2.3.b). 
Māori have a higher participation rate than Pacific peoples, but lower than the European/white group for the years 2008, 2009 and 2010 (refer to table 2.3.c).

Comparing the labour force participating rate of Māori women with historical data shows that, in 2004, the labour force participation rate of Māori women was 56\% (Ministry of Māori Development, 2007). In September 2011, it was 59.6\% (Statistics New Zealand, 2011b). There has been a progress of 3.6\% over the last seven (2004-2011) years. This means that there has been a growth of the number of Māori women entering employment. In addition, the labour force participation rate of Māori women has been rising every year, since 2004. This increase may be caused by different reasons. It may mean that the labour conditions may be improving for Māori women. It may also signify that Māori women have been increasingly entering the workplace, despite the conditions they may face in the workplace. There may also be other factors, such as the growth of the New Zealand/Aotearoa economy, which may cause Māori women to enter the workplace in higher numbers than previous years. 
The unemployment rate

The unemployment rate is important in my study because it provides information on the proportion of people aged 15 years and older who are not employed and actively seeking work. It also gives an indication of the ease with which people are able to change employers or move around in employment. It is also an indicator for an economic condition of Māori women.

Table 2.4.a

The unemployment rate in September 2011 by race and gender

\begin{tabular}{|l|l|l|l|}
\hline & \multicolumn{2}{|c|}{ Gender } & \\
\hline Race & Males & Females & Total \\
\hline White / European & $4.7 \%$ & $5.2 \%$ & $4.3 \%$ \\
\hline Māori & $14 \%$ & $\mathbf{1 2 . 2 \%}$ & $15.1 \%$ \\
\hline Pacific peoples & $14 \%$ & $14.9 \%$ & $13.8 \%$ \\
\hline Total & $\mathbf{6 . 3 \%}$ & $\mathbf{7 \%}$ & $\mathbf{6 . 6 \%}$ \\
\hline
\end{tabular}

Statistics New Zealand. (2011b). Household Labour Force Survey: September 2011 quarter - tables. Wellington: Statistics New Zealand.

Referring to table 2.4.a, the unemployment rate in New Zealand/Aotearoa was 6.6\% in September 2011 (Statistics New Zealand, 2011b). The Māori group $(15.1 \%)$ has more than double the national unemployment rate $(6.6 \%)$. The unemployment rate for Māori women is $12.2 \%$, which is higher than that of white females (5.2\%), and above that of Pacific peoples (14.9\%). A high unemployment rate for Māori women means that it may be harder for them to move around jobs compared to white males, who have a lower unemployment rate. It could also mean that Māori women, generally, find it harder to find employment compared to other groups with lower unemployment rates. There are different factors that affect unemployment, such as, having educational qualifications and necessary skills for a job. The objective of this section is to provide a high level over-view of the general economic conditions of Māori women, without focusing on detailed analysis of all variables affecting employment and unemployment situations. 
The table below (Table 2.4.b) shows the unemployment rate of different racial groups and gender from the years 2008 to 2010 .

Table 2.4.b

Historical unemployment rate per race and gender for the years 2008, 2009, and 2010

\begin{tabular}{|l|l|l|l|l|l|l|l|}
\hline & \multicolumn{5}{|l|}{ Male } & \multicolumn{3}{l|}{ Female } & Total \\
\hline & Māori & White/ & Pacific & Māori & White/ & Pacific \\
peoples & & European & \\
& & European & & & \\
\hline $\mathbf{2 0 0 8}$ & $9.6 \%$ & $3.1 \%$ & $6.6 \%$ & $\mathbf{9 . 3 \%}$ & $2.9 \%$ & $9.1 \%$ & $4.2 \%$ \\
\hline $\mathbf{2 0 0 9}$ & $12.8 \%$ & $4.4 \%$ & $12.9 \%$ & $\mathbf{1 3 . 7 \%}$ & $4.1 \%$ & $13.6 \%$ & $6.1 \%$ \\
\hline $\mathbf{2 0 1 0}$ & $15.7 \%$ & $4.2 \%$ & $12.6 \%$ & $\mathbf{1 5 . 4 \%}$ & $4.6 \%$ & $15.5 \%$ & $6.5 \%$ \\
\hline
\end{tabular}

Statistics New Zealand. (2011c). Household Labour Force Survey: Table Labour Force Status by Sex by Sing/Comb Ethnic Group (Annual-Dec).

The table below (Table 2.4.c) shows the unemployment rate of different racial groups from the years 2008 to 2010 .

Table 2.4.c

Unemployment rate per racial group for 2008, 2009 and 2010

\begin{tabular}{|l|l|l|l|}
\hline & & & \\
\hline & $\mathbf{2 0 0 8}$ & $\mathbf{2 0 0 9}$ & $\mathbf{2 0 1 0}$ \\
\hline Māori & $\mathbf{9 . 5 \%}$ & $\mathbf{1 3 . 2 \%}$ & $\mathbf{1 5 . 6 \%}$ \\
\hline Pacific peoples & $7.7 \%$ & $13.2 \%$ & $13.9 \%$ \\
\hline $\begin{array}{l}\text { White/ } \\
\text { European }\end{array}$ & $3.0 \%$ & $4.3 \%$ & $4.4 \%$ \\
\hline Total & $\mathbf{4 . 2 \%}$ & $\mathbf{6 . 1 \%}$ & $\mathbf{6 . 5 \%}$ \\
\hline
\end{tabular}

Statistics New Zealand. (2011c). Household Labour Force Survey: Table Labour Force Status by Sex by Sing/Comb Ethnic Group (Annual-Dec). 
For the years 2008, 2009, 2010 and 2011, consistently, the unemployment rate for Māori is more than double the national unemployment rate. Also, the European/white group has a lower unemployment rate than the national one for the years 2008, 2009, 2010 and 2011. Of interest is that the unemployment rate of Māori women has been slightly lower than that of Māori men since 2008, except in the year 2009 where it was $0.9 \%$ higher than Māori men. Despite these proportions, the unemployment rate of Māori women is still high compared to the national unemployment rate for the years 2008-2011.

The status of Māori women in the public and private sectors

The objective of this section is to highlight the differences of representation in top-management for Māori women between the private and public sectors. Māori women are more successful in the public sector than the private sector, in general. I attribute the success in the public sector to the presence of the EEO policy. In New Zealand/Aotearoa, I could not find statistics on the number of women in management in different ethnic groups. This information could have assisted in understanding the top-management structure, in terms of ethnic groups of women, in New Zealand/Aotearoa.

In this section, I discuss the proportion of Māori women who are in topmanagement roles. Māori women's proportion in top-management should be understood in relation to the labour force participation and unemployment rates. This means that the proportion of Māori women in top jobs should be interpreted in the context of the percentage of those Māori women who are available for and in employment, aged 15years and older. The understanding of Māori women in top-jobs should also be comprehended in the context of the ease of Māori women to move around jobs in order to obtain the necessary experience enabling them to progress up the organisational ladder.

Access to top-management roles has been challenging for Māori women. Across the whole New Zealand economy, Māori women Chief Executive Officers (CEO) and Managing Directors (MD) were in just $1.1 \%$ of the total positions (Mintrom $\&$ True, 2004). Other studies state that there were still only $8 \%$ of women in senior (top three tiers) management and $54 \%$ in junior management across the 
whole economy (Burns, 2001; Fawcett \& Pringle, 2000). All these studies conclude that there are few Māori women in top-management roles.

Both Māori and women have not been well represented in top-jobs in the private sector. Māori women in top-management in the private sector were $1 \%$ (Ministry of Māori Affairs, 1994). Women in general, in senior (top three tiers) management of the private sector were, 26\% (EEO Trust, 2007). Other studies (McGregor, 2002) in the private sector indicate that women were 9\% of senior (top three tiers) management. In the private sector, six of the top 200 private sector companies had a woman CEO in 2001 (Burns, 2001; EEO Trust, 2001; Olsson \& Pringle, 2004). Similarly, Māori in general are under-represented in the private sector in top-management roles. Māori were $4 \%$ of senior (top three tiers of management) management (EEO Trust, 2007). In senior management, they were less than a third of their demographics (14.6\%). In the private sector, the disadvantaged groups are not well represented at top-management levels.

On the other hand, Māori and women are better represented in top-management in the public sector than the private sector. The Table (Table 2.5) represents the EEO groups (focusing on women and Māori) in relation to other EEO groups in senior (top three tiers) management in the public sector. The table highlights the improvements for women and Māori in senior (top three tiers) management over the past few years $(1998-2002)$, in the public sector. 
Table 2.5

Representation of the EEO groups (Mãori and women) in senior (top three tiers) management over the years in the public sector

\begin{tabular}{|l|l|l|l|l|l|}
\hline $\begin{array}{l}\text { EEO } \\
\text { Groups }\end{array}$ & $\begin{array}{l}\mathbf{1 9 9 8} \\
\%\end{array}$ & $\begin{array}{l}\mathbf{1 9 9 9} \\
\%\end{array}$ & $\begin{array}{l}\mathbf{2 0 0 0} \\
\%\end{array}$ & $\begin{array}{l}\mathbf{2 0 0 1} \\
\%\end{array}$ & $\begin{array}{l}\mathbf{2 0 0 2} \\
\%\end{array}$ \\
\hline Māori & $\mathbf{8 . 2}$ & $\mathbf{7 . 6}$ & $\mathbf{8 . 7}$ & $\mathbf{9 . 8}$ & $\mathbf{1 0 . 4}$ \\
\hline $\begin{array}{l}\text { Pacific } \\
\text { peoples }\end{array}$ & 1.4 & 1.7 & 1.4 & 1.9 & 1.6 \\
\hline $\begin{array}{l}\text { Women in } \\
\text { general }\end{array}$ & $\mathbf{2 9 . 4}$ & $\mathbf{3 2 . 7}$ & $\mathbf{3 3 . 6}$ & $\mathbf{3 3 . 0}$ & $\mathbf{3 5 . 9}$ \\
\hline
\end{tabular}

State Services Commission (2003). EEO progress in the public service: Report

with special focus on Māori Wellington: State Services Commission.

The statistics show that while, both Māori and women are successful in entering jobs in the public sector, they are not successful in entering top-management roles. In 1992, only $17 \%$ of managers were women. However, women's access into into-management has been improving since the year 1992. For example, in 2002, women were $57.5 \%$ of employees in the public service, and they comprised $35.9 \%$ of senior (top 3 tiers) management in that year (refer to table 2.5) (Mintrom \& True, 2004; State Services Commission, 2003). Later studies (EEO Trust, 2007) indicate that the public sector has $29 \%$ of women, in general, in senior (top three tiers) management. Similarly, Māori are successful in entering jobs in the public sector, but are unsuccessful in entering topmanagement roles within the same sector. The Māori proportion of the workforce in the public service has been increasing from $10 \%$ in 1998 to $18 \%$ in 2002 (State Services Commission, 2003). Māori in senior ( top three tiers) management in the public sector have slightly increased from less than $8 \%(7.6 \%)$ in 1999 to more than $10 . \%(10.4 \%$ ) in 2002 (refer to Table 2.5) (State Services Commission, 2003). Ten percent of senior management representation is below the workforce proportion of $18 \%$ that represent Māori in the public service. Later studies present a worse picture and state that Māori are 7\% in the public sector in senior (top three tiers) management (EEO Trust, 2007). Although the public sector is able to attract both Māori and women into the workforce, there 
seem to be challenges for them in penetrating senior (top three tiers) management roles.

In relation to Māori women specifically, in top-management roles in the public sector, their proportion has been growing since 1998. In top-management, the proportion of Māori women in the public sector has increased from just under 3\% in 1998 to 5\% in 2002 (State Services Commission, 2003). Nevertheless, the rise of Māori women in this sector is minimal taking cognisance of their workforce proportion in the public service. This is less than half of their workforce proportion, of $6.1 \%$ in 1988 and $11.1 \%$ in 2002, in the public service. On the other hand, Māori men were 5.2\% in 2002 in senior (top three tiers) management and their workforce proportion was $6.4 \%$ in 2002 in the public service (State Services Commission, 2003). In senior (top three tiers) management in the public sector, Māori men are better represented than Māori women.

However, the improved representation of Māori women in top-management in the public sector could be for several reasons. The presence of the EEO policy in the public sector is positive for Māori women. It provides a policy framework for Government departments to include the EEO policy in their overall strategic Human Resources strategy (State Services Commission, 2003). Also, it encourages Government departments to have EEO targets of individuals from the designated groups (including Māori women). Tremaine (1991) espouses the idea that the public sector tends to be progressive on EEO issues because it is driven by the specific sector legislation and EEO policies. Additionally, there could be better conditions for women in larger corporations, such as the public sector, than smaller ones, as larger organisations tend to have standardised practices and policies (Pringle \& Olsson, 2002). The public sector tends to be bigger and more structured than the private sector, especially in New Zealand/Aotearoa, which is a country of small private businesses. As a result, policies in big organisations tend to be established and usually there is capacity within such organisations to develop new Human Resources (HR) Policies. In the private sector, there are no formal Government requirements for the EEO programmes targeting organisations. The public sector is more progressive in implementing the EEO 
activities than the private sector (Burns, 2001) and has a supportive culture (Olsson \& Pringle, 2004) to promote women and Māori.

\section{Overview statistics of African women}

This sub-section explains the representation of African women in topmanagement roles. To comprehend the representation of African women in topmanagement roles, it is important to understand their population distribution percentage, labour force participation rate, and unemployment rate as well as their representation proportions in top-management of organisations.

Table 2.6 reflects the population distribution percentage per race and gender. The table is important in understanding the percentage of African women in topmanagement roles in relation to their population demographics.

Table 2.6

National population distribution percentage (Census 2011)

\begin{tabular}{|l|l|l|l|}
\hline \multirow{2}{*}{ Population group } & \multicolumn{2}{|c|}{ Gender } & \multicolumn{1}{c|}{ Total } \\
\cline { 2 - 4 } & Male & Female & \\
\hline African & $38.4 \%$ & $\mathbf{4 1 \%}$ & $\mathbf{7 9 . 4 \%}$ \\
\hline Coloured (Mixed) & $4.3 \%$ & $4.6 \%$ & $8.9 \%$ \\
\hline Indians & $1.2 \%$ & $1.3 \%$ & $2.5 \%$ \\
\hline White & $4.4 \%$ & $5.0 \%$ & $9 \%$ \\
\hline Total & $\mathbf{4 8 . 4 \%}$ & $\mathbf{5 2 \%}$ & \\
\hline Statistics South & &
\end{tabular}

Statistics South Africa. (2011) .Mid-year population estimates. Pretoria: Statistics South Africa.

As demonstrated in the table (Table 2.6), African females have the highest national population distribution. This means that they are the majority population group in the Republic of South Africa/uMzansi Afrika at 41\%, followed by African males at $38.4 \%$, and the African race being the majority at 79.4\%. Women in general are $52 . \%$ of the adult population (Statistics South Africa, 2011) . 
Tables 2.7a, and 2.7b. show the labour force participation rate over different years. In the Republic of South African/uMzansi Afrika context, the labour force participation rate is the proportion of the working-age (15-64) population that is either employed or unemployed seeking employment (Statistics South Africa, 2011). It excludes those under the age of 15 years and above the age of 65 years.

Table 2.7a

Labour force participation rate per race and gender in June 2011

\begin{tabular}{|l|l|l|l|}
\hline \multirow{2}{*}{ Population group } & \multicolumn{2}{|c|}{ Gender } & \multirow{2}{*}{ Total } \\
\cline { 2 - 4 } & Male & Female & $51.9 \%$ \\
\hline African & $58.1 \%$ & $\mathbf{4 6 \%}$ & $60.1 \%$ \\
\hline Coloured (Mixed) & $68.4 \%$ & $52.6 \%$ & $60.2 \%$ \\
\hline Indians & $73 \%$ & $47.6 \%$ & $68.3 \%$ \\
\hline White & $77 \%$ & $60.2 \%$ & $\mathbf{5 4 . 5 \%}$ \\
\hline Total & $\mathbf{6 1 . 3 \%}$ & $\mathbf{4 8 . \%}$ & \\
\hline
\end{tabular}

Statistics South Africa. (June 2011). Quartely labour force survey. Pretoria: Statistics South Africa. 
Table 2.7b

Labour force participation rates from 2002 to 2007 per race and gender

\begin{tabular}{|c|c|c|c|c|c|c|c|}
\hline & & $\begin{array}{l}\text { Sept } \\
2002\end{array}$ & $\begin{array}{l}\text { Sept } \\
2003\end{array}$ & $\begin{array}{l}\text { Sept } \\
2004\end{array}$ & $\begin{array}{l}\text { Sept } \\
2005\end{array}$ & $\begin{array}{l}\text { Sept } \\
2006\end{array}$ & $\begin{array}{l}\text { Sept } \\
2007\end{array}$ \\
\hline \multirow[t]{4}{*}{ Male } & African & 61.4 & 59.1 & 58.8 & 61.2 & 61.8 & 60.6 \\
\hline & $\begin{array}{l}\text { Coloured } \\
\text { (Mixed) }\end{array}$ & 78 & 75.7 & 74.1 & 76.8 & 76.3 & 75.5 \\
\hline & Indians & 77.7 & 76.3 & 76.3 & 79.1 & 73.7 & 74.7 \\
\hline & White & 75.4 & 77.2 & 76.6 & 74.8 & 75.6 & 76.9 \\
\hline Total & & 65.2 & 63.3 & 62.8 & 64.7 & 65 & 64.2 \\
\hline \multirow[t]{4}{*}{ Female } & African & 49.4 & 45.9 & 44.5 & 49 & 50.3 & 47.7 \\
\hline & $\begin{array}{l}\text { Coloured } \\
\text { (Mixed) }\end{array}$ & 61.2 & 62 & 60.8 & 61.3 & 63.4 & 61.9 \\
\hline & Indians & 53.8 & 48.7 & 44.5 & 49.9 & 47.6 & 43.8 \\
\hline & White & 57.3 & 57.4 & 58.8 & 58.9 & 56.2 & 57 \\
\hline Total & & 51.5 & 48.8 & 47.5 & 51.2 & 52.1 & 49.8 \\
\hline \multirow{4}{*}{$\begin{array}{l}\text { Both } \\
\text { sexes }\end{array}$} & African & 55 & 52.1 & 51.2 & 54.7 & 55.7 & 53.8 \\
\hline & $\begin{array}{l}\text { Coloured } \\
\text { (Mixed) }\end{array}$ & 69.3 & 68.6 & 67.1 & 68.7 & 69.5 & 68.4 \\
\hline & Indians & 65.9 & 62.5 & 60.5 & 64.7 & 60.8 & 59.4 \\
\hline & White & 66.1 & 67.2 & 67.5 & 66.7 & 65.7 & 66.7 \\
\hline Total & & 57.9 & 55.6 & 54.8 & 57.6 & 58.2 & 56.7 \\
\hline
\end{tabular}

Statistics South Africa. (2009). Labour Force Survey: Historical Revision September Series 2000 to 2007. Pretoria: Statistics South Africa. 
The labour force participation rate for African females indicates the extent in which African females participate in the economic activity of the Republic of South Africa/uMzansi Afrika. For African females, the labour force participation rate means that of the proportion of African females from the age of 15 years to 65 years, only $46 \%$ of them are available for work or are in employment. The percentages do not add to $100 \%$ because each group is a percentage of the total labour force participation rate. In June 2011, 42\% of those who were not economically active and not available for work were students and 20\% homemakers (Statistics South Africa, 2011). In the past few years (refer to tables 2.7a and $2.7 \mathrm{~b}$ ), women may have a lower labour force participation rate than men for different reasons; for example, women may not be available to work because they tend to be the primary carers for children. Also, $21 \%$ of the total population is under the age of 10 years and $85 \%$ of them are African children (Statistics South Africa, June 2011). African women are likely to be the primary carers for their children; this affects their likelihood to be in employment or looking for work. In addition, the labour force participation rate may be low for African women because they may not have the necessary training and skills that allow them entering the workforce. Issues of access to training and education resulting from the legacies of the Apartheid system may still be a problem for African women. The statistics are from the period of positive changes. Nevertheless, they signify that there may be barriers for African women entering employment.

For both the African females and Coloured females, the peak of the labour participation rate was in 2006. This co-incided with a peak in the national labour force participation rate, in the same year. In the Republic of South African/uMzansi Afrika context, researchers suggest that an increase in the labour force participation of females may be driven by a decline in female access to male income (Kingdon \& Knight, 2007). This is contributed by unemployment amongst males because of an HIV epidemic and an increase in the number of households headed by females due to changes in the household structures (Kingdon \& Knight, 2007). Another reason is the abolition of Apartheid policies that inhibited women from participating fully in the labour market. However, overall, the labour force percentage participation rate of African females has been roughly the same around the high 40 s to $50 \mathrm{~s}$. 
For most groups, the labour force participation rate has decreased, comparing the 1995 (refer to table 2.7b) and June 2011 (refer to table 2.7a.) data, except for the white group for both males and females. These figures may reflect the global economic crises originating mostly from the USA financial markets. This is because the Republic of South Africa/uMzansi Afrikan rand currency is hedged and linked to the US dollar currency through the Republic of South Africa/uMzansi Afrikan rand's Government central currency reserves. These figures may also reflect the political activities that were occurring in this country that may have had an impact on the economic condition of the country. For instance, in 2009, there were national elections and the Government might have been investing and focusing on political campaigns to win the elections rather than on policies developing the economy. Also, in 2010, the country was hosting the soccer world cup. It is possible that Government's activities were focused on hosting a successful world-cup rather than new activities that would have attracted more indigenous women to access employment. In addition, some African women may have been starting their own businesses instead of joining already established organisations. For example, in 1996, there was a promulgation of the National Small Business Act. This co-incided with a large number of women starting their own businesses. There are 1,021,059 Black women working for themselves compared to 853,558 Black men and 119671 white women (International Finance Corporation, 2006). Black women are the largest self-employed group of the population (International Finance Corporation, 2006), which may in part explain the low labour force participation rate for them. 
Table 2.8a

National unemployment rate per gender and race (Census 2011)

\begin{tabular}{|l|l|l|l|}
\hline \multirow{2}{*}{ Population group } & \multicolumn{2}{|c|}{ Gender } & \multicolumn{1}{c|}{ Total } \\
\cline { 2 - 4 } & Male & Female & \\
\hline African & $27.2 \%$ & $\mathbf{3 3 . 4 . \%}$ & $\mathbf{3 0 \%}$ \\
\hline Coloured (Mixed) & $21.8 \%$ & $24.5 \%$ & $23 . \%$ \\
\hline Indians & $9.3 \%$ & $13.1 \%$ & $10.8 \%$ \\
\hline White & $4.2 \%$ & $5.8 \%$ & $5 \%$ \\
\hline Total & $\mathbf{2 3 . 2 \%}$ & $\mathbf{2 8 . 7 \%}$ & $\mathbf{2 5 . 7 \%}$ \\
\hline
\end{tabular}

Statistics South Africa. (2011). .Mid-year population estimates. Pretoria: Statistics South Africa.

Referring to Table 2.8a, the unemployment rate is the highest for African females at $33.4 \%$ compared to the national unemployment rate at $25.7 \%$. The national unemployment rate is the proportion of the labour force (15-64 years) that is unemployed (Statistics South Africa, 2011). It is the lowest for white males at 4.2\%. Generally, the Republic of South Africa/uMzansi Afrika, has a high unemployment rate $(25.7 \%)$. However, according to the statistics, African women feel this impact the most. The statistics also translate to mean that it is the most difficult for African females, compared to most groups, to move around jobs. This may also be an indication that the economic structure of the Republic of South Africa/uMzansi Afrika still privileges white males. This is despite positive policies and legislation promoting indigenous women. 
Table $2.8 b$

Historical unemployment rate per gender and race

\begin{tabular}{|l|l|l|l|l|l|l|l|}
\hline & & $\begin{array}{l}\text { Sept } \\
\mathbf{2 0 0 2}\end{array}$ & $\begin{array}{l}\text { Sept } \\
\mathbf{2 0 0 3}\end{array}$ & $\begin{array}{l}\text { Sept } \\
\mathbf{2 0 0 4}\end{array}$ & $\begin{array}{l}\text { Sept } \\
\mathbf{2 0 0 5}\end{array}$ & $\begin{array}{l}\text { Sept } \\
\mathbf{2 0 0 6}\end{array}$ & $\begin{array}{l}\text { Sept } \\
\mathbf{2 0 0 7}\end{array}$ \\
\hline Male & African & $\mathbf{2 6 . 5}$ & $\mathbf{2 5 . 6}$ & $\mathbf{2 2 . 9}$ & $\mathbf{2 2 . 3}$ & $\mathbf{2 0 . 7}$ & $\mathbf{2 0 . 5}$ \\
\hline & $\begin{array}{l}\text { Coloured } \\
\text { (Mixed) }\end{array}$ & 22.2 & 22.4 & 21.9 & 22.3 & 17.7 & 23.4 \\
\hline & Indians & 13.6 & 13.9 & 11.4 & 15.2 & 7.2 & 8.4 \\
\hline Total & White & 5.4 & 4.2 & 5.1 & 3.8 & 4.2 & 3.5 \\
\hline Female & African & $\mathbf{3 6 . 0}$ & $\mathbf{3 3 . 3}$ & $\mathbf{3 0 . 9}$ & $\mathbf{3 1 . 8}$ & $\mathbf{3 1 . 1}$ & $\mathbf{2 7 . 8}$ \\
\hline & Coloured & 28.2 & 25.1 & 26.5 & 26.3 & 25.2 & 23.4 \\
\hline (Mixed) & & & & & & \\
\hline Total & Indians & 24.0 & 18.8 & 13.8 & 18.9 & 12.6 & 11.3 \\
\hline Total & White & 6.8 & 5.8 & 5.9 & 6.7 & 4.0 & 4.9 \\
\hline Both & African & $\mathbf{3 1 . 0}$ & 29.2 & 26.6 & 26.8 & 25.6 & 23.9 \\
\hline & White & 6.0 & 4.8 & 5.5 & 5.1 & 4.1 & 4.1 \\
\hline & $\begin{array}{l}\text { Coloured } \\
\text { (Mixed) }\end{array}$ & 24.9 & 23.6 & 24.1 & 24.2 & 21.3 & 23.4 \\
\hline & Indians & 17.8 & 15.8 & 12.3 & 16.6 & 9.3 & 9.5 \\
\hline & & $\mathbf{2 6 . 6}$ & $\mathbf{2 4 . 8}$ & $\mathbf{2 3 . 0}$ & $\mathbf{2 3 . 5}$ & $\mathbf{2 2 . 1}$ & $\mathbf{2 1 . 0}$ \\
\hline & & & $\mathbf{2 8 . 4}$ & $\mathbf{2 6 . 6}$ & $\mathbf{2 7 . 8}$ & $\mathbf{2 7}$ & $\mathbf{2 4 . 3}$ \\
\hline & & & & & & \\
\hline
\end{tabular}

Statistics South Africa. (2009). Labour Force Survey: Historical Revision September Series 2000 to 2007. Pretoria: Statistics South Africa. 
Generally, the national unemployment rate has decreased since 2002; in 2007, it was at the lowest at $21 \%$ (refer to tables $2.8 \mathrm{a}$ and $2.8 \mathrm{~b}$ ). African females had the lowest unemployment rate, of $27.8 \%$, in 2007. All population groups experienced a decline in unemployment, except African males, who had a $0.7 \%$ increase in unemployment rate between September 2002 and June 2011. The group that has showed the best improvement in unemployment rate is the Indian female category with a decline of $10.9 \%$ (refer to tables $2.8 \mathrm{a}$ and $2.8 \mathrm{~b}$ ). Consistently, over the years African females have the highest unemployment rates, and it is above the national rate each year.

The status of African women in the public and private sectors

In the Republic of South Africa/uMzansi Afrika, entry into top-management positions of organisations is challenging for African females. Women in general and Africans are over-represented at the lower-levels. This is despite the fact that the economy of the Republic of South Africa/uMzansi Afrika has been growing. The Republic of South Africa/uMzansi Afrika has been growing at 5\% over each of the past three years, that is 2005-2007 (Government Communications and Information Republic of South Africa, 2008; Isa, 2008; Whiteford, 2008). This is the highest economic growth in 25 years (Government Communications and Information Republic of South Africa, 2008). 
Table 2.9a reflects changes in different occupational groups by females and males between the years 1995 and 2005 in different sectors.

Table 2.9a

Changes in employment by occupational group and gender

\begin{tabular}{|l|l|l|l|l|}
\hline \multirow{2}{*}{} & \multicolumn{2}{|c|}{1995} & \multicolumn{2}{c|}{2005} \\
\hline Managers & Male & Female & Male & Female \\
\hline Professionals & $\mathbf{7 7 . 8 \%}$ & $\mathbf{2 2 . 2 \%}$ & $\mathbf{7 0 . 8 \%}$ & $\mathbf{2 8 . 9 \%}$ \\
\hline Clerks & $36.9 \%$ & $50 \%$ & $49.9 \%$ & $50.1 \%$ \\
\hline $\begin{array}{l}\text { Services and sales } \\
\text { workers }\end{array}$ & $58.7 \%$ & $41.3 \%$ & $55.8 \%$ & $44.2 \%$ \\
\hline $\begin{array}{l}\text { Skilled agricultural } \\
\text { and fishery workers }\end{array}$ & $86.1 \%$ & $\mathbf{1 3 . 9 \%}$ & $54.1 \%$ & $\mathbf{4 5 . 8 \%}$ \\
\hline $\begin{array}{l}\text { Craft and trade } \\
\text { workers }\end{array}$ & $88.4 \%$ & $11.6 \%$ & $83.6 \%$ & $16.4 \%$ \\
\hline $\begin{array}{l}\text { Operators and } \\
\text { assemblers }\end{array}$ & $85.5 \%$ & $14.5 \%$ & $87.4 \%$ & $12.6 \%$ \\
\hline $\begin{array}{l}\text { Elementary } \\
\text { occupations }\end{array}$ & $75.5 \%$ & $\mathbf{2 4 . 5 \%}$ & $58.5 \%$ & $\mathbf{4 1 . 5 \%}$ \\
\hline $\begin{array}{l}\text { Domestic workers } \\
\text { Total }\end{array}$ & $12.7 \%$ & $87.3 \%$ & $3.4 \%$ & $96.6 \%$ \\
\hline Departm & $\mathbf{6 0 . 9 \%}$ & $\mathbf{3 9 . 1 \%}$ & $\mathbf{5 7 . 4 \%}$ & $\mathbf{4 2 . 6 \%}$ \\
\hline
\end{tabular}

Department of Labour Republic of South Africa. (2006). Women in the South African Labour Market 1995-2005. Pretoria: Chief Directorate of Communication.

Referring to table 2.9a, there has been an increase in female managers from $22.2 \%$ in 1995 to $28.9 \%$ in 2005 . However, the largest increase of women has been in the elementary occupations. Research also supports the idea that an increase in female employment reflects an increase of women working in lower paid jobs (Casale, Muller, \& Posel, 2004). 
Table $2.9 \mathrm{~b}$ shows a proportion of both men and women working in the public sector.

Table 2.9.b.

Percentage of women in the public sector in 2010 and 2011

\begin{tabular}{|l|l|l|}
\hline Year & Men & Women \\
\hline $\mathbf{2 0 1 0}$ & $42.3 \%$ & $57.7 \%$ \\
\hline $\mathbf{2 0 1 1}$ & $41.8 \%$ & $58.2 \%$ \\
\hline
\end{tabular}

Businesswomen's Association of South Africa. (2011). South African Women in Leadership Census 2011. Johannesburg: Business Women Association of South Africa.

In the public sector, there are more women than men. Women were $57.7 \%$ in 2010 compared to $42.3 \%$ of men in the same year. There was a slight increase of women in the public sector in 2011 to $58.2 \%$, which was followed by a slight decrease of men $(41.8 \%)$.

Table $2.9 \mathrm{c}$ shows the spread of women in different levels in the public sector

Table 2.9c

Women of all races combined in the public sector across different levels

\begin{tabular}{|l|l|}
\hline Organisational level & Percentage of women (all races included) \\
\hline Top-management & $\mathbf{0 . 5 \%}$ \\
\hline Middle management & $15.9 \%$ \\
\hline supervisory level & $\mathbf{4 5 . 5 \%}$ \\
\hline Production level & $\mathbf{3 5 . 1 \%}$ \\
\hline
\end{tabular}

Businesswomen's Association of South Africa. (2011). South African Women in Leadership Census 2011. Johannesburg: Business Women Association of South Africa.

Referring to table 2.9c, women are mostly represented in lower levels in the public sector, which are supervisory and production levels. 
The table below (table 2.9d) shows progress on gender representation in the public sector by gender between the years 2010 and 2011.

Table 2.9d

Progress on the gender composition in top-management in the public sector (all races included)

\begin{tabular}{|l|l|l|}
\hline Year & Men & Female \\
\hline $\mathbf{2 0 1 0}$ & $64.7 \%$ & $35.3 \%$ \\
\hline $\mathbf{2 0 1 1}$ & $65 \%$ & $35 \%$ \\
\hline
\end{tabular}

Businesswomen's Association of South Africa. (2011). South African Women in Leadership Census 2011. Johannesburg: Business Women Association of South Africa.

In the public sector, men are represented less $(41.8 \%)$ than females at $58.2 \%$ in the public sector in 2011 (refer to table 2.9b); yet, they occupy the majority of top-management roles (refer to tables 2.9.c., and 2.9d). 
Table 2.9e shows the representation of different groups per race and gender in top-management roles. It shows the proportions for different groups compared with the proportion of African women in top-management of different types of organisations.

Table $2.9 \mathrm{e}$

Workforce population distribution for top-management for all employers

\begin{tabular}{|l|l|l|l|}
\hline Population group & \multicolumn{1}{|c|}{ All employers } & \multicolumn{1}{|c|}{ All government } & \multicolumn{1}{|c|}{ All private } \\
\hline African Males & $14.2 \%$ & $40.6 \% \%$ & $10.1 \%$ \\
\hline Coloured Males & $3.7 \%$ & $8.0 \%$ & $3.0 \%$ \\
\hline Indian Males & $5.6 \%$ & $4.1 \%$ & $5.8 \%$ \\
\hline White Males & $54.5 \%$ & $15.4 \%$ & $60.6 \%$ \\
\hline African Females & $\mathbf{6 . 1 \%}$ & $\mathbf{2 3 . 1 \%}$ & $\mathbf{3 . 4 \%}$ \\
\hline Coloured Females & $1.3 \%$ & $3.3 \%$ & $1.0 \%$ \\
\hline Indian Females & $1.3 \%$ & $1.3 \%$ & $1.3 \%$ \\
\hline White Females & $9.3 \%$ & $3.6 \%$ & $10.2 \%$ \\
\hline
\end{tabular}

Department of Labour Republic of South Africa (2010). 10th CEE Annual

Report 2009-2010. Pretoria: Department of Labour.

Referring to Table 2.9e, entry into top-management roles is a challenge for African women. In top-management for all employers, studies indicate that African women are $6.1 \%$, less than half the percentage of African males (14.2\%) and less than an eighth of the rate for white males (54.5\%). This means that out of those people who work, African women are least represented in topmanagement roles. This is despite the fact that they are the majority population group at $41 \%$. Also, their labour force participation rate, meaning those of the working population group (15-64 years) who work and those looking for work, is $46 \%$ in June 2011. These numbers mean that the majority of African women are in lower levels of employment and under-represented in top-management of organisations. This indicates that the current economic structure of the Republic of South Africa/uMzansi Afrika does not promote advancing African women into top jobs. 
On the contrary, white males dominate and are over-represented in topmanagement roles of all employers. White people (both males and females) are 9.\% of the population (Statistics South Africa, 2011); yet they represent more than $60 \%$ in top-management roles of all types of employers. Women in general constitute less than $20 \%$ of top managers in the country, yet they represent $52 \%$ of the population and have a labour force participation rate of $48 \%$. Males of all racial groups are higher in top-management than females of the same race and dominate in these roles.

Table 2.9e demonstrates a similar picture to that of New Zealand/Aotearoa; in the Republic of South Africa/uMzansi Afrika, indigenous women are better represented in top-management of the public sector organisations than in the private sector. In top-management, African females are $23.1 \%$ in the public sector and $3.4 \%$ in the private sector. On the other hand, in top-management of the private sector, white males are almost twenty times the proportion $(60.6 \%)$ and white women three times the proportion (10.2\%) of African females. In the public sector, African males dominate in top-management roles. They are more than twice the proportion (40.6\%) of African females. The higher percentage in the public sector than the private sector of African women may be attributed to several initiatives by Governments to promote indigenous women. These initiatives include aggressive targets to improve the representation of women in management. For example, from 2008 the performance contracts of the CEOs in the public sector include the recruitment of women into senior management positions (Warby, 2008). 
Table 2.9f below shows the proportion of women in top-management by race over the past three years (2009-2011) in the private sector. The data was obtained from State Owned Entities (SOE) and those listed on the Johannesburg Stock Exchange (JSE). State Owned Enterprises are business organisations that are partly or fully owned by the State; they exclude the public sector.

Table 2.9.f

Women in top-management by race in the private sector (JSE and SOE only)

\begin{tabular}{|l|l|l|l|l|}
\hline Year & African & White & Indian & $\begin{array}{l}\text { Coloured } \\
\text { (Mixed) }\end{array}$ \\
\hline $\mathbf{2 0 0 9}$ & $22.6 \%$ & $66.2 \%$ & $5.9 \%$ & $4.9 \%$ \\
\hline $\mathbf{2 0 1 0}$ & $25.6 \%$ & $62.0 \%$ & $5.8 \%$ & $6.1 \%$ \\
\hline $\mathbf{2 0 1 1}$ & $14.4 \%$ & $70.6 \%$ & $6.9 \%$ & $7.4 \%$ \\
\hline
\end{tabular}

Businesswomen's Association of South Africa. (2011). South African Women in

Leadership Census 2011. Johannesburg: Business Women Association of South Africa.

Table 2.9.f shows that there is a large proportion of white women in the private sector in top-management roles in relation to African females, in organisations listed on the JSE and SOEs. Of all women in the private sector in topmanagement in 2009 , for example, there were $66.2 \%$ white women compared to $22.6 \%$ of African women (the majority population group). In 2011, African women were $14.4 \%$ in top-management in the private sector. The number appears lower than previous years because some organisations did not verify their information; therefore, they were excluded from the executive management results (Businesswomen's Association of South Africa, 2011).

Other studies indicate different figures for women in top-management of organisations. Only 4.4\% of CEOs are women (Businesswomen's Association of South Africa, 2011). According to Businesswomen's Association of South Africa, in 2011, there are 21.6\% female top-managers in the Johannesburg Stock Exchange and State Owned Enterprises, but $70 \%$ are white and only $14.4 \%$ are African (2011). In the private sector, white women occupy the majority of 
positions held by women in top-management (Mathur-Helm, 2005). Nevertheless, progress is being made in accessing top-management entry for African women.

In summary, in both New Zealand/Aotearoa and the Republic of South Africa/uMzansi Afrika, the public sector in both countries has a better representation of indigenous women in top roles than the private sector. I attribute this point to the EEO policies in New Zealand/Aotearoa and progressive BEE targets in the Republic of South Africa/uMzansi Afrika present in the public sector of these countries.

In both New Zealand/Aotearoa and the Republic of South Africa/uMzansi Afrika, it is still a challenge for indigenous women to access top-management roles. In both countries, the unemployment rates are still above and labour force participation rates are below national averages, in spite of positive legislation to improve the conditions of indigenous women in the workplace. Indigenous women show a pattern of disadvantage in the work-force. The labour statistics indicate that indigenous women tend to be at the bottom of labour conditions, which puts them at a disadvantage to access higher level jobs. They may also face challenges accessing employment, which impact on their progression up the organisational ladder to top-management. Positive legislation and / policies in both countries have not yet produced race and gender equality. They have provided equality of access to organisations for a limited number of indigenous women, particularly in top-management roles. Research participants for my study are a minority, in terms of numbers, and do not represent a break-through for the majority of indigenous women, which makes this group of women interesting for me to study.

Although I have produced similar statistics for both the Republic of South Africa/uMzansi Afrika and New Zealand/Aotearoa, statistics between different countries should not be compared because there are different economic and social factors that influence labour statistics of a country beyond the scope of this study. In addition, my intention is not to compare these countries, but to show 
the employment conditions of indigenous women in top-management roles taking cognisance of the general labour conditions of both countries.

\section{Conclusion}

In this chapter, I have shown the political and labour contexts for my research subjects in order to understand the later chapters of this thesis. Indigenous women, particularly in both New Zealand/Aotearoa and the Republic of South Africa/uMzansi Afrika, are a different type of an ethnic minority because of their location in history. They were occupying the land, prior to the arrival of European colonisers. Indigenous women in New Zealand/Aotearoa and the Republic of South Africa/uMzansi Afrika have particular characteristics that make them distinctive for understanding the intersection of race and gender in top-management roles, in former British colonies. These particular characteristics are different from countries that have ethnic minorities without the histories and politics of indigeneity in understanding the intersection of race and gender in top-management. Histories and politics affect the perceptions and experiences as well as participation of indigenous women in the labour market in top-management roles in both these countries. It is important to understand the histories and politics of New Zealand/Aotearoa and the Republic of South Africa/uMzansi Afrika because they shape Government solutions for indigenous women, which affect their movements in organisations.

In the Republic of South Africa/uMzansi Afrika, there has been a strong tradition for women to express their interests across organisations and political party lines since the liberation struggles. Women's organisations were key to the struggle for democracy in the Republic of South Africa/uMzansi Afrika (Goetz, 1998). Research suggests that women's section of an organisation plays an important role for support networks for women politicians in creating women's policy (Curtin, 2008). Women activists in the Republic of South Africa/uMzansi Afrika have targeted the National Constitution-writing processes as an initial step in ensuring gender equality in a democratic State to effect change in different women's spheres institutionally and legally. The increased numbers of indigenous women entering top-management roles has been the result of Affirmative policies and legislation implemented by the ANC Government. 
Affirmative Action means positive measures to redress the disadvantaged individuals who have historically suffered by being minoritised in gaining access to equal opportunities to occupy positions of influence (Wing \& Carvalho, 1995). The success of adopting these policies has been the work of women in the ANC who influenced policies to be adopted at national level.

In New Zealand/Aotearoa, women often led political activities and were present in political activism. In New Zealand/Aotearoa, political activism was largely encouraged by failure of the Crown to honour the terms of the Treaty of Waitangi. The major debate was around acknowledging the status of the Treaty and the recognition of Māori culture. The improvement of the labour conditions for Māori women in top-management has been the result of EEO policies and Treaty claims. Also, women organised to influence policy issues with a focal point on Māori people, particularly women. Collective political mobilisation led to institutional rights for indigenous women.

Although there has been a numerical increase of the number of indigenous women in top-management roles over the past ten years, in Chapter Eight I will discuss whether this has led to the representation of indigenous women's interests in top-management roles, particularly in predominantly white organisations. I do not assume that having an increased number of women in top-management of predominantly white organisations automatically leads to the promotion of the differences and values being brought by indigenous women to decision-making roles and processes. In Chapter Eight, I will also discuss whether the current legal, statutory and policy changes in these countries to increase the number of indigenous women in top-management roles have been met with modifications in attitudes of those who are in power, or who have to share power to make room for new faces of indigenous women in these roles.

In regard to the facts and figures I present in this chapter, I argue that they indicate the presence of 'barriers' for indigenous women entering topmanagement levels. In the Republic of South Africa/uMzansi Afrika, for example, Apartheid policies were concrete and hard evidence of discrimination of indigenous women in the workplace, which acted as a 'barrier' in the labour 
environment for indigenous women. However, indigenous women may currently be facing unlegislated 'barriers' when entering top-management roles. In democratic states, of which New Zealand/Aotearoa and the Republic of South Africa/uMzansi Afrika are a part, hard evidence of discrimination is hard to identify because it is often subtle. I will elaborate on this point in Chapter Three by explaining evidence of discrimination in the workplace from previous studies that focus on women in management. In this study, I examine the 'barriers' that may exist when entering top-management roles and those that may be present at different managerial levels. The statistics that I discuss in this chapter are during the positive changes. In spite of this, there seems to be a 'concrete-ceiling', a concept that I discuss and define in Chapter Three, because only a few ethnic minority women are in top-management. The 'concrete-ceiling' is also a concept that my study explores further, to investigate its existence for those indigenous women who are already in top-management roles. 


\section{CHAPTER THREE}

\section{THEORISING ETHNIC MINORITY WOMEN IN TOP-MANAGEMENT: 'RACIALISED-GENDER' AND THE 'CONCRETE-CEILING'}

This thesis investigates the interactions between issues of race and gender as they affect top-management. I draw from women in management literature to design, understand and conceptualise this study to understand change for ethnic minority women into top-management roles through the compounding effects of race and gender. In particular, I use the 'concrete-ceiling' theoretical concept / metaphor, which is central to ethnic minority women, as an analytical tool to understand the empirical data of the experiences and perceptions of indigenous women from New Zealand/Aotearoa and the Republic of South Africa/uMzansi Afrika entering top-management roles. My theoretical contribution is to studies focusing on women in management. My contribution to this literature addresses two aspects, which are chiefly absent within this literature. Firstly, I argue that, in theorising about ethnic minority women in management, the local context which is largely absent from the literature, is important. The theorisation of the experiences of ethnic minority women in management is influenced by the history and politics of a country. Secondly, I argue that the problem with studies focusing on women in management is that experiences of indigenous women are chiefly omitted. These are the gaps this study fills within this literature by including the experiences and perceptions of indigenous women in topmanagement and local context for my study. I draw a research sample from two groups of indigenous women in two countries, that is, New Zealand/Aotearoa and the Republic of South Africa/uMzansi Afrika, both of which had a presence of British rulers.

The theoretical concept of the 'concrete-ceiling' is important in my study because it is within these studies that I centre my debate and conclusions for this research. This metaphor focuses on the inequalities of race and gender for ethnic minority women at management levels in the workplace. This theoretical concept unifies three important concepts in organisations - management, gender 
and race. The concept of the 'concrete-ceiling' is associated with theories of race and gender in the context of management. This idea also explains the reasons for the large absence of ethnic minority women in management roles of predominantly white organisations. Studies discussing the 'concrete-ceiling' conclude that it is difficult for ethnic minority women entering top-management roles because of the discrimination in the workplace towards them attributed to the combination of their female gender and ethnic minority race status (Holvino, 2010; Pomper, 2011). There are several reasons for the existence of the 'concrete-ceiling' that are discussed in women in management literature. One of the explanations for the 'concrete-ceiling' is that, in management there are gender and race based biases that disadvantage ethnic minority women. The race and gender biases are systems, processes, structures and attitudes that are present in a society overall and organisations reflect them (Acker, 2009). Another reason for the existence of the 'concrete-ceiling' relates to self-selection of women (Brett, 1992; Fagenson, 1990; Ross-Smith \& Chesterman, 2009). In this chapter, I discuss further reasons for the existence of the 'concrete-ceiling' in detail, as presented in the current literature of women in management. The lack of ethnic minority women in top-management, under the 'concrete-ceiling' metaphor espouses both external 'barriers' to the individual and choices made by women, as preventing them entering top-management roles.

Although my focus is on the 'concrete-ceiling' theoretical concept, that is, interested in ethnic minority women in management roles of organisations, I acknowledge that gender and race issues are present at different levels of organisations and jobs. However, I do not use race and gender as the theorisation of my study. I focus on those studies discussing race and gender issues in management within the context of women in management. For ethnic minority women, they have to negotiate both their race and gender effects in organisations to move up the ladder. This is because throughout the organisational ladder, ethnic minority women are exposed to both racist and sexist processes (Beal, 1969). Ethnic minority women experience negative perceptions attributed to both gender and race throughout the different levels of organisations (Mattis, 1995). This may be because stereotypes based on historical roles still persist (Dubno, 1985; Powell, Butterfield, \& Parent, 2002; Thomas \& Alderfer, 1989). 
For indigenous women, race becomes intertwined with the history of being the 'last'/'first' occupants of the land, prior to European colonisation. They may be thrice disadvantaged based on race, gender and history, which may impact the advancement of indigenous women into top-management roles.

In this chapter, I also discuss propositions for the 'strategies' and success of ethnic minority women entering top-management roles, which are discussed in the women in management literature. In particular, studies focusing on the 'concrete-ceiling' tend to relegate the answer to the problem of not having a large number of indigenous women in top-management to the individual woman. Within these studies there are ideas about 'strategies' on which women may embark to enhance their chances of succeeding in top-management roles. As an example, they include having a mentor (Bhatta \& Washington, 2003). I elaborate later in this chapter on other 'strategies' and problems as currently presented within the woman in management literature.

In addition to the 'barriers' and 'strategies', in the women in management literature, movements of ethnic minority women are described as complex and needing management because of the stresses associated with moving between two - white and Black - different bicultural cultures (Bell, 1990). In New Zealand/Aotearoa, writers use the term 'biculturalism' specifically to mean power-sharing between two ethnic cultures, usually Māori and Pākehā (white). In the New Zealand/Aotearoa context, 'biculturalism' refers to two different approaches targeting Māori and Pākehā resulting from the Treaty of Waitangi agreement. Māori sovereignty from the mid 1970s led to the 'bicultural' approaches between Māori and Pākehā (Moss, 2005; Seuffert, 2002). In this document, I use the term 'biculturalism' to mean both New Zealand/Aotearoa's Government policy related notion and Bell's (1990) concept, making it clear which is relevant in a given context, as they both mean different concepts.

My empirical focus is on indigenous women who have succeeded in topmanagement roles and broken through the 'concrete-ceiling' 'barriers'; (refer to Figure 3.1). It is generally agreed in the women in management literature that women are able to access lower levels of management. The top-management 
entry is still a challenge for women. Because of the shifting levels of management access for women from junior management to top-management positions, studies focusing on the women in management overlap between junior, middle, senior and top-management. The definitions of senior and topmanagement vary from study to study. For ease of organisation of the academic literature focusing on different levels of management, I present these studies together under the women in management literature. I maintain my focus on the top tier of organisations deriving my literature from studies focusing on the different layers of women in management, as they are important to understanding broader issues in management.

Figure 3.1 My study focus

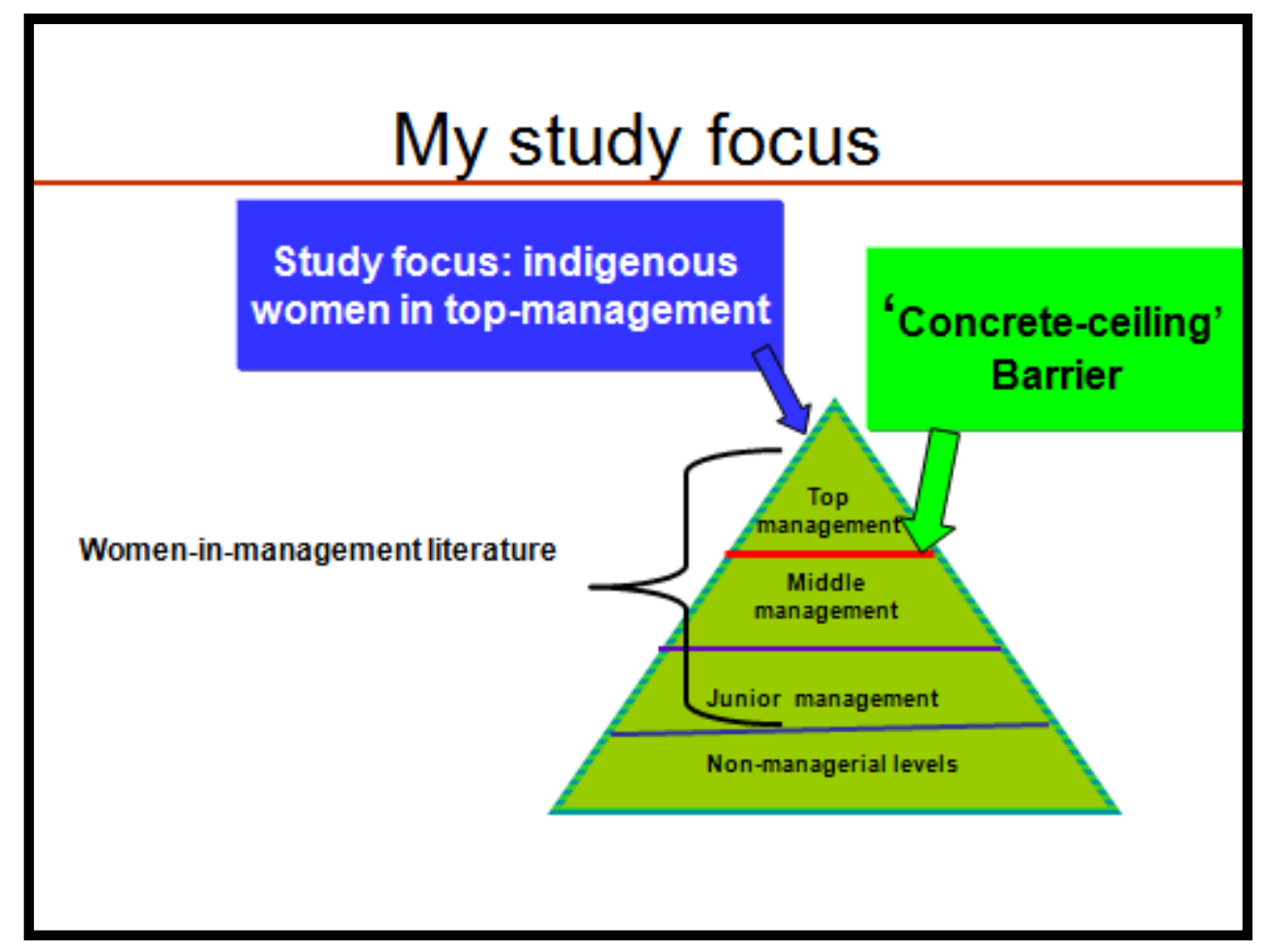


In the next section, I discuss my background and its influence on my theoretical and literature choices, as well as, explain the 'concrete-ceiling' theoretical concept / metaphor and its assumptions. Thereafter, I explain the 'barriers' present within the 'concrete-ceiling' metaphor for women entering topmanagement levels drawing from international, then New Zealand/Aotearoa and the Republic of South Africa/uMzansi Afrika studies, focusing on women in management literature. Subsequently, I discuss 'strategies' that facilitate women's entry to top-management roles. I follow with a section that discusses 'biculturalism' to explain the movements of ethnic minority women in two different spaces.

\section{The 'concrete-ceiling' concept}

In this section, I address my influences for choosing the concept of the 'concreteceiling' to understand my empirical work. In addition, I elaborate on the origin of the 'concrete-ceiling' theory, its features and context of current usage in the women in management literature.

As I started my reading for this study, being a woman in management from a practitioner point of view was familiar to me, as I was one. The experience of being a woman in management from a practical manner influenced my choice of selecting the literature focusing on women in management. In addition, I could relate to and understand concepts present in women in management literature from a practical point of view of having my own challenge advancing into higher levels of management. Choosing this literature gave me an opportunity to reflect on my own experiences of being a Black woman in management of predominantly white organisations. As I was interested in progressing to upper levels of management, I was already familiar with the concept of a 'glassceiling', which I define later in this chapter. Through my readings, I came across the concept of 'concrete-ceiling' and settled with this theoretical concept because I was already familiar with the idea of being an ethnic minority woman in management facing 'barriers' in moving up the salary levels. 
The 'glass-ceiling' studies are criticised by many scholars for assuming that women of all races face similar experiences because their initial samples were primarily based on white women (Bhavnani \& Coyle, 2000; Thomas, 2001). Assumed in these studies are values, such as, individualism and challenges of being a white female manager. However, the 'glass-ceiling' theoretical concept provides the reasons and rationale for the limited number of women in topmanagement positions. It is used to describe 'barriers' women face to get into top-management positions (Mathur-Helm, 2006). Researchers (Carli \& Eagly, 2001; Ridgeway, 2001), use the concept of 'glass-ceiling' to describe the invisible 'barrier' for women preventing them from succeeding in organisations. It is invisible because it is subtle and not easily identifiable. The idea behind the 'glass-ceiling' metaphor is that women face 'unseen' challenges when moving up the organisational ladder that reflect the gender difference that is not explained by job relevant characteristics of an employee (Cotter, Hermesen, Ovadia, \& Vanneman, 2001). Women experience these challenges particularly at topmanagement levels, regardless of their qualifications or achievements. Core to the 'glass-ceiling' metaphor is the notion that women are discriminated against in the workplace because of their gender (Ryan \& Haslam, 2005). The 'glassceiling' is a worldwide phenomenon (Burke, 1997; Pai and Vaidya, 2006) and many studies provide evidence of its existence (Chernesky, 2003; Maume, 2004).

Building onto the 'glass-ceiling' theoretical concept, in the women in management literature, many studies, such as Davidson (1997), use the metaphor of the 'concrete-ceiling', as a theoretical concept, to explain the scarcity of ethnic minority women in management. Korac-Kakabadse and Kouzmin describe the 'concrete-ceiling' metaphor as 'the barrier is more often than not more visible with concrete-like qualities of opaqueness' (1997, p. 207). For ethnic minority women, 'barriers' are a combination of both race and gender when entering topmanagement roles, according to Bell and Nkomo (2001). For ethnic minority women, the 'ceiling' of entering top-management levels is 'concrete' because they also have race to negotiate. The 'ceiling' is visible, which means that they can often observe the limitations to their career progression up the organisational ladder because ethnic minority women are often not represented in large numbers in top-management of predominately white organisations (see statistics in 
Chapter Two). For ethnic minority women, the 'ceiling' is not as 'unseen' as the 'glass' for white women; however, it is visible and thick, metaphorically. In addition, the 'concrete-ceiling' needs a drill to be broken through instead of just a brick to smash the 'glass', entering management roles, metaphorically. The 'concrete-ceiling' is also harder to break than the 'glass'. However, once broken through, the 'concrete-ceiling', the success is experienced more than smashing the 'glass-ceiling'.

In addition, the 'concrete-ceiling' is visible for ethnic minority women compared to the subtle 'glass-ceiling' for white women because ethnic minorities and white women have different experiences. White women, particularly middle-class, have enjoyed the privileges of pursuing professional opportunities (Holvino, 2010). Ethnic minority women also have to address negative career outcome expectations stemming from belonging to both race (ethnic minority) and gender (female) that is associated with being low in status (Hackett \& Byars, 1996). Compared to white women, ethnic minority women in management continue to be underrepresented in higher grade employment (Bhavnani \& Coyle, 2000). Ethnic minority women also experience lower promotion rates than white women (Bell \& Nkomo, 1994). The combination of both race and gender compound the experiences of ethnic minority women, according to Bell and Nkomo (2001).

Also, the 'ceiling' is 'thicker' for ethnic minority women because negotiating both race and gender in management is difficult to separate and has multiple effects of belonging to two groups (female and ethnic minority) that are economically and socially disadvantaged, in general, in relation to white males. Researchers contend that both race and gender are linked and experienced concurrently in an inter-locking system that create unique experiences for ethnic minority women (Andersen, 2005). This is because race is 'gendered' and gender is 'racialised' in such a manner that fuse and create interdependent opportunities for different social groups (Browne \& Misra, 2003). These social groups, race and gender, are not separate categories that can be just added together, argues King (1989). In this chapter, I use the term 'racialised-gender' to discuss the linkages of race and gender, as well as explain a new concept that I developed and found in my results. In organisations, both race and gender have a 
hierarchy. Management is segregated by both gender and race such that women and ethnic minorities are limited in top-management roles, in positions that have influence (Ibarra, 1993). Ethnic minority women are in a lower hierarchy compared to white women and white men who dominate management roles (Essed, 2000). Ethnic minority women have an inter-sectionality that disadvantages them in terms of both gender and race, argues Bell and Nkomo (2001). This means that race and gender are experienced concurrently in an interrelating manner. The influence of both gender and race places ethnic minority women at the bottom of the ladder in terms of advancement and opportunities relative to white men and women.

There are problems with generalising conclusions in studies focusing on the 'concrete-ceiling' metaphor in the women in management literature. 'Concreteceiling' studies tend to draw their participants largely from the USA (Giscombe \& Mattis, 2002; Hite, 2007; Reskin \& Hartmann, 1986) and UK (Bhavnani \& Coyle, 2000). Because of research samples being drawn largely from the USA and UK, these studies embed the assumption of being an ethnic minority woman with a history of slavery present in the USA, or being a migrant in the UK. Studies focusing on ethnic minority women in management largely ignore different ethnic cultures or groups within the samples of ethnic minority women managers and tend to focus mostly on the African-American in the USA (Bell \& Nkomo, 1994) and Black in the UK (Bhavnani \& Coyle, 2000) experiences. Scant studies incorporate different groups of ethnic minority women (Holvino, 2010; Muller, 1998); however, they still tend to embed the American historical experience. Research conclusions of 'concrete-ceiling' studies perpetuate the western values of individualism, which may not apply to other groups of ethnic minority women managers located outside the UK and USA. Scholars within the area of 'concrete-ceiling' in the women in management literature tend to articulate western concepts and experiences dressed in 'Black clothes', which may be different, for instance, from the perspective of a Māori woman manager trained in a Māori Tertiary Institution. These studies assume sameness of experiences based on the shared Black race identity, ignoring, for instance, the ethnic minority Brown women and Black women from Africa within different historical contexts. Studies focusing on ethnic minority women in management 
in the women in management literature largely fail to acknowledge the local content in shaping the experiences of the participants from the countries from which samples are drawn.

Acknowledging local content is important in theorising about women in management, I contest. This is because the perceptions and experiences of women in management should be understood in broader social, political and historical issues, impacting on their experiences in management. For example, in both New Zealand/Aotearoa and the Republic of South Africa/uMzansi Afrika, indigenous women face different experiences from ethnic minority women in the USA and UK, where the majority of research samples were drawn to reach research conclusions based on the 'concrete-ceiling' metaphor. In the Republic of South Africa/uMzansi Afrika, as an example, African women fight issues similar to those of a developing nation in Africa. They face issues such as unemployment, equal rights, health, polygamy, customary law (laws of traditional African societies), lobolo (dowry) and racial discrimination (Cock \& Bernstein, 2001). In the workplace, African women tend to emphasise concern for employees' interdependence and collective mutual support (Booysen, 2001; Littrell \& Nkomo, 2005). Challenges for African women in management reflect those challenges present for them in society as a whole. In New Zealand/Aotearoa the gender identity requires a Māori woman to overcome being a Māori, woman and ethnic minority in organisations at top-management levels. Indigenous women have challenges of being indigenous, female and a statistical minority in top-management in their own countries.

Contrary to the 'concrete-ceiling' studies, my research locates the experiences and perceptions of indigenous women in top-management, of predominately white organisations, within the history and politics of these countries. My study focuses on the experiences and perceptions of women who are indigenous in two former British colonial countries, New Zealand/Aotearoa and the Republic of South Africa/uMzansi Afrika. I grappled with my initial academic readings, to attempt to relate those experiences present in these journal articles to my former practical working situation. The reason is that the research conclusions in women in management literature are based on 'white folks' experiences' of 
women in management (Ross-Smith \& Chesterman, 2009). As I read deeply, I found a few studies that 'talk about Black folks' women's experiences' (Giscombe \& Mattis, 2002; Hite, 2005). I cannot relate to some of the thinking such as individualistic concepts of succeeding as a woman in a management position, assumed within the women in management literature and being a Black woman in management in the USA and UK. This is because my situation is that of being a Black woman who experienced Apartheid and democracy within one lifetime. I belong to a country that is bringing about massive change through reconciliatory efforts and dismantling the legacy of the Apartheid structures (see Chapter Two), policies, and mentality. My country has a different history and politics from the USA and UK. Within this literature, women in management, I also realised that other groups of women in management, such as Māori, are not discussed.

Although I acknowledge that indigenous women like me are not present in women in management literature; nevertheless, I take lessons from the experiences of women of different races (mostly white and a few Black from the UK and USA) present within this literature. I use the term 'white woman' to limit my discussion to the experiences of women who belong to the white race by self-definition. I use the term 'woman' to describe experiences that are applicable to all females of different racial groups. Being an indigenous woman in a top-management position may be complex because of having special 'rights' to the land and resources based on indigeneity, which is additional to being an ethnic minority woman. I draw from the women in management literature to understand what indigenous women in management could learn from this literature.

In the next section, I discuss 'barriers' preventing women entering management roles, as stated in the women in management literature.

International literature on the social, organisational and attitudinal 'barriers' for women entering top-management

In this section, I discuss factors that contribute to the 'concrete-ceiling' effect. These factors are 'barriers' ethnic minority women face entering top- 
management roles. I also explain and elaborate on the types of 'barriers' preventing women's progress through the different managerial levels. I discuss various theories present in women in management studies that explain reasons for the 'glass-ceiling' / and 'concrete-ceiling' effect (s). I group 'barriers' preventing women entering top-management roles into four main categories: social, organisational, attitudinal and self-selection 'barriers'. I focus on the discussions that were most helpful to me to analyse my data. I do not attempt to cover all the 'barriers' present in the women in management literature because they are not part of my study design.

\section{Social 'barriers'}

One of explanations that ethnic minority women are not largely represented in top-management roles of organisations is that the structure, process and systems of organisations is the reflection of a society. This concept is called the inequality regimes, that is the inequalities organisations produce structurally to disadvantage women (Acker, 1990, 2006). Under this view, the reason for the lack of women in management is that organisations reflect inequalities present in a society. Also, societal expectations produce and maintain inequalities between genders, according to Wood and Eagly (2002). These differences are attributed to the socialisation of men and women (Powell, 1988; Riger \& Galligan, 1980). They are developed through socialisation in various stages of life, such as schooling and work life (Bartol, Martin, \& Kromkowski, 2003). These gender roles that have been developed through socialisation then spill over into organisational roles (Eagly \& Johnson, 1990). Wharton (2005) contends that the manner in which work is organised both within and outside an organisation reflects gender. Jobs are associated with inequalities in terms of both gender and race present in a society (Acker, 2009). Gender is present in the sub-structures in understanding the functioning of organisations (Alvesson, 1998) and is organised in a hierarchy. These gender (and race) structures and inequalities hinder women from progressing through promotion (Maume, 1999). The theory of inequalities of regimes centres its argument on the role of society in producing inequalities in gender, and organisations being reflective of those inequalities. 
Following the logic of the inequality regime's explanation for the large absence of ethnic minority women in management, white males particularly in countries where the majority of studies focusing on women in management drew their samples (e.g. the USA, UK and Australia) tend to control resources, which gives them social and economic powers. These societal and economic powers are transferred into organisations, where white males are advantaged to occupy positions of influence, such as, top-management roles because of their positions in the society that privileges them. The assumptions, under this view, are that for ethnic minority women to be able to penetrate top-management roles the society needs to change structurally so that ethnic minority women have more power in their countries in order for the newly acquired power to be reflected in organisations enabling them to occupy positions of influence, such as, topmanagement roles. Unfortunately women in management studies do not currently engage social structures, which are influenced by politics of a country, as part of their theorisation of women in management, in particular, where the samples are drawn to reach research conclusions.

\section{Organisational 'barriers'}

Because both women and ethnic minorities occupy lower levels of influences in western countries compared to white males, they face organisational 'barriers' entering top-management roles that reflect their societies. In organisations, ethnic minority women are disadvantaged because of both their gender and race (Giscombe \& Mattis, 2002). This disadvantage may be reflected in organisational features, that is, systems, processes and structure of organisations where they may act as 'barriers' preventing ethnic minority women from entering top-management roles. An example of organisational 'barriers' are specific organisational practices and biases (Connell, 1987; Oakley, 2000; Rindfleish, 2000). The organisational practices may be biased against women and ethnic minority groups, contend Jackson (2001), Morrison, White and Van Velsor (1988). Organisational practices such as recruitment, retention, and promotion (Oakley, 2000) may exclude women and ethnic minorities from participating positively in organisations. Another example of an organisational practice may be institutional racism meaning an organisation may fail to meet the needs of ethnic minorities through its systems and processes (Fearfull \& 
Kamenou, 2006). Organisational practices may not favour women's advancement into management roles because of their positions of relative low power in their societies, which may be reflected in organisations.

\section{Race and gender attitudinal 'barriers'}

In addition to organisational 'barriers' ethnic minority women face entering topmanagement roles, they face negative gender and race attitudinal 'barriers' resulting from their positions in a society. This is because they face historical negative stereotypes about their groups, which still persist and these perceptions spill into organisations. Social attitudes towards what constitute 'male' and 'female' jobs, spill into individuals in organisations where management is associated with being a white male and its associated privileges. In this section, I discuss gender and race attitudinal biases towards ethnic minority women, which disadvantage them from entering top-management roles, as per studies focusing on women in management literature.

One of the 'attitudinal barriers', which prevent ethnic minority women entering top-management roles is the negative attitude towards women and ethnic minorities. Prejudicial attitudes towards women are the reason they often obtain negative assessment in filling management roles (Eagly \& Karau, 2002; Itzin \& Newman, 1995). Lyness and Heilman (2006) argue that women are less likely than males to be promoted and that if they are promoted they need to have stronger performance ratings than males. This leads to higher expectations of them than males, particularly for ethnic minority women (Catalyst, 1999; Crawford \& Smith, 2005; Thomas \& Gabarro, 1999) as they also have race to negotiate. Cross (1992), Powell (1993), Greenhaus and Parasuraman (1993), and Thomas and Higgins (1996) argue that ethnic minority women need to overperform to be perceived as credible, to compensate for their numeric and ethnic minority statuses. They have to compensate their numeric and ethnic minority statuses by working harder than the dominant group (Crawford \& Smith, 2005; Kanter, 1977a), who dominant top-management roles.

The gender related 'attitudinal barrier' present in a society that spills into organisations, preventing ethnic minority women entering top-management roles, 
are perceptions of the role of a manager. There are perceptions that associate 'management' with 'male' (Heilman, 2001; Lyness \& Heilman, 2006; Schein, 2007). These perceptions are prominent when women occupy roles that are traditionally associated with men, such as engineering (Catalyst, 2007) and management. This association makes it difficult for a woman to behave or occupy a role outside the norm of the expectations of what constitutes a 'woman'. This means that there is a 'lack of fit' between management roles and the stereotypical attributes of women, argues Wood (2008). Women have to adjust their behaviours and themselves to fit the expectations of being a manager (De Fries, Webb, \& Eveline, 2006; Kamenou \& Fearfull, 2006) to manage negative attitudinal biases towards them. They have to meet the expectations of being a manager, which is often different from the perception of being a woman (Simpson, 2000). This suggests that masculinity in management compares women's behaviours to the male norm of what constitutes management. Many researchers investigated the relationship of gender and the stereotypes of management characteristics (Duehr \& Bono, 2006; Powell \& Butterfield, 2002; Willemsen, 2002). Studies found the 'think manager - think male' (Schein, Mueller, Lituchy, \& Liu, 1996) phenomenon. The 'think manager - think male' concept means that the beliefs about management are more similar to the beliefs about men than women, signifying that managerial roles are welcoming to men. All these studies at different magnitudes conclude that men and management share similar characteristics and the extent of the problem vary from country to country.

There is a challenge with associating masculinity with management. The challenge with this gender stereotype is that it is prescriptive in that people expect both men and women to behave in gender-consistent types and roles (Bligh \& Kohles, 2008). Women compete with men as female professionals, which is a weaker position than for men (Nicolson, 1996). For women to be successful in organisations, they need to minimise the effects of femininity as a requirement to join top-management levels (Coates, 1998). This may explain the reasons that some women may adopt masculine stereotypical attributes when in management (Kerfoot \& Knights, 1998; Wacjman, 1998). The gender stereotypical view confines both men and women in narrow categories of 
behaviours and styles and limits other behaviours, or a range of behaviours, that may be effective in the workplace (Catalyst, 2007). This approach assumes that masculine and feminine characteristics are mutually exclusive (Catalyst, 2007) and this view is centred in heterosexual relationships of females and males (Pringle, 2008). Women are disadvantaged under this perspective for being 'women'.

Also, race attitudinal 'barriers' exist that associate management with being white. Researchers (Tomkiewicz, Brenner, \& Adeyemi-Bello, 1998) investigated the effects of race and managerial stereotypes. Research indicates that jobs are stereotyped according to race (Terpstra \& Larsen, 1980). Studies conclude that white people hold more positive perceptions about other whites than about ethnic minorities (Gaertner \& McLaughin, 1983; Leonard \& Locke, 1988). In management, a person of a white race is assumed and expected. This becomes a problem for ethnic minorities and indigenous people because they have to manoeuvre within the white norms and expectations of management. They have to negotiate both their ethnic minority status of being a manager within an environment where a white race is assumed and preferred. This may bring uncertainties and ambiguities for ethnic minority women.

In addition to management associated with being white, there are other race related attitudinal 'barriers' that disadvantage ethnic minority women entering top-management roles. An example of an attitudinal 'barrier' is aversive racism that may be practised by individuals in organisations and a reflection of a practice in a society. Wells (1998) describes aversive racism as a form of discrimination that is marked by systematic barriers to turn away ethnic minorities. It is veiled (Hite, 1996). Dovidio (1993) defines it as racially motivated behaviours that are masked with a socially accepted motive by those who do not want to view themselves as racist or prejudiced. It is 'a subtle, often unintentional form of bias' often found in individuals who 'possess strong egalitarian values and who believe that they are non-prejudiced' (Dovidio, 2001, p. 834). Although these individuals articulate equality, they unconsciously have negative beliefs based on racial difference (Hite, 2005). Aversive racism is found in individuals and may be reflected in organisational practices. Aversive 
racism may be reflected as a bias disadvantaging ethnic minority groups. This is a 'barrier' for ethnic minority women in management and is often invisible.

Because of the lack of a large number of ethnic minority women in topmanagement roles (see Chapter Two), those ethnic minority women occupying top-management roles face negative racial attitudinal 'barriers' regarding their suitability in top-management. Ethnic minority women in management are perceived by their colleagues to be 'under-qualified'. Turner, Myers and Cresswell (1999) contend that the colleagues of ethnic minorities expect them to be less qualified or less likely to make a significant contribution. Other studies (James, 1994; Kossek \& Zonia, 1994) indicate that white colleagues expect ethnic minorities to be under-qualified and/ hired solely to meet quotas. In management, ethnic minority women have to address issues in respect of educational qualifications that relate to perceptions about their race, which may hinder them in management. This is because ethnic minority women are largely disadvantaged economically, mostly due to the historical and political reasons in their countries, in particular in New Zealand/Aotearoa and the Republic of South Africa/uMzansi Afrika.

In top-management of organisations, ethnic minority women are described as 'tokens' because they are not well represented in these roles and face challenges of breaking stereotypes associated with the low status of their social categories in their societies. Kanter (1977a) found that when women were less than $15 \%$ of the total numbers in occupations, they became visible, their difference from the majority group were highlighted and their traits were often distorted to fit within gender stereotypes. Token women are women in male-dominated and masculine occupations where they are under-represented (Yoder, 1994). For women, these occupations include management levels (Fairhurst \& Snavely, 1983) and professionals in male dominated occupations (Macke, 1881). Being tokens created performance pressures for women in roles that were stereotyped to be masculine such as management (Gutek, 1985). These negative effects of being tokens only occur for members of social categories that are of lower status, for example women, than to white males (Alexander \& Thoits, 1985). Ethnic minority women as tokens, their individual characteristics are misrepresented to 
be in line with stereotypes about their social group (Spangler, Gordon, \& Pipkin, 1978). At top-management levels, ethnic minority women are vulnerable to stereotyping because they are a few and their limited numbers make them visible.

\section{Self-selection 'barriers'}

In addition to the race and gender attitudinal 'barriers' preventing ethnic minority women entering top-management roles, ethnic minority women choose not to progress up the organisational ladder of organisations. This is because of the challenges that women face in organisations due to their gender and the demands of top-management roles being a female manager (Ross-Smith \& Chesterman, 2009), which reflect power structures in a society, disadvantaging women. Some women choose to opt out of top-management roles for several reasons (Probert, 2005). Women may be reticent and ambivalent about occupying management roles (Ross-Smith \& Chesterman, 2009) because of role conflict (Gummer, 1990), preferred leadership style (Oakley, 2000), long hours, sexual harassment, women's isolation, lack of support (Itzin and Newman, 1995; Olsson and Pringle, 2004), lack of appropriate experience and education (Carli \& Eagly, 2001; Doherty \& Manfredi, 2010), and sex-role stereotypes (Simpson, 2000; Singh, 2003). Based on these studies focusing on women in management, which state that self-selection is part of the reason for women to opt out of management, the majority of them are conducted on white women samples. The assumptions in the research conclusions in these studies are that women view promotion as self-success rather than social upliftment of women in general. Some women choose to opt out of top-management roles because the requirements and expectations of being a manager and female are contradictory, based on societal attitudes, which are reflected by individuals in organisations.

\section{'Barriers' focusing on studies in New Zealand/Aotearoa and the Republic of South Africa/uMzansi Afrika}

In this section, I discuss research studies that draw samples from New Zealand/Aotearoa and the Republic of South Africa/uMzansi Afrika focusing on women in management. In both New Zealand/Aotearoa and the Republic of South Africa/uMzansi Afrika, ethnic minority women face negative attitudinal 'barriers' of being women and / ethnic minorities in management. This becomes 
problematic for indigenous women because they have to manage perceptions of being a manager, indigenous, and female in top-management, which are often contradictory. I discuss these studies because they influenced my expectations that my participants would discuss particular issues as 'barriers' during the interview.

In the Republic of South Africa/uMzansi Afrika, studies focusing on women in management suggest that the lack of African women in top-management roles is attributed to attitudinal 'barriers' of being a woman (Erasmus, 1998) and Black in management (Mathur-Helm, 2002). These negative attitudinal 'barriers' are the result of the legacies of the 'Apartheid' policy (see Chapter Two), which was a political Government policy, privileging white males socially and economically, I contest. Denton and Vloeberghs (2002) and Sunter (1997) argue that men in the corporate world of the Republic of South Africa/uMzansi Afrika do not appreciate the skills of women because of the patriarchal society. In addition, 'management' is associated with 'male' (see section under attitudinal 'barriers' in this chapter) in the Republic of South Africa/uMzansi Afrika, which is a similar research finding to the international literature (April, Dreyer, \& Blass, 2007; Booysen \& Nkomo, 2010). Indigenous women face dual challenges to get into top-management positions because of challenges associated with being both of an ethnic minority race and female gender (Booysen, 1999; Mathur-Helm, 2005), which are both not associated with management. Similarly, studies indicate that the lack of Africans in top-management positions has been attributed to discrimination based on their race (Commission for Employment Equity, 2001; Mathur-Helm, 2002). Human and Allie (1989) argue further that Africans are largely absent in top-management roles because of negative attitudes towards Africans. Human (1996) and Human \& Hofmeyr (1987) contend that research conducted in the Republic of South Africa/uMzansi Afrika confirms that white professionals, in general, believe that indigenous people are inherently less capable than whites. Negative perceptions towards Black females act as attitudinal 'barriers' for African women entering topmanagement roles and are part of the challenges of building a non-racial and non-sexist society, in the Republic of South Africa/uMzansi Africa. 
Similarly, in New Zealand/Aotearoa, studies suggest that negative attitudes towards women in management are a 'barrier' for women entering topmanagement roles. Studies performed in New Zealand/Aotearoa have similar research conclusions as those conducted internationally. The negative perceptions of women regarding their capability of managing have been found to be one of the reasons for the lack of women in top-management (Baldwin, 2000; Holmes, Burns, Marra, Stubbe, \& Vine, 2003). In addition, studies conducted in New Zealand/Aotearoa, suggest that the attitude towards the selection approach and process in top-management roles favours males (Baldwin, 2000) because the approach and process are not objective and rely on informal networks, that tend to be male (Fawcett \& Pringle, 2000). Also, because 'management' is associated with 'male', as also confirmed by studies conducted in New Zealand/Aotearoa (Fawcett \& Pringle, 2000; Olsson \& Walker, 2004), which is also a similar research conclusion as those studies conducted internationally, the response from women are contradictory behaviours. Women may behave inconsistently because they are managing views of being female and manager, which are different. Olsson \& Walker (2004) confirm the paradox that some top managers who are women deny gender as a factor that affects their career progression. However, other women assert their femininity as the reasons for their success (Olsson \& Walker, 2004). For Māori women, the paradox may arise from belonging to both groups that are socially and economically disadvantaged female and indigenous - in management, neither of which is associated with management roles. These complexities lead women in top-management to have equal or better education than men (Fawcett \& Pringle, 2000; Olsson \& Walker, 2004) and extensive experience (Olsson \& Pringle, 2004). In the western norms and traditions, there seems to be a positive link between success in formal education and success in the job market (Taylor, 2002). However, for ethnic minority women this link is not so clear and not so positively correlated (Reskin \& Charles, 1999; Taylor, 2002) and fused with race because of belonging to two groups that are marginalised.

In the next section, I discuss 'strategies' to overcome these 'barriers' focusing on the 'concrete-ceiling' theoretical concept in the women in management literature. 


\section{'Strategies' for top-management entry}

In this section, I use the concept of 'strategies' to discuss approaches that facilitate entry into top-management roles for women, particularly ethnic minority women, or that facilitate progression through management levels, as per studies focusing on women in management.

\section{The development of people skills}

In this section, I discuss the development of people skills to build relations as necessary for a woman to acquire and maintain in order to succeed entering topmanagement roles, as per women in management studies. The women in management literature assumes that an individual has the responsibility to develop the skills to obtain success.

For an ethnic minority woman to enhance her chances of entering and succeeding in top-management roles, individual skills are important, as per the women in management literature. For example, a leadership style that is collaborative, and inclusive of other groups that are not dominant in top-management roles, assists in incorporating women into top-management roles (Crampton \& Mishra, 1999). For women entering top-management, factors such as hard-work (McClelland, 1965; White, 1995), interpersonal or people skills, competency on the job, and taking risks are necessary (Wentling, 1992). In New Zealand/Aotearoa, the ability to choose fights (Fawcett \& Pringle, 2000), build positive relationships (Olsson \& Pringle, 2004) and having people skills (Pringle \& Olsson, 2002) are important in facilitating management entry.

Other studies suggest that there are organisational policies, processes and systems that enhance the environment for women. These enabling organisational policies, processes and systems are influenced by the legal and political position of a country, I argue. For example, the enabling policies and practices of an organisation facilitate progress of women into top-management roles (Kottke \& Agars, 2005). Although positive policies, such as Equal Employment Opportunities, may assist in creating a positive environment for ethnic minority women, the accountability of success is up to a woman herself to use her 
individual skills to succeed within an organisation with such policies, as assumed in the women in management literature.

My challenge with these 'strategies' as framed in the women in management literature is that they are individualist in that they do not include broader social change to help an individual woman to succeed in top-management of predominantly white organisations. They place the responsibility on the individual woman to employ these strategies in order to create success for herself. There are also those 'strategies' identified in the women in management literature that rely upon collaboration with other individuals. For example, the existence of networks and sponsors support the movement of women into topmanagement roles (Crampton \& Mishra, 1999). In addition, having a role-model facilitates management entry (Catalyst, 2003; Gibson, 2004). However, within this literature, these 'strategies' are discussed in the context of how the individual woman manager uses this support through her own skills to help her advance.

In the next sub-section, I discuss mentors. I address this idea in detail because it is part of my study design.

\section{Mentors}

Gaining an ability to acquire and maintain a mentor is important for ethnic minority women entering top-management roles. Having a mentor is one of the factors that supports the movement of women entering top-management roles (Bhatta \& Washington, 2003; Scandura \& Williams, 2001). Mentors can provide both psychosocial support and career enhancing functions. Researchers (Thanacoody, Bartram, Barker, \& Jacobs, 2005) define career enhancing functions as including sponsorship, coaching, exposure, protection and provision of challenging assignments, whereas psychosocial support includes acceptance, counselling, emotional support and role modelling. The mentoring functions should serve as both career enhancement and psychosocial support (Thanacoody, et al., 2005). For ethnic minority women, having a mentor facilitates success in organisations, particularly for ethnic minority women, according to Blake-Beard (1999), which means that an ability to attract and maintain mentoring relationships is beneficial for organisational success for ethnic minority women. 
Reciprocally, there are benefits to being a mentor. Allen, Lentz and Day (2006), Bozionelos (2004), Scandura (1992), suggest that mentoring other individuals is a prerequisite for success for mentors themselves, and not only for protégés. This indicates that, for women in management, mentoring other individuals is also a benefit to them as individuals who have already reached management roles. Mentoring other individuals may provide them with opportunities to grow as both managers and individuals. It also provides them with opportunities to learn from the experiences of their protégés. For women already in management, to continue to succeed in organisations, research suggests that mentoring others also benefits them as mentors.

Gender is an issue for negotiation in mentoring relationships. Those researchers in support of women being mentored by other women, argue that a lack of women in management is the reason that other women do not have mentors who can act as mentors for others. These studies assume that women in management are willing to mentor other women. This theory puts the responsibility of mentoring women to other women who are in management. Under this view, women are disadvantaged in receiving mentorship because there are not sufficient numbers of women in management who can act as mentors for other women (Cleveland, Stockdale, \& Murphy, 2000; Schwiebert, et al., 1999). This is particularly true for ethnic minority women (Collins, 1990; Hite, 2004; Kogler $\&$ Gant, 2000) as they also have race to negotiate. Some studies (Clark, 2000; Quinlan, 1999) indicate that female protégées prefer female mentors because they can provide gender-related advice. However, not all studies provide evidence of support for a woman manager mentoring other women wishing to progress into management roles (Feeney, 2006). According to Kram (1985), and Chao (1997), being comfortable with the mentoring relationship is important.

In studies focusing on mentoring relationships, researchers largely focus on oneon-one formal relationships within the same organisation. Current studies on mentorship largely focus on dyads and include members of unequal status (Baugh \& Sullivan, 2005), such as a supervisor or superior and a less experienced individual (Monserrat, et al., 2009). Most research studies are 
largely within the organisation. A limited number of studies, for example Ehrich (2008), Ragins and Cotton (1999), and Touise (2005) - include informal mentoring within the same organisation. Informal mentoring is considered by some researchers to be more effective than formal mentoring (Blake-Beard, 2001; Chao, Watz, \& Gardner, 1992; Hurley \& Fagenson-Eland, 1996). Other scant studies - for example Kram and Isabella (1985), and Parker and Kram (1993) - touch on informal mentoring relationships that takes place between different organisations (Chandler \& Kram, 2005) and group mentoring relationships. Informal mentoring relationships that exclude one-on-one individual interaction are largely absent from research studies, which is a gap in mentoring studies.

Recognising the culture in defining mentoring relationships is important to understanding the parameters of these relationships for both mentors and protégés. Researchers (Monserrat, et al., 2009) conclude that mentoring practices may be influenced by culture. For indigenous women, culture affects issues that are part of their daily lives in their communities. For a mentor to understand culture of a protégé is important in order to provide the appropriate guidance (Blake-Beard, 2009). For example, based on my own experience, indigenous people in both New Zealand/Aotearoa and the Republic of South Africa/uMzansi Afrika believe in the interaction of both the living and the spiritual world. This may shape the definition and understanding of the mentoring relationships, especially if a mentor is someone who is deceased. Current debates in mentoring relationships assume that both mentors and protégés are alive. Also, indigenous groups from both the Republic of South Africa/uMzansi Afrika and New Zealand/Aotearoa are collective in their values, based on my own experience. This value may impact on how the mentoring relationships are structured and managed. For example, in New Zealand/Aotearoa, it is important to structure mentoring relationships around the whanau (family/extended family), according to Hook, Waaka, Raumati (2007), Ratima and Grant (2007). Currently, there is not extensive research on the impact of ethnic culture regarding mentoring relationships, particularly for indigenous women, which is also a gap in mentoring studies. 


\section{'Biculturalism'}

In addition to 'barriers' and 'strategies', 'biculturalism' is an important concept in women in management, in studies focusing on the 'concrete-ceiling' metaphor. 'Biculturalism' is a compromise strategy that defines the lives and movements of ethnic minority women in two different communities - their own and their organisations. 'Biculturalism' is relevant to ethnic minority women as they move between their Black/indigenous cultures in their communities and white cultures in their organisations, as per definition of both the USA (Bell, 1990) and New Zealand/Aotearoa contexts. The objective of this section is to explain the lives and movements of indigenous women and the issues that may affect them in succeeding in top-management roles. I discuss issues of 'biculturalism', as this concept impacts on ethnic minority women in executing their jobs in management.

In management studies focusing on ethnic minority women, most AfricanAmerican scholars use the term 'biculturalism'. They use this term to define the movements of ethnic minority women between white and Black communities. Bell (1990) introduced this term to define the lives of ethnic minority women in management. She (Bell, 1990) defines 'biculturalism' as a concept where ethnic minorities have to fit into both the white and ethnic minority worlds. Other researchers (Bell, et al., 1993) contend that ethnic minority women have to adopt the new cultural identity of their organisations, which tend to be white. This is because there are implicit expectations of norms and behaviours in predominantly white organisations (Liff \& Cameron, 1999). The challenge for ethnic minority women as statistical minorities in management is that they have to fit within that culture (Kamenou \& Fearfull, 2006). If they are unable to 'fit' within that white culture, as statistical minorities, they are perceived as problematic (Kamenou \& Fearfull, 2006). Bell (1990) contends that ethnic minority women move from a 'professional' persona to a relaxed 'home' persona; a switch very common for ethnic minority women in organisations, particularly in management roles. In order to survive in both these two different worlds, they compartmentalise their lives (Bell, 1990). 
There are challenges of moving between two cultures. Bell (1990) talks of 'bicultural' stress that is associated with moving in two different worlds with different norms and culture. This type of stress relates to role demands from both cultures and significant individuals, such as friends and family of an ethnic minority woman. In their organisations, they often have to fit into the existing mainstream culture to be able to advance into top-management (Kamenou \& Fearfull, 2006) and manage being a 'woman' in their communities. Ethnic minorities from a non-dominant culture choose how to manage stress associated with moving between the two cultural systems (Bell, 1990). In managing different identities, they face pressures to conform to the requirements of their organisational culture that tend to be white, while also meeting the expectations of being a Black woman in their communities (Bell, 1990). This is a way ethnic minority women choose to organise their lives culturally so that they can remain centred in their Black communities and move in the white world in their organisations (Bell, 1990). Movements between two different cultures with different norms and behaviours are associated with the stress of managing one's identity.

The current model of 'biculturalism' (Bell, 1990) does not incorporate indigenous women in their communities as they define their gender roles. It assumes that a man and woman have a similar exchangeable role within the social and organisational environments. These studies only focus on the race interpretation aspect of ethnic minority women, ignoring the definitions of gender in both Black and white communities. They ignore the importance of ethnic cultures in defining a 'woman'.

In the New Zealand/Aotearoa context, Māori women face a dilemma of double consciousness as they struggle to function in two distinct worlds, one Pākehā and the other indigenous (Fitzgerald, 2003). The double consciousness results from knowing norms and behaviours for two different cultures. Māori society has specific Māori protocols and concepts, which define Māori as a community (Henry \& Pringle, 1996). At top levels of organisations in New Zealand/Aotearoa, the culture is predominately European/Pākehā. Amongst other things, the white male majority at those levels influence the culture. For a 
Māori woman, she has to be able to switch and adapt between the Pākehā and Māori cultures. She requires different 'survival' skills in top-management than a Pākehā woman who only deals with issues of gender. Nevertheless, in the New Zealand/Aotearoa context, Māori women may be 'bicultural' and the spaces between Māori and Pakeha may not always be exclusive and independent of the other.

\section{Conclusion}

There are challenges with the assumptions of research conclusions in studies focusing on the 'concrete-ceiling'. The current model of the 'concrete-ceiling' concept present in the women in management literature assumes that the individual, through her sole efforts, breaks through the 'concrete-ceiling'. This literature focuses on the idea of women having the personal characteristics, to do with their own skills and abilities, to attain top-management roles. Her success is largely attributed to her sole ability to manoeuvre in top-management in breaking through the 'concrete-ceiling'. She does so by using different 'strategies', such as having a support network (McGlowan-Fellows \& Thomas, 2005; Thomas, 1990) present within this literature. Within these studies, third-party interventions such as government initiatives to assist women entering management roles are largely unacknowledged. Women are presented as having the sole responsibilities of ensuring their successes as individuals rather than as a collective. Although within the women in management literature, the 'concreteceiling' metaphor is primarily based on the research conclusions of Black women from the USA (Giscombe \& Mattis, 2002; Hite, 2004) and UK (Bhavnani \& Coyle, 2000), it is useful to assess its relevance to other ethnic minority women in management, such as indigenous women. This study also assesses whether this model of the 'concrete-ceiling' metaphor works in a similar manner in respect of indigenous women in top-management roles.

I contribute to the women in management literature through the theoretical understanding of the 'concrete-ceiling' metaphor by using a sample that was colonised by former British rulers: New Zealand/Aotearoa and the Republic of South Africa/uMzansi Afrika. I apply the 'concrete-ceiling' concept in the context of New Zealand/Aotearoa and the Republic of South Africa/uMzansi 
Afrika. Other researchers, such as Prasad (2001) also place the importance on locating academic theories within the historical moments. For indigenous women, there are also complexities resulting from being the 'first'/'last' occupants of the land prior to the European colonisation. My study provides the new era in the women in management literature that proposes a different conception of the phrase 'ethnic minority', which is indigenous and outside the USA and UK. As part of my conceptual design in understanding the experiences of indigenous women in top-management, I contextualise their experiences within the history and politics of New Zealand/Aotearoa and the Republic of South Africa/uMzansi Afrika (see Chapter Two).

In the next chapter, I will discuss the methodology guiding my study. 


\section{CHAPTER FOUR}

\section{INDIGENOUS AND WESTERN PERSPECTIVES}

This research uses a combination of western and indigenous perspectives. I use the term 'western' to mean ideologies and assumptions emanating mostly from North America, Europe, Australia and New Zealand/Aotearoa, influenced largely by white researchers. I also use the term 'western' to represent the historical tradition in which most management science research is based. I combine interpretive approaches from western perspectives, with aspects of indigenous perspectives: Kaupapa Māori from New Zealand/Aotearoa and an Afro-centric framework from the Republic of South Africa/uMzansi Afrika. The rationale for using both perspectives is influenced by my status as an indigenous researcher moving between two separate spaces: western and indigenous. Also, these different perspectives are relevant to understanding the experiences of my participants as they move between their indigenous communities and organisations that are predominantly non-indigenous and white. In this chapter, I discuss what I mean by interpretive and indigenous perspectives. I also elaborate on what it meant for my research to combine these research perspectives in terms of methodology.

The next section of this chapter discusses my reasoning for choosing both indigenous and western approaches. Then, I elaborate on the origin of my research questions and discuss indigenous as well as cross-cultural methodologies. I follow with a section that explains a Kaupapa Māori framework in researching Māori. Then, I present an Afrocentric framework that guides my study. Thereafter, I discuss interpretive approaches and the philosophies directing my study. I follow with a section that explains what I did, that is, the practical implications of combining western and indigenous perspectives (methods). The section on what I did explains my pilot study, interviews, sample and data analysis. 


\section{Reasons for choosing a combination of methodologies}

In this section, I elaborate on my reasons for choosing a combination of research methodologies.

The research approaches guiding my study are a combination of paradigms, that is, both interpretive and indigenous philosophies (Afrocentric in the Republic of South Africa/uMzansi Afrika and Kaupapa Māori in New Zealand/Aotearoa). As an indigenous woman who is a researcher, I wanted to approach my interviews and this study in a culturally appropriate manner whilst also meeting the requirements of a $\mathrm{PhD}$ in a white western university in New Zealand/Aotearoa. Māori and African cultures became important as an aspect of understanding the world that is shaping the experiences of my participants. However, I do not study culture in depth. I affirm it to make sense of the experiences of my participants as an element that influences their sense-making of being indigenous women in top-management. Stanley (2009) contends that articulating the experiences of ethnic minority women needs to be conducted through discourse or theories that challenge the beliefs of the dominant groups and should incorporate indigenous research discourses to reflect their lives and experiences. My research paradigms attempt to achieve this.

I consciously chose a combination of research paradigms to conduct research and theorise about my study. As I was reading the different western research paradigms, I failed to locate or 'box myself' in only one of them. I agreed with some aspects of several of them. As an indigenous woman, I felt I had a duty to promote indigenous research paradigms in management studies, because I could relate to them and they were part of me as an indigenous woman. I used a combination of methodologies. I used different research methodologies (western - interpretive approaches and indigenous - Kaupapa Māori in New Zealand/Aotearoa and Afrocentric in the Republic of South Africa/uMzansi Afrika) at different stages of my research. Some researchers (Burrell \& Morgan, 1979; McCourt, 1999) promote the idea that researchers should operate from one paradigm at any point and not reconcile paradigms. They contend that paradigms contradict each other and have opposing meta-theoretical assumptions. Contrary to these studies, other researchers (Mingers \& 
Brocklesby, 1997; M. Parker \& McHugh, 1991; Pfeffer, 1993) support a multiparadigm approach to research. Most of these studies discuss the usage of a combination of research paradigms within a western context. Other researchers (Fitzgerald, 2006) suggest indigenous research methods for indigenous women. However, they do not indicate a combination of research strategies with western approaches, when researching indigenous women.

I use a combination of research paradigms to claim my space as an indigenous woman in a research context focusing on women in management positions. Smith (1999) argues that the term 'research' is associated with western imperialism and colonialism. The research studies focusing on women in management are dominated by white women from western societies and Black women from mainly the USA and UK. In Chapter Three, I explained the problems and challenges associated with this dominance. In claiming my space as an indigenous woman in research focusing on ethnic minority women in management, I create space for similar thinkers, who had not had the courage or opportunity to do so. I claim my sense of identity in the white western research space. I do so to change my status of being an outsider by having to fit myself into well established so called 'management science' with its traditions and methodologies. I use this approach to encourage diverse research paradigms and debates focusing on women in management.

I used a combination of research paradigms because I appreciated and understood both indigenous and western research paradigms. This also reflects my movement in both the academic and personal spaces. My indigenous research paradigms do not need to be 'civilised'. However, I integrated them with western epistemologies to show awareness and comprehension of both views in shaping who I am as a researcher. I am an indigenous woman, who studied in white western universities within university faculties that focus on western research methodologies. I was raised in a Black township and community in the Republic of South Africa/uMzansi Afrika. Socially, I live in both indigenous and white communities. My socialisation, upbringing and current interactions have been influenced by both indigenous and western values. 
Choosing a combination of research paradigm is a reflection of who I am as an individual and researcher.

I initially hesitated to use both indigenous and western research paradigms because of the risks. I believe that sometimes writing unconventionally as a novice researcher may be precarious, because most management researchers have been trained to study mainly the western research paradigms and socialised academically to present themselves as individuals. Unfamiliar or unconventional concepts and traditions such as collectivity, the collective and combined research paradigms may bring ambiguities and / uncertainties within themselves, as these are concepts or traditions with which other academics are not familiar or which they have not been trained to evaluate academically. Presenting my work as such, I may be requesting that these researchers read and comprehend my work in a manner that would be outside their frame of reference or outside the eyes they have been conditioned to use to evaluate research studies. Presenting different epistemologies together in one study was cumbersome. I do so to bring forth my indigenous way of collectivity and inclusivity by weaving this knowledge with that of the insider community who promote individualism, and western methodologies / epistemologies.

Another risk associated with writing unconventionally is to lose credibility as a researcher. Collins (1989) argues that knowledge claims must be consistent with the existing body of knowledge that the group controlling the interpretive context accept as true. Knowledge that is understood in one particular cultural context, may not always be understood through the tools that govern the belief system and worldview of a different cultural or research context (Jahnke \& Taiapa, 1999). Scheurich and Young (1997) contend that researcher's 'clothing' is tailored for a white worldview. Research activities have positioned the white western models as the only legitimate processes of conducting research (Fitzgerald, 2004). Indigenous epistemologies are yet to be 'internationally recognised' (Muwanga-Zake, 2009). This impacts on the decision of what is accepted as valid and useful research knowledge that is still held outside the indigenous research paradigms. Paradigm preferences are reinforced by institutions of like-minded individuals (Mingers \& Brocklesby, 1997). They are 
also associated with university/research funding and prestige, argues Scheurich and Young (1997). Hendrix (2001) contends that another risk is an unwritten preference during the publication review process. Yet, if I were to ignore my indigenous worldview, I would be perpetuating what Scheurich and Young (1997) call 'epistemological racism' where 'civil' racist doctrine favours a white worldview. This act leads to the 'slow death' of indigenous research epistemologies.

The next section addresses the research questions that I answer in Chapters Five, Six and Seven.

\section{Research questions}

The inspiration for my research questions arises from my own work and study experiences as an indigenous woman.

Through my working experience, and through studying in western universities focusing on subjects that address issues regarding a woman in a management position, I became aware of the absence of the experiences of indigenous women in shaping the academic studies. I felt we were invisible (Collins, 1986) as indigenous women in these studies and we had not been shaping the understanding of this literature. Our history as indigenous people is important in defining our ethnic minority status as women, in top-management. Because of my standpoint then, as both a student and practitioner, I lacked the necessary skills, tools and legitimacy of being a 'recognised researcher' to shape knowledge regarding indigenous women in management. Through my studies, I gained the confidence, opportunity and 'legitimacy' to address my point of interest regarding the experiences of indigenous women entering topmanagement roles.

Prior to beginning this study, I became aware that some of the concepts present in studies focusing on women in management were outside my experience of knowing and understanding as an indigenous woman. As I was conceptualising my research, I wondered whether other indigenous groups had similar or different views about understanding the world in comparison to current debates 
that I address throughout this thesis on women in management. I was particularly interested in drawing understanding from an indigenous group that shared some aspects of history with the Republic of South Africa/uMzansi Afrika. I chose New Zealand/Aotearoa. Although these countries both share a history of British Settler States, apartheid was unique to the Republic of South Africa/uMzansi Afrika.

My main research question is: how do gender and race impact on promotion to top-management roles?

The research sub-questions are:

1. What barriers/issues do indigenous women face when they move into topmanagement roles?

2. What strategies do indigenous women implement to enhance the opportunities to advance into top-management roles?

3. What do indigenous women believe are the lessons for other indigenous women entering top-management roles?

My original first research sub-question changed as I progressed with this research study. Initially, my first sub-question had been: what are the 'barriers' indigenous women face when moving into top-management roles? After interviewing about five women in New Zealand/Aotearoa I realised that my participants stressed successes rather than barriers. Although, they mentioned barriers that they had encountered, they largely focused on what made them successful top managers, who were also indigenous women. They shared their successes without being asked the question directly. Their success stories became important to my research. I then realised through my initial interviews that I was interviewing a group of indigenous women who are beginning to change history. I realised that my participants were at a point in history in both New Zealand/Aotearoa and the Republic of South Africa/uMzansi Afrika where these Governments were compensating indigenous women for the historical wrongs based on their indigenous status. These Governments were proactively implementing policies and legislation to advance indigenous women, particularly 
in organisations. How they entered their current roles became important for my study. I then changed the word 'barriers' to 'issues' to include a range of aspects impacting on their entering top-management roles.

The first research sub-question is: what barriers/issues do indigenous women face when they move into top-management roles? This question came from my readings before I conducted the interviews and my experiences during the interviews. From my readings on journal articles focusing on women in management, the 'glass-ceiling' and 'concrete-ceiling' metaphors became important (see Chapter Three). Within these studies, 'barriers' for ethnic minority women entering top-management roles in western cultures are identified. I became interested in investigating the relevance and applicability of these 'barriers' to indigenous women resulting from being both indigenous and women. In my selection of the sub-question on 'barriers' indigenous women faced when entering-top-management roles, I kept the question broad. I also included the word 'issues' later on after my initial interviews, as I explain above. In so doing, I left room for other aspects that may not be 'barriers', but are behaviours, actions and activities affecting ethnic minority women in topmanagement. Issues may also include 'barriers'. I intentionally did not want to select any specific 'barrier' because I did not want to be presumptuous or preempt the experiences of my participants. For me to leave the question broad, made room for the identification of any 'barrier' that they encountered that may or may not be present in studies focusing on the 'concrete-ceiling' theory.

The origin of the second sub-question came from my readings. The second subquestion is: what strategies do indigenous women implement to enhance their opportunities to advance into top-management roles? From the women in management literature, I drew up a list of questions on 'strategies' to enhance the mobility of women entering top-management roles. They included aspects such as mentors, role-models, sponsors and a network. I asked questions around all these aspects (mentors, role-models, sponsors and a network) to assess the type of success or support strategy my participants used. I discussed 'strategies' for ethnic minority women entering top-management roles. In Chapter Six, I will 
discuss mentorship because, in the findings, it became more important than other support mechanisms.

The third sub-question is: what do indigenous women believe are the lessons for other indigenous women entering top-management roles? This question came from my own wish to know. I wanted to know if there was any learning that I could implement for myself after my studies. In addition, I wanted to pass on knowledge to other indigenous woman aspiring to be in a top-management roles; knowledge which will be practical and applicable.

In the next section, I explain indigenous approaches that I use in my research. I also discuss my different positions in this research.

\section{Indigenous and cross-cultural methodologies}

As my identity contributes to my research conceptualisation, it is important to understand my stand-point in this research. In this section, I discuss my different locations and situations in my research. I explain my insider/outsider status in relation to this research. I also elaborate on the importance of my race in relation to conducting research with Māori and issues in cross-cultural research. In addition, I discuss some of the issues that I had to address when researching Māori as I'm a non-Māori researcher as well as ethics associated with such research.

\section{Insider/outsider perspectives in my research}

Because of my experiences, influences and identity, my stand-point in writing and conducting my research is that of 'outsider-within' (Collins, 1986). In my life experience of being socialised as an indigenous woman and in my thoughts, I largely do not identify with the concepts present in studies focusing on women in management. However, I am part of that community by virtue of conducting this research, my ability to engage with researchers in the field, and my new group membership of being an academic writer. This means that I am conscious of the different worldviews, including western paradigms, but remain committed to my own indigenous viewpoint. As a researcher, I engage with the 'insidercommunity', who are researchers focusing on women in management studies. 
This 'insider-community' tends to focus on western thinking, values, cultures and paradigms. I remain rooted in my indigenous worldview in this research. For the academic purposes of this study, I move between indigenous and western worldviews. I am committed to improving the lives and understanding of indigenous women in top-management roles in both New Zealand/Aotearoa and the Republic of South Africa/uMzansi Afrika. I believe that I am the qualified as an informant to conduct this study, as I understand both the western and indigenous world-views.

In addition to being an 'insider-within' in writing my research, in relation to my participants, I am both an insider and outsider, as per Adler and Adler's concept (1994). Researchers (Jewkes \& Letherby, 2001) state that insider/outsider relationships are complex and should be continuously negotiated. I am an insider because I am part of the social group that I study: indigenous woman from the Republic of South Africa/uMzansi Afrika. Being an insider, there were common understandings on gestures, non-verbal communication and culture-bound phrases with my participants. These behaviours did not need interpretation. However, I am both an insider and outsider to New Zealand/Aotearoa and Māori. My indigenous status to Māori makes me an insider, but my location in the Republic of South Africa/uMzansi Afrika and African identity make me an outsider to New Zealand/Aotearoa and Māori. However, I am not a total stranger to the Māori community. I understand some of the shared indigenous cultural values that are similar between Māori and my indigenous community. My participants accepted me as an insider by inviting me into their homes. In living and interacting within the Māori communities throughout my $\mathrm{PhD}$ journey, my outsider status gradually became transferred to that of an insider. However, I cannot be a full insider (in the context of being Māori) because I am not Māori. My insider status in both New Zealand/Aotearoa and the Republic of South Africa/uMzansi Afrika saved me time as I understood commonly shared indigenous concepts, norms, worldviews, and values.

I address strategies associated with the challenge of being too familiar with behaviours and norms because of being an insider. I studied in a different country from my own to establish a distance from my home environment. Also, 
I developed another specialisation, different from being a practitioner, as a researcher. The change in specialisation enabled me to temporarily become a member of another group, while also belonging to my indigenous community in the Republic of South Africa/uMzansi Afrika. Being a member of another group facilitated my questioning of norms and behaviours in my own culture from the research perspective. In addition, I reflected upon my actions by keeping a record of my methodological decisions, as I explain later in this document.

\section{Cross-cultural research}

Although I am an insider/outsider to my research, I am also non-Māori conducting research on Māori, which makes this study cross-cultural in nature. In this subsection, I discuss issues in cross-cultural research in management because they are relevant to my study.

My research responds to calls by Burke (2010) to increase cross-cultural research in management studies. A lot of cross-cultural research compares two or more groups in observing behaviours in an attempt to identify similarities and differences (Hofstede, 1980, 2006; House, Hanges, Javidan, Dorfman, \& Gupta, 2004). Behaviours such as leadership styles across different groups in different countries are examples of cross-cultural research studies (Jogulu \& Wood, 2008). A limited number of studies, for example, Adler (1993) and Berhoin Antal and Izraieli (1993) consider the role of women managers in the expanding world economies. Contrary to these studies, in my study, my intentions were not to compare the experiences of Māori from New Zealand/Aotearoa and Black from the Republic of South Africa/uMzansi Afrika women in top-management. However, they were to understand two groups of women in two different countries. I apply the 'concrete-ceiling' concept to assess its applicability in both these countries for indigenous women in top-management without the intention of comparing these two groups of women. Historical and political contexts are important to my arguments in this thesis. So I am conscious of differences between the two groups, but I do not set out to compare them as a key research objective. Rather I am interested in what they may have in common in comparing each sample with the western literature. As far as I know this is only study that examines the experience of two groups of indigenous women in 
management in different countries. There is little research where an indigenous person researches another indigenous group in a different country from his/her own, in management. My original contribution to management studies includes examining two groups of indigenous women in different countries.

Cross-cultural research has a tendency towards 'academic western colonisation', thus disadvantaging indigenous communities. The history of management was also a history of colonialism (Jack \& Westwood, 2009). Most theories used in cross-cultural research emerge largely from USA researchers using USA participants and publishing in USA journals, so the extent of generalisability to other countries is questionable, according to Adler (1983). These studies are conducted within the management cultures of largely the USA and UK. Adler (1983) further argues that research conclusions reflect the values of western societies and their researchers, who tend to be mostly American. This, I believe, is a new form of colonisation, which is 'academic' because they embed western values of conducting research. In addition, they become the master narrative of theories in management in different cultures without being tested. My study is biased towards American theories because it uses the 'concrete-ceiling' concept that emerged from the USA literature. To affirm the indigenous communities in management research, I study them within their cultural context, taking cognisance of history and politics in the context of their experiences.

\section{Māori and non-Māori research}

To affirm indigenous communities in this research, I had to understand both African and Māori cultures. In this sub-section, I discuss Māori and non-Māori research.

My identity in relation to Māori is important because I'm an indigenous woman researching another indigenous group. As my status is that of an indigenous woman from Africa, I do not make claims to knowledge and wisdom of Māori ways of doing things. However, I attempt to understand the experiences of Māori women within their social contexts, and make useful interpretation of the research data together with the research participants. I also study my own group, indigenous women in the Republic of South Africa/uMzansi Afrika, in an 
attempt to understand experiences of both indigenous groups of women in topmanagement. Growing up in the Republic of South Africa/uMzansi Afrika as a Black woman during the peak of Apartheid, I understand through my own experiences of living in a society of unequal powers, the discomforts associated with research that is intended to marginalise a group. I do not wish to repeat the same past mistakes and actions as those colonisers, especially as a previously relatively disadvantaged individual myself.

In New Zealand/Aotearoa, there have been studies discussing non-Māori conducting research on Māori. Debates around who can research Māori have been on differences between Māori and non-Māori (Wilson, 2008). This literature about the non-Māori individual/s conducting research on Māori always assumes that the non-Māori person is not indigenous. It assumes that the nonMāori person is white. It is mainly about Pakeha/white New Zealanders researching Māori (Barnes, 2000; Cram, 2001; Tolich, 2002; Wilson, 2008). I have not found a study discussing Māori research in the context of another indigenous group from another country researching Māori. This makes my study original. It is different because I am not in the same position as a white researcher who is privileged. I am indigenous, but am a non-Māori researcher. I am in a unique position. The important point is that there is a shared history and politics between my own group, African from the Republic of South Africa/uMzansi Afrika, and Māori in New Zealand/Aotearoa of having a presence of former British rulers in both these countries (see Chapter Two). In addition, both groups are economically marginalised, generally, in these countries (see Chapter Two for statistics). There is a need to broaden debates on non-Māori researching Māori to include other cultural groups from other countries. As I wanted to understand the experiences of my participants from New Zealand/Aotearoa within their social, cultural and political contexts, a Kaupapa Māori framework became important in investigating my study. It became important because it is a Māori approach to understanding the world.

In the next section, I will talk about what I consider to be a Māori worldview and what I understand to be Kaupapa Māori research in my study. 


\section{Research in a Kaupapa Māori framework}

In this section, I discuss the Kaupapa Māori framework in the context of my research and its implications for my study.

To understand my Māori participants within their social, cultural and political contexts, I had to learn, amongst other things, Māori culture. Māori culture embeds a Māori worldview in research, which is called Kaupapa Māori research. In this section, I discuss Kaupapa Māori and explain how I implemented this framework into my research. As I started to prepare and teach myself about Māori culture, I read the literature about Kaupapa Māori that helped me to think differently about methodology. Kauapapa Māori research is a set of philosophical beliefs and practices (Henry \& Pene, 2001). It is a search for understanding within a Māori worldview, according to Bishop (1996) and Barnes (2000). In New Zealand/Aotearoa, my research was influenced by aspects of Kaupapa Māori principles. The Kaupapa Māori principles in my study were an understanding of Māori culture, managing politics regarding what is knowledge and how to treat it, within the Māori context as well as conducting research in an ethical manner within a Māori worldview.

In this study, Kaupapa Māori includes culture because of the way Māori approach and deal with people in treating knowledge, which is important for a Māori cultural perspective. Kaupapa Māori research attempts to find space for Māori people and honours Māori culture, according to Smith (2005). Māoricentred research takes into account the culture, values, realities and needs of Māori people (Tolich, 2002). As part of Kaupapa Māori for my research, I developed trust with the participants and I invested effort and time in relationships in learning about Māori culture. For instance, I learnt the Māori language by taking a Māori language course offered by Victoria University of Wellington. Learning Māori language was a crucial step to understand Māori knowledge. I developed relationships with my participants. I interacted with the Māori community to learn the culture, and tikanga (Māori protocols, customs and traditions) thereof. I wanted to understand them as individuals and not just research participants. I sought advice from other senior Māori individuals on different aspects relating to Māori such as the best protocol to approach a Māori 
woman in top-management. For my study, this was part of the mentorship provided by an elder in a Māori community, which embeds the concept of 'whanau' where an elder provided guidance and supervision for handling research, as per Smith's (1999) concept. Māori individuals quickly brought me into a community of Māori women in Wellington, later New Zealand/Aotearoa, that I did not know, and they gave me advice. I was working with other Māori individuals in sharing knowledge. To me Kaupapa Māori meant treating knowledge with respect and being accountable to people as well as understanding knowledge in the manner that the participants intended to impart knowledge to me and to treat it in a sensitive manner. In addition, my relationship was collaborative with Māori individuals.

In my study, another aspect to Kaupapa Māori is the politics regarding researching an indigenous group. When it comes to indigenous issues, previous research has side-lined indigenous people and put them in a negative light regarding what is considered to be knowledge (Wilson, 2008). Most research on Māori has been of little benefit to Māori themselves, with a focus on negative statistics and without sufficient information on how they can bring positive changes (Jahnke \& Taiapa, 1999). Indigenous communities are increasingly becoming concerned about research affecting them, because research in the past has been used negatively towards them, according to Smith (1999). Indigenous research frameworks such as Kaupapa Māori provide alternative research models to the western research models when investigating indigenous people. By including indigenous perspectives in my research, it is in part a step towards decolonisation in defining knowledge in management studies. In addition, I wanted to affirm Māori individuals on how they view and understand knowledge. It is part of a broader de-colonising political programme of empowering indigenous people and myself as an indigenous researcher. By using an indigenous perspective, I wanted to promote indigenous people in a positive light, as this study focuses on the experiences and perceptions of a group of indigenous women, who are successful. 
Researchers (Barnes, 2000; Cram, 2001; Tolich, 2002; Wilson, 2008) discuss whether a non-Māori person may use Kaupapa Māori to research Māori. Māori researchers use the concept of Kaupapa Māori for research conducted on Māori people by Māori, argues Smith (2005). As I am not Māori, but conducting research on Māori women, I could not use the Kaupapa Māori research paradigm to the fullest. A Māori person would have established the Māori and familial genealogical links, I could only explain my genealogical links within the African context in the Republic of South Africa/uMzansi Afrika. I became aware of Kaupapa Māori through my readings in New Zealand/Aotearoa as I was grappling with the understanding of my research literature and Māori culture. It was not on the basis of my own culture that I initially thought about Kaupapa Māori research. Also, my participants raised concepts of Kaupapa Māori that included guidance on conducting research with Māori, during my pilot study (see section on pilot study in this chapter). That is something that I learnt in effect from these women. As I learnt more about Kaupapa Māori, I could see the connections with what I was familiar with in my own culture. Then I started thinking about my methodology and the role of indigenous methodologies in research. It was ironic, because it was not out of my own environment, but through a different culture that I gained consciousness and deeper insight into my own self.

In the next section, I discuss ethics that are associated with researching a different culture from my own. I elaborate on some of the issues in being an indigenous person researching another indigenous group.

\section{Ethics of researching across cultures}

In this sub-section, I discuss ethics of conducting research in different cultures. In addition, ethics were part of Kapupapa Māori in my research. There are ethical and methodological challenges in conducting research across cultures (Liamputtong, 2008). For this study, my challenges were enhanced because I had to understand another culture, Māori, different from mine. For my study, I had to invest time to learn the Māori culture with its customs/tikanga as well as constructs, which are outside my culture and reference of being a Zulu woman in the Republic of South Africa/uMzansi Afrika. I was being respectful, humble, 
willing to 'listen' and learn from a Māori perspective. I was careful to acknowledge the mana / standing / prestige of my participants and Māori community, as per Smith's (2000) concept. In learning the Māori culture, I was also attempting to represent the voices of my participants through the understanding of their environments. Researchers (Stubben, 2001) have argued that cultural awareness of the researcher improves relationships with ethnic minority groups. This in turn, hopefully, improves the quality of data.

An aspect of ethics for my study was to create sustained relationships, particularly with Māori women to understand their experiences within the context of their culture, history and sense-making of being a Māori woman. Creating relationships went beyond just getting permission from my participants to participate in my research. As part of my way of creating relationships, I would go to different hui (Māori gatherings) to learn about Māori culture and issues facing Māori, in general. Māori gatherings included social, cultural, business and academic conferences/gatherings focusing on Māori. I developed long-term relationships. Part of the ethics of researching another culture included creating relationships with which I and participants were comfortable. I also created sustained relationships to be an effective and competent researcher on issues affecting Māori individuals.

Another aspect of research ethics for my research was to conduct research of mutual benefit to myself and Māori. Kaupapa Māori research aims to benefit both the researcher and the research participants (Russell Bishop, 1999). My research was a mutual relationship between myself and my research participants. Research ethics included being accountable to my participants and developing the reciprocity of knowledge between myself, as a researcher, and the participants. My participants were supportive and came to my presentation at Victoria University of Wellington where I presented my research proposal. During and after the research proposal presentation, they forwarded me inputs on how to improve my project in shaping this research. Throughout my research, communication with my participants was on-going and open through email, telephone and face-to-face. I reciprocated by sharing information about myself. As a researcher, I benefited from using the Kaupapa Māori research in that I 
understood the situation of the participants better than prior to my conducting this research. Also, I gained a network of Māori individuals. Reciprocally, this research project brings light to Māori women who wish to be in top-management roles. The awareness of the experiences may facilitate social change, hopefully bring difference and transform the lives of those Māori women who aspire to be in top-management positions of organisations. Additionally, it supports Māori community aspirations and developments by bringing forth knowledge about Māori women in top-management. This study affirms and validates Māori women in a positive manner, as successful individuals.

In addition to the Kaupapa Māori framework, I have ethics for my research, which are consistent with the indigenous methodologies. Confidentiality was part of my ethics for this cross-cultural study. Confidentiality was especially important because of the limited number of indigenous women in topmanagement roles. Research ethics are particularly important when investigating indigenous women because previous research did not affirm them. I obtained ethical approval to conduct my $\mathrm{PhD}$ research studies at Victoria University of Wellington prior to the data collection of this study. Some researchers (Tolich, 2001; Tolich \& Davidson, 1999) provide guidance on conducting research in New Zealand/Aotearoa. These researchers contend that participants should voluntarily agree, provide their informed consent to participate, and preferably be informed of the truth about the intentions of the study, and that the researcher should protect their identity. I conducted my study in terms of these principles.

I held confidential interviews with my participants in both New Zealand/Aotearoa and the Republic of South Africa/uMzansi Afrika. I report my findings in this document in such a manner that it is not possible to identify the participants or organisations. Because there are limited numbers of indigenous women in top-management roles, I use words such as 'industry' and 'sectors', and alphabetical letters to identify and represent the sample, organisations of the participants and other organisations. In other instances, I deleted some words or sentences that might identify an individual or organisation. My participants had the option to withdraw from the study before the data analysis was completed. After this date, it might have been difficult for the participants to withdraw from 
this study as I needed to start analysing my research data and drafting this $\mathrm{PhD}$ thesis. All the participants were given the information leaflet, explaining their options to opt out of the study (see Appendix C). I also communicated this information to the participants orally, during the interviews. They could refer to the information leaflet anytime during and post the $\mathrm{PhD}$ thesis as well as contact me or my supervisors at any stage of the research, regarding research issues. I obtained informed consent from my participants to conduct interviews. The consent was for my participants to agree to participate in my research study and voluntarily take part in one-on-one confidential interviews.

\section{Research in an Afrocentric framework}

In this section, I discuss Afrocentric framework, which is relevant for my participants in the Republic of South Africa/uMzansi Afrika in understanding their experiences within their social, cultural and political contexts. It is a worldview that centres knowledge from the African Perspective.

In the Republic of South Africa/uMzansi Afrika, my research methodology was influenced by the Afrocentric theoretical perspective and followed its principles. According to Mazama, it is important for the Afrocentric paradigm to develop a liberation from oppression (Mazama, 2001). I first came across the concept of Afrocentric perspective through my informal education. Informal education means education that I obtained outside a formal academic institution, such as, a university. As part of the resistance movement against the Apartheid system, senior comrades would teach us, new recruits, philosophies that have aims to decolonise our minds and empower us against the system. The Afrocentric perspective was one of the philosophical perspectives that senior comrades would teach us informally and promote. This learning shaped my understanding of myself as an African woman from the Republic of South Africa/uMzansi Afrika who was affected by the Apartheid system as I was de-colonising my mind of its psychological effects. I then started to become conscious of my Africaness and heritage roots.

My African consciousness of making sense of the world was further developed when I enrolled for African-American history courses at a historically Black 
university in the USA. I slowly became grounded in understanding my identity, African consciousness, and liberation of my mind from the Apartheid system. As I was learning African-American history from a western stand-point, I noticed some of the omissions in these classes, regarding indigenous worldviews. I started to understand the importance and need of promoting concepts and worldviews originating from the African heritage to analyse some of western concept present in the USA history that comprise African-American history. I also realised that some of the university lecturers who were only trained in western thought and philosophies, did not understand African worldviews even though they were teaching African-American history. During these classes, I felt privileged because I understood the background to some of the historical philosophies of African-Americans from an African position. This understanding heightened my understanding of African knowledge.

In grounding myself within the Afrocentric framework, I acknowledge my position (Prichard, Jones, \& Stablein, 2004) in shaping knowledge from the African perspective, for my research. I also acknowledge my participants from the Republic of South Africa/uMzansi Afrika in understanding their experiences of being top-managers from an African perspective. The Afrocentric framework is 'essentially a quality perspective or approach rooted in the cultural image and human interest of African people' (Karenga, 1988, p. 404). This research concept requires a knowledge base that comes from life experiences of people from African descent (Alkebulan, 2007; Kershaw, 1992). This knowledge facilitates understanding from an African perspective worldview. The African proverb 'education begins at home', captures my stand-point in this research. This means that I begin with educating myself about who I am as a researcher, as I embrace western worldviews. I did not want to conduct this research as just an 'agent' from the west, articulating only western worldviews, while denying my own historical and political locations of resisting colonial imperialism in the Republic of South Africa/uMzansi Afrika.

In addition, the Afrocentric framework should address the needs of people from African descent to be considered for it to be relevant (Alkebulan, 2007). This research addresses the needs of African woman as marginalised groups in the 
economy of the Republic of South Africa/uMzansi Afrika. It affirms them because it views research knowledge from the African perspective, in addition to the traditional western philosophies. In my research, Afrocentric perspective meant that I could promote African ideologies and cultural ways of knowing. As a means to embrace African ideologies, worldviews and cultural ways, for example, I addressed most of the participants as Sisi (sister) and then added their first names. This is reflective of the African cultural norm in the Republic of South Africa/uMzansi Afrika that you do not address someone who is older than you by just their first names. If they are old enough to be your older sister, you put the words Sisi in front of their names as a sign of respect. Doing so was also symbolic that I acknowledged and understood the African culture and context and that I was part of it. This type of address signals a 'sister to sister talk' where sisters are talking to each other about themselves. Afrocentric perspective also meant an understanding of presenting my research in a manner that Africans, in particular my participants make sense of their experiences from an African stand-point and perspective. This means consciousness and conceptualisation of my research in the manner of knowing from an African perspective.

In the next section, I discuss interpretive approaches, which are framed within traditional western research worldviews. I integrate these approaches with aspects of Kaupapa Māori and Afrocentric frameworks.

\section{Interpretive approaches}

In this section, I explain my reasons for choosing interpretive approaches. I also explain my role as a researcher. Interpretive research is a sub-set of qualitative research, according to Prasad and Prasad (2002). Denzin \& Lincoln (2000) define qualitative research methods as a broad class of empirical procedures, which are designed to express and interpret the experiences of research participants in a setting of a specific context. Additionally, qualitative research answers questions about experiences and meanings people attach to aspects of their lives and social worlds (Fossey, Harvey, McDermott, \& Davidson, 2002; Hewitt, 2007). Interpretivism implies Post-positivism. 
The interpretive approach, which is a western perspective to research, goes well with aspects of indigenous paradigms, which has to do with respecting different voices with respect to experience. This means that my participants attach different meanings to their experiences, under this perspective. In this study, I acknowledge that my participants were not speaking for all Māori or Africans as having the absolute indigenous knowledge in representing indigenous people in their countries. However, they were expressing their opinions on the basis of their own personal experiences of being a Māori or African woman in topmanagement of predominately white organisations. Their experiences in topmanagement were affected, amongst others, by the social structures of the Republic of South Africa/uMzansi Afrika and Zealand/Aotearoa, their class, family and status.

I chose an interpretive approach because I was seeking for an approach which would allow me to focus on people's experiences and perceptions from their point of view, within the framework of western epistemologies consistent with the indigenous approaches. Interpretivism meets this intention because it has the objective of studying participants' lived experience of reality (Sandberg, 2005). Interpretivism is a broad philosophy of social construction (Berger \& Luckmann, 1967). There are several approaches under the label interpretivism, according to Prasad (2005). However, they are primarily characterised by having a human interpretation as a starting point for analysis, with a focus on social construction of reality (Cassell, Bishop, Symon, Johnson, \& Buehring, 2009). For my study, this approach also meant that I gained insights into how my participants interpreted their experiences in top-management roles. I take the position that my participants know and understand their experiences by putting meanings and interpretations to them. Interpretive approaches provide this understanding of the lived experience from the perspective of those who live it (Schwandt, 1994). I am interested in the meaning my participants assign to their experience.

In addition, I was searching for an approach where I could examine my research through the historical and social contexts. Interpretive research focuses on interpretations of participants regarding their actions within a social context (Fossey, et al., 2002). During the interviews, my participants raised issues 
regarding the ways of knowing that are located in history and politics of New Zealand/Aotearoa and the Republic of South Africa/uMzansi Afrika. For example, they all raised historical and political issues that influenced their consciousness of who they were as indigenous women. In New Zealand/Aotearoa, it included witnessing the 1981 Springbok (South African rugby team) tour of New Zealand/Aotearoa and its impact on New Zealand/Aotearoa because it polarised opinion amongst New Zealanders on the politics of the Republic of South Africa/uMzansi Afrika and its role in the game of rugby. They also experienced the Māori political activism in the 1960s and 1970s. These events brought consciousness on how they understood the world and their environments. In the Republic of South Africa/uMzansi Afrika, they spoke of their experiences of Apartheid in shaping and influencing their experiences and understanding the world as indigenous women (see Chapter Two). Through interpretivism, I could locate the experiences of my participants within the historical, political and social contexts of their countries. This was suited for my study because I take a view that the description of the world for my participants is influenced by their culture and history as well as politics of New Zealand/Aotearoa and the Republic of South Africa/uMzansi Afrika in understanding of their realities. In investigating my study, I accept that the experience of my participants may be limited to the locality of their organisation, their countries (New Zealand/Aotearoa and the Republic of South Africa/uMzansi Afrika), the time in history and their socialisation. Their constructions of their experiences are embedded in these structures and the meanings attached to them within their environments.

Interpretivism in my research also means that this study is not completely objective. This approach acknowledges that the interpretations of events by the participants are important and cannot be separated from the objective reality (Phillips \& Burbules, 2000). I did not ask my participants either to be objective or articulate their experiences in an unbiased manner. The study was not about finding the facts about their situations. However, it was about what they perceived to be their experiences in top-management. Their perceptions are their realities of their situations and experiences. I am making sense of their perceptions and interpreting them as they understand their situations of being 
indigenous women in top-management of predominantly white organisations. However, I do intend to make truthful claims in my study about how I believe that the world operates.

\section{My role as a researcher}

I recognise my role as a researcher to interpret data and represent the information stemming from my interviews. In this study, I present my interpretations of participants' understandings of their experiences. I make claims and proposals about the situation for indigenous women in top-management roles.

For this research, interpretive research meant that I came to my own conclusions, as a researcher. This means that I analysed and concluded, as a researcher, on what my participants perceived to be their experiences and issues in topmanagement. In so doing, I collected a variety of information to understand their situations, that is, statistics I presented in Chapter Two, one-on-one qualitative interviews with participants and the literature focusing on women in management with a focus on ethnic minority women in management. All this data helped me in reaching my own analysis, as a scholar and writer. What my participants said during one-on-one qualitative interviews do not prove anything as such; however, it is my interpretation of their accounts that give meaning to their experiences. My participants created and enacted meanings to their actions. As I analysed their actions, I was becoming part of the world that I studied, which was created through active involvement and interaction with people. As I understood how research participants made sense of their lives and experiences through the interviews, I began to make sense of their meanings and actions. This means that I became an active receiver of my data (Charmaz, 1990; Glaser, 1978). I was not passive in understanding the data. I made my own interpretation based on my understanding of the world, their worlds and views as well as statistical information that was available to me. I make prepositioning about reality based on my knowledge, gender, race, class, social status, and those of my participants because they influence our perspectives and my research conclusions.

In my role as a researcher, I also brought both intellectual and personal experience pre-understandings to this research. The intellectual pre- 
understanding means that I read and understood studies focusing on women in management. I engaged the literature on women in management to contextualise and understand the experiences of my participants. I also understood concepts of being a woman in management through my practical experience of studying in western universities. I brought personal experience pre-understanding by reflecting on my own experiences of being a woman in management. This preunderstanding facilitated me to gain an understanding of the interpretation of the lives of my participants to draw conclusions and analysis of their experiences by engaging women in management literature.

\section{Philosophical assumptions}

In this subsection, I discuss the philosophical assumptions embedded in my study. I outline the ontological (what is reality or the nature of reality), and epistemological (what is knowledge or how is the world known) assumptions as well as the methodology through which that knowledge is gained. I also discuss the axiological (role of values) and rhetorical (language of research) issues influencing my research. Philosophical assumptions are vital in the design of the study, according to Smith (2005). I focus my philosophical assumptions within Interpretivism, Kaupapa Māori and the Afrocentric approaches. These assumptions were important in my study because they guided my research design.

In this thesis, I describe my philosophical stance on ontology (nature of reality), epistemology (how the world is known), and methodology (how knowledge is gained about the world) as paradigms, argues Creswell (2007). Guba defines a 'paradigm' as "a basic set of beliefs that guide action" (1990, p. 17). Methods are tools that take meaning in relation to the chosen methodology (Silverman, 2000). Research paradigms refer to concepts that govern the thinking and action of an inquiry. These choices about research assumptions are important in writing the study as they influence the investigation, according to Creswell (2007). My choices and actions in this study support a set of beliefs that define my worldview in the context of this study as a researcher with an identity of having both indigenous and western influences. 
In this study, I address the philosophical issue of ontology in terms of how people view the world and what they perceive as reality. I approach my study such that the people view the world differently and according to their socialisation and experiences. For my participants, I style this research in the manner that the participants view their realities in line with their experiences. Reality in this study is based on how the participants construct their realities and make sense of them. I take the stance that reality is based on the experiences of my participants and has foundations in both the indigenous oral and western written cultural traditions, histories and socialisations of the participants as indigenous women raised in either New Zealand/Aotearoa or the Republic of South Africa/uMzansi Afrika. In this study, experience is the legitimate source of knowledge. While, I may have different realities from those of my participants; that does not negate the experiences of my participants. My participants responded to my questions by providing examples to demonstrate their experiences or situations encountered. To reflect this, in my analysis chapters, I use quotes in words of the participants as evidence of different perspectives and themes.

In my study, I address the epistemological (what is knowledge or how is the world known) issues underpinning my study. Researchers (Crotty, 1998) contend that this branch of philosophy permits one to understand the assumptions about how knowledge is obtained and developed. In my study, particularly in New Zealand/Aotearoa, in general, I had more than one interaction with the participants before and after the one-on-one qualitative interviews. The objective of this was to understand the environments of my participants on how they understand their knowledge about events affecting them. This was to achieve what Creswell (2007) calls the lessening of the distance between the researcher and the participants. The interactions were both in my environment and the environments of the participants. This included visiting them in their homes or social settings, sharing different aspects of their lives and disclosing information about myself. In the Republic of South Africa/uMzansi Afrika, the interactions with the participants were mostly in their environments and after the one-on-one qualitative interviews. Exposing myself to the environments of the participants, I believe, provided me with the context of what the participants were sharing with 
me during the one-on-one qualitative interviews. Having more than one contact with the participants helped me to understand the participants and research in the context of the lived experiences of the participants. I take the standpoint that knowledge comes from experience, and that the best way of understanding the truths of my participants was to share the experiences that led them to form their ideas.

In my study, the 'truth' claims are based on the subjective experiences of the participants. They are intangible and provide relevant insights, argues Smith (2005). Truth in my research is also located in the culture of indigenous people. For indigenous women, new knowledge claims are mostly developed through dialogue with other members of the community, argues Collins (1989). Dialogue is rooted in the oral history tradition and for ideas to be tested as well as validated, everyone in a group must participate, according to Collins (1989). Inclusivity is a concept that is associated with indigenous communities in both New Zealand/Aotearoa and the Republic of South Africa/uMzansi Afrika. I show the concept of inclusivity by also articulating minority views, in terms of numbers, in my results. Key principles of Afrocentric research are that truth is grounded in the experiences of the participants and they have the authority to determine truths (Reviere, 2001) and their truths. Also, my data analysis was within the social context through which Māori women in top-management understood and defined their lives. In my study, experience is a criterion for truth, which means that living the experience is a legitimate source of knowledge that is based on the truth that is understood by my participants. Truth is subjective and based on their realities, that is, experiences that are meaningful to my participants based on their socialisation and understanding.

I address the axiological (role of values) issue in my study. This study is what researchers (Denzin \& Lincoln, 2000) call value-laden and I position myself in the study. I acknowledge my biases that encouraged me to conduct this study. My conclusions and critique should be understood in line with the framework of my stand-point. My biases are on my identity: an indigenous woman from the Republic of South Africa/uMzansi Afrika studying a PhD at Victoria University of Wellington in New Zealand/Aotearoa. My identity, location in history and 
geography are my stand-point. I am committed to the emancipation of women from all oppression and uplifting indigenous women.

In my study, I address the rhetorical (language of research) issue. As a qualitative researcher, I use an informal writing style. It is a personal voice. This choice allows me to write this study in the first person pronoun 'I'.

\section{What I did}

In this section, I address what I did in conducting my research. What I did is part of my research methodology. It included a pilot study that I conducted prior to this research, interviews with my participants, the identification and characteristics of my sample as well as data analysis for this study.

\section{A pilot study}

Prior to my $\mathrm{PhD}$ research, I conducted a pilot study in New Zealand/Aotearoa, as part of a Graduate research course. I limited my pilot study to New Zealand/Aotearoa because it was not my country and I had to familiarise myself with the Māori culture. I wanted to learn more about issues that might have impacted on my research as an outsider to New Zealand/Aotearoa and Māori. The pilot research had several other objectives. They were to set a foundation for this current study, to identify methodological issues as well as understand issues of conducting research with Māori women in top-management. As part of the pilot study, I interviewed five Māori women in top-management, in different sectors. I did not re-interview my pilot participants for the main research study.

I learnt useful lessons from the pilot study. For example, I understood the importance of understanding the Māori culture in the context of knowledge. It was during the pilot study that I had an opportunity to understand Māori protocols, which gave me time to consider my interview approach for the main study. I started to understand that I had to invest time in my $\mathrm{PhD}$ plan to learn Māori language. I also learnt about the importance of maintaining relationships as an exchange between the participants and researcher. This awareness made me realise that I had to adjust my $\mathrm{PhD}$ project plan to invest time and effort in building sustained relations as well as learning about making connections. In 
addition, it was during the pilot phase that I met one of the participants who became my informal mentor and guided me on culturally appropriate ways to carry out the main research successfully. Her guidance has helped me to think differently about my research methodology and the importance of incorporating indigenous methodology into my study design. The lesson that also shaped the design of my main research was that I was able to use the digital-recorder without my participants having problems with being recorded for my main research. Initially, I hesitated to use the digital recorder. However, during the pilot study, the participants suggested that I recorded the interviews before I even asked them. This suggestion indicated to me that the participants for the main study may equally not have issues with being recorded as I had wrongly assumed prior to conducting the interviews. Also, my pilot study helped me clarify my interview questions for the main study because my participants for the pilot were actively recruited.

In the next section, I discuss interviews I had with my participants.

\section{Interviews}

The interview was the methodological tool to collect data for this thesis. I collected primary data directly from participants. I asked all the participants similar questions. The interviews were face-to-face and one-on-one. They comprised a semi-structured questionnaire with open-ended questions. An example of open-ended question that I asked my participants was: please explain your current role in your organisations? This question was to ensure that my participants had the seniority that I required for my study. It also gave a participant an opportunity to direct an interview to any angle to cover issues that were important to her. Then I would follow that discussion with specific themes to cover and ask semi-structured interviews. Semi-structured interviews facilitate a focused exploration of a specific topic, or follow up on specific issues that emerge during data collection (Fossey, et al., 2002; Rubin \& Rubin, 1995). I asked semi-structured interview questions to ensure that I systematically address similar issues amongst all participants. An example of a semi-structured interview question that I asked my participants was: how were you recruited into your current role? This question is flexible and allows space for further 
questions to be asked depending on the response of the participant. However, the question also addresses aspects relevant in being recruited into the current role. The nature of semi-structured interviews is the foundation of the relationship with the participants and the wish to understand rather than explain (Fontana \& Frey, 2005). In my study, face-to-face, one-on-one semi-structured qualitative interviews facilitated other forms of communication, like non-verbal behaviours, which were essential communication components, and I was able to follow the non-verbal cues with follow up questions.

The reason for choosing the qualitative interview to collect data was that this research focuses on experiences. Interviews facilitate reliable access to the lived experience of the other (Fossey, et al., 2002; Hewitt, 2007). It is the best method to allow the person who has lived the experience to narrate that experience (Nunkoosing, 2005). Although a participant may choose any manner to construct his or her story, the nature of the interview encourages participants to talk and think at both conscious and unconscious levels (Nunkoosing, 2005). The participant, together with the researcher, plots to construct stories (Nunkoosing, 2005). In epistemological terminology, the interviewer facilitates the participant in the generation of knowledge. Burgess (1991) asserts that qualitative interviewing has a focal-point on understanding the perspective of the participants and the researcher's presence encourages the space for the insights to be achieved. In qualitative interviews, one hears 'the meaning of what is being said' (Rubin \& Rubin, 1995, p. 7).

There are advantages and disadvantages to the qualitative interviews. The disadvantages are noted by Bryman (2006) and Greenbaum (1998). They are difficult to analyse compared with other methods, being static, time-consuming, and tending to be costly, and biases are difficult to ignore. Despite these disadvantages, I conducted qualitative interviews because I wanted to hear the voices of indigenous women and to interact with them at a personal level. The qualitative interview is the best way to construct first-person accounts of the experience (Polkinghorne, 2005). Experiences need to be explored and are difficult to understand in other data collection methods than interviews (Denscombe, 2002). Also, the interview is best suited to collect data on sensitive 
topics as it provides the interviewee confidentiality and interaction with the researcher, argues Richards and Schwartz (2002). Additionally, this research is based on sensitive issues, which are experiences of certain groups of people, that is Māori and African women, within a society. Taking cognisance of the sensitivity of personal experiences of Māori and African women, I would not do justice to the information if I did not interact with the subjects to facilitate further probing on issues. The advantages of the interview are in obtaining detailed information from a few samples (Denscombe, 2002). Other advantages are flexibility, adaptability, providing a platform to observe, the ability to interpret non-verbal cues, one-on-one interaction, providing a platform to clarify questions and a higher response rate compared to most methods (Robson, 1995). In my study, the value of conducting qualitative interviews was that I was able to gain new understanding that my participants were at a point in history where their Governments were correcting the injustices of the histories. Had I not conducted qualitative interviews, I would not have been able to gain this insight through other methods, such as questionnaires or surveys.

I address the origin of my interview questions. The interview questions came from both myself and women in management literature. I wanted to keep my interview questions open to any information that may not be currently addressed in women in management literature, whilst also addressing specific themes that are present within this literature. For example, I asked my participants: do you have a strategy to assist your career mobility? This question does not direct a participant to any strategy, but it keeps it open for any strategy that a participant may use to succeed. It also keeps it open for the participant to re-direct a conversation to not having a strategy to succeed. I also asked specific questions, such as: do you have a network, do you have a mentor, and do you have a rolemodel? These specific questions of having a mentor, role-model and network are stated in the women in management literature as factors that enhance management entry for women, particularly for ethnic minority women. I wanted to know whether these specific strategies for success, as examples, were also applicable to these groups of women and how they manifested themselves. 
My experiences of the interviews

In this sub-section, I address issues that were important in my interviews. This included sequence of data gathering, duration, space, structure and language of the interviews.

I first gathered the data in New Zealand/Aotearoa then in the Republic of South Africa/uMzansi Afrika. The reason for this sequence is the location of the resources at Victoria Management School at Victoria University of Wellington enabling support from the supervisors as it was the first stage of data gathering. I travelled around New Zealand/Aotearoa collecting data in various locations. Then I travelled to the Republic of South Africa/uMzansi Afrika to collect data. In the Republic of South Africa/uMzansi Afrika, I was located in Johannesburg and I conducted all my interviews in this city. The reason for this is that Johannesburg is a 'business hub' in the Republic of South Africa/uMzansi Afrika, I believe.

All the participants were warm and welcoming. They were forthcoming and upfront with information. On average, the qualitative interviews in both New Zealand/Aotearoa and the Republic of South Africa/uMzansi Afrika lasted about 90 minutes. In New Zealand/Aotearoa, I interviewed most participants in their own homes. Two participants were in their work environments, and one participant came to my study environment. In the Republic of South Africa/uMzansi Afrika, I interviewed all the participants in their work environments, except two. One participant invited me to a hotel where she was staying to conduct the interview. Another participant invited me to a social setting to conduct the interview there. This was important to me to socialise with other people who were part of the network of the participant to gain an insight of understanding. Researching participants in their environment facilitates the insider perspective on the interpretation of the data (Anastas, 2004; Creswell, 1998; Padgett, 1998). In this case, the insider is the research participant.

I approached the interviews in the manner that empowered the indigenous worldviews of both New Zealand/Aotearoa and the Republic of South Africa/uMzansi Afrika. Prior (2006) argues that cultural values of the 
participants have to be included in the research design for the research to be empowering to the indigenous people. As part of the study design, I greeted the participants in line with the cultural contexts of both New Zealand/Aotearoa and the Republic of South Africa/uMzansi Afrika. I acknowledged my insider status as an indigenous woman researcher. As part of the Afrocentric framework, I shared my family history and clan, and revealed personal information about myself to enable my participants to understand me more and be at ease with me by knowing other aspects of me. In New Zealand/Aotearoa, I explained my genealogy and geographic location in the Republic of South Africa/uMzansi Afrika as well as sharing some cultural issues relating to my status as an indigenous woman. In the Republic of South Africa/uMzansi Afrika, I explained my background in terms of events leading to my research and family background. So, the participants from both New Zealand/Aotearoa and the Republic of South Africa/uMzansi Afrika tended to be relaxed and talked openly about their experiences. I confirmed my insider status as an indigenous woman throughout the interviews by adhering to the cultural protocols.

In both New Zealand/Aotearoa and the Republic of South Africa/uMzansi Afrika, I approached the interviews in the same manner and according to indigenous protocols in that I divided the interviews into three parts. Firstly, I disclosed information about myself, about the intentions of the research, and about who I was as an individual. The objective of the first part was to create comfort and share my influences to this study. Secondly, I asked the participants the research questions. Thirdly, I ended the qualitative interview by encouraging the participant to ask me for any other information about me. This section tended to end with a discussion on personal information, such as personal relationships, politics, my experiences of the $\mathrm{PhD}$ process and future plans. The objectives of dividing interviews into three parts were to ensure that I also shared personal information about myself may be of interest to my participants and built trust. Prior (2006) contends that research focusing on indigenous people should include meaning and truth through a relationship of trust and reciprocity, and have research methods that are true to the context in harmony with the cultural values of the indigenous people. In my study, this approach was in line with indigenous women from both New Zealand/Aotearoa and the Republic of South 
Africa/uMzansi Afrika in that the cultural content allowed for integration of work and personal lives. It also allowed me, as a researcher, to share my personal information, such as my background, with the participants.

I address the language of the interviews. Language is the primary access to the experiences of participants (Polkinghorne, 2005). In New Zealand/Aotearoa, I interviewed all the participants in English. In the Republic of South Africa/uMzansi Afrika, I took cues from the participants. Some interviews I conducted in English. Other interviews were in a combination of English and another indigenous language, such as Zulu. Few interviews were totally in an indigenous language. Africans in the Republic of South Africa/uMzansi Afrika, particularly the age group that is currently in top-management roles, do not speak English as a first language. However, they are fluent in speaking and writing the English language. The reason to let the participants use the language of choice was to make them feel comfortable and create rapport with them. For those interviews that I conducted in English, translations and transcriptions were easy because they were already in English, which was the language for my $\mathrm{PhD}$ thesis. The transcription of data was in the language the interviews were conducted. For harmony, those interviews that I conducted in indigenous languages, I later translated into English, as I am competent in both writing and speaking these languages. The translation was in a manner that defined a concept, so that metaphors and stories were told in the context of the expressions, language and experiences to retain the meaning.

\section{Sample identification: Snowball sampling}

I used a snowball sampling strategy to obtain participants from both New Zealand/Aotearoa and the Republic of South Africa/uMzansi Afrika to interview for the study. The advantages and disadvantages of snowball sampling are well documented (Robson, 1995). Bailey (1994) defines it as 'a non-probabilistic form of sampling in which persons initially chosen for the sample are used as informants to locate other persons having necessary characteristics making them eligible for the sample' (1994, p. 438). Snowball sampling is non-random sampling and is preferable for a sample that is not easily accessible or identified (Anastas, 2004). Noy (2008) defines this sampling procedure as the process 
where the researcher access participants through contact information that is provided by other participants. Hence, the growing 'snowball effect' portrayed in a metaphor that focuses on its core quality of this sampling procedure: it is accumulative (Noy, 2008). Arber (1993) argues that this approach is appropriate when there is no adequate list that could be used as a sampling frame. For indigenous women in top-management, there is not an adequate list of sampling frame to identify them. Similarly, indigenous women in top-management in both New Zealand/Aotearoa and the Republic of South Africa/uMzansi Afrika know of one another because there are few in these roles. Sudman and Kalton (1986) state that the concept underpinning snowball sampling is that there is a rare population and members are familiar with one another. According to Morse and Field (1995) the limitations of snowball sampling are that it might be biased in that people who are referred might have similar views to initial or referred subjects. However, it ensures that key characteristics of sample are present.

In New Zealand/Aotearoa, I obtained my research participants through personal referrals. I used Māori networks that assisted me in finding my participants. This was in line with the Māori cultural approach in terms of the importance of maintaining and keeping human relationships. From my pilot study (see section on pilot study in this chapter), I had already established a relationship with a few Māori women in top-management. These contacts through my pilot study agreed to assist me in identifying possible research participants for the main interviews for this project. The key person who assisted me with locating the research participants was a Māori woman in top-management. She had a database of Māori women in top-management roles. Every now and then as my research progressed, she would ask me if I had enough participants, if I needed more, she would supply three or four names at a time. She would usually send emails directly to the potential participants requesting them to participate in my study. If they agreed, they would respond to me directly by email. We would then decide on a time and venue with the new participant to meet and communicate directly. The convenience of getting referrals for my participants influenced the design of my study. This process of referrals saved me a lot of time in finding the participants and it was easier for the participants to agree to be part of the 
research, in my view, because the referral was someone they already knew and trusted.

Two other Māori individuals assisted me in locating my participants. I met one at a function at Victoria University of Wellington through an introduction of my Māori friend. I met the second individual at a public function in Wellington also through an introduction of a different Māori friend. Both these individuals became my friends. They were both involved in the Māori communities. They also had a vast network of Māori people and worked with Māori communities, associations and different organisations at different levels. After they had been to a Māori hui (function) or gathering, they would usually forward me a list of a couple of names of possible participants they met or remembered throughout New Zealand/Aotearoa. By the time they forwarded me the name of possible participants; they would have done the introductions for me to the potential participants in my absence. They would already have asked that person if she was willing to participate in my study. I would usually follow up with an email attaching my research information leaflet (see Appendix C), which I would then follow with a telephone call. By the time I had phoned them, they would have agreed in principle to be part of the interview. The purpose of the telephone call was to introduce myself and initiate contact with the possible participant. This process of being introduced by a Māori individual was effective for my research purposes because it made it easier for me to find research participants. Referrals to my participants were made within the Māori tikanga/protocols.

Prior to me meeting the participants, my referrals would typically provide me with privileged information about the prospective participants. This information included a brief résumé about the participants, their current organisations, their personalities and other important issues about them. I also searched the participants on publicly available sources to understand a little bit more about them, prior to the date of the research interview. This gave me a chance to understand them more as individuals and to gain an insight into their personal interests and careers. According to my referrals, there were a few Māori women who did not agree to take part in the study because they were busy. However, I did not get to meet or approach these Māori women because they had already 
refused to participate in my study due to time pressures. My friends believed that most individuals that they requested were happy to be part of the research.

Similarly, I used snowballing to collect data from the Republic of South Africa/uMzansi Afrika, after having collected data from Zealand/Aotearoa. Fortunately, when I arrived in the Republic of South Africa/uMzansi Afrika from New Zealand/Aotearoa to collect data, it was August 2009. This month in the Republic of South Africa/uMzansi Afrika is associated with being a month dedicated to women. There were various celebrations in the country regarding different events, issues and profiles of women who have made contributions in their industries. Different types of magazines profiled different women, including those in top-management roles, as women who contributed in their occupations. As a strategy for my research to identify indigenous women in topmanagement roles in predominately white owned organisations, I bought different magazines to view profiles of successful top-women managers. My focus was those women of indigenous heritage. After identifying possible participants, I would locate their current organisations. This information was mostly disclosed in the magazines. Then I would locate numbers for those organisations from the telephone directories and their organisations' websites. Most of the time, I would make several calls within the organisation or be transferred to different individuals in those organisations until I located the potential participants. Mostly, I would get through to their Personal Assistants (PA). I would introduce myself and request the PA's advice on the best way to contact that top-manager. PAs would suggest emails, telephone calls and giving the information to them to forward to that manager. Once the indigenous women had agreed to be interviewed, I would forward an information leaflet about myself and my research. Mostly, the logistics of the interview were coordinated between myself and the PAs.

During or after the interviews, participants would provide me with additional names without me asking them directly. Subsequent participants were excited to be interviewed and were willing to provide assistance in achieving the objectives of the research and to increase the researcher's network of relevant indigenous women in top-management. I had several advantages in collecting data in the 
Republic of South Africa/uMzansi Afrika. I understood the business culture of the Republic of South Africa/uMzansi Afrika. Also, I had an understanding of how to initiate a request of such a nature to an indigenous woman who is a topmanager, as I am also an indigenous woman who has worked in the business sector in this country. All but one of the candidates agreed to be interviewed. The individual who refused to be interviewed cited time pressures as a factor to refuse, since I had a time limitation of collecting data in the Republic of South Africa/uMzansi Afrika. The time limitation was to allow me to progress with my studies and for financial reasons. In general, I had a positive experience of the interview process.

In the next section, I discuss the composition of indigenous women I interviewed.

\section{Characteristics of sample}

In this subsection, I discuss the profile of my participants. Please refer to the table below (4.1) for a profile summary of my participants. As I explained earlier in this chapter, in New Zealand/Aotearoa I collected data mainly from the public sector (10 participants from the public sector and 5 participants from the private sector) and in the Republic of South Africa/uMzansi Afrika, the private sector because of convenience, time limitations and established contacts. 
Table 4.1 Summary profile of participants

\begin{tabular}{|c|c|c|}
\hline & $\begin{array}{l}\text { Republic of South } \\
\text { Africa/uMzansi Afrika }\end{array}$ & New Zealand/Aotearoa \\
\hline Name of sector & Mostly private sector & Mostly public sector \\
\hline $\begin{array}{l}\text { Number of } \\
\text { participants }\end{array}$ & $\begin{array}{l}\text { Interviewed } 17 \text {, but used } \\
\text { data from } 12 \text { participants }\end{array}$ & $\begin{array}{l}15 \text { participants (10 from } \\
\text { the public sector and } 5 \\
\text { from the private sector) }\end{array}$ \\
\hline Age & More than 45 years & More than 50 years \\
\hline City location & $\begin{array}{ll}\text { Mostly from } & \text { Johannesburg city }\end{array}$ & $\begin{array}{l}\text { Throughout New } \\
\text { Zealand/Aotearoa cities }\end{array}$ \\
\hline Degrees & Mostly business degrees & $\begin{array}{l}\text { Mostly degrees related to } \\
\text { health, social and } \\
\text { educational fields }\end{array}$ \\
\hline First language & $\begin{array}{l}\text { All - } \text { Indigenous } \\
\text { language as a first } \\
\text { language, learnt English } \\
\text { as a second language }\end{array}$ & $\begin{array}{l}\text { All except one - English } \\
\text { language as a first } \\
\text { language, learnt Māori as } \\
\text { a second language }\end{array}$ \\
\hline
\end{tabular}


In New Zealand/Aotearoa, the participants were Māori women in topmanagement roles from different industries, mainly in public sector organisations (10 from the public sector and 5 from the private sector). I interviewed a total of 15 Māori women in top-management roles. All the participants were above 50 years old. Only five participants were from the private sector, the rest were employed in publicly funded organisations. The participants were employed in organisations located in different cities and regions throughout New Zealand/Aotearoa. They held varying senior titles and positions such as Chief Executive Officer (CEO), Managing Director (MD), Senior General Manager, and Senior Manager. The participants mostly had degrees related to health, social and educational fields, for example, degrees in social work and teaching. Most participants had post-graduate degrees or qualifications such as a master's degree or graduate diploma. Only one participant had a $\mathrm{PhD}$ degree, and two did not have a bachelor's degree, but had tertiary post-high school formal qualifications such as certificates, and diplomas. All the participants had children and had been married at least once. Only two of the participants indicated not to have been raised according to the Māori traditional norms, values and family structures. They did not grow up practising Māori tikanga/customs as children; they had to learn it later in life. Only one of the participants spoke Māori language as a first language. The rest of the participants spoke English as a first language and learnt Māori as a second language. All the participants identified themselves as Māori women in terms of ancestry, affiliations and choice. The key characteristic of the participants was that they were successful Māori women in their professional life, and were in top-management already.

In the Republic of South Africa/uMzansi Afrika, I originally interviewed a total of 17 indigenous women, but only used data from 12 participants for this thesis document. This was because five of the interviewees turned out not to be suitable. Three of the participants were not top-managers because their roles were not sitting at EXCO (Executive Council) and I discovered this information during the interview. Two other participants were migrant Black women 
originally from other countries in Southern Africa. I believe that their experiences as migrants were influenced by different events than those women from the Republic of South Africa/uMzansi Afrika. I did not use their information either for the research purposes. All the participants had degrees, mostly business degrees, such as a Master of Business Administration, and a Master of Business Leadership. Others had junior business degrees, such as Bachelor of Arts in Accounting, and certifiable qualifications, such as in Chartered Accounting. Two of the participants had Doctor of Philosophy degrees. Most of the participants were more than 45 years old. All the participants spoke English as a second language and had an indigenous language as a first language that they used mostly in their communities and home environments. Most of the participants experienced the working professional life both under the Apartheid era and post the first elected national democratic elections in 1994. Only two of the participants indicated that they did not have children. All the participants were raised in a traditional African environment and Black communities. They grew up in areas that were designated for Africans, during the Apartheid regime. This included Black townships, such as Soweto.

In the next section, I explain how I made sense of data I collected from one-onone qualitative interviews to reach my own conclusions as a scholar and writer. I discuss the steps leading to my analysis of the information that I obtained from my participants.

\section{Data analysis}

In this section, I explain the analysis of data in order to answer my research questions. My data collection and analysis were simultaneous. This means that I started analysing data while I was still collecting it. This timing was to ensure that I had sufficient information, identified gaps and issues on which to followup to grasp the understanding of the experiences of my participants.

I digitally recorded all the interviews and, after each interview, transcribed the tape myself without the mmmms, silences, tone of voice and laughter. Oliver, Serovich, \& Mason (2005) calls this method denaturalism in transcription. It is 
concerned with meanings and perceptions created and shared during the interview (Oliver, et al., 2005). After transcribing, the data was coded and divided into data that could be used and data that was unclear. Unclear or inaudible data was not used.

The truth as the participants perceived it was important for the data analysis of the qualitative interviews. 'Truth' can be defined as lived experiences of truth (Jorgens, 2005; Lyotard, 1991) within the social and political contexts. Their accounts of the participants may vary in their truths depending on how they construct their experiences. In my findings, recorded in Chapters Five to Seven, the reality will be the construction of stories within the socio-political contexts of the Republic of South Africa/uMzansi Afrika and New Zealand/Aotearoa. My analysis reflected the manner in which the participants interpreted and told their stories, events or phenomena. I also present the description of the psychological event, experience or phenomenon of the participants. Truth is the meaning of the research object as it appears to the researcher (Jorgens, 2005). Therefore, it is possible that another researcher may have different interpretation of the results. I have kept a written audit trail as evidence for my justification for the interpretation of my analysis indicating procedures I have followed and reasons for doing so.

\section{Accuracy and truthfulness of data}

In this subsection, I address accuracy, transferability and truthfulness in my study. Accuracy and truthfulness are among words that are used in qualitative research to define honesty and explicability of data. Other words and concepts that are used are: trustworthiness (Anastas, 2004; Lincoln \& Guba, 1985; O'Leary, 2004), truthfulness (Forbat \& Henderson, 2005; Husserl, 1962), authenticity (Nunkoosing, 2005), quality (Nunkoosing, 2005), transferability (O'Leary, 2004), and verification (Denzin \& Lincoln, 2000). In my study, the approach of using history and politics to theorise about women in management is transferable to other future empirical studies. I present truth in my research by asking all my participants similar questions. Truth is also my representation of the voices of my participants. Through data collection and analysis, I incorporated the practices of the indigenous people's value systems, social 
relations and 'taken for granted' ways that indigenous people live their lives. 'Truth' in this project was achieved by understanding the participants' understanding of themselves and the meanings they attach to their existences as human beings in both their indigenous and western spaces. I used different methods to address issues of accuracy and truthfulness of data. I employed strategies of introspection, reflection, joined analysis and audit trail.

I used reflection and introspection to enhance the accuracy and truthfulness of data. In this project, I value women's ability to produce their own meaning in respect of their experiences. I interpret the interviews and incorporate my own experiences as an indigenous woman with experience of entering a management role. I provide meaning through both the insider and outsider lenses, which provides credibility and authority for the project. As a researcher, I am an outsider and as an indigenous woman who worked as a manager, I am also an insider to this project. Reflection enhances trustworthiness of the data (Anastas, 2004). Through my analysis of this research, I reflect on my own experiences and assumptions as a form of introspection as an insider to the project. This process also brings forth my biases to the project. Through reflection and interrogation of my own biases that I discuss in this chapter, I am able to recognise them as such and question their existence. At the end of each individual interview, I reflected on the interview contents, my impressions, speculations and process. I drafted my impressions and thoughts after each individual qualitative interview. This process served as a cognitive post-mortem evaluation of the interview, facilitated anticipation of other issues and improved future interviews. Reflection and introspection also acted as strategies for enhancing the quality in data analysis.

As a strategy of combined analysis, during the interview, I took handwritten notes as well as using a digital recorder to tape the interview proceedings. Using both methods ensured that I had comprehensive and accurate notes. This procedure ensured that each method acted as a substitute in case the other method failed. The advantage of using a digital-recorder was that it provided the exact details of the conversation including pauses. The disadvantage of using a digital recorder was that it took a long time to listen to an audio-file and to 
transcribe data. Reading my hand-written notes provided me with a quick overview of the interview.

I also maintained an audit trail of all the documents that I used to collect and analyse data. These documents include typed transcribed manuscripts, my own handwritten notes, thoughts, ideas and methodological decisions about this project. Seale (1999) argues that auditing, that is, multiple sources of data, is a task that includes the provision of a methodological self-critical account of the choices in the study. I plan to keep this information for three years following the completion of this research in case another researcher wishes to replicate the study. I obtained permission to keep records for this study from the participants. Please refer to Appendix $\mathrm{C}$ to view the details of confidentiality regarding storage of information. Writing and keeping records enabled me to become conscious of my decisions, as a researcher.

During the interviews, I offered to forward interview transcripts to the participants for them to edit any contents of the interview, before I used the information for the thesis. All the participants indicated that they did not need me to do such because they were busy individuals. They consented orally that I could use the information as per interview transcripts, without forwarding it to them. Mostly, they indicated that they trusted me with the information and that they had time constraints. However, they requested me to update them on my $\mathrm{PhD}$ progress, which I do on a constant basis using different methods such as email, telephone and in person. They would comment on progress, issues I would be facing and offered further guidance as well as enlightenment to the research.

\section{Data coding}

As part of my data analysis, I used interview transcripts from digitally-recorded one-on-one interviews with my participants, my hand-written notes about each participants and thinking notes which I kept as part of reflection, as resources. My analytical conclusions are based on diverse data: interviews, field-notes and interaction with my participants. It is during this phase that I made sense and interpreted the data to come up with my own conclusions of this research. I did 
not request my participants to be involved in the data analysis of my findings because it was not part of the study design.

There were several steps in my data analysis. See figure 4.1 for my diagrammatical analytical steps. After each interview, I listened to the audiorecorder several times before I began transcribing data. This was to familiarise myself with the data (Mehmetoglu \& Levent, 2006). In addition, I reviewed each transcript several times to gain an in-depth understanding of each woman's experience. This process allowed me to improve my research interview for the subsequent participant. In addition, I took every interview transcript and wrote a word or phrase next to the text, per line segment of the interview transcript, to reflect my own understanding of the meaning of the interview. Researchers call the concept of dividing data in an analytical manner to give meaning: coding (Charmaz, 2006; Saldana, 2009). See figure 4.2 to view a paragraph of my example of a coded interview transcript, which was part of an interview, as an example. During this phase, coding was based on interview transcripts, as per responses of my participants to my interview questions. It was my own understanding of the responses of my participants to my interview questions. As I developed my codes, I was forced to think about the contents of the interview in an innovative manner that may differ from the interpretation of my participants. The codes were my views; I chose the words that constituted the codes based on the data. It was my understanding and interpretation of the data. I described what I saw happening in the data. I looked for what my participants understood their situation and beliefs to be and how they explained their experiences. Then I interpreted them as I wrote the codes. 
Figure 4.1 My analytical steps

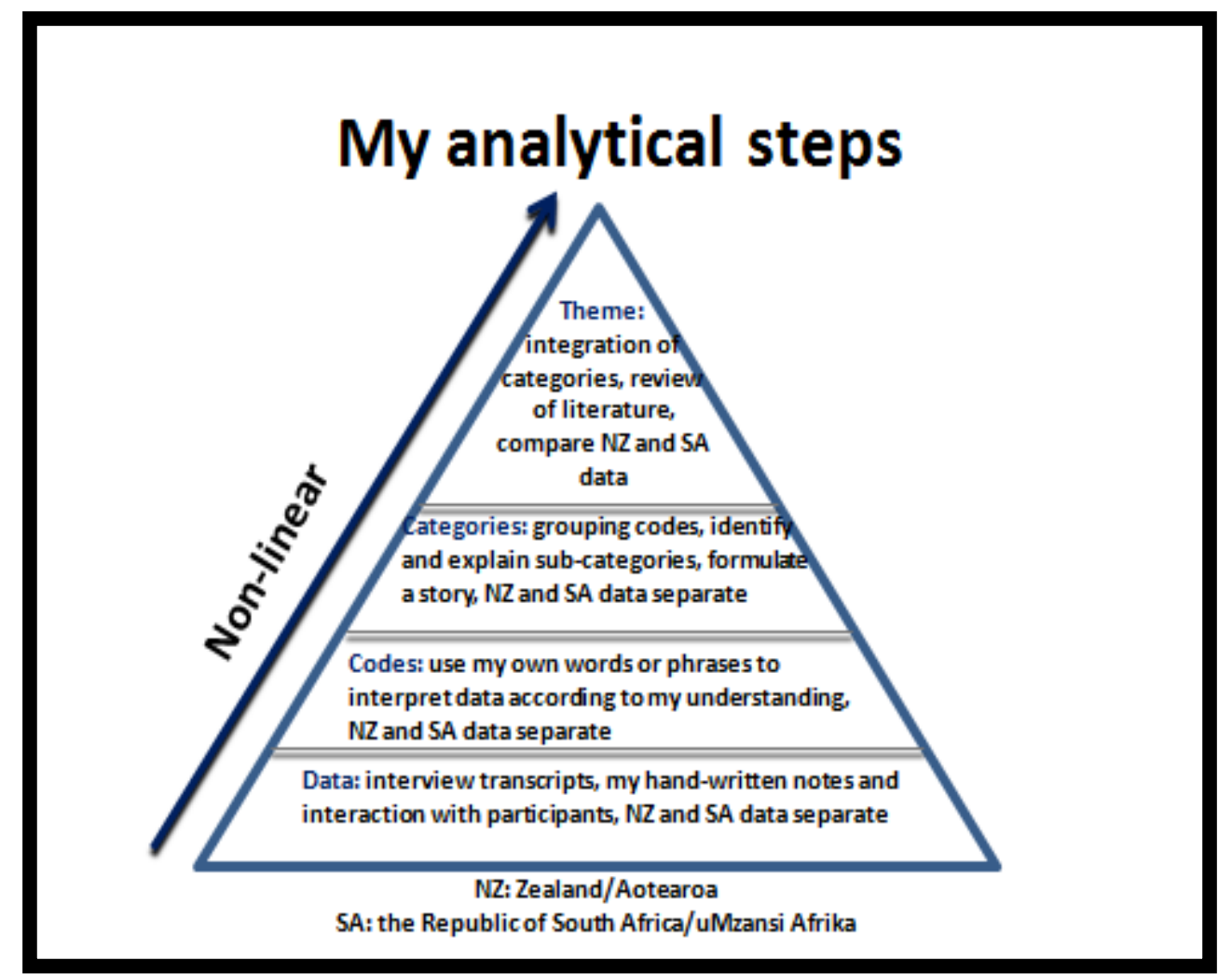




\section{Figure 4.2 An example of a coded interview transcript}
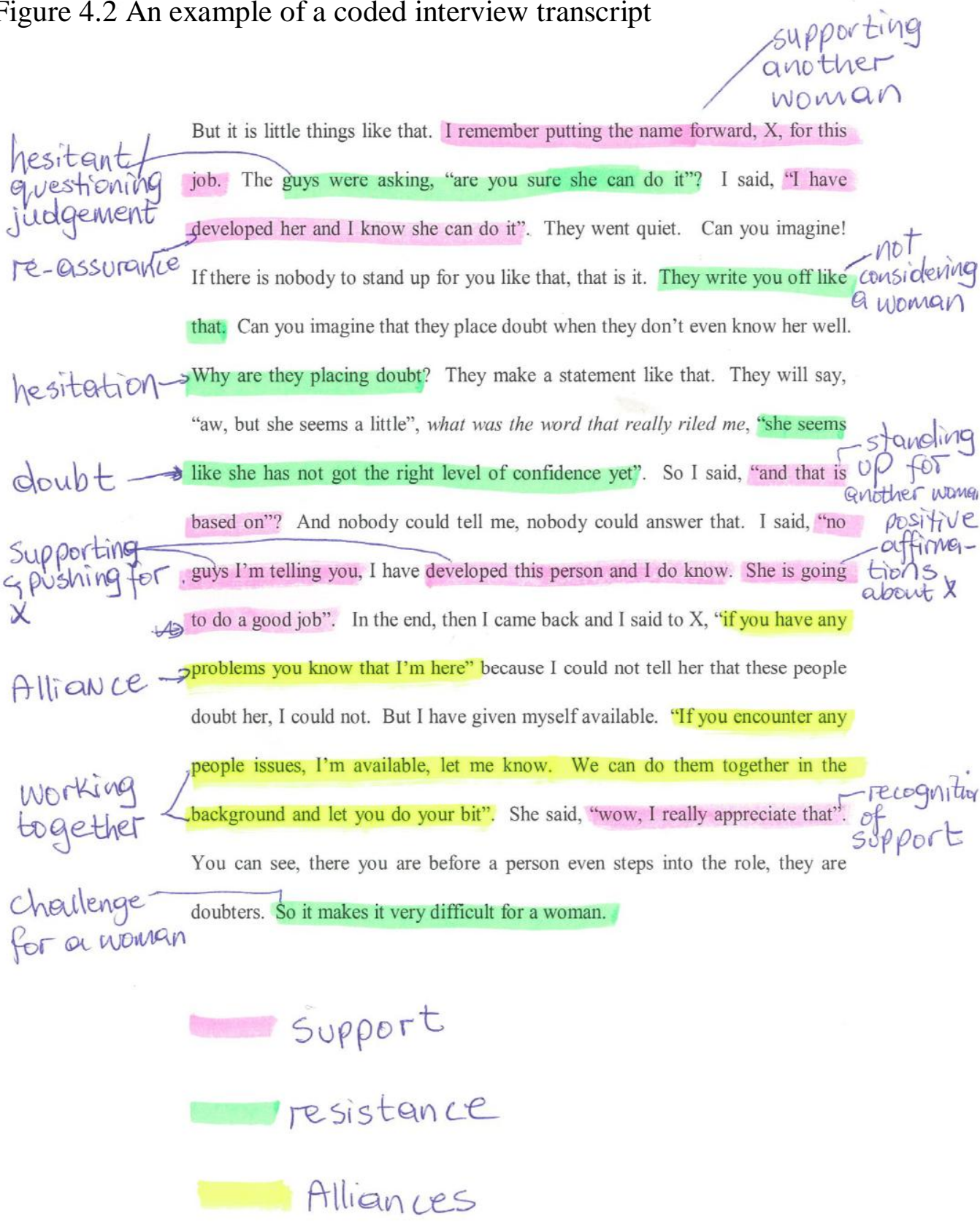
Initially, for my first four interview transcripts, I started with focused coding because there were specific concepts that I was looking for which were present in the women in management literature that describe the experiences of ethnic minority women in management. I focused on 'barriers' as categories present in studies focusing on the 'concrete-ceiling' effect. After realising that my participants were reluctant to reflect on their challenges as ethnic minority women in management, I went back to the initial four interview transcripts and re-coded openly. This means that I coded without specifying topics, but covering all the contents of the interview scripts as per participants' responses of the interview and my understanding of the interview. Open coding is a process of separating data into smaller components or parts, assessing, comparing, conceptualising and grouping it (Strauss \& Corbin, 1990). Open coding divides the data into categories (Dey, 1999).

After carrying out open codes, I started grouping my codes into categories. Richards and Morse (2007) define categorisation as moving from the diversity of data to the pattern of the data, as ideas are being represented. I took all the codes and grouped them according to meaning. For example, from figure 4.2, the two main categories from the codes became 'support' and 'challenges for women'. This means that, for example, under the category support, I described the subcategories emanating from the interview scripts. For example, sub-categories for 'support' became community upliftment, sponsors, alliances, solidarity, and networks. Under each sub-category, I developed a story. Some researchers call an explanation of the categories memos (Charmaz, 2006). A story meant that I made sense and interpreted each sub-category based on the data. In so doing, I drew diagrams and arrows based on my field notes and interview transcripts. For example, community upliftment consisted of ideas such as the importance of the role of the community in advancing into top jobs. As I developed the subcategories, I reviewed my field notes to develop ideas and re-examined the data. In so doing, I discussed the characteristics of the sub-categories, relationship with the main category and developed an argument. 
Because I started collecting data in New Zealand/Aotearoa, I started my data analysis with the New Zealand/Aotearoa data. I kept my analysis for New Zealand/Aotearoa and the Republic of South Africa/uMzansi Afrika data separate. Within both the New Zealand/Aotearoa and the Republic of South African/uMzansi Afrika data, I compared later interviews with earlier ones. As I developed the categories in both New Zealand/Aotearoa and the Republic of South Africa/uMzansi Afrika, I developed them for both similarities and differences. This means that I developed a popular narrative present within the stories of the majority of the participants, while noting the minority views, in terms of numbers, within the categories for both countries.

I categorised my data in an iterative manner. This means that when I was presented with new information from a new interview, I would go back to my previous interview transcripts to view, assess and compare with new information. This means that I was conducting constant-comparison between old and new information. This was not a linear process. Some of my discoveries in the data, forced me to re-look at my initial codes and data with 'fresh eyes'. Sometimes, this led me to re-investigate issues that I had missed during the interviews. Also, categorisation and sub-categorisation changed. I came up with tentative categories at the beginning of data collecting stages, which changed as I kept collecting data. As I was progressing with my analysis, I sought data that best described the gaps that were manifested through my data, in addition to the ones that confirmed or rejected the current data. As I was filling gaps to the data, I explored areas of ambiguity, similar and different issues with my subsequent participants to refine my emerging analytical categories. For example, in the paragraph I presented (figure 4.2), after looking with 'new eyes', I realised that person $\mathrm{X}$ was indigenous. I also realised that it was important for the participant to support her because of uplifting her community. This realisation of 'Māori/African upliftment' as a sub-category of 'support' became apparent to me after having had a few interviews with other participants and reviewed earlier interview scripts with later ones. This idea was confirmed by other participants later in the data collection process. 
I then integrated categories into an idea or theme. A theme is an idea describing more implicit processes in the data (Rossman \& Rallis, 2003). I re-visited the previous categories and initial codes to understand different relationships, similarities and differences. The data were re-grouped again. I wrote notes for explanations, associations, and re-defined categories, sub-categories and ideas. My data analysis started to demonstrate themes and relationships to them. I compared my emerging themes with the existing literature (Creswell, 1998). This included what was similar and/different in my findings from the literature focusing on women in management as well as the reasons for similarities and differences. I eventually came up with the most frequent themes for both New Zealand/Aotearoa and the Republic of South Africa/uMzansi Afrika. After having developed themes for both New Zealand/Aotearoa and the Republic of South Africa/uMzansi Afrika separately, I compared the similarities and differences between the data of both these countries. I then grouped my themes according to my research questions. I chose the most frequent themes as part of my data chapters. I continued reading the transcripts to keep in touch with my data until I finally submitted my thesis. Coding the data led me to my thematic interpretation of the data, presented in Chapters Five, Six and Seven, addressing my three research sub-questions, stated at the beginning of this chapter. It led me to link the stories of my participants from the interview manuscripts to come up with my conclusions of what it means to be an indigenous woman in topmanagement of predominantly white organisations.

I used Constas (1992) as a guideline to present my results according to themes that I will discuss in Chapters Five, Six and Seven (see figure 4.3). Constas (1992) presents a framework for explaining thematic choices made in qualitative data analysis. This framework sets out how conclusions are made into thematic decisions. This may be initiated before, during, or after formal analysis and derive from the theoretical literature, from terms used by participants or from ideas developed by the researcher. The names of the themes were a combination of my own, ideas from the women in management theory, and terms used by my participants. To verify the naming of themes, I compared them with the literature to ensure consistency on the names and interpretation of the comparable phenomena. During the research process, naming of themes changed 
several times until I believed that the idea that I was describing was fully defined by the name that I used and supported by the academic literature (women in management). For instance, I use the term 'shoulder-tapping' for the New Zealand/Aotearoa data and 'head-hunting' for the Republic of South Africa/uMzansi Afrika. I will define both terms in Chapter Five. These concepts were terms that my participants used and I decided to use both names for my thesis in describing the ways that they were recruited into top-management roles. Another example, in Chapter Six, I use the word 'mentor' to describe the main strategy for support for my participants. 'Mentor' is a concept that is present in studies focusing on women in management literature. My participants did not always directly use the word 'mentor'; however, they were describing activities that were conducted by a 'mentor' and reflective of mentoring relationships. The name 'mentor' is a word that is used in the women in management literature and I decided to use it to interpret as well as present my findings. As an example of a theme that I created, in Chapter Seven, I use the term 'racialised-gender'. It is a term that I developed while analysing data to understand lessons for other indigenous women wishing to penetrate top-management roles. I will explain the concept in Chapter Seven. I developed this idea after re-thinking and analysing my data. 
Figure 4.3 Naming of themes

\section{NAMING OF THEMES}

\begin{tabular}{|l|l|l|l|}
\hline THEME & \multicolumn{3}{|c|}{ WHEN DEVELOPED } \\
\hline $\begin{array}{l}\text { WHERE DID IT COME } \\
\text { FROM? }\end{array}$ & $\begin{array}{l}\text { BEFORE DATA } \\
\text { COLLECTION }\end{array}$ & $\begin{array}{l}\text { DURING DATA } \\
\text { COLLECTION }\end{array}$ & $\begin{array}{l}\text { AFTER RETHINKING } \\
\text { AND RE-COMBINING }\end{array}$ \\
\hline $\begin{array}{l}\text { FROM PARTICIPANTS } \\
\text { (A term they used in } \\
\text { the interviews) }\end{array}$ & $\begin{array}{l}\text { Head-hunting - SA } \\
\text { Shoulder-tapping- } \\
\text { NZ } \\
\text { (Chapter 5) }\end{array}$ & \\
\hline $\begin{array}{l}\text { FROM THEORY } \\
\text { (literature or } \\
\text { preliminary idea) }\end{array}$ & $\begin{array}{l}\text { Mentor } \\
\text { (Chapter 6) }\end{array}$ & & \\
\hline $\begin{array}{l}\text { FROM ME } \\
\text { (A concept I } \\
\text { developed while } \\
\text { analysing the data) }\end{array}$ & & & $\begin{array}{l}\text { Racialised-gender } \\
\text { (Chapter 7) }\end{array}$ \\
\hline
\end{tabular}

NZ: Zealand/Aotearoa; SA: the Republic of South Africa/uMzansi Afrika Used as a guideline to naming themes for data analysis

Based on: Constas, M. (1992). Qualitative analysis as a public event: The documentation of category development procedures. American Educational Research Journal, 29 (2) 253-266 
Figure 4.4: An example of analytical steps from data to a theme

\section{AN EXAMPLE OF ANALYTICAL STEPS FROM DATA TO A THEME}

\begin{tabular}{|l|l|}
\hline THEME & MENTORSHIP (CHAPTER SIX) \\
\hline CATEGORY & SUPPORT \\
\hline CODE & POSITIVE AFFIRMATIONS ABOUT X \\
\hline DATA & "XIS GOING TO DO A GOOD JOB" \\
& \\
\hline
\end{tabular}


Referring to figure 4.1, my analytical steps, I provide an example of different steps (that is data, codes, categories and themes) that I followed to arrive at the themes I present in Chapters Five, Six and Seven. For example, the statement "X is going to do a good job" from my example of a coded manuscript (refer to figure 4.2), is my data. In my example of a coded interview manuscript, figure 4.2, I placed my own meaning to the phrase to mean 'positive affirmations about $X$ '. The code is 'positive affirmations about $X$ '. This code along with other similar codes from different interview manuscripts, such as the code called 'reassurance' (refer to figure 4.2) and my own ideas from my interview notes, became the category called 'support'. 'Support' as a category is a grouping of similar codes (my own wording from a transcribed manuscript). The integration of categories such as 'support', 'alliances' and 'resistance' became a theme that I call 'mentorship'. Within this theme, I developed a story, that is, my interpretation of the data based on the categories to come to my own conclusions in discussing the form and issues surrounding mentorship for my participants as I present them in Chapter Six.

\section{Conclusion}

To incorporate inaudible voices and minds of indigenous women in management in terms of their sense-making of the world, I use a combination of paradigms: western and indigenous. I take the position that my participants construct their social realities of the lived experience to privilege their own understanding to make sense of their interpretations of the experiences of being top-managers. This experience is based on living in both indigenous communities and western worlds of their organisations that shapes this understanding. Understanding and interpreting the experiences of my participants cannot be excluded from their environments, contexts and culture; this is my research stance. For me to understand and interpret the lived experience of my participants, I had to understand their socialisation embedded within their cultural norms and values. This was one of the reasons for me to learn Māori culture and language as well as being conscious of my own African heritage. It is not an objective of this thesis to investigate and compare indigenous cultures in-depth. I am concerned with indigenous cultural issues in order to create appropriate relationships and be able to understand my research from my participants' lived experience point of view. 
This value of learning Māori culture and understanding my own African cultural worldview, facilitated my mental position to write and conduct this research in both the indigenous and western spaces. I also needed this cultural understanding in interpreting my data and putting my conclusions into context.

My research design also affirms indigenous ways of knowing the world by locating the experiences of my participants within their indigenous cultural ways. The reason for this approach is that I believe a person and the world are linked through lived experience of the world. This becomes their truth, as participants, which is lived (Lyotard, 1991). Social reality is locally and specifically constructed (Andrade, 2009) by human beings through their interaction. Reality is how participants define it to be. Understanding social reality necessitates the comprehension of practices and meanings formed through a language and implied shared norms by a group (Andrade, 2009). Within this perspective, social reality is constructed through the meaningful interpretation of my participants, as per concept of Prasad and Prasad (2002). Through my research design, I address how my participants understood the 'concrete-ceiling' theory as top-managers in predominately white organisations taking cognisance of who they were as individuals.

In the next chapter, I will present my findings. 


\section{CHAPTER 5}

\section{POSITIVE POLICIES FOR INDIGENOUS WOMEN FACILITATING TOP-MANAGEMENT ENTRY}

I found that the policies and actions of Governments in both New Zealand/Aotearoa and the Republic of South Africa/uMzansi Afrika was the major reason my participants entered their top-management roles. This is because these Governments were at their points in history conducting conciliatory processes to correct the historical wrongs for indigenous people. They were returning resources back to the indigenous people. Indigeneity became important for my participants in entering top-management roles because of the solutions provided by these Governments based on history. Nearly all my participants entered top-management through Government solutions to correct history for indigenous people. They were the first wave of indigenous women entering top-management roles and were able to take advantage of topmanagement positions because of the positive changes in Government policies. They were head-hunted in the Republic of South Africa/uMzansi Afrika and shoulder-tapped in New Zealand/Aotearoa. Shoulder-tapping is a process where a prospective suitable candidate is encouraged to apply for a new role. Whereas head-hunting is more aggressive, tends to be organised, in the form of executive search firms, and is concerned with finding the suitable candidate. This became possible because of activism of indigenous people in these countries.

The objective of this chapter is to address the research sub-question: what issues do indigenous women face when they move into top-management roles? During the early stages of my project, I expected that the participants would articulate many 'barriers' that they encountered in their organisations, as per 'concrete ceiling' studies. My initial sub-question was: what are the 'barriers' indigenous women face when moving into top-management roles? During the interviews the participants rather emphasised success, which was contrary to my expectations. Although they mentioned barriers, they largely focused on their successes. As I listened deeply to the stories of my participants, I realised that they were riding on a wave of political change at this point in history. I also 
realised that their initial top-jobs were risky in that the new job involved change related to the implementation of positive legislation empowering indigenous people. I explain later in this chapter what I mean by positive legislation promoting indigenous people. This chapter is the first of the three chapters that discuss and analyse the findings of my participants.

In this chapter, I present the Government policies in both New Zealand/Aotearoa and the Republic of South Africa/uMzansi Afrika that assisted my participants entering top-management roles. I follow with a section on shoulder-tapping and head-hunting activities in these countries. Thereafter, I discuss the nature of initial appointments for my participants. I then explain that my participants were the first to change history in these countries.

\section{Government policies to enhance opportunities for Indigenous women}

In both New Zealand/Aotearoa and the Republic of South Africa/uMzansi Afrika Government strategy played a role to make it possible for my research participants to reach their current levels through legislation and / policy. In New Zealand/Aotearoa, Government policy and legislation facilitated entry into top roles for indigenous women. All my research participants, without exception, entered top-management levels through either the Equal Employment Opportunities (EEO) or Waitangi Treaty settlement vehicle. The findings were that all the participants entered initial top-management roles in the 1990s, which co-incided with major Waitangi Treaty settlements. These Treaty settlements gave rise to the need of more Māori people to drive and manage enterprises or be in existing organisations to address issues relating to Māori. Because of the initial time entering top-management roles at the time of the interviews in 2009 all the participants had already occupied more than one top-management role. The participants were in a position to penetrate top-management roles as Māori women because of the legislative and policy changes at the time of initial entry.

Similarly, African women from the Republic of South Africa/uMzansi Afrika largely reached their top roles because of legislative changes in the country, particularly in the workplace. The political climate in the country made it 
possible for the participants to occupy their current roles. The political climate was the first democratic election of 1994 for all the citizens of the Republic of South Africa/uMzansi Afrika. There was also an emergence of the need to have indigenous women in top-management roles to address inequality in the workplace and correct historical injustices of the marginalised groups, including African women. The Employment Equity Act 55 of 1998 (EEA) and the Black Economic Employment (BEE) legislation made it possible to achieve this need. Because of the introduction of the legislation to promote African women from the Republic of South Africa/uMzansi Afrika in top-management jobs, different organisations had a need to employ them to comply with the legislation. Also, the Government created new organisations because of the promulgation of the legislation in different sectors. Through Government legislation, the participants were able to occupy positions that they were previously excluded from entering.

\section{Māori women}

Since the 1980s and 1990s there has been a political shift to redress the inequities towards Māori people and women through various legislative and policy frameworks such as the EEO. These shifts have resulted in different initiatives by Government to improve the conditions of Māori women. There was an emergence of incorporating Māori people and women into the public sector. A participant explained:

I met all those $\mathrm{X}$ [decision making bodies in the sector] and all of them interestingly were Pākehā [white] men, no women, no women, certainly no Māori, no Pacific people. They were old Pākehā men. That was the nature of the $\mathrm{X}$ sector in the early $90 \mathrm{~s}$. It was run by men and the majority of whom were Pākehā. EEO has a lot to do with beginning to challenge the system and the way it worked.

Another participant elaborated: "Around the same time [early 90s], government had been challenged on the lack of Māori in middle and higher management".

These comments as examples reflect the political climates of New Zealand/Aotearoa and the Republic of South Africa/uMzansi Afrika, which most 
of my participants experienced. The EEO policy and its implementation through various government processes created opportunities for Māori women to advance into top-management roles, particularly in the public sector. Some of the participants were involved in the EEO programmes to increase the number of either Māori or women in certain sectors, such as health. The Ministry of Women's Affairs administered some EEO programmes targeting Māori women to occupy top-management positions. The State Services Commission administered other programmes. The outcome of the EEO policy and practice was the increase of the numbers of the under-presented groups in topmanagement, particularly Māori women.

Another finding was that the Treaty of Waitangi settlements facilitated the creation of several Māori organisations and Māori roles within Pākehā (white) organisations. A participant explained:

Back in the 1980s, early 1990s there used to be [the] Treaty of Waitangi training [in various sectors such as health] that was the PC [politically correct] thing at the time. It was about the true history of New Zealand and the impact of colonisation and what happened to Māori people and why it is that we were at this point where our status is so low and poor.

The comments were similar for most participants. The first major Treaty settlements were in the 1990s. These Treaty settlements gave rise to new institutions, organisations and Māori roles within existing organisations. As a result of the initial major Treaty of Waitangi settlements, Māori wealth grew. These Treaty settlements created opportunities for people with similar interests to connect and discuss issues relating to Māori compensation in relation to aspects, such as Māori land and rights.

\section{African women}

Similarly, Black women from the Republic of South Africa/uMzansi Afrika largely entered their initial top-management roles around the late 1990s. Most of them cite government legislation as being the main enabler that made it possible for them to reach their current levels. Most were in roles, such as Black 
Economic Empowerment (BEE) executives, as their initial positions at topmanagement levels. These roles were largely created because of the promulgation of the BBE and EEA legislation, amongst others, with an objective of compensating indigenous people of the wrongs based on history. There was a need for organisations to present different rainbow faces of the Republic of South Africa/uMzansi Afrika and both genders. Government passed various legislation to address different forms of discrimination in the workplace, which were resulting from the Apartheid policy. As part of this process, new organisations were created, amongst others, to return resources back to indigenous people. A participant noted:

I was approached by X, he said, a Bill has been passed for Y [name of organisation] --- and the only structure that is in place that they have approved is the CEO and the Commissioners. We don't have anything else. I have been assigned to come and tell you that you'll be starting work on Monday.

The comments as examples show a new organisation that was formed as a result of the introduction of new legislation. The participants were able to occupy topmanagement roles in these newly created organisations. After they occupied these organisations, it was easier for them to occupy other top-management roles in different organisations. They had already proved their capabilities and competencies at top-management levels. Changes in the legislation created opportunities for the participants.

\section{Shoulder-tapping / Head-hunting activities for the participants}

In both New Zealand/Aotearoa and the Republic of South Africa/uMzansi Afrika, my participants were mostly encouraged and approached to apply for their current roles because of the positive Government changes. In both New Zealand/Aotearoa and the Republic of South Africa/uMzansi Afrika, the 'job looked for them and found them' instead of them looking for jobs. 


\section{Māori women}

For some participants, cultural connections that facilitated the shoulder-tapping of the participants consisted of Māori people who were part of a Māori group or identity. A participant expressed:

I was asked to apply. I was shoulder-tapped. There was a Māori recruitment person. He contracted [with X organisation] and he'll get me my next job. That is how we operate. That is the significance of whakapapa (genealogy) of that network. All my mates look out for me.

The comments of the participants as examples indicate the importance of Māori connections as a crucial link in the recruitment of other Māori professionals. These views were shared by most participants in New Zealand/Aotearoa.

Other participants moved around jobs because of professional connections. The professional connections sometimes had a connection to Māori networks. A participant expressed:

I have not been out in the public sense looking for a position, I've been approached. --- I was a member of the X [name of board] Board and got requested to be acting CEO.

Also, another participant narrated her story:

He had been asking around because he was about to create a new position at Z [name of organisation]. He particularly wanted a Māori woman, and he was asking around, who are the Māori women qualified with experience who might be wanting to apply for the job. So he had been given my name you see. After he said my name is $\mathrm{X}$ you just have to be $\mathrm{Y}$ [name of participant], he said I've got a job for you.

These remarks are examples to suggest that it is important for Māori women in top-management to invest in both Māori and non-Māori professional networks because some of my participants are recruited by non-Māori through a network. 
These networks are a route to advance the occupations of Māori women into higher management levels.

The rest of participants got into their current positions because their previous positions and roles changed within the same organisation. They were requested to take additional responsibilities. A participant remarked:

$\mathrm{X}$ came, we're restructuring, we're not going to restructure your position. You're coming with me. He moved up into the CEO and I moved up again. --- So did others of the management team. Because there was such a likeness of the position, responsibility, we didn't advertise. So I moved like that.

Another stated: "I did not have to apply for this role, --- I was in the organisation already and the responsibilities got bigger, so I was requested to take this position".

In New Zealand/Aotearoa scholarly studies focusing on women in management, recruitment and selection practices and / procedures centre on 'barriers'. For example, Baldwin (2000) argues that issues such as recruitment, selection, and placement procedures may negatively affect the promotion of the potential candidate, particularly for women. However, for these participants the recruitment process was positive because they had choices to choose their employers and became desirable employees in the market for different strategic reasons associated with changes in politics. Also, Fawcett \& Pringle's (2000) case study of eight companies concentrates on 'barriers' regarding the selection practices of executives in that they are not objective and rely on informal connections, which tend to be male. Because the selection of the CEOs relies on informal networks, the appointments to CEO positions tend to be offered to those candidates who were not seeking alternative job offers (Fawcett \& Pringle, 2000). They also argue that the candidate is then enticed and solicited into the position. These studies focus on the possible recruitment and selection 'barriers' for women in top-management roles. However, my findings are contrary to their 
studies in that Māori women in top-management roles are highly visible in the market and actively recruited at these levels at this point in history, particularly for roles that are new.

\section{African women}

In the Republic of South Africa/uMzansi Afrika, some participants were recruited through their personal and professional connections. The participants and their connections tended to move around jobs together as a group once they were comfortable working with one another. A participant noted:

$\mathrm{H}$ [name of individual], recruited me via $\mathrm{X}$ [name of another person], $\mathrm{X}$ was the CEO of Y organisation. --- X had been my mentor somebody that I had looked up to over the years. --- So H said, 'no, F [name of participant], we want to start a group corporate account management and $\mathrm{X}$ is always raving about how $\mathrm{G}$ [name of organisation for the participant at the time] is doing this and I want to introduce this to $\mathrm{Y}$ and since you have started doing that at G why don't you come to start that at $Y^{\prime}$ ?

A different participant added:

In fact, when I left, I left to go to X organisation, $\mathrm{Z}$ [name of the director at $\mathrm{Y}$ organisation], came back to $\mathrm{B}$ [name of current organisation] at the time and he heard I was going to X and he said 'there is no way, I can allow you to be my competitor. I have to find a way of recruiting you back', --- so I came back to B [name of current organisation] in 2001.

These comments are examples to reflect that both personal and professional connections are an important part in recruiting the indigenous women in topmanagement roles. Also, for some participants they tended to move together with people that they trusted because they were comfortable with them and trusted their competencies. Personal and professional connections are one of the avenues, which gave the participants informal work references. 
The minority view in terms of numbers that was stated by four participants was that they left their organisations and joined them later at a higher level. It was easier for these Black women to come back to the same organisation for which they had previously worked. Their work references were within the firm and the employer had developed relationships with them. The employers or decision makers within the firm understood their strengths and weaknesses. A participant noted:

The advantage that I had was that when I left $X$ [name of the organisation] I had left with sabbatical, they did not want me to leave. So they said, "we are going to give you sabbatical [leave] for a year, if it does not work out, you can always come back'. So a year later, I went back to them and said 'I think it is still ok'. I then formally resigned, but I gave them assurance [that] should I decide to go back to corporate I would give them first right. Then in 2006, I called them up and I said 'I'm back in the market I have not sent out my cv [curriculum vitae], --are you willing to give me a job'? They said 'excellent, our BEE exec [executive] left a few months ago and we have a post of BEE exec. It seats at EXCO, if you take that, we would love that'. So that is how I came to $\mathrm{X}$ in 2006.

The comments as examples reflect that the participants built a good reputation for themselves such that they had positive relationships with their employers by the time they resigned from their jobs. Because of their good reputation, they gained a competitive advantage with their employers when they sought employment to an extent that the previous employers would be willing to re-hire them after they had left the organisations.

Drawing from research studies focusing on women in management in the Republic of South Africa/uMzansi Afrika context, most of them concentrate on 'barriers' as a reason that Black women are not in top-management roles. In the Republic of South African/uMzansi Afrika context, studies of Fischer (1995), Mathur-Helm (2005), Mathur-Helm (2006), Erasmus (1998), Govender \& Bayat (1993), and Naidoo (1997) on women in management also focus on 'barriers'. 
However, Mathur-Helm (2006) in her study found that, her participants largely believed that women get head-hunted into top-management roles. My findings agree strongly with her study that successful women get head-hunted in topmanagement. This practice is particularly true for African women in topmanagement.

In summarising head-hunting and shoulder-tapping activities in both New Zealand/Aotearoa and the Republic of South Africa/uMzansi Afrika, indigeneity became important in my study. This is because these Governments were addressing history and politics that co-incided with the composition of the characteristics for my participants, indigeneity. The participants have unique issues as Māori / African women in top-management. Belonging to two previously disadvantaged (Māori / African and women) groups may have a positive effect once the individual has broken through the 'concrete ceiling' at this point in history in these countries. As Māori / African women who occupy top-management positions, they are visible in the market because of their limited number. However, my participants were over concentrated in roles that included EEO in New Zealand/Aotearoa and BEE in the Republic of South Africa/uMzansi Afrika initiatives. These roles involved strategic change of their organisations.

\section{Initial appointments}

Although my participants were desirable in the job market, they were initially promoted into positions to keep the current power structures. Their initial organisations appointed indigenous women at top levels outside their competency areas and / underestimated their competencies. These organisations became more concerned with the numbers for indigenous women, rather than a combination of both numbers and the appropriate skill and / competency match. The participants indicated that they were aware of these practices of wanting a Brown / Black woman who will not make a significant contribution to change power structures in organisations. For example, a participant from New Zealand/Aotearoa noted: 
Then the manager did not know what to do with me because I was Māori. She struggled. --- So I did not last long because she did not know what to do [with me], she did not know how to manage people, also a little bit added [made it more confusing for her] because I was Māori.

Another participant from New Zealand/Aotearoa explained:

Often they underestimate me, woman Māori, oh no [she did hand and face signal to mean being a Māori woman you don't know anything]. They under estimate me, --- their expectations are low, I can only do good. So it gives you a bit of a head start. They don't have expectations of you. --- They often think you're there as a token. Sometimes you are there as a token. I don't care, I can prove my own worth.

Also, a participant from the Republic of South Africa/uMzansi Afrika added:

I was at $X$ [name of the organisation] for 18 months, terrible, the culture is unbelievable, when they give you a big title, benefits, you get this, --you get that, but the responsibilities are not there --- it is the title only. --They call you a General Manager and you have no responsibilities.

A different participant from the Republic of South Africa/uMzansi Afrika remarked:

$\mathrm{Y}$ [name of the individual], phoned me and pestered me [insisted] until I came [to this organisation] because at $\mathrm{Z}$ [name of the organisation] I was frustrated, anyway so I just left because I was disempowered. I was under-employed at $\mathrm{Z}$.

Appointments of keeping power structures within organisations particularly at the initial entry of top-management levels were common for most participants in both New Zealand/Aotearoa and the Republic of South Africa/uMzansi Afrika. Most participants resigned from the roles that they were not able to turn 
positively to their opportunities. They believed that they were under-valued and under-utilised by those organisations. The comments as examples suggest that the participants preferred to contribute positively to the organisations. As top managers, they wanted to influence the direction of their organisations positively. They wanted to make a difference. They then joined and stayed in organisations that gave them scope to grow their skills and allowed them to contribute to the organisational activities. According to McClelland (1965) individuals in topmanagement roles typically have a need for empowerment and achievement. For my participants their empowerment came from conducting responsibilities that were commensurate with their capabilities and abilities that they accumulated through their professional lives. Once, they felt that they could not maximise their skills they would join other organisations. They stayed in those positions that gave them legitimacy as competent top-managers. In their current positions at the time I conducted my interviews, they were making significant contributions as top-managers who were utilising their skills effectively and appropriately. They were already in roles that made them responsible.

\section{Visible projects facilitating entry into top roles}

As a strategy to succeed and turn around token appointments, my participants from both New Zealand/Aotearoa and the Republic of South Africa/uMzansi Afrika were involved in visible projects that helped them to be noticed in the job market. The fact that they were indigenous women gave them the scope to do their projects unconventionally. The participants claimed that the point that they looked different, that is Brown in New Zealand/Aotearoa and Black in the Republic of South Africa/uMzansi Afrika in top-management structures, that gave them the opportunity to work differently from their colleagues who were predominantly white male.

In New Zealand/Aotearoa, Māori women mostly developed high profile projects that assisted them to be involved in other high profile roles. The high visible projects assisted participants to enhance their skills. For example, a participant explained: 
I developed all those programmes that would help Māori working in the $\mathrm{X}$ [name of sector] sector considering $\mathrm{Y}$ [name of occupation] as a career and knew the pathways they needed to go down to get there. So I had a real opportunity to develop my skills then.

Another participant added:

I have been appointed to lead, to create, a major research programme called the $\mathrm{X}$ to do the project planning, build a team, and to manage the research programme --- that was the government review team of $\mathrm{Y}$, the $\mathrm{Y}$ movement. The government wanted the review of the whole movement.

Participants made unique contributions to their organisations. A participant commented:

Once, I started to understand perceptions, I then started to realise how I was going to be able to add my value. --- It is alright to be different. In fact I like that I am different because I'm not like them. So I can say different things, it is ok because I'm already different. --- I say to people learn to be uncomfortable and learn to like it.

Conducting visible projects differently and success in high profile projects helped the careers for the participants, particularly in New Zealand/Aotearoa.

Similarly, in the Republic of South Africa/uMzansi Afrika, other participants attained top-management roles because they were able to manage visible high profile projects successfully. Organisations with similar challenges to those that the participants had shown they were able to successfully manage, sought their competencies. A participant remarked:

I got promoted to do $\mathrm{Z}$ at $\mathrm{X}$ city. --- I had to manage that, it was the largest --- deal in the organisation. It was worth about US \$ $\mathrm{T}$ million dollars per month so I had to do the management of the city. So there I 
started interacting with the executive management and that I believe was my break at this organisation.

A different participant added:

So I got an offer from $\mathrm{X}$ [name of organisation] as the head of $\mathrm{Y}$ [name of occupational area]. I think that was the defining moment for me because I was the first one to be appointed, I had to set up the whole division. And it went very successfully well because in one of the years, I think it was 2002, I was nominated as the Y [name of professional occupation of the year] --- across the board, private and public sectors. I think that is how I got to know a lot of people, a lot of people got to know me. I used to sit on the $\mathrm{Z}$ [name of professional body] technical committee, representing the whole public sector, all the $\mathrm{Y}$ in the public sector. So anything which was technical where they had a problem, I needed to articulate, I had to clarify.

The participants attributed their skills of being in demand to some of their visible projects that were successful. Visible projects earlier in their roles provided them access to key decision makers. Once they succeeded in those projects, as they were high profile projects, the market tended to require their skills for similar future projects.

\section{Pioneering work}

As a strategy to turn around initial appointment to favour my participants, the participants from both New Zealand/Aotearoa and the Republic of South Africa/uMzansi Afrika also became involved in pioneering work that helped them to be in the spotlight in their occupations. They have largely initiated projects. Pioneering work earned them a good reputation because the projects were successful. Mostly indigenous women from both New Zealand/Aotearoa and the Republic of South Africa/uMzansi Afrika engaged in different activities in their occupational areas by starting new projects. These projects became the base of measurement for other similar projects. A participant from New Zealand/Aotearoa remarked: 
$\mathrm{X}$ [name of occupational field], very male dominated, --- so I started up training on how to do it properly and better and that training was taken on board by the New Zealand $\mathrm{X}$ [name of organisation that regulates the industry]. They said you show us what your programme is. So now a lot of the training that is delivered by the $\mathrm{X}$, I helped to develop.

A different participant from the Republic of South Africa/uMzansi Afrika remarked:

The CEO --- was resisting the transformation. So I guess somebody had told them what I did at X [name of organisation]. So they called me in for an interview --- one of the board members. --- So I went in and did the interview and I was appointed to be the CEO. The same challenge was about transforming the organisation. --- They had same pattern as at the $\mathrm{X}$.

Another participant elaborated:

I think where I really proved myself was when my MD [Managing Director] said it is so difficult to find Black talent, can you assist. I went to look for the best talent. If they said an engineer, I would get the best engineer for them, if they said a financial person, I would get the best financial person, in so much that the people that I recruited into the company, --- went out to become powerful government people, --- the guy I recruited --- as an P [name of profession] is now the MD [of that organisation]. He is a Black guy. $\mathrm{T}$ [name of university] Business School started hearing of our programme as well and they started using us as a business case on transformation. --- We became $70 \%$ Black in that company and $30 \%$ white --- and the representation across [the organisational structure]. 
In both the Republic of South Africa/uMzansi Afrika and New Zealand/Aotearoa, indigenous women started new projects that were noticeable in different areas of the working environment.

In summary, the participants, as a strategy to be victorious and expand the significance of their initial appointments, took advantage of opportunities by engaging in pioneering work and / visible projects that made them noticeable in their fields. This concurs with other studies (White, 1995), which show that successful women in management were successful on work assignments that were given to them earlier in their occupations. Ragins and Mattis (1998) continue to argue that successful women seek challenging assignments to give themselves opportunities and develop unique skills to become indispensable. In their study, the participants also sought visible assignments, which were responsible for their level of success. My study is in agreement with Ragins and Mattis (1998) in that my participants were known in their areas for their success and at times were sought for their specific unique skills. Pioneering work and / visible projects 'opened doors' for the participants to be in demand at topmanagement levels in predominantly white organisations. However, this pioneering work and visible projects were largely the result of the EEO and BEE policies.

\section{First face of change}

Because of the broader political changes, my participants from both New Zealand/Aotearoa and the Republic of South Africa/uMzansi Afrika then became the first indigenous women to occupy their roles and they had to overcome personal 'barriers' of acknowledging to themselves that they had to lead the way for other indigenous women. Being the first face in top-management roles marks the beginning of historical and political change in both New Zealand/Aotearoa and the Republic of South Africa/uMzansi Afrika.

In New Zealand/Aotearoa the participants were the first Māori women to occupy their positions. From New Zealand/Aotearoa, a participant stated: 
So by the time this role became available, they 'sorted' me out, I did not seek them in the initial, in fact I had to be convinced. --- I thought gender then, I really thought gender because of this role, I'm really the first Māori woman and when I was asked to come on board, I said don't be silly it's a man's role. I just know, I'm not even going to bother --- three or four years before I was in the position, you generally had to be a male to get into this position. I think the mood is changing now.

Another participant elaborated: "There was a huge protest and that's how the position came out, $\mathrm{X}$ and Y identified me as a Māori woman they would like to take the position".

A different participant added: "Nearly all the jobs I have been into, I have been -- the only Māori”.

The above comments are examples to indicate that my participants were largely the first face of change in their respective organisations. Also, they had to overcome personal 'barriers' of accepting within themselves that they are the first indigenous women in their roles.

Similarly, in the Republic of South Africa/uMzansi Afrika, the participants were the first face of change in their organisations as indigenous women. For example a participant remarked:

Other than myself the fact, --- a person who is a $\mathrm{X}$ [name of occupation], there is nobody else who is a Black African in $\mathrm{Y}$ [name of organisation] in Sub-Saharan Africa, which means then that I represent hope. I represent hope for the Black people in Y.

A different participant remarked: "I was the only woman, I was the only Black person at EXCO [executive committee] level".

These comments are examples to illustrate that the participants from both New Zealand/Aotearoa and the Republic of South Africa/uMzansi Afrika were largely 
the first wave of indigenous women to be in their current roles. My participants used their new power strategically to 'open doors' for other women and / indigenous people who are not treated fairly in terms of promotion. As an example, a participant noted:

Now, when I go to meetings, I'm very open, I don't pretend. Whatever, they get is what they see. So in meetings I'm not shy to talk about transformation, if somebody is treated unfairly in terms of promotion, I would say it.

The participants were willing and prepared to accept the top-management rolesnot only personally as individuals, but in terms of how they perceived the advancement of their communities. Success for them was an opportunity for advancing their communities. By contrast, studies of Marshall (1995) and RossSmith and Chesterman (2009) focusing on women in management, indicate that (white) women are ambivalent about accepting and occupying top-management positions. For my participants, advancement to top-management roles was also about a collective commitment to access jobs that make a difference to many and therefore to supporting each other to get into these jobs and survive in them.

\section{Conclusion}

In this chapter, I responded to the question: what issues do indigenous women face when they move into top-management roles? I highlighted the importance of government strategy to initiate EEO policies to redress the historical-political wrongs of both New Zealand/Aotearoa and the Republic of South Africa/uMzansi Afrika that had sidelined indigenous women from the workplace in management roles. Through these EEO / similar programmes, my participants were able to penetrate top-management roles, which is contrary to the discussion of top-management access in studies focusing on women in management. This literature tends to consider success in entering top-management levels as the responsibility of the individual woman. On the other hand, in my study, Governments took the responsibility of addressing the problem of having a limited number of indigenous women in top-management as political and social 
issues, which needed fixing by introducing policies. The current theorisation of women in management in the women in management literature does not engage political or social interventions in discussing the interactions between issues of gender and race in management. My findings indicate that a political solution can be effective in uplifting a group of indigenous women and enabling their efforts in entering top-management roles.

The next Chapter will elaborate on how the participants viewed promotion as a vehicle to support other indigenous women while also supporting themselves as a collective strategy. From my findings, the concept of promotion was about community upliftment. It was about success of the Māori and the African community as a collective. For the participants their means of uplifting themselves in organisations was through informal mentoring structures and working together supporting one another as a community. They developed support mechanisms to support one another and themselves. They mentored one another, as a support strategy, in a distinctive manner that was reflective of the indigenous ways in both New Zealand/Aotearoa and the Republic of South Africa/uMzansi Afrika. 


\section{CHAPTER 6}

\section{MENTORSHIP AS A COLLECTIVE STRATEGY}

I found that collective support is an important strategy to the characteristics that define the participants as insiders and outsiders of their organisations. I was amazed as I was analysing the data of the similarities in the findings between New Zealand/Aotearoa and the Republic of South Africa/uMzansi Afrika as participants from both countries used similar collective strategies to support themselves. I was surprised because these individuals are two groups located in different countries. I did not anticipate similarities of strategies between these different individuals. Informal mentoring was the main support strategy that the participants provided for themselves. Informal mentoring for my participants was distinctive in that it was a combination of a group / peer and one-on-one. Also, it was often provided by individuals who were both outside and within the organisations of the participants. The participants had a variety of informal mentors who guided their professional lives. The characteristics of these relationships are manifestations of the influence of Māori and African cultures in New Zealand/Aotearoa and the Republic of South Africa/uMzansi Afrika where the concepts of collective support and reciprocity are strong and often informal.

The participants also raised issues that result from being an insider in an organisation at top-management, while also being an outsider belonging to their Māori/African communities, and managing an identity of being a Māori/African woman. Their values, accountabilities and culture about professional advancement were about uplifting other Māori/African individuals or groups. Their support strategy was reciprocal in a way that is characteristic of a collective. The participants received support for themselves through informal mentorship to strengthen their skills as the top managers of their organisations. Reciprocally, they provided various supports according to their expertise to their communities. This reciprocal support is what defines, builds and strengthens the participants as indigenous women in top-management. This kind of support has a purpose of uplifting the collective, which is the indigenous community. My findings were interesting, I believe, because the participants from both these 
countries used similar strategies to cement their insider/outsider status through the mentoring relationships in that they were informal and were both within and outside their organisations. This chapter addresses the research question: what strategies do indigenous women implement to enhance their opportunities to advance into top-management roles?

In this chapter, I present the cultural indigenous issues in informal mentoring. This focuses on the cultural indigenous issues that need to be taken into consideration when discussing mentoring with indigenous women in New Zealand/Aotearoa and the Republic of South Africa/uMzansi Afrika. I follow by a section on informal group peer mentoring. Informal peer group mentorship explains how indigenous women as peers in a group informally mentor one another. Thereafter, I discuss one-on-one-informal mentorship. Then I outline the challenges and benefits in cross gender, same gender and same race as well as gender in one-on-one informal mentorship. I follow with the section on how the participants reciprocated mentoring support to other indigenous people. In this section, I explain the collective reciprocal support mechanisms for the participants that define them as indigenous women and top managers. Thereafter, I present a section on participants as both insiders and outsiders of their organisations.

\section{Cultural issues in informal mentoring}

In both New Zealand/Aotearoa and the Republic of South Africa/uMzansi Afrika, there were distinctive cultural issues focusing on informal mentoring. These issues reflected the collective culture of indigenous people represented by my participants. In New Zealand/Aotearoa, the Māori cultural roots assisted with professional collaboration. Also, the participants had a connection with both the living and the deceased informal mentors. In the Republic of South Africa/uMzansi Afrika, the participants were in a structure that was similar to African women informally mentoring one another within the cultural context.

In New Zealand/Aotearoa the cultural roots and connections facilitate the creation of professional support for Māori people. Māori people connect at both personal and genealogical levels before connecting professionally. A participant 
explained a culturally appropriate approach on how to engage a Māori person professionally: "I'll come and say where are you from"?

She explained further that the question meant that a Māori person would like to know where you were brought up, your whakapapa (genealogy) and / family line because they are important for Māori. She continued to explain that after that introduction, Māori people will talk about everything else, except work. She added:

Then they'll say I know such and such from there, yea, yea, that is such and such a great place. That is part of the relationship and connecting. They'll start connecting --- and within that comes all that trust and all those other things that are important to speak for each other and conduct yourselves.

These comments are examples to indicate the importance to give a base for Māori people to know someone and to build trust as well as rapport with an individual. Once Māori have built trust and the connections, it is easier to liaise at a professional level. The result of being able to relate at a personal level is that it makes it easier for professional relationships to develop because the personal connections have already been established.

Also, the participants from New Zealand/Aotearoa continued to reflect on past advice as well as guidance through the spirits of those deceased mentors. They continue to reflect on the teachings from the deceased informal mentor or mentors. Another participant indicated an example of this:

Most closely, I was mentored by my family. My grandmother lived until 86 and then by her memory and by my mother's memory. And that's a concept that some people may find it difficult to understand, but it's not difficult for me at all --- I have had very close relationship with Kuia [older women / grandmother], so that's the cultural equivalent of what you'd call mentoring --- these were tribal women who were not direct descent line elders to me, but tribal elders in a generic sense who watched 
out for me whenever I saw them. A number of them had taught with mum, so they were able to tell me stories about me as a baby and about our family.

Spiritual mentorship is something that is not present in mentorship studies perhaps because it is a concept with which most white researchers may not identify. Spirituality is part of real life in the Māori communities in that it connects with the living and provides guidance to the participants. Ratima and Grant (2007) concur that Māori have a connection with the spiritual level and it is important for them to re-connect with their spiritual aspects, particularly on issues relating to the workplace. Middleton (2007) adds that a Māori worldview is centred on spirituality and connectedness. The participants also had deceased and familial mentors. The spirit of the mentor continued to guide the protégé after the death of the physical body. This idea reflects the culture of Māori/African people that believes in the connection between the physical and spiritual realms. The concepts of spiritual and physical worlds are currently not addressed in mentorship studies.

In the Republic of South Africa/uMzansi Afrika within the African cultural context, based on my own experience, knowledge, maturity, and age brings about certain obligations to the younger ones. The informal group structure of the participants in collaborating with one another is similar to the manner in which African women guide one another in a cultural context. For example in a Zulu traditional culture, older women initiate a younger woman into womanhood informally in a group structure. During the initiation process, the younger woman is guided about womanhood. The older women also guide her when she enters a marriage union. When her marriage does not turn out in the manner that she expected, the elders in a group would advise the younger couple. Informal group counselling is part of informal structure of the African culture. This cultural support concept tends to extend to other informal support areas of one's life such as social, cultural and psychological aspects. The participants transferred this cultural strategy of support into the progression of their occupations into top-management roles. All the participants regardless of age were socialised in African communities and raised within the traditional values 
of the African society. They use their cultural process and structures of socialisation to support one another as a group at top-management levels.

Mentoring indigenous women brings cultural issues into the public debate of mentoring ethnic minority women in management. Blake-Beard (1999) argues that the understanding of ethnic minority cultures by a mentor is important to increase communication when mentoring ethnic minority women.

\section{Informal group peer mentoring}

The participants from both New Zealand/Aotearoa and the Republic of South Africa/uMzansi Afrika were informally part of a peer group mentoring. This structure played an important role in developing and sustaining the professional profile of the participants. It is a form of mentorship for the group members. It also operates as a source of career guidance, support and plays a role in advancing the occupations of indigenous women into top-management levels.

In New Zealand/Aotearoa, the participants built professional, social, and cultural relationships with like-minded people to support one another, as a strategy to survive in top-management levels. A participant explained:

Some [relationships] are in business, some are in cultural things, some are in land. It is important that whatever bubble level you're at, that it is important that you know who the others are in the other sectors so that you can cross [meet] and keep up. $\mathrm{X}$ [name of person] is a good example, so if things are going on I can call her up and say 'what's going on over there'.

Because of the Māori cultural belief of supporting one another and the power of relationships, the comments were not surprising. The comments as examples indicate that Māori women in top-management value the importance of collective and group relationships as well as their benefits. 
In New Zealand/Aotearoa, the purposes of the group mentoring relationships for the participants were to keep in touch with what happened professionally at different organisations and to strategise as a group. A participant explained:

I've got vast support. I keep a tap on what the trends are and what the issues are and check if they align with our policy and priorities. I will bring them [relevant Māori issues] to our policy analysts.

Another participant elaborated:

I'll phone them up. They are my sounding board. Well as far as some of the ideas around how I may strategise --- so it is a group, --- we usually meet regularly. We act as a small component, but I've got them on call, on tap. I would never survive otherwise.

These comments are examples to show that the participants had a group mentoring structure that was trusted for professional interaction. It provided professional support, and guidance and it was a structure of like-minded people where they could discuss issues that affected them as Māori women professionals in top-management levels. Participating in a peer group mentoring was a strategy for success in top-management for Māori women. The participants discussed their group peer mentoring structures as individuals or groups of individuals who represent parts of their identity (Māori, women, profession).

In New Zealand/Aotearoa, through the peer group mentoring the participants discuss issues that they face in their organisations and at times the participants bring the issues from their mentoring groups to policy makers inside their organisations. This act ensures the collective alignment of achieving the objective of uplifting other Māori individuals or groups across the organisations in which the members of the peer group mentoring operate. Also, it demonstrates that Māori women in top-management are accountable to other Māori individuals outside their organisations. They do not work in isolation. 
Similarly, my participants from the Republic of South Africa/uMzansi Afrika engaged in peer group mentoring informally. The group acts as a support structure where the same individuals share their experiences as indigenous women in top-management. This process becomes a group 'therapy' for the participants. For example, a participant noted:

$\mathrm{X}$ [name of organisation] is unique in that it's a technology company, it's an interesting company. The challenges [of the technology company] are different from other organisations. However, the challenges are somewhat similar for other women, for other Black people. --- You have somebody to listen to your challenges and you just talk out loud has always been helpful. In my view in so doing hopefully even when you do encounter something that is similar to what you're experiencing, you'll be able to relate and draw strength. But it is important to have that support structure.

The participants from the Republic of South Africa/uMzansi Afrika largely had peer group mentors rather than formal ones. For example a participant remarked: "Basically, it is my friends [support structure]. You know how you have friends and you can talk openly to --- and friends who can be honest with you as well. We tend to talk shop".

A participant from the Republic of South Africa/uMzansi Afrika explained the reasons why she and her peers - top managers above 45 years of age - do not have formal mentors:

It was not easy to find a mentor [formal] per se, it was oppression for Black people, for all of us so when the Apartheid policy officially ended in 1994, I was amongst those who rose quickly. So a formal mentor, no.

These comments are examples to show that the participants who were over 45 years of age tended to be the first indigenous women to occupy top-management positions in the Republic of South Africa/uMzansi Afrika. There is no previous generation of African women in top-management of white organisations, who 
can act as formal mentors for them. These comments also indicate that the participants mostly had a group of friends who acted as their informal group peer mentors.

In New Zealand/Aotearoa, there are studies that support group mentoring for Māori women in organisations. The reason for this appeal according to Hook, Waaka and Raumati (2007) is that relationships and collectivity for Māori are opposite to the individualism of Pākehā (white) people. The collective relationships are firstly about one's relationship with own whānau (family / extended family), then the connection to other people and the rest of the natural world (Ratima \& Grant, 2007). This holistic approach gives base for Māori the inclusivity and collectivity for them as individuals in their interaction with family, other people and nature. Ratima and Grant (2007) make calls for group or whānau (family / extended family) mentoring for indigenous people in New Zealand/Aotearoa, as they have a more collective approach than the New Zealand/Aotearoa Pākehā (white).

Studies focusing on mentoring suggest different reasons women engage in peer group mentoring. Parker and Kram (1993) debate that women who are limited in numbers in management may seek other women who are their peers outside their organisations for support. These findings concur with my study that my participants obtained informal peer support mainly outside their organisations. King and Ferguson (2001) argue that for many ethnic minority professional women, they had to develop effective support systems due to their marginalised status. Kram and Isabella in their study of peer mentoring, concluded that 'special peers' were a rare type of relationship characterised by high level of trust, self-disclosure and sharing ambivalences as well as personal dilemmas in work and family aspects (1985, p. 121). They contend that such relationships take several years to develop and have a stability and continuity over many years. My findings were similar to those of Kram and Isabella (1985) in that there was also a lot of trust amongst the different individuals involved in the peer group mentoring. There was also a lot of time that was invested in the group peer mentoring relationship. This support tended to be limited to indigenous women of a similar age group, between (45 - 55) years old, who have known each other 
over a long time, more than 20 years. It is difficult for the newcomer to penetrate this closely knit group because trust and relationships have been built over a long period of time. Peer group mentoring was important in my study.

There are other reasons that motivate indigenous women in top-management to engage in peer mentoring. Mentorship literature focusing on the 'concreteceiling' studies states that lack of 'similar others' (Giscombe \& Mattis, 2002) and access to mentors (Catalyst, 2000) may lead to lack of formal mentorship relationships. A study of African American senior academic faculty and administrators (Crawford \& Smith, 2005) found similar findings as mine that their participants did not largely have formal mentors. Lack of formal mentorship for my participants might have encouraged them to develop peer relationships to be effective in their roles. Another reason that encouraged peer mentoring were the collective culture of Māori and Africans.

Studies focusing on mentoring provide mixed results on the advantages of peer group informal mentoring. Allen, Russell and Maetzke (1997) in their peer formal mentoring study found that vocational and psychological support provided to MBAs were related to satisfaction with their mentors. Also, Kram and Isabella (1985) confirm that peers may offer support. However, unlike Allen, Russell and Maetzke (1997), they argue that peer mentoring is not able to provide similar support as a mentor within an organisation. Mentorship has carried the implicit assumption that the mentor is older and more mature than the protégé (Quinlan, 1999). However, in my study, the logic of older mentor, younger protégé is challenged in that the role of the mentor and protégé changes and tends to be at peer level. In my study, reciprocity was also important for my participants in that they reciprocated the career advising to their peers. Kram and Isabella (1985) in their study concur that reciprocity was an important factor of peer mentoring. Ensher, Thomas and Murphy (2001) contend that as long as the protégé feels that the relationship is reciprocal, then the relationship is likely to be satisfactory. Despite the findings in these studies, in my study, peer group informal mentoring was useful for my participants. 


\section{One-on-one informal mentoring}

Although my participants from both New Zealand/Aotearoa and the Republic of South Africa/uMzansi Afrika had peer group mentors, they also largely had oneon-one informal mentoring relationships both within and outside their organisations. They had more than one one-on-one informal mentors, who continued to advise them in their current top-management roles. Also, throughout their lives they had informal mentors both within and outside their organisations.

A participant from New Zealand/Aotearoa expressed:

I had a fabulous mentor who taught me how to write policy, to publish, to research, although it is not intensive research, but she taught me how to research. And that transformed my X [name of previous occupation for participant] skills into one of becoming a planner. At having the best mentor in the world, I have had fabulous mentors and bosses that have helped guide me on what a good manager is.

Another participant from the Republic of South Africa/uMzansi Afrika explained:

The informal ones [mentors] I think they are the ones --- that are making sense to me because there is no structured way of doing it, you just pick up the phone, you phone the person, I'm stuck with this --- and he will advise me.

These remarks are examples to illustrate that nearly all the participants from both New Zealand/Aotearoa and the Republic of South Africa/uMzansi Afrika had useful successful informal mentors. Powerful mentors include individuals who are chairs of boards. They continue to make use of the mentors even though they have reached top-management levels. The participants generally indicated a preference for informal mentors rather than formal ones. 
Research studies on informal mentoring support the notion that it is more effective than formal mentoring relationships. The participants from both New Zealand/Aotearoa and the Republic of South Africa/uMzansi Afrika largely had one-on-one informal mentors who they defined as someone enhancing their careers through promotion in addition to having peer group informal mentoring. Some studies (Blake-Beard, 2001; Ehrich, 2008; Touise, 2005) compare formal and informal mentoring relationships. Most studies (Chao, et al., 1992; Hurley \& Fagenson-Eland, 1996) support that informal mentorship provides greater results than formal mentoring. Underhill (2006) in her study found that informal mentoring produced significant positive career outcomes rather than formal mentoring. Kram (1985) and Ragins and Cotton (1999) comment that informal mentoring relationships are usually longer ( 3 to 6 years) than formal mentoring relationships (6 months to 1 year). My findings concur with the findings of Kram (1985) and Ragins and Cotton (1999) in that one-on-one informal mentoring relationships are long-lasting. My participants continued to use the same informal mentors, in addition to attracting new informal mentors, when joining different new organisations. The relationship for my participants was mostly an informal process.

In my study, mentoring relationships were often accidental for both my participants from the Republic of South Africa/uMzansi Afrika and New Zealand/Aotearoa. It was upon reflection that the participants were able to indicate that they had informal mentors. They reflected during the interviews on these individuals and called them their informal mentors because they relied on them for professional guidance and advice. These individuals often opened 'professional doors' for them to enhance their promotion prospects. It was only upon reflection that they could identify their informal mentors without realising at the initial stages of the relationship that the relationship was that of mentorship. Kram (1985) and Ragins and Cotton (1999) also confirm that informal mentoring relationships develop spontaneously. Other studies indicate that informal mentorship relationship develop from the perceived competence and interpersonal comfort (Kalbfleisch \& Davies, 1993; Okurame, 2008), mutual interest and identification (Okurame, 2008). Piper and Piper (2000) contend that mentoring is an elusive term. Also, there is no consensus over its meaning 
(Ehrich, 2008). Clutterbuck defines informal mentoring as an arrangement where individuals working in a similar or related field discover their mutual interests and decide to 'establish a developmental alliance' (2004, p. 24). In my study, the participants from both New Zealand/Aotearoa and the Republic of South Africa/uMzansi Afrika, were not always consciously aware that they were developing an informal professional relationship and establishing a professional alliance.

In the Republic of South Africa/uMzansi Afrika, some participants believed that their white male counterparts were opportunistic in that they would offer to mentor them after the participants were successful in their projects. The participants indicated that their white counter-parts volunteered to mentor them after the participants had demonstrated success. A participant from the Republic of South Africa/uMzansi Afrika commented:

Now I feel probably the first 6 months in my role, everybody was watching to see if I was going to drown or not and now they [my superiors] notice that my head is above the water everybody wants to mentor me, every white male, around the world. --- I have countless emails, they say, I would love to mentor you, bla, bla, bla. I say I already have mentors.

These comments are examples that show that the participants believed that their white male counterparts were not openly willing to mentor them at 'face value'. Because of the professional success of my participants, they believed that the white males in their work environments tended to volunteer to mentor them after my participants were successful in projects. My participants believed that this was because white males associated mentoring ethnic minority women with risks.

Mentorship studies confirm that ethnic minority women face 'barriers' related to assumptions of their performance in attracting mentors. Cross (2006) contends that women in general face barriers to attract powerful 'organisational players' who could act as mentors. Some studies (Cleveland, et al., 2000) suggest that 
there is evidence that it is difficult to find a mentor for women. For ethnic minority women the difficulty of finding a mentor could be compounded by race. Blake (1999) and Catalyst (1999) contend that ethnic minority women face greater 'barriers' in accessing and fully utilising mentoring relationships. Separated from the majority culture, they must negotiate sexism and racism when seeking mentors (Hite, 2004). Cross (2006) argues that gaining access to a mentoring relationship is a difficulty for women in general because many men in top-positions are reluctant to mentor female managers for fear of damaging their own professions through a mentoring association with an 'unsuccessful' female protégés. Ragins and Cotton also indicate that mentors select high-performing protégés who are considered to be 'rising stars' (1999, p. 530). My participants believed that they were able to attract mentors because of their performance. They believed that once they were successful, most white males in their work areas wanted to mentor them as the mentoring relationship was perceived to be less risky by potential mentors because they had already demonstrated success. O'lian et al (1993) investigated informally developing mentoring relationships among bank managers. Their findings were that mentors were more willing to mentor high performing protégés as they anticipated greater rewards from high performers compared to moderate performing protégés. This concept was also confirmed in the academic context by Green and Bauer (1995). In their study graduate students perceived by the academic staff to have a high ability were mentored more than those students who were perceived to have lower ability. For my participants, as I have demonstrated in Chapter Five that they have been high performing throughout their lives, this is one of the reasons that they have several mentors and are able to attract more mentors throughout their careers, I believe.

\section{Cross gender in one-on-one informal mentoring}

My participants from both New Zealand/Aotearoa and the Republic of South Africa/uMzansi Afrika mostly had men as their one-on-one mentors. Men within their organisations tended to mentor them after they had succeeded in different projects. In general, the participants had mentors who were varied in terms of gender and race, but men were often present in addition to other women mentors. 
A participant from New Zealand/Aotearoa remarked:

I have worked with men all my life because mostly the X system was full of men and not women, so the women who have mentored me have been outside the professional relationship.

Another participant from the Republic of South Africa/uMzansi Afrika stated: "I do have mentors, the funny [interesting] part they are mostly the his [men rather than women]".

Another participant from the Republic of South Africa/uMzansi Afrika elaborated: "I also have a --- mentor in the firm --- I have a mentor now, he is Indian".

These comments are examples to indicate that the informal one-on-one mentors also included men.

Mentorship studies focusing on women in management have mixed findings on cross-gender mentorship. Mentoring studies found that men and women protégés benefited differently from a mentoring relationship that was provided by a male mentor. Studies of Reich (1986), Reich (1985) focusing on the gender of the protégé contend that male and women reported to benefit differently from men in mentoring relationships. Gender in mentoring relationships affects males and females differently (Scandura \& Williams, 2001). Burke and Mckeen (1994), Ragins and Cotton (1999), and Sossik and Godshalk (2000) also add that career functions are more common in male mentor-female protégé. Fitt and Newton (1981) in their study found that in entry management, women need more help than men with career goals and organisational legitimacy and the needs differ at different stages of their careers. Burke (1984), Noe (1988), Reich (1986), Stonewater, Eveslage and Dingerson (1990) contend that gender differences indicate that female protégés are more likely than male protégés to report experiencing psychosocial support from their mentors. On the other hand Allen and Eby (2004) found that mentors reported providing more psychosocial 
mentoring to females but no relationship to career-related mentoring and protégé gender. In contrast, other mentoring studies focusing on gender (Koberg, Boss, \& Goodman, 1998; Turban \& Dougherty, 1994) found no difference in the functions provided to female and male protégés. Interestingly, in Tharanou's study (2005), mentoring for psycho-social support only were not related to either men's or women's advancement. In my study, male mentors for my participants played a role to progress the careers of the participants positively. Mentoring studies with a focus on cross-gender mentoring has mixed results regarding the benefits to a protégé. In my study, I cannot comment on the benefits of the male protégé because my study was limited to individuals I interviewed who were women.

\section{Same gender in one-on-one mentoring}

In addition to men mentoring my participants, they also had women who were mentoring them. Some participants from both New Zealand/Aotearoa and the Republic of South Africa/uMzansi Afrika had women who mentored them oneon-one, in addition to men mentors. Women informal mentors were usually in the minority, in terms of numbers.

A participant from New Zealand/Aotearoa commented: "I have two, I have got a man and a woman. He was the person I guess who mentored me from middle to top-management. The second mentor is a Pākehā [white] woman”.

A participant from the Republic of South Africa/uMzansi Afrika noted:

In fact when I was working at X [name of previous organisation], --- at X, I used to like X [name of a Black woman] because she used to chair our cluster meetings, and then one day I spoke to her and said "I would really like you to [informally] mentor me"--- so when I was at T [name of different organisation], there was this woman, $\mathrm{Z}$ [name of a white woman], I said to her "I would really love you to [informally] mentor me". 
The comments are examples to show that mentors for the participants included women who were both indigenous and white.

\section{Indigenous women in one-on-one informal mentoring}

Most participants from both New Zealand/Aotearoa and the Republic of South Africa/uMzansi Afrika with informal mentors had other indigenous women as mentors in addition to informal mentors who are of different gender and race as them. For all the participants from both New Zealand/Aotearoa and the Republic of South Africa/uMzansi Afrika with informal mentors, the indigenous women mentors were additional to other mentors of different races and gender. Two of the participants from New Zealand/Aotearoa and three from the Republic of South Africa/uMzansi Afrika expressed a minority view, in terms of numbers, and preferred mentors who were similar to them in terms of identity. This includes race, or gender, or career path or thinking or an ideology. They believed that their mentors needed to understand them as individuals, comprehended their values and challenges. Who the mentor is for the participants was important in aiding their careers.

There are limited studies that focus on a similar gender and race combination on mentorship regarding women in management. Research supports that access to mentors in influential positions contributes to career success for ethnic minority groups in management (Catalyst, 1999; Giscombe \& Sims, 1998; Thomas, 2001). My research challenges the traditional white Anglo-American model of mentorship and contributes to the 'concrete-ceiling' studies regarding their mentorship models. There is extensive data (Ehrich, 2008; Sosik \& Godshalk, 2000) documenting the challenges of white women regarding mentorship. Current research on women and gender has little emphasis on race (Noe, 1988). Ragins and Cotton (1993) suggest that mentoring relationships are enhanced when both the protégé and mentor are of the same gender. Because the majority of studies were conducted on white samples, same race in mentorship studies is assumed to be white. Studies in support of similar race and gender (Enomoto, Gardiner, \& Grogan, 2000) cited mentors with similar race and gender as protégés provided ease of communication, greater affinity and role models for the protégés. Other studies (Kogler \& Gant, 2000) support the idea that for 
ethnic minorities similarity of gender and race with the mentor was found to be important for increased psychosocial support and satisfaction with the mentoring relationship. Ethnic minority women have not been acknowledged in the race and gender mentoring relationships (Bell, et al., 1993). Blake-Beard (1999) is one of the initial studies that discuss the intersection of race and gender in mentoring studies. More research needs to be conducted on ethnic minority women in management to investigate more benefits and / disadvantages of same race / gender mentorship.

Most participants had informal mentors who were across race and gender, in addition to indigenous women informal mentors. Turner (1997) supports the idea that mentoring relationships that provide both similar and mixed race interactions reduce the potential gap in mentoring ethnic minority women. Coll, Cook-Nobles and Surrey (1997) add to this debate that a combination of both similar and mixed race interactions provide interaction opportunities that minimise the potential discomfort that surround cross race communication. Maniero (1994) confirms that most women and ethnic minorities tend to rely on a diverse pool of mentors who vary in organisational affiliation, status, and personal characteristics than white men. My participants seemed to show a preference to emulate someone who was similar to them and represented some aspects of their identity - race, gender, top manager, or community. They still viewed their success as top-managers in the light of who they were as individuals, gender and race. Ethnic minority women are an 'insider within' (Collins, 1998) in top-management roles. This is a concept that refers to the disempowerment of ethnic minority women within an interactive system of race, gender and / social class. Collins (1990) argues that for ethnic minority women to succeed in such an environment, they should identify the powerful structures and / individuals that constrain their powers and engage in activities that resist or eliminate those structures (Collins, 1990). For my participants to engage with a diverse number of mentors in terms of race and gender was their way of enhancing their careers in dealing with the multiple challenges of being a statistical minority within a minority context, in terms of numbers, in an organisation. They had to maintain different relationships to maintain their 
different identities - race, gender, community members, and top managers of their organisations.

Mentorship studies suggest that marginalised groups have more mentors than the dominant group. In a study conducted by Blake-Beard (1999), African American women who had MBAs from prestigious research universities received more mentoring than white women of a similar calibre. Although these women are not representative of the general ethnic minority women's experiences, they are successful individuals who share similar characteristics of achievement as my participants. Similarly, in New Zealand/Aotearoa, Bhatta and Washington (2003) found that women were more likely than their male counterparts to have a mentor. They found that $28 \%$ of women managers compared to $16 \%$ of male managers had a mentor in the public service. The majority of women in management were largely white women, in their study. Also, as part of their findings were that $25 \%$ of Māori compared to $16 \%$ non-Māori at different levels of organisations had a mentor. Mentoring has been linked to positive organisational outcomes, including more promotions (Blake-Beard, 2001; Dreher \& Ash, 1990; Scandura, 1992) and valuable for the development of women's careers (Bhatta \& Washington, 2003; Feeney, 2006; Tharanou, 2005). Burke and McKeen (1994) argue that mentoring relationships are important for men but essential for women, as female managers face organisational, interpersonal and individual barriers to advancement. White women managers have gender issues to negotiate in their organisations because of their historically marginalised status, which is one of the reasons they could need more mentors than white men. For ethnic minority women, there is both race and gender to manage at topmanagement levels to be successful. I found that they are obtaining more mentors than white women because they have race issues to address in comparison to white women, when all elements are constant. Future research is needed to examine the level of support received by ethnic minority women in top-management levels in comparison to other groups.

\section{Participants reciprocating mentoring support to other Indigenous people}

Mentorship for my participants reflected the indigenous collective value of reciprocity. Although the participants from both New Zealand/Aotearoa and the 
Republic of South Africa/uMzansi Afrika received professional support from informal one-on-one and / peer group mentors, they were also willing to give support to other indigenous people / structures both within and outside their organisations. All the participants, without exception, were dedicated to uplift and empower other indigenous individuals / groups. All the participants from both New Zealand/Aotearoa and the Republic of South Africa/uMzansi Afrika were reciprocating support to other individuals in their communities. They achieved this by informally mentoring individuals from their communities and by being involved in structures, activities that promoted the economic status of the indigenous communities.

In New Zealand/Aotearoa, the participants helped other Māori individuals and their communities. For example, a participant remarked:

I had my first university paper [course] in 1970s and I finished my $\mathrm{PhD}$ in 2000s because for all those years, there was always somebody more important than me. There was always something more important than my career and my own qualifications. I definitely missed opportunities because I did not have a PhD. But looking back, I am very happy with what we were able to achieve because I never ever want to arrive at a place on my own without our people or without other opportunities for other people.

Another participant noted: "A government can only do so much. Our own people have to do. If it has to be anybody who's gonna do it, it will have to be us".

Examples of helping other Māori included serving on / membership of certain Māori boards, or Iwi (tribe) structures to contribute to Māori economic progress. Other participants took less prestigious roles to uplift Māori people. Some took salary cuts or were paid less than market value to be involved in roles that uplift Māori people. A participant explained: "But for those activities [Māori upliftment], you don't do it for money. You've got another drive”. 
The participants have influenced policies at various levels, such as the National Consultancy on the Equal Employment Opportunities (EEO) Task Team, regarding Māori and would like to make a difference regarding the Māori people. A participant noted:

The big thing though that keeps me going is that Māori development is moving fast and we've all got something to offer. It is not about me. It is about my children and grandchildren.

Another participant revealed: "We don’t want Māori to fail, we want Māori to succeed, we want to build the capacity and capability".

These comments are examples to show that my participants engaged in activities that empowered the collective which is the Māori community.

Similarly, the participants from the Republic of South Africa/uMzansi Afrika reciprocated the support by being involved in different initiatives both in their communities and in their organisations to uplift African communities. They also mentored other indigenous people informally. For example, a participant remarked:

The other thing I started to do at X [name of organisation] is to organise internships, learnerships where at least $50 \%$ of young people are Black women and because I just thought we need to start somewhere. It's really been fulfilling that way, not all of them necessarily stay with $\mathrm{X}$ but they go somewhere in the sector. It's fine, I'm not saying they have to stay with $\mathrm{X}$ but to give them a start.

Another participant added: "I've got a Black young lady that I have employed from $\mathrm{X}$ who I'm in the process of putting her into the advanced leadership program".

My participants were also offering practical skills and advice to their communities in the areas of their competencies. They sat in Boards to advance 
indigenous people and were involved in various community activities. These comments are examples to indicate that for the participants the idea of moving up the organisational structure includes an obligation to uplift others too.

Mentoring studies indicate that there are risks associated with being a mentor for an ethnic minority woman. According to Raggins and Cotton (1991), because of the limelight focused on ethnic minority women, the potential failure of a protégé is a much greater risk for a top woman manager to take on than for a top man manager. However, the participants were not deterred from being a mentor of other indigenous people. The participants believed in preparing the next generation of indigenous women for top-management roles. They believe in having success with a successor. Their achievements also included assisting others. My participants viewed promotion as a vehicle to support other indigenous people. The concept of promotion is about community upliftment. It is about success of the indigenous community as a collective. For the participants their means of uplifting themselves in organisations is through support structures and collectively as a community.

\section{Participants as outsiders and insiders of their organisations}

The concepts of insider-outsider status are useful in drawing the data together. Through the informal mentoring process, the participants raised issues that result from being an insider and outsider in an organisation at top-management level, while being an outsider belonging to their Māori/African communities, and managing an identity of being a Māori/African woman. Both groups of the participants from New Zealand/Aotearoa and the Republic of South Africa/uMzansi Afrika described themselves as both insiders and outsiders of their organisations. Their accountabilities as indigenous women in topmanagement were also about uplifting other Māori/African individuals or groups. The needs of the group (Māori/African community) supersede those of the individual. Their views of promotion are the collective sponsor and giving back to other Māori/African individuals. They achieved this by informally obtaining mentorship for themselves and reciprocally they mentored and gave them to their communities. Once the participants reached top-management levels, they took the opportunity to empower other Māori/African people. For example, the 
participants would often use words such as "to serve", which often reflect a subservient role and an obligation to improve their communities. They had responsibilities to their communities and they felt accountable to them. They "give-back" to their communities, outside their organisations, in terms of their expertise. The participants also used words such as 'I have paid my dues' meaning the participant has done her share to promote her community. "Paying dues" has connotations of paying taxes as if it is an obligation that one has to do. "Paying dues" has legal implications as if they have paid back what ought to be "paid" and was demanded. The idea of professional advancement included aspects of being responsible to other Māori/African individuals / groups. They defined themselves as individuals with two identities. One, they are top managers of powerful organisations driving the strategic goals and direction of their organisations. Secondly, they described themselves in terms of their obligations to their indigenous communities that were marginalised. Who they are seems to shift from top managers of powerful organisations to being unrepresented in their organisations.

For the participants to minimize their internal tensions of being outsiders in their organisations, they supported themselves by engaging in collective strategies with other indigenous people. My participants acted in outsider ways within their organisations by adopting a support solidarity strategy with other indigenous people. They encouraged and acted in outsider ways (Māori/African ways) within their organisations. In their organisations, they informally mentored and assisted other indigenous people in the form of one-on-one informal mentoring. They supported those who were in a less fortunate position as them. Freire (1970) confirms that oppressed people that become freed and enlightened may respond by acting as agents and serve to liberate other oppressed people. For my participants they chose to help their communities who were disadvantaged relative to them. Since their numbers in management have increased over the years, they are the first Māori/African group to advance other aspiring indigenous women to access top-management levels. They are the first generation of indigenous women mentors to assist other groups / individuals of Māori/African women who are interested in climbing up the organisational ladder into top-management roles. The participants also acted in outsider ways 
as top managers of their organisations in the manner they supported themselves. They supported themselves through peer group informal mentoring. Peer group mentoring and informal mentoring are reflective of both the African culture in the Republic of South Africa/uMzansi Afrika and the Māori culture in New Zealand/Aotearoa.

\section{Conclusion}

In this chapter, I answered the question: what 'strategies' have indigenous women implemented to enhance their opportunities to advance into topmanagement roles? I indicated in this chapter that the 'strategy' my participants implemented to enhance their opportunities in top-management roles were collective strategies that were in solidarity with other individuals, using mentorship. Collective 'strategies' included supporting themselves through informal mentoring in a manner that reflects the indigenous cultures of both New Zealand/Aotearoa and the Republic of South Africa/uMzansi Afrika. Informal mentoring was a combination of peer group, and one-on-one. It also included cultural factors such as spiritual and familial mentorship. The participants received informal mentoring for themselves both in a peer group and / one-onone. The informal mentors and protégés were individuals who presented a part of their identity - race, gender, top-manager and community member. They had a combination of male, female and indigenous women mentors. In return, they mentored and advanced other indigenous communities. The participants had a vast support structure and system to cement their identity as top managers who were ethnic minority women.

In this chapter, I contribute to the interactions between issues of race and gender mentoring literature focusing on a woman in management. Mentoring studies are skewed towards western norms that are formal and individualistic (one-on-one) within an organisational context. Ethnic minority women in management have to bargain both race and gender, sometimes culture, as they progress in their careers. This study provides an alternative model to mentoring a woman in management, particularly those who are in the statistical minority at management levels. 
The next chapter will address the lessons for other indigenous women aspiring to be in top-management roles. The lesson that I address in the next chapter will focus on how indigenous women negotiate the effects of the combination of both race and gender in top-management for themselves to achieve. I will explain how indigenous women downplay both their gender and race when manoeuvring for success. In so doing, they align with white women or indigenous men to address issues of race and gender. They also live in both white and indigenous communities with different expectations of these environments. 


\section{CHAPTER SEVEN}

\section{PAYING INDIGENOUS WOMEN'S TAX}

I found that participants from both New Zealand/Aotearoa and the Republic of South Africa/uMzansi Afrika experience 'racialised-gender', a concept that I define later in this document. As an individual strategy, they respond to 'racialised-gender' by largely 'paying tax', I found. Paying 'indigenous women's tax' is a concept that I use in this chapter to describe the implicit payment the participants believed that they had to pay for occupying roles that are prestigious, top-management roles, as ethnic minority women. The participants understood the terms of payments for this implicit tax. It is similar to the 'sin' tax, which I equate to the government tax that individuals in a country pay on items such as tobacco. It is an excise duty and additional to the normal tax such as VAT (valued added tax) levied on goods and services (Warner, 1986). An excise duty applies to a narrower range of products, is heavy and specific. For my participants, it applied to them in top-management roles resulting from being ethnic minority women of indigenous heritage. In this chapter, I explain what I mean by 'paying tax'.

My participants 'paid tax' in several ways. They paid 'indigenous women's tax' through their sweat by working harder than those in power, white malecolleagues, to be on a par with them and credible. My participants believed that they had to work harder than their white male colleagues in their organisations. Also, they 'paid duty', I found, by mostly downplaying their own gender and race to fit in predominantly white gendered organisations at top-management levels. I define white gendered organisations later in this chapter. They achieved this by individually strategising to downplay the sexist and racist encounters that were fused with stereotypical images of what constituted an indigenous woman. In so doing, they aligned with indigenous men and or white women in their organisations to increase their voices as statistical minorities at top-management levels. They pay 'indigenous women's tax' metaphorically, which is an excise duty, for representing an anomaly in top-management that is minority status of race and gender, in terms of numbers, in top-management. As 
a compromised individual strategy for them to succeed, the participants lived in both indigenous and white communities with different identities. The participants largely used all these individual strategies simultaneously as top managers. In this chapter, I discuss the question: what do indigenous women believe are the lessons for other indigenous women entering top-management roles?

I initially present concept that I call 'racialised-gender' that defines the experiences of the participants in their organisations. I then follow with sections focusing on the individual strategies the participants in which engaged. The individual strategies were downplaying race and gender to address 'racialisedgender'. Other sections on individual strategies are alignment with white women and indigenous men to address 'racialised-gender'. After that section, I present the 'indigenous women's tax' concept. This is the analogy I introduce to women in management studies to define the hard work for indigenous women that they believe they have to do to be successful in their roles. These sections are followed by 'biculturalism' which explains the movements of indigenous women in management and is also an individual strategy to succeed in their organisations.

\section{'Racialised-gender'}

In this chapter, I draw on the concept of 'racialised-gender' to mean racism that is entangled with the social construction of a gender stereotype for the victim, in this case, indigenous women. Researchers use different names for the combined effects of race and gender that intersect. For both New Zealand/Aotearoa and the Republic of South Africa/uMzansi Afrika, the findings were skewed towards race and a combination of race as well as gender rather than issues of just gender. The participants felt that issues affecting them were more about being Māori or Black than just women. However, being an indigenous woman multiplied their experiences. They were confused and doubtful on labelling their experiences sexism or racism because it was an interaction of both race and gender entangled together. All the participants, without exception, from both New Zealand/Aotearoa and the Republic of South Africa/uMzansi Afrika experienced 
what Bell and Nkomo (2001) call 'racialised-sexism'. In this chapter, I use the term 'racialised-gender' to add to the concept of Bell and Nkomo (2001). The participants were often confused about whether racism or sexism was behind certain actions and behaviours from their colleagues or clients. 'Racialisedgender' created ambivalence amongst the participants from both New Zealand/Aotearoa and the Republic of South Africa/uMzansi Afrika.

In New Zealand/Aotearoa, being a Māori woman in top-management level brought about ambivalence regarding issues relating to race and gender. The combination of the two (racism and sexism) confused the participants in distinguishing one from the other. For example, a participant explained: "it is more about being Māori. I don't think that it has to do with being a woman although I could be wrong”.

Throughout her experiences it:

has never been about gender. It has always been more about ethnicity. It is because Māori women have got their own issues to deal with. It is more about the ethnic and first and fore-most for me that's what my issue is. It is about being of an indigenous group and trying to be heard.

However, some participants largely believed that race and gender issues may be interrelated. For example one of the participants stated:

I might be able to identify things that are occurring to me because of my race or my ethnicity than necessarily I might identify that things are happening to me because of my gender, but they're probably interrelated so there's probably that gender thing that is playing out and it is hard to unpick them.

Other participants felt that personal, gender and race issues may be difficult to differentiate. One of the participants stated: 
gender and race issues --- are the hardest thing about identifying whether they're interacting with you because it is an entirely a personal response, whether it is driven by racism, whether it is driven by sexism and it is difficult at that personal level what's driving that response

These comments show that the combination of race and gender compound the experiences of the participants. 'Racialised-gender' was confusing to the participants because it was difficult to differentiate gender from race and personal issues.

Similarly, Black women from the Republic of South Africa/uMzansi Afrika, felt that a combination of race and gender compounded their experiences. For example a participant noted:

Yes, I do work with a group of white people, I often say to people that the thing is we tend to think that reconciliation and whatever this thing white people think what happened after 1994, in the last 15 years it's done. It has not been even done. --- So we constantly need to remind them of either insinuations of being a racist or sexist, because it is not only being a Black woman looking amongst whites, it is also being a woman working with men.

Another participant added:

And sometimes, I remember I fought one time with one of the white women here because of the way she talks --- and I said to her, 'I'm not your maid, you don't talk to me as if you're talking to your maid". --You find it is someone she is also a GM [General Manager] just like you, but the way that they talk to you is that they are so used to talking to their maids like that so they don't see anything else but a maid. --- or even the tone sometimes. That happens a lot --- Black women I think we have more challenges because I think we are women and we are Black, our mothers and great great-mothers were maids. Then somebody sees you you're an executive you're just a maid plus you're Black and you're a 
woman. I think we have even more challenges than Black males, much more.

Black women from the Republic of South Africa/uMzansi Afrika felt that race and gender compounded their challenges regarding stereotypes of what constituted a top manager.

In New Zealand/Aotearoa, the participants felt mostly that they faced negative stereotypes about being a Māori woman in top-management. A participant stated that because of her level in the organisation and her identity as a Māori woman:

Pākehā men find it hard, then, I happen to be Māori as well. Then they just find it confusing. There's a picture of what a Māori woman is. How come you don't --- you appear to have a brain, men find it confusing and hard. The fact that I'm a Māori woman is not expected.

Another participant summed it up:

they put you in a box. It is a Māori woman's box because you look like a Māori woman so that's all what you must be thinking about. Nobody says to a Pākehā [white] woman --- you only think about the Pākehā women's things. But they do it to you. That must be all you think about because you're a Māori woman.

The comments are examples to show that the participants feel that they are unjustly punished for being Māori women in top-management. Their performances are incorrectly evaluated in a negative stereotypical way of what constitutes a Māori woman.

Similarly, in the Republic of South Africa/uMzansi Afrika, the participants equally felt that they largely faced negative stereotypes of what constituted a Black woman. A participant noted: 
I don't think he really thought when he appointed me because you know how people judge people from afar, I presented myself as a very nice person, easily manipulated, one who could be manipulated, I think that is the impression he got about me. He was going to do whatever, but he would say that here is the first Black female General Manager who would do $\mathrm{X}, \mathrm{Y}, \mathrm{Z}$ for me, but who I would use as a PR [public relations] exercise. So when I started raising issues, he felt uncomfortable.

A different participant stated:

There are activities and actions that do lead me to say that white people in the firm think that you are not just Black, but you're Black and dumb. --They think that us Black people don't think, the way they do things, they think you are not thinking. You don't see what they are trying to manipulate. Then that is a serious problem for me that they think as such at times especially that I'm at a time in my career at $X$ [name of organisation] now I think where I feel my voice is heard loudly.

The participants believed that they had to address the negative stereotypes of being an indigenous woman in top-management roles. My research confirms similar findings with studies focusing on ethnic minority women in management in that the entanglement of race and gender confuse and compound the experiences of ethnic minority women. The participants encountered negative perceptions that were intertwined with race and gender. Race and gender negative stereotypes were experienced in the same manner as the 'concreteceiling' studies (Bell \& Nkomo, 2001; Combs, 2003) in that they compounded the experiences of my participants because of belonging to both groups that are economically marginalised in a society. It is difficult to separate gender from race as they are interlinked (Andersen, 2005; Hite, 2005). For indigenous women as ethnic minority women in management, 'racialised-gender' was experienced in a similar manner to those studies focusing on ethnic minority women in management. 
'Racialised-gender' is sometimes subtle. The participants felt that they had to fight to be heard. Their colleagues would ignore them because they are indigenous women. For example, a participant from the Republic of South Africa/uMzansi Afrika noted:

Or maybe you are in a meeting you are talking and you mention something and people don't comment and after that a white Director will say the same thing and they will say, oh I agree.

Another participant noted:

Others it would be very subtle where you sit in a meeting and you say something and somebody says "she is trying to say" --- and you are saying, "no, I'm not trying to say, I'm saying".

A participant from New Zealand/Aotearoa added:

But I'm certainly aware that I can be in a meeting and people not know that I'm Māori ---, they only know me as part of X [name of organisation] and that I have been at meetings where people have listened to what I have said, taken, being quite attentive, had a good experience, once they find out by whatever means, [that I'm Māori] their interaction with me entirely changes. So when that happens, I clearly can tell they have a very narrow view about what I as a member of the Māori community think I can contribute to the bigger picture. They tend to just encapsulate you in this silo.

These remarks indicate the complexities of being a top manager and managing both a gender and racial status of being an indigenous woman. They also indicate that 'racialised-gender' has complex parameters and may exhibit itself in different situations.

I summarise the 'racialised-gender' concept and link it to studies focusing on women in management. My findings indicate that the top-management positions 
were something considered as 'male' in gender-type and 'white' in race type. Marshall (1984) and Powell (1993) debate that western societies largely are categorized by social systems that are patriarchal. Also, Essed (1991) and Hooks (1989) contend that social systems are characterised by white-centric norms. My findings show that the participants believed that their organisational systems were intertwined with both patriarchy as explained by both Marshall (1984) and Powell (1993) and had white centric norms (Essed, 1991; Hooks, 1989). Schein (2007) contends that gender stereotyping bias for roles in management positions favour males. Schein and Davidson (1993), Schein et al (1996), Schein (2007), argue that to think of a manager is to think of a male person. They coined the phrase think manager - think male. Booysen and Nkomo (2010) explored the intersection of gender and race in the Republic of South Africa/uMzansi Afrika using Schein's concept of think manager-think male. My results indicate that the persistent stereotype that indigenous women face in top-management is racism that is confused and compounded with sexism, particularly in white gendered organisations. Elaborating on Schein's concept, to think top-manager is not just to think of male, but to think top-manager is to think of a white male, 'think top manager - think white male'.

Studies (Acker, 1990) suggests that the progress of women through the organisational hierarchy has been inhibited by the fundamental structures of organisations. Acker $(1990,1998)$ debates that organisational structures are not gender neutral, images of female and male bodies are embedded in the organisational processes of the organisations. She (Acker, 1990, 1998, 2006) also contends that organisations construct images, symbols that explain, reinforce or oppose gendered division of labour. This includes processes amongst others that consist of gendered conceptualizations of elements of organisational structure and activities that affect formal and informal messages, which socially construct men and women's attitudes, behaviours and experiences. In management, women are devalued while men maintain their dominant positions in creating the social structures with clear divisions along gender lines (Acker, 1990, 1998, 2006). 
Using and elaborating on Acker's (1990) concept of hierarchy, in my study, organisations from which participants came represented images of white male bodies in their processes and structures, particularly at top-management levels. In both New Zealand/Aotearoa and the Republic of South Africa/uMzansi Afrika findings of my study indicate that there were both racial and gender organisational sub-structures in the organisations from which participants came that disadvantaged indigenous women at top-management levels. I define the racial organisational sub-structure as an organisational structure that is representative of a race. The underlying organisational structure represents a particular race through its norms, customs, traditions, policies and practices. The racial structure operates below the structures, processes and policies of the organisation. In my findings, the racial organisational sub-structure was monoracial and Pākehā in New Zealand/Aotearoa and white in the Republic of South Africa/uMzansi Afrika. In the organisations from which the participants came, there were indications that additional to the organisational structures, processes and practices, there was a structure that promoted the norms and traditions of one race and indigenous women felt that they were not welcomed within those structures. These organisational structures had racial characteristics in addition to the male gender features. In the top-management structures, the characteristics of the organisations were white and male. The roles in the organisations of the participants were structured according to 'racialisedgenderly', favouring white males. Building on Acker's (Acker, 1990, 1998, 2006) work, the organisations of my participants were demarcated racialisedgenderly', particularly at top-management levels.

My findings concur with Acker (2006) that hierarchies are gendered and racialised at top-management levels of organisations. Ibarra (1993) also concurs that management ranks tend to be segregated by race and gender such that ethnic minority women are limited in influential positions such as top-management. For my participants the hierarchy was the entanglement of race with gender. In top-management levels of their organisations, the hierarchy was male and white. Being a top-manager was associated with being a white male. 
Individual strategy to work harder than the majority group

As an individual strategy to respond to 'racialised-gender', my participants worked harder than the dominant group to be on par with them.

In New Zealand/Aotearoa, the participants mostly believed that they had to outperform their white peers for the same rewards. A participant explained:

--- they will forgive him in things as a Pākehā man but they will never forgive you. They will let him do things that they will never let you do. The standards for you will be 10 times higher than for anybody else.

Another participant added: “--- but a Pākehā will excuse a Pākehā for saying it but if I'm Māori it won't be the same because they have their name underneath it".

Another participant commented: "--- sometimes $200 \%$ times more than what a non-Māori person could do. I think we are doubly discriminated against because of the woman and Māori factor".

A participant noted that in all her jobs, including her current role: "I was the most highly qualified person there, even here now. I don't have the top job, but I have the highest qualifications. I think it has to do with that I choose to relate in being Māori”.

These comments as examples indicate that the participants believed that their colleagues judged them unfairly because they chose to relate as indigenous.

Similarly, in the Republic of South Africa/uMzansi Afrika, the participants believed that they had to outperform their white counterparts to be perceived as credible and competent. For example, a participant noted:

It is not always easy because technicians would support one another. If you're a man they assume you can do it, if you're a woman, well they are 
not so sure. You have to prove yourself. If you are Black, you have to work twice as hard to be half as good.

Another participant commented:

You have to prove yourself ten times than someone else --- before people gain respect for you. They have to see you in action a bit longer and you have to work harder than everybody else to gain that respect. Then once you've got that, it changes, they relax, you're one of us. They relax, it just takes time. So that's why you can't come in and slack off as a Black person, you don't have that liberty.

These comments as examples suggest that my participants believed that they had to compensate for their status as indigenous people by working harder than their white male counterparts.

There are relevant studies that also suggest that ethnic minorities need to work harder than the dominant group to be as 'equal' as them. Studies focusing on ethnic minority women in management provide different reasons ethnic minority women in management have to work harder than the dominant group. Powell (1993) argues that being an ethnic minority woman in management interferes with performance in that one has an additional pressure to perform. He contends further that it is attributed to the physical difference, and what one says and does is different because one is physically different. He argues further that the mere presence of statistical minority groups in management highlights those things that are shared by the majority. A minority individual, in terms of numbers, is more visible in the presence of a majority (Fitzgerald, 2006). Cross (1992) argues that when one is seen not only as different, but also inferior, particularly for ethnic minority women, the response is to compensate by working harder than the dominant group. Thomas and Higgins (1996) debate that the ethnic minority women as statistical minorities in management do not have the privilege of 'implicit faith', that is, belief at face value by their organisations to acknowledge their skills and capabilities as an important central element for ethnic minority women as professionals. 
For the participants they thought that stereotyping became a major hindrance for them in their organisations. Davidson (1997) attributes this to some degree to stereotyping, where an individual gets located into a particular group and is ascribed characteristics on the basis of the group membership. Other studies (Davids \& Watson, 1982; Dubno, 1985; Powell, 1988; Thomas \& Alderfer, 1989) suggest that deficiencies are presumed even when there are no differences because of stereotypes based on historical roles that are still persisting. Additional studies (Crawford \& Smith, 2005; McLeod, 1995) on ethnic minority women concur that their participants also believed that hard work and professional work were important to achieve. Kanter (1977b) argues that ethnic minorities in management carry extra burdens of visibility and are subject to more performance pressure than members of a dominant group. The above studies focusing on ethnic minority women in management confirm that ethnic minority women have pressure to perform to compensate for their minority status, in terms of numbers, in management roles.

\section{Downplaying race and gender to address 'racialised-gender' as an individual} strategy

As well as working harder, my participants from both New Zealand/Aotearoa and the Republic of South Africa/uMzansi Afrika, largely downplayed both gender and race to minimise their effects of difference to their white male colleagues, as an individual strategy.

In New Zealand/Aotearoa, the participants downplayed their race by consciously not responding to issues relating to their race when asked by their white counterparts for their opinions. For example, a participant from New Zealand/Aotearoa remarked:

--- probably the biggest challenge is the perception that the organisations can have that your only contribution is Māori. That your only view will be on a Māori issue and not whether the structure of the lending programme is right for the products that you've got. --- It is a perception and you have to work very hard to break it. So it means that sometimes 
you would speak up for things in an executive meeting. You might see a gap that some idea is going to disadvantage or not work for Māori. Sometimes I won't speak up on those issues so that I'm not up in that box. --- I'm very careful with it. You have to be. Otherwise you become like some advocate. Then people will think you don't have a brain to apply to any other issue.

These comments are examples that the participants are careful on how they articulate issues relating to their indigenous communities in their organisations. A participant from the Republic of South Africa/uMzansi Afrika commented:

We went for a course and I was with this one lady from Y [name of city], $\mathrm{Z}$ [name of an ethnic minority group] lady, other than that it was white females and white males. --- It was a 6 weeks course, this guy, lecturer from $\mathrm{P}$ [name of organisation] refused to look at us. No eye contact for 6 weeks. We will try to get attention from the lecturer trying to ask him a question, he will not look at me, he will not take a question from me, he refused to do so. So eventually we strategised at the end of the first day with one of our colleagues from the same company to sit in-between me and $\mathrm{T}$ [name of another ethnic minority woman]. If I had a question, I would write it on a piece of paper and put in front of her. And she would ask the question and that was the only way of communicating.

The remarks as examples indicate that the participants sometimes choose to publicly ignore race issues and deal with them in a subtle manner. Publicly, they would sometimes downplay the race issues and employ a subtle strategy to address them.

Similarly, the participants from both New Zealand/Aotearoa and the Republic of South Africa/uMzansi Afrika minimised tensions amongst themselves and their male colleagues by staying away from behaviours that are associated with women that men view --- in a negative light. The participants understood that men were in the majority in their levels, in terms of power, and they believed that they had to gain credibility as top managers from them. As an individual 
strategy, they gained credibility from their male colleagues by suppressing traits, such as being emotional, that are traditionally negatively ascribed to women. They succeeded in a male environment under the male terms, succeeding at the 'male's own games'. For example, a participant from the Republic of South Africa/uMzansi Afrika noted:

I would challenge those things, but I don't challenge things aggressively. I found that women, some women wait until they are fed-up. --- Then they explode and then they become irrational in a meeting --- and men like those confrontations because they are going to show how emotional and hormonal you are. --- Those are skills that you learn, --- I'm not saying that I don't get emotional about it. I regretted most of the outbursts that I had because they were counter-productive because you were actually playing into their hands ---

These comments indicate the need for the participants to stay away from gender stereotypical behaviours. In New Zealand/Aotearoa, the participants also stayed away from gender stereotypes. A participant from New Zealand/Aotearoa noted:

I will not make a cup of tea. No, I will not do that. But having said that, now I am a lot more known, --- I have a little more credibility. Now that I have my own confidence, I don't mind making them a cup of tea, it's alright now because I know that they don't see me as a cup of tea lady. They see me as a top manager being polite and offering. So it is different. But when I first came, no, I would not offer. I did not want to be seen in those stereotypical feminine roles, and I think it is worse if you're Brown, you don't want to be seen in those slavery-type of roles with your apron. But I think as I say once you get to the point where you believe you're getting an equal level of respect, then I'm happy to get them a cup of tea.

These comments illustrate the importance of managing perceptions for my participants about themselves and of their counterparts in their organisations. 
My findings concur with studies in the women in management literature. Research studies focusing on women in management support the notion that management is synonymous to the male gender characteristics. Berthoin Antal and Izraeli argue that the 'probably single most important hurdle for women in management in all industrialized countries is the persistent stereotype that associates management with being male' (1993, p. 63). Heilman, Block, Martell and Simon (1989) and Schein, Mueller and Jacobson (1989) contend that a management role is ascribed to qualities that are possessed by a man. Klenke (1996) also confirms that women are perceived in gender stereotyped roles. This means that they are perceived in roles that are traditionally conducted by women, such as, support work. Klenke (1996) and Jackson 's (2001) studies confirm that most organisations support the culture of being a male at top-management levels. Literature on management has contributed to the gender stereotypes between males and females by presenting the male manager as the norm (Olsson \& Walker, 2003). For indigenous women, the anomaly may result from being both indigenous and women in top-management. As an indigenous woman in a topmanagement role, gender is a combination of being an ethnic minority, who is an indigenous woman, in a world dominated by white males and some white females.

Alignment with white women as an individual strategy to address 'racialisedgender'

The participants from both New Zealand/Aotearoa and the Republic of South Africa/uMzansi Afrika also raised issues of gender.

In New Zealand/Aotearoa, a few participants raised strong issues of gender. They believed that pressing issues for them were more about gender than race. However, they also articulated issues of race. One of those participants also indicated that she was not brought up in a typical Māori family, her issues were more about her experiences of sexist tendencies in typically white male sectors where she has operated at top-management levels. She stated her experiences and said: 
a lot of men are not used to dealing with women as their superior in work.

--- I think I mostly feel them as being a woman rather than a Māori. Because I'm direct, pushy kinda, people perceive my personality as such because I have so much energy; I'm in your face. --- I'm fairly driven and direct, and it does --- not suit a lot of men in general to be honest with you. I don't think it is racial, I think it is just gender.

Another participant added:

Chauvinism and gender biases are alive and well. Yes, women progress in those organisations in those $\mathrm{X}$ sectors, but the attitude of the men --they are still chauvinistic. --- People want good people to do it [the job]. But if they find a good man, they'll take him. If they can't find a good man [the job], they'll take a good woman. It is chauvinistic, it is the boys' club and like a locker-room. --- It is just that the culture is very locker-room. When you play a game of rugby, you always go to the locker-room to get changed. They are gross. It is always boys' humour. Women find it grope [inappropriate] and men find it humorous.

These comments illustrate the challenges of women in predominantly male industries.

Similarly, a few participants from the Republic of South Africa/uMzansi Afrika believed that their issues were more about gender than race, but also articulated issues of race. A participant explained how she managed to challenge white men in her organisation about continuously appointing white males in top roles and ignoring other capable women (including white women), before she got promoted to her current role:

--- and the first thing that they did when they split us into teams, --- they immediately appointed white male team leaders. --- So when they announced it, I went and asked, some of the guys they appointed I had more or less the same --- experience and qualifications as them. So I went and I asked the head at the time, and I said, does that mean a woman 
can't lead? --- yea, oh no X [name of participant], very embarrassed, it is just that you know you were a big group. --- We quickly had to put something together. I said even when you were quickly putting something together, did you not think there were two women at a time $\mathrm{Y}$ [name of white woman] and myself. Y just as capable. --- How do you sit in the room and just choose guys and all white ones.

These comments are examples to indicate that the participants are able to increase their voices by joining or aligning with another group that is marginalised in their organisations.

My analysis is that ethnic minority women in management side with white women as a strategy. Some participants chose to align with white women as an individual strategy. They achieved this by highlighting the gender aspect of who they were as individuals. In so doing, I found that they stress the gender side of themselves to side with other women who may share similar gender experiences as them. In their organisations, women in management who were in the majority were white women. However, they also raised issues that relate to race, as a barrier for them in top-management roles as indigenous people. This is contradictory because they articulated both race and gender issues as challenges for them, but chose gender as an issue of concern for them. This act demonstrates the psychological challenges and entanglement of 'racialisedgender'. For the participants to adopt a gender stance as the minority group, in terms of numbers as ethnic minority women in top-management, it is a strategy to side with white women to address gender issues within their organisations. When the participants discussed issues regarding their alignment with other white women, they highlighted their gender and minimised their race. This strategy of aligning with white women increases their voices as marginalised individuals because white women in both New Zealand/Aotearoa and the Republic of South Africa/uMzansi Afrika are relatively greater in numbers in management compared to indigenous women. 
Alignment with indigenous men as an individual strategy to address 'racialisedgender'

In addition to aligning with white women, other participants also dealt with the issues of 'racialised-gender' by aligning with indigenous men, as a strategy. They addressed race issues in a direct manner. When they did so, they then highlighted their race and minimized their gender. When the participants used this strategy, they would justify the reasons within the indigenous cultural and race contexts. They became creative and strategic in solving issues regarding race in their organisations. For example, a participant from New Zealand/Aotearoa explained:

--- if people start talking, "let's prioritise Māori because they are poor". Then they say "there are lots of poor people in New Zealand/Aotearoa". Then I say "Māori people have tangata whenua [the original people] status here. There is a Treaty. That is the framework for engaging with Māori. Let's look at framing the Treaty statement for our accountability document so that we can hang the Māori policies off something stronger than just a wishlist”. So I look for a solution, --- sometimes, you've got to get a bit higher up.

A participant from the Republic of South Africa/uMzansi Afrika explains how she used a direct approach to address racism issues within her previous organisation:

--- we did a product course --- it was only the 3 of us the Black people the rest were white --- it was some kind of a training --- programme. --- You know your cleverness, you know who you beat in class or programme. There was a white person who finished first, who I knew would beat me. Then it was me, I knew chances were I was number two in the class in terms of scoring. Then there was a white woman. Then there was a guy who was marking. He put my script aside, --- he continued to mark and marked the others. After that he marked ours and he called us, Blacks, separately and said "no, we didn't pass da, da, da" --- and I chose people and I said to him "can you please take Y [name of work colleague]'s"? I 
called Y in particular. "Y's answer sheet, put it here" because they all passed white people, except us, and mine put it here and mark the two and lets see what happens. --- Initially they marked me 60something, when he re-marked I got about 95\%, --- Y was weak, I knew, she was just pushed. --- I did not even choose the cleverest, I said "Y, put it here, put mine here". And I didn't even choose --- the weakest, --- and you could see he was nervous. --- He was so embarrassed, --- you should see the letter that he wrote me asking for apology, I still have it today.

These remarks as examples show support to the indigenous issues.

The comments from the participant suggest that an indigenous woman has to be creative with her solutions in addressing issues affecting her or other indigenous communities. Also, sometimes it may be necessary to use a direct approach to address issues of race. This direct approach was used by a statistical minority number of the participants. In challenging race issues directly, I found that the participants promote indigenous issues. In support of indigenous issues, I found that they consciously or unconsciously use the strategy of supporting issues relating to the indigenous group, which includes indigenous men. They are indirectly siding and aligning with indigenous men and forming solidarity with the indigenous race. Most participants used subtle strategies to address 'racialised-gender'. All the participants from both New Zealand/Aotearoa and the Republic of South Africa/uMzansi Afrika shifted in their allegiance between white women and indigenous men. At times, they had simultaneously conflicting loyalties to both groups.

\section{Paying Indigenous women's tax}

I summarise and analyse the 'racialised-gender' concept as well as apply it to my participants. Indigenous women paid 'indigenous women's tax' for being top managers in predominantly white organisations. The term 'indigenous women's tax' is a new term that I use for ethnic minority women in management. It is similar to paying 'sin' tax that governments levy to goods such as tobacco, alcohol and some countries such as the USA for gambling. 'Sin' tax is typically an excise tax. It means that it is generally additional to the value-added tax 
(VAT). Governments generally add this type of tax on specific goods and services that they perceive to be vices. It has aims to discourage individuals from partaking in such 'bad' activities such as smoking. It is on specific goods. The logic behind excise tax is to 'protect' citizens of a country and punish the undesirable behaviour through additional tax. This type of tax is paid for 'deviant behaviour', such as being a smoker. For the participants it was for occupying roles in top-management positions as ethnic minority women. Extensive literature focusing on women in management that I presented in Chapter Three explains challenges women in general face in management. Women are minorities in terms of numbers at management levels, they pay tax, I found, for being women in a world dominated by males. For ethnic minority women, the challenge is both race and gender. They pay 'double tax' for being an ethnic minority group within a statistical minority context at top-management levels.

My participants believed that the role of a top manager in their organisations was assumed to be for white males together with their norms and traditions. As the participants were both not male or white, they had to compensate by overperformance to acquire their 'rights' or entitlement to sit in the 'chair' of a top manager. The structures, systems, norms and organisational customs of their organisations represented white male traditions. The organisations of the participants typically had limited number of indigenous women or men in topmanagement. They felt that over-performance was required for them to be in a role of a top-manager. Because of their ethnic minority status and what they believed were the negative perceptions that existed about them as indigenous women in both New Zealand/Aotearoa and the Republic of South Africa/uMzansi Afrika, the participants thought they had to outperform their white counterparts for the same rewards. I found that they had to pay 'indigenous women's tax'. They had to pay for their racial and gender difference in top-management roles through their sweat. They claimed to work harder than their white male-colleagues to be on par with them in exchange for occupying prestigious roles of being top managers. 
In both New Zealand/Aotearoa and the Republic of South Africa/uMzansi Afrika, the participants paid 'indigenous women's tax' by also consciously choosing to downplay their race and gender to reduce challenges for them as indigenous women in top-management roles. Consciously not responding to race issues was their way of managing the effects of their race and acted as top managers and not just indigenous women in top-management roles. Minimising the effects of their race, I found, is a tax they paid for being minorities, in terms of numbers, in top-management. The participants wanted their counterparts to treat them as top managers and not just experts on issues of indigenous people. In New Zealand/Aotearoa, they downplayed their race by selecting to be silent on Māori issues, sometimes. In the Republic of South Africa/uMzansi Afrika, the participants chose not to respond on every racial incident that they encountered. Participants then became selective on how they responded to racial experiences or issues to minimise the effects of their races to their white colleagues. The participants also 'paid tax' for belonging to the female gender in top-management. They paid this tax by downplaying their gender in staying away from gender stereotypes. In the Republic of South Africa/uMzansi Afrika, they suppressed behaviours that men viewed negatively in women, such as, expressing emotions. In New Zealand/Aotearoa, they stayed away from gender roles in the presence of their male colleagues. They downplayed their gender or race to side with either white women or indigenous men or suppressing a part of their identity. When they sided with white women, they tended to magnify their gender and minimise their race. On the other hand, when they aligned with indigenous men, they highlighted their race and downplayed their gender. I attribute these contradictions to the complexities of being a top manager, while also belonging to different statistical minority groups in top-management structures.

In dealing with 'racialised-gender' the participants are dealing with the demands of being a top manager which is traditionally associated with the attributes ascribed to white men. On the other hand, they are also managing being an indigenous woman and business like. Wacjman (1998) debates that women face contradictory demands of being feminine and business like. Simpson (2000) argues that women may succeed by minimising their gender difference to their 
male colleagues. By so doing, they are disassociating themselves from other indigenous women to conform to their male colleagues' expectations of management. Bryans and Mavis (2003) confirm that if you are a top manager as a woman and your peers are male, it is difficult not to develop behaviours and a style congruent with your male colleagues. Collins (1989) argues that ethnic minority women in organisations are challenged to de-myth the stereotypical images of their ethnic minority status. Also, those who enter management in organisations have done so by adopting existing organisational norms, framed by white male majority, as matter of organisational survival (Cox, 1994). For my participants, they downplayed their gender and race to minimise tensions with their colleagues who were in the majority at top-management levels.

Other studies (Kamenou \& Fearfull, 2006) focusing on ethnic minority women in management argue that ethnic minority women have to fit into the existing dominant culture if they want to take advantage of opportunities. For my participants, fitting into the dominant culture meant for them minimising the effects of their gender and race status to their white male counterparts. The participants adopted behaviours that were not natural to them in the presence of white males in their organisations. They became what De Vries, Webb and Eveline (2006), Cockburn (1989), Liff and Cameron (1999) call 'fixing women'. They 'fixed' themselves as individuals rather than addressing the core issues in their organisations or fixing the system of their organisations such as addressing diversity issues. Jones (1986) concurs that there are pressures experienced by minority groups, in terms of numbers, to succeed and to fit into their employer's organisational culture. Fitting into the organisational cultures of the participants came at a tax premium of denying a part of who they were as individuals.

The findings of my study supported both the gender-centred (Horner, 1972; Riger \& Galligan, 1980) and race centred approaches regarding the explanation why there are limited number of indigenous women in top-management roles in organisations of my participants. The gender-approach supports that gender influences the manner in which men and women think and behave in an organisation. Any gender behaviour, attitudes, and traits are attributed to the socialisation of men and women (Powell, 1988; Riger \& Galligan, 1980). Adler 
and Izraeli (1994) argue that the differing of women's behaviours from male norms is the result of the limited representation of women in management. For ethnic minority women, according to Collins (1990), it is impossible to separate their twin self - gender and race - because their identity places them in two oppressed groups - women and ethnic minority. The participants thought that when all factors were similar, a white male appeared and was assumed to be qualified, by virtue of his both race and gender alone, than other women or Black people, in top-management roles.

\section{'Biculturalism' as an individual strategy to address 'racialised-gender'}

'Biculturalism' is a strategy that explains the movements of indigenous women. In addition to the previous individual strategies, as a compromise, my participants from both New Zealand/Aotearoa and the Republic of South Africa/uMzansi Afrika lived in two different worlds - indigenous and white. Bell (1990) introduced the term 'biculturalism', from the USA, in women in management to explain the movement of ethnic minority women in management. 'Biculturalism' is also a concept that is used in New Zealand/Aotearoa to mean living in two different cultures with different norms and expectations, Māori and Pākehā. In the New Zealand/Aotearoa context, the spaces between Māori and Pākehā may not be mutually exclusive. From the South African perspective, it means living in both white and Black worlds. In this chapter, I use the word 'biculturalism' to mean both Bell's (1990) concept and moving between two different cultures- indigenous and white.

In New Zealand/Aotearoa, the participants sought a compromise in their organisations and Māori communities by altering their behaviours. They developed an understanding, of behaviours, of norms, and of values from both the Māori and the Pākehā societies. They moved between the Māori and Pākehā contexts with separate identities. A participant explained: "I was brought up in two worlds, grounded in my own culture but having an experience in the western culture".

For example, another participant described an incident that involved another Māori person. She noted: "we've got the Minister of X sitting on the left hand 
side, --- but if it was just us, we would be OK and we would all have a big fat laugh" about the incident. She added: "we can do that to each other, but in front of Pākehā people that can be seen as really belittling and they'll see that person in a different light".

The incident she described was not the appropriate behaviour in a Pākehā society, taking cognisance of the calibre of people who were at the function. The participants developed mechanisms to function in a Pākehā organisation and also a Māori structure.

In the Republic of South Africa/uMzansi Afrika, the participants had to adapt to the white western way of conducting business having been raised in an indigenous manner. For example, a participant commented:

I am not stuck in my ways or the ways that I grew up with or what I know, --- but there are also basics. --- It is about basics, cultures, rituals, that will never change for me as a Black woman. And it's not something you can bring to the workplace. It is something that remains in the Black community.

Another participant added:

we come in this environment it is one amongst how many around the table? Ok, so you end up doing business their way because if you don't, they don't take you seriously. So that part can change your personality and who you are and I consciously kept reminding myself who am I? --But at the same time, you can't afford to allow people to walk all over you.

These comments illustrate that the participants feel that they have to conduct business in a white western manner because in predominantly white organisations they are few in top-management structures. They have to be also conscious of their behaviours and continuously evaluate them against their own 
value system and judgements. The comments also indicate that the indigenous women are in top-management roles according to the 'white male terms'.

In a 'bicultural' context, the participants from both New Zealand/Aotearoa and the Republic of South Africa/uMzansi Afrika moved between indigenous and white communities. The participants developed an identity that was acceptable in the white world and that facilitated them in moving in that world. They had behaviours that were acceptable to the white communities that made white people comfortable about them. When they operated in an indigenous environment, they also assumed a different identity that was acceptable to indigenous people. They had different behaviours that they portrayed in the indigenous and white communities. In New Zealand/Aotearoa, they studied in white schools with western values. They learnt the white western values in their homes as some participants had both Māori and Pākehā families. They maintained links with both their white and indigenous communities. For the participants from the Republic of South Africa/uMzansi Afrika, mostly, their closest initial relationship with a white person was in a workplace. They leant English as a second language in schools and universities. They learnt the western norms in the workplace, while having lived, and been educated in the indigenous way. They were raised as indigenous people, but at work, they operated in a white western framework. The participants from both New Zealand/Aotearoa and the Republic of South Africa/uMzansi Afrika lived in two different worlds, indigenous and white.

In New Zealand/Aotearoa, discourses on 'biculturalism' gained momentum in the 1970s resulting for a need of national unity in New Zealand/Aotearoa (Seuffert, 2002). Moss (2005) debates that the guarantee of Māori sovereignty (rangatiratanga) from 1975 has led to the separate government institutions for Māori Development. It is a constitutional requirement to provide for the cultural needs of Māori people (Moss, 2005). In most, state-funded institutions there are 'bicultural' approaches for both Māori and Pākehā (white) individuals. However, at top-management levels of predominantly Pākehā (white) organisations, my results indicate that the participants were living within the white cultural contexts. 
Current research mostly from the USA focusing on ethnic minority women in management support the idea that ethnic minority women live in two separate spaces and with different lives. Bell, Denton and Nkomo (1993) contest that the situation for ethnic minority women in predominantly white male organisations dictates that they should abandon commitments to their culture and adopt a new cultural identity for them to be successful. Liff and Cameron (1999) attributes the reason to the fact that organisations tend to have a dominant culture that is usually white male with implicit expectations that employees of different social groups have to 'fit in' into the new organisation. If women and ethnic minority groups do not 'fit in' they may be perceived as problematic, rather than questioning the organisation as a problem (Kamenou \& Fearfull, 2006). Hite (1996) contends that the adjustment from a 'professional' to a 'home' persona is typical for ethnic minority women in management. Dubois (1961) call this concept 'double-consciousness', the state of being a member and an alien of two different cultures. The different behaviours and assumptions need to be managed in two different worlds, indigenous and white. Even 20 years after Bell's (1990) study her research is still valid and relevant for ethnic minority women in management.

\section{En/gendered 'biculturalism'}

New Zealand/Aotearoa and the Republic of South Africa/uMzansi Afrika, my participants articulated the importance of feminine traits and roles for them as indigenous women in a cultural context. They believed that as indigenous women they had different roles from those of men. It was appropriate and necessary for them to keep the traditional feminine behaviours for cultural protocols.

In New Zealand/Aotearoa, for example, the participants stressed the importance of different gender roles between men and women in indigenous communities. For example, a participant from New Zealand/Aotearoa remarked: 
--- it is always about balance mahi tane, mahi wahine [there's men's work and women's work]. Māori women would never move without our Māori men. That is a just a given, day and night, high tide low tide, sunset sunrise. There's always balance and it is always maintaining that equilibrium. The roles and responsibilities --- it's been clear that they are complementary. In a government department that does not happen, it is not always easy to implement and always understand. When we go home to the Marae [focal point for Māori community / Māori Community Centre] though, we have the living and the dead. We have the balance. We talk to our dead. So, as a Māori woman even with policy issues, you have to consider Māori women in the context of their collective that they belong to. It could be one person or it could be a thousand.

Another participant from New Zealand/Aotearoa added:

--- and in some ways from a cultural view point --- we see our men as our spokespersons, they are our protectors. For the woman we tell them what to say, so it is OK. --- So this is where a lot of Pākehā [white] women find it difficult. They say to me why do you sit at the back, you should be at the front --- I say I'm happy, that is his role. He knows where my thoughts are, he knows where my position is.

The participants are comfortable with allowing Māori men to represent them as women in an indigenous context.

My contribution to literature on 'biculturalism' from the USA, in this chapter, focuses on the movements of ethnic minority women in management. I build on previous studies conducted by Bell and Nkomo (2001), Bell (1990), Bell, Denton and Nkomo (1993), Kamenou and Fearfull (2006) that define the bicultural lives of ethnic minority women in management. These studies define the lives of ethnic minority women in management roles, on how they live in two different cultures: white and Black. They focus mainly on the racial aspects of the indigenous and white communities as well as the role of ethnic minority women in their communities. My contribution is that the norms of both white and 
indigenous communities are 'gendered-biculturally'. There are also expectations to manage the gender identity of a woman, in a white society, particularly in topmanagement structures of organisations as an ethnic minority woman. As the participants moved from an indigenous culture to a white culture and back and forth, they had to also learn the gender role expectations of that culture of what constituted a woman in a community. They also had to live by the norms of understanding the status of women in that community and adjusted their behaviours according to the cultural protocol of that culture. For indigenous women, they had to manage the expectations of being indigenous and women, within both the white and indigenous cultures. The concept of 'biculturalism' regarding studies focusing on ethnic minority women in management, the roles of women are mainly focused on ethnic minority communities. The movements of the participants within the 'bicultural' context required them to understand both the gender and racial norms of that culture or society regarding the role of women within that culture. In this study, I build on the role of ethnic minority women as women in both white and ethnic minority communities.

\section{Conclusion}

In this chapter, I discussed the lessons for other indigenous women on how my participants individually 'strategised' for themselves to succeed in their organisations as they experienced 'racialised-gender'. They 'strategised' for themselves to survive and to be accepted, as well as to be perceived as credible in predominantly white gendered organisations by responding either in race or gender terms. This means that my participants highlighted an aspect of their identity: gender or race, which often caused contradictions within themselves. Attempting to 'unpack' race and gender is a challenge that my participants faced because their identity is interlinked. I was amazed at the similarities of the individual strategies of the participants from New Zealand/Aotearoa and the Republic of South Africa/uMzansi Afrika that they adopted in their organisations. My participants were often faced with implicit and explicit choices between their interests in terms of their gender or in terms of their race and at times these two were in conflict with one another. They 'paid indigenous women's tax' to compensate for their ethnic minority status at top-management 
levels. My participants became gender and race conscious as an intentional individual strategy to succeed in top-management roles. They became race and gender conscious when achieving because they believed that top-management roles in their organisations were associated with white male characteristics. The lesson for indigenous women wishing to penetrate top-management roles is to be aware of their ambivalence, struggles and strategies to empower themselves, when experiencing 'racialsed-gender'.

In the next chapter, Discussion, I will discuss how I have contributed to the women in management literature. In so doing, I will recap my research questions and summarise my responses to them as well as engage the literature in filling the research gap. I will also outline the historical-political model and its contribution to the theorisation of women in management literature. In addition, I will discuss my contribution regarding the 'concrete-ceiling'. In relation to my findings, I will also explain my contribution to management studies. I will end the next chapter by reflecting on my $\mathrm{PhD}$ journey. 


\section{CHAPTER EIGHT}

\section{CONCLUSION}

In this thesis, I wanted to find out how ethnic minority women reach top jobs and succeed in them. Because of my identity as a Black woman from the Republic of South Africa/uMzansi Afrika, I got interested in understanding this group of women and a similar group in another country. I drew on the experiences and perceptions of Black (from the Republic of South Africa/uMzansi Afrika) and Māori (from New Zealand/Aotearoa) women in top-management. Although both groups of women are indigenous, I do not use indigeneity to theorise about this study. However, I am interested in the interactions of race and gender in topmanagement, drawing from the women in management literature. Within these studies, I focused on those drawing samples from ethnic minority women in management, using the concept of the 'concrete-ceiling'.

In this final chapter, I will reflect on and integrate what I learned from this study. Firstly, I will discuss what I learned from the research process, and how I developed a methodology that I argue would also be transferable and valuable to other research contexts. I then highlight my key findings, organising these in terms of my key research sub-questions. I explain how these findings contribute to theorising race and gender in management, especially top-management. My participants shared a wish to pass on specific lessons to other ethnic minority women on how women get into top jobs and succeed in them. In spite of the crucial wider context of political struggle, individual women still seek practical individual guidance. I summarise the key points my participants made as lessons for others. I then discuss scope and transferability of my study and implications for future research. Finally, I reflect on what I have learnt personally from my thesis.

I used two approaches to conduct my research. Firstly, my approach to this research was to locate the experiences and perceptions of my research subjects in the histories and politics of their countries (New Zealand/Aotearoa and the Republic of South Africa/uMzansi Afrika). I argue that in order to understand 
experiences and perceptions of ethnic minority women in top-management, it is important that their experiences are understood within the historical-political contexts of the countries from which ethnic minority women are located. The second approach to carry out my study is that I developed a combination of western and indigenous methodologies. Because of who my research subjects were, that is ethnic minority women, I approached them in a culturally appropriate manner using a combination of indigenous protocols (Kaupapa Māori in New Zealand/Aotearoa and Afrocentric framework in the Republic of South Africa/uMzansi Afrika), while also applying western paradigms (interpretive approaches).

\section{Methodology}

I developed a historical-political approach to understand my study, which can be relevant to all race and gender research. I also formulated a combination of methodologies, which drew on Māori and African cultural protocols, as well as western paradigms. In addition, I chose a data set that is invisible in the women in management literature - indigenous women in top-management roles.

\section{A historical-political approach}

I contribute to the women in management studies by introducing a historicalpolitical approach that contextualises issues of race and gender in management. I argue that this is an important contribution because the experiences of ethnic minority women are shaped by histories present in their countries. Prasad (2001) also places importance on locating academic theories within the historical moments present in a country. Although other groups of women, such as white women in different countries, might have been assisted by the introductions of the Equal Employment Opportunities (EEO) related policies entering management roles, that is the history and politics of the time in their countries, my participants were consciously aware of and discussed the difference that history and politics made to them entering top-management roles. My participants were very aware of the politics and history that made it possible for them to penetrate top-management roles. I used this approach as part of the background to my study, which is helpful for all empirical studies. In addition, I used this perspective to understand what my participants meant during the 
interviews because I argue that history and politics are important in all race and gender research. I also employed this approach to explain the problem of disadvantage facing ethnic minority women, in particular indigenous women as my sample group.

Indigenous women have to address issues related to indigeneity, as the 'first' and / 'last' occupants of the land, prior to European colonisation. Indigeneity is associated with collective right and group claims (Roach \& Egan, 2008). For example, in the Republic of South Africa/uMzansi Afrika, they face issues such as unemployment, inequality, health, polygamy, customary law (laws of traditional African societies), lobolo (dowry) and racial discrimination (Cock \& Bernstein, 2001). These challenges are different from those in a developed nation such as the USA or UK.

Indigenous women, particularly in New Zealand/Aotearoa and the Republic of South Africa/uMzansi Afrika, are addressing the legacies and effects of British colonisation in their countries. These effects are peculiar to countries that have a history of a presence of European colonisers and this varies from country to country. For example, in the Republic of South Africa/uMzansi Afrika, the legacy of the Apartheid system robbed indigenous women of their resources and access to economic opportunities as indigenous people. In New Zealand/Aotearoa, Māori women face challenges of the acknowledgement of the contents of the Treaty of Waitangi as well as the return of their resources as indigenous people. The Treaty acknowledges Māori as 'tangata whenua' (people of the land) that is, indigenous (Fitzgerald, 2003, p. 17). Indigenous women face issues relating to their indigeneity where the colonisers sidelined them economically while the colonisers were attaining resources from these countries. However, due to the role of indigenous women in the liberating struggles, in both New Zealand/Aotearoa and the Republic of South Africa/uMzansi Afrika, indigenous women were able to fight and lobby their Governments to obtain equal access of opportunities. The newly acquired access led to the institutional bodies such as the Ministry of Māori Affairs in New Zealand/Aotearoa and legislation promoting indigenous women (see Chapter Two). For indigenous women in both New Zealand/Aotearoa and the Republic of South 
Africa/uMzansi Afrika, history and politics were important in shaping the experiences and perceptions of my participants and are an important aspect that I include in theorising their experiences in management, as ethnic minority women in management. Indigenous women may be triple disadvantaged, based on history, race and gender.

The current debates focusing on the 'concrete-ceiling' categorise ethnic minority women in management as uniform without the distinction of history and politics in their countries. The challenge with these studies, for example the studies of Hite (2004) and Davidson (1997), is that they do not acknowledge history and politics that influence the experiences of ethnic minority women in management. They largely fail to contextualise the experiences of ethnic minority women in management within the context in which the samples were drawn. This history is important because it impacts on the experiences of those women who are within those countries in management.

\section{Combination of indigenous and western methodologies}

This thesis contributes research methodology to management studies. I do so by incorporating both the indigenous and western research paradigms. I could not find a study that incorporated the manner in which ethnic minority women in management lived their lives in their communities and white environments in top-management. This is also an important contribution because it impacts on the definition of understanding of knowledge within the broader gender studies in management. I used the interpretive western approaches and indigenous epistemologies (the Kaupapa Māori framework in New Zealand/Aotearoa and Afro-centric framework in the Republic of South Africa/uMzansi Afrika) to guide my research design. It is an important contribution because I acknowledge the manner in which indigenous women live their lives in two separate spaces. They operate in top-management of organisations with the norms and traditions that tend to promote the western cultures. In their communities, they practice indigenous protocols and behaviours. Other researchers (Stanley, 2009) also state the importance of incorporating ideas into the manner in which ethnic minority women live their lives. I also acknowledge and promote the indigenous beliefs and philosophies to broaden the debates of ethnic minority women in 
management to indigenous women, which are important in defining knowledge. I could not find a study that included a combined research paradigm by incorporating both western and indigenous epistemologies in the management studies.

I believe that, this is one of the first studies that is cross-cultural in terms of the sample choice - indigenous women - to explain the experiences of ethnic minority women in management who are located in two different countries and cultures. In management studies, most cross-cultural research has been largely based on American theories (Jack \& Westwood, 2009). In addition, I argue that the experiences of women in management have been largely studied within the context of American theories of management. So the extent of generalisability to other countries is questionable, according to Adler (1983). Also, in management, most cross-cultural studies that include an indigenous group assume that the researcher is also non-indigenous, which is not the case with my study. I am an indigenous person, who is researching two groups of indigenous people. My participants were Māori women in New Zealand/Aotearoa and African women from the Republic of South Africa/uMzansi Afrika. They belong to Māori and African cultures respectively in these countries. This research responds to calls by Burke (2010) to increase cross-cultural research in management studies. I believe this study is ground-breaking in terms of connecting the cultural and continental boundaries in the management studies.

\section{Unique data sets}

This study contributes to the women in management literature by incorporating indigenous women as research samples. This study is one of the very few studies in the women in management literature that has indigenous women in topmanagement positions as research subjects. Most studies in the women in management literature primarily draw their participants from white women (Hite, 2005). A limited number of studies draw their samples from ethnic minority women in management (Kamenou \& Fearfull, 2006). Those few studies that do address the interaction of gender and race draw their samples mostly from Black women in the USA (Bell \& Nkomo, 1994; Hite, 1996) and UK (Kamenou \& Fearfull, 2006). Within these studies, there is an embedded assumption of being 
a slave in the USA or a migrant in the UK. There have been very few studies drawing that draw their samples from indigenous women in management (Muller, 1998) and these very limited studies focus on the American experience.

My study draws samples from indigenous women from countries (New Zealand/Aotearoa and the Republic of South Africa/uMzansi Afrika) with a presence of former British rulers. I focus on the experiences and perceptions of indigenous women without a history of slavery or migration from New Zealand/Aotearoa and the Republic of South Africa/uMzansi Afrika as research participants. This unique data set allows me to test my findings against those familiar from the 'concrete-ceiling' literature, and to adapt and develop theories of race and gender in top-management in line with my findings.

There are issues in studies focusing on ethnic minority women in the women in management literature. These studies assume there is a sameness of experiences based on the shared identities of ethnic minority status and gender. They perpetuate what they accuse the 'glass-ceiling' studies of doing (Schein, 2007; Thanacoody, et al., 2005; Weyer, 2007; Wirth, 2001) by not acknowledging other types or differences amongst women. The 'glass-ceiling' studies are primarily based on research conclusions of white women. The voices of indigenous women are important, including those indigenous women from countries with the presence of European colonisers. Although recent studies have included diverse backgrounds in the experiences of Black women managers (Giscombe \& Mattis, 2002; Pomper, 2011); they still exclude indigenous women, particularly outside the USA. These studies largely ignore Black women from Africa and Brown women in the Asia Pacific Region. My study addresses the problem of ignoring the experiences of indigenous women outside the USA, in focusing on women in management.

\section{Theoretical contribution}

In this section, I discuss how I contribute to the women in management literature, using theorisation of the interactions of race and gender in management. 


\section{Theories of race and gender in management}

For my study, the 'concrete-ceiling' theoretical concept worked slightly differently from what is understood about ethnic minority women in management. Applying this metaphor to understand the experiences and perceptions of ethnic minority women in management using indigenous women as research samples confirmed some aspects of the 'concrete-ceiling' literature, while also adding new perspectives on familiar themes. I discuss the metaphor in the context of my research questions and answers.

\section{Access to top-management jobs}

The new perspectives to the 'concrete-ceiling' concept were that my participants accessed top-management differently from what is assumed in studies focusing on ethnic minority women in top-management. I discuss access to topmanagement for my participants in terms of how it differs to the 'concreteceiling' literature.

The current model of the 'concrete-ceiling' theoretical concept assumes that an individual breaks the 'concrete-ceiling' by using her sole efforts and 'strategies' present within these studies. This model also suggests that ethnic minority women encounter both organisational and attitudinal 'barriers' in accessing topmanagement roles. Examples of 'barriers' include attitudes such as the masculinity of management (Schein, 2007) and organisational practices that exclude ethnic minorities and women (Jackson, 2001). The rationale present in the 'concrete-ceiling' studies is that an ethnic minority woman is solely accountable through her efforts to break through both the organisational and personal 'barriers' to access top-management and achieve in this role. She 'pushes' through the 'concrete-ceiling' using her own abilities and skills. Within this literature, over-coming 'barriers' into top-management roles, is assumed to be the responsibility of the individual woman.

Contrary to the current model of the theoretical concept of the 'concrete-ceiling' present in the women in management literature, my study provides a different 
method of access to top-management entry for ethnic minority women, in particular indigenous women. My findings were that Governments in both New Zealand/Aotearoa and the Republic of South Africa/uMzansi Afrika contributed to the rise of indigenous women into top-management roles by providing a 'ladder' for my research subjects through the introduction of legislation and policies favouring indigenous women. These Governments provided a political solution for the national problem of having a limited number of indigenous women in top-management roles present in these countries (see statistics in Chapter Two). These positive policies were based on the history of having a presence of European rulers and were for redressing historical wrongs. Governments in both New Zealand/Aotearoa and the Republic of South Africa/uMzansi Afrika took the approach of taking the responsibility of uplifting indigenous women as a collective, rather than leaving the problem of not having a high number of ethnic minority women in top-management solely to the skills and abilities of the individual woman. Nevertheless, my participants had to have the skills and abilities to access those opportunities provided by Governments as well as be competent to succeed.

I had a research question: what issues do indigenous women face when they move into top-management roles? The answer to this sub-question was that indigenous women were requested to occupy top-management roles. They were head-hunted in the Republic of South Africa/uMzansi Afrika and shouldertapped in New Zealand/Aotearoa. In the Republic of South Africa/uMzansi Afrika context, a study (Mathur-Helm, 2006) supports the idea that women, no matter what their racial background is, get head-hunted into top jobs. A study, drawing research participants from Australia, also found that their participants were encouraged to apply entering top-management roles (Ross-Smith \& Chesterman, 2009). Also drawing from my own experience of being a management consultant and former Human Resources practitioner, I am aware that high-achieving and successful women are requested to occupy positions that they are not seeking. However, this practice, based on my own observations, started around the 1990s, which co-incided with the historic period of positive changes (refer to Chapter Two). In New Zealand/Aotearoa, my participants' initial top-management entry co-incided with the Government changes to 
incorporate Māori and women into organisations through processes such as the Equal Employment Opportunities (EEO) policies and Waitangi Treaty settlements. In the New Zealand/Aotearoa context, recruitment at topmanagement levels relies on an informal network that tends to be male (Fawcett \& Pringle, 2000) which disadvantages women. However, all of my participants from both countries occupied their initial top-management roles because of the Government legislative changes favouring indigenous women. For example, a participant summed up the reason by saying "around the same time (1990s) Government had been challenged on the lack of Māori in middle and higher management". These compensations came into effect largely because of political activism by indigenous people in these countries. For example, a participant commented, "there was a huge protest and that's how the position came out. X identified me as a Māori woman they would like to take the position". Political activism played a role in the current emergence of indigenous women in topmanagement roles.

Being an indigenous woman was attractive for the employers of my participants. Although my participants were actively in demand, their initial entry into topmanagement roles of predominantly white organisations was in risky positions. Their initial roles were risky because the positions were new and visible in almost all instances, which created pressures to succeed under scrutiny. These positions were newly created because of the changes in the political climate in both the Republic of South Africa/uMzansi Afrika and New Zealand/Aotearoa. They included a focus on their communities, or transforming organisations, or relating to the Equal Employment Opportunities (EEO) in New Zealand/Aotearoa and Broad-Based Black Economic Empowerment (BEE) compliance initiatives in the Republic of South Africa/uMzansi Afrika. In their initial roles, my participants tended to be mostly approached to either fill the legislative requirements of BEE in the Republic of South Africa/uMzansi Afrika context or address the needs of the Māori communities in organisations in the New Zealand/Aotearoa context. My participants accepted these roles because they viewed them as opportunities and windows for success into topmanagement roles. 
After being supported by positive policies and legislation, my participants in their initial jobs encountered challenges. In both countries, most of my participants believed that they were recruited into their initial top-management roles as tokens, I argue that these actions were unintended consequences of positive legislation to uplift indigenous women. For example, a participant explained "they called you a General Manager and you had no responsibilities". In my findings, although organisational 'barriers' preventing top-management entry for women were minimised, the participants faced negative attitudes of prejudice from their colleagues. The negative attitudes against my participants were experienced in a similar manner to those studies focusing on ethnic minority women in management. Studies (Catalyst, 1999; Lyness \& Heilman, 2006) suggest that ethnic minority women face prejudicial attitudes in management, disadvantaging them. Research also indicates that the colleagues of ethnic minorities expect them to be less likely to make a significant contribution, argues Turner, Myers and Creswell (1999). Other scholars (James, 1994; Kossek \& Zonia, 1994) indicate that white colleagues expect ethnic minorities to be under-qualified to occupy their roles. My participants were able to overcome these obstacles through their strategic manoeuvring, they were later appointed to positions of influence (see Chapter Five). For example, a participant commented, "I had to manage the largest deal in the organisation". Once, they entered top-management roles, they found opportunities to demonstrate that they were competent. My findings indicate that addressing organisational 'barriers' through legislation is not sufficient to improve the situation for women as my participants also encountered personal prejudice of being ethnic minority women managers.

My contribution to the women in management literature is that successful ethnic minority women in top-management are in demand and actively recruited, particularly in New Zealand/Aotearoa and the Republic of South Africa/uMzansi Afrika. In the women in management literature, I could not find a study that shows that ethnic minority women became in demand and were actively recruited without looking for jobs after having broken through the "concreteceiling'. In different countries, being in demand and actively recruited may also be practices for successful women managers (Ross-Smith \& Chesterman, 2009). 
However, these practices of being in demand and actively recruited for successful women have not yet tallied with the current debates in the women in management literature. When studies in the women in management theorise, they do not incorporate the practice where in certain countries women in management are actively recruited.

\section{Support to succeed in top-management}

My participants used familiar strategies to succeed, which are similar to the ones discussed in the 'concrete-ceiling' literature. However, my participants used these strategies from new perspectives based on their cultural and political backgrounds. In my study, my participants used mentorship differently from what is discussed in the literature, as a main strategy to succeed in topmanagement roles.

My participants as a strategy supported themselves using indigenous principles of collectivity and reciprocity. This meant that they obtained mentorship for themselves in an indigenous structure, such as a group, reflecting the culture of collectivity. For example, a participant commented, "we just mix and mingle because there is not a lot of us at this level, so we just share and talk together. It is a support structure. It is not formal". Reciprocally, they mentored other individuals in their communities. They supported their communities and imparted their skills to other indigenous communities. During the interviews, the perceptions of my participants changed from top managers, leading their organisations to unrepresented individuals in their organisations. They presented themselves as both insiders driving their organisations and outsiders as members of the group that is marginalised in both the societies of New Zealand/Aotearoa and in the Republic of South Africa/uMzansi Afrika. They were able to 'detach' themselves from their organisations as both insiders and outsiders while also participating in them. Collins (1998) uses the term 'outsider-within' to describe dual identity developed through involvement in a new community as well as being excluded from that community through unequal powers. My participants support themselves in their organisations to succeed in 'outsider-ways' as a collective. 
I had a question: What strategies do indigenous women implement to enhance the opportunities to advance into top-management roles? The answer to these 'strategies' that indigenous women implemented was to have mentors as the main 'strategy' in structures that reflected both indigenous and western cultures, values and principles. Having mentors is also an important 'strategy' for women in management roles (Bhatta \& Washington, 2003; Scandura \& Williams, 2001), based on the women in management literature. Within this literature, studies suggest that individual abilities such as hard work, interpersonal / people skills, competency on the job and taking risks are necessary for advancement (Wentling, 1992), in addition to having mentors. In the New Zealand/Aotearoa context, choosing fights (Fawcett \& Pringle, 2000), building relationships (Olsson \& Pringle, 2004), and having people skills (Pringle \& Olsson, 2002) are important for success into top-management roles. There are also those 'strategies' present in the women in management studies that are in collaboration with other individuals. For example, the existence of networks and sponsors as well as having a role model, can support the movement of women into topmanagement roles (Catalyst, 2003; Gibson, 2004). As the main strategy, my participants had mentors when entering top-management roles, which concurs with studies in the women in management literature in that a mentor enhances a career for a woman.

The structure of informal mentoring was similar in both New Zealand/Aotearoa and in the Republic of South Africa/uMzansi Afrika. It was both one-on-one and peer group. Informal one-on-one mentors were across and within race as well as gender. Informal mentors for my participants were people who represented an aspect of themselves, such as a top manager, female, or indigenous person. This strategy addressed their different types of needs: top manager, gender and race. The peer group structure reflected the indigenous cultures and principles of reciprocity and collectivity in both countries. Because of the period when my participants entered top-management roles, the peer group informal mentors might have been encouraged by being the few amongst the many in the topmanagement structure. As a peer group, the participants were able to strategise and implement changes in their industries. The peer group tended to be individuals who had known one another over a long period, about 20 years in 
general. The challenge for a younger indigenous woman, as a possible candidate for top-management, is that it may be difficult to join an existing peer group of informal mentors because there was a lot of trust invested in these groups over the years, and they were closely knit groups.

Unlike the Republic of South Africa/uMzansi Afrika, in New Zealand/Aotearoa, cultural connections were important for my participants. My participants believed that the introductions and connections facilitated relationships and links for them in New Zealand/Aotearoa. Once the genealogical and familial lines were established, it was easier to make connections with other families, possible friends and colleagues. My participants believed that the establishment of genealogical and familial lines made it possible for the participants to converse with one another because the cultural links and connections have been addressed. They also believed that when forming new relations for informal mentoring purposes, establishing genealogical links was important at the beginning of relationships.

This study provides a different model of mentorship. Mentoring studies largely focus on formal mentoring relationships, which contrast with the informal mentoring relationships for my participants. A few existing studies (BlakeBeard, 2001; Chao, et al., 1992) on informal mentorship indicate that informal mentoring relationships are more effective than formal ones. In addition, many mentorship studies (Thanacoody, et al., 2005) discuss one-on-one mentoring relationships. Mentorship studies assume that a mentor is someone older and / more experienced than a protégé (Quinlan, 1999). Group and peer informal mentoring are rarely discussed in mentoring relationships. The few studies, such as Kram and Isabella (1985) and Parker and Kram (1993), that do discuss peermentoring do not include cultural values such as reciprocity, spirituality and collectivity. In my study, these cultural aspects include the indigenous values present in their communities.

There are implications when mentoring indigenous women. The roles of Māori and African cultures were important in mentoring relationships for indigenous women. For indigenous women to succeed, it was important that they supported 
themselves to advance their communities. Success was associated with the success of the community. Future research, investigating ethnic minority women in management, may compare the effectiveness of collective and reciprocal mentoring relationships with those that are individualistic one-on-one relationships.

\section{Lessons for other indigenous women}

In my study, I also found themes confirming the 'concrete-ceiling' literature. My participants faced negative stereotypes that were ethnically specific about ideas of femininity. I elaborate below.

My research confirms similar findings to those in the women in management literature in that the entanglement of race and gender confuse and compound the experiences of ethnic minority women. Other studies also reported that ethnic minority women are subjugated to stereotypes that drew on ethnically specific ideas about femininity (Liff \& Dale, 1994). My participants also believed that they encountered negative perceptions. Race and gender negative stereotypes were experienced in the same manner as the 'concrete-ceiling' studies (Bell \& Nkomo, 2001; Combs, 2003) in that they compounded the experiences of my participants because of belonging to two groups that are economically marginalised in a society. It is difficult to separate gender from race as they are interlinked (Andersen, 2005; Hite, 2005). In my study, for indigenous women as ethnic minority women in management, 'racialised-gender' was experienced in a similar manner as the research conclusions within studies in women in management.

In addition, I had a question: what do indigenous women believe are the lessons for other indigenous women entering top-management roles? The lessons for other indigenous women are to be conscious of their behaviours to manage negative perceptions resulting from belonging to two marginalised groups indigenous and female. The perceptions result from negative stereotypes of being an indigenous woman. To manage these perceptions, my participants used individual strategies. In interpreting my data, I developed the term 'indigenous women's tax' a concept that I coined and defined in Chapter Seven. The 
indigenous women's tax is a type of tax that my participants had to pay in exchange for occupying top-management roles. They pay tax in different ways and simultaneously through different methods. Firstly, they believed that they worked harder than their white male colleagues to be on par with them. Secondly, they 'paid tax' by downplaying their gender in siding with indigenous men. Thirdly, they paid tax by downplaying their race in siding with white women. This is also one of the complexities of attempting to 'unpack race or gender' when they are tangled together. Their experiences produce contradictions within themselves and in responding to their 'racialised-gender'. My participants believed that they encountered negative stereotypes that were associated with a combination of both race and gender concurrently. I explained the term 'racialised-gender' in Chapter Seven. For example, a participant explained "there is a picture of what a Māori woman is. How come you have a brain? They find it confusing".

In this study, my participants believed that top-management was perceived to be associated with both 'male' and 'white'. For them to 'survive' and succeed, they had to assimilate masculine (Ross-Smith \& Huppatz, 2008) and white norms of values and expectations. In the literature, one of the explanations for attitudinal 'barriers' such as negative perceptions preventing women from management entry is the concept that management is associated with male and white characteristics. It is widely acknowledged within this literature that management is associated with male characteristics (Bligh \& Kohles, 2008). Many studies (Lyness \& Heilman, 2006; Schein, 2007) suggest the think-management thinkmale concept. This has a negative impact on women because they are judged because of their gender when occupying management roles (Priola, 2007), which is incongruent with a stereotype of being a manager that tends to be associated with male. Also, some studies (Leonard \& Locke, 1988; Tomkiewicz, et al., 1998) indicate that management is associated with being white. However, there was only one article (Booysen \& Nkomo, 2010) I could find that addressed the interactions of race and gender regarding the perceptions of managerial positions. Most studies address either gender or race in management regarding stereotypes of a manager. The implication for future research is that more studies should 
investigate the interactions of race and gender regarding the attitudes and characteristics of a manager.

\section{Research implications to theory}

In this section, I discuss the implications for my findings in the context of the 'concrete-ceiling' metaphor. I contribute to the 'concrete-ceiling' theoretical understanding found in the women in management literature by providing a different meaning for indigenous women, which changes the understanding of the metaphor in the literature.

My participants were at historical and political moments where their Governments were redressing political wrongs towards ethnic minority women favouring these groups (see Chapter Five). Organisational 'barriers' preventing women entering top-management roles, present in the women in management literature, were minimised by the Governments through policies and legislation. The elimination of organisational 'barriers' entering top-management roles led to my participants to be in demand in top-management roles. Studies in other countries focusing on women in management found that organisational practices may be biased against women and ethnic minority groups (Jackson, 2001; Morrison, et al., 1988). Organisational practices such as recruitment, retention, and promotion may exclude women and ethnic minorities in participating positively in organisations (Oakley, 2000). However, in this study, organisational 'barriers' related to organisational entry were favouring indigenous women in top-management for various strategic reasons.

My findings show a different concept of success from studies focusing on women in management. My participants were willing and prepared to accept the top-management roles - not only personally as individuals, but in terms of how they perceived the advancement of their communities. Success for them was also about a collective commitment to access jobs that make a difference to many and therefore support one other to get into these jobs and survive in them. By contrast, studies in the women in management literature, suggest that (white) women are ambivalent about accepting and occupying top-management positions (Ross-Smith \& Chesterman, 2009). This may be because they see jobs as an 
individual option rather than seeing themselves as someone accountable to her people. For my participants, they believed that accepting top-management roles was a commitment to uplift their communities and promoting widespread social change, even though the roles were associated with risk. In addition, studies focusing on ethnic minority women in management, mainly from the USA (Hite, 2007) and UK (Fearfull \& Kamenou, 2006), also view success of entering into top-management as success for the individual rather than for the ethnic minority community, which is contrary to my findings.

Up the 'ladder', my research subjects encountered some hurdles. Once my participants were in top-management levels of organisations, they encountered attitudinal 'barriers' towards them as ethnic minority women, who are not represented in positions of power, which was similar to the 'concrete-ceiling' effect present in the women in management literature. Indigenous women believed that they had to manage attitudinal 'barriers' stemming from their colleagues that resulted from the composite effect of being indigenous women who belonged to both a race and gender that were low in status in their societies. My participants believed work colleagues' attitudinal 'barriers' impeded women from achieving in top-management roles. However, ethnic minority women achieve success by adopting norms in their organisations that were framed by white males (Cox, 1994). My participants also believed that they had to overperform in order to prove themselves competent. Other studies also suggest that ethnic minority women often have to present and provide evidence of being competent professionals against the existence of stereotypical images of being ethnic minority women, argues Blake-Beard (1999). My participants had to 'fix' themselves by adjusting to the dominant patriarchal (De Fries, et al., 2006; Ely \& Meyerson, 2000; Liff \& Cameron, 1999) and racial modes of their organisations that favoured white males and their norms in top-management. My findings indicate that my participants achieved success without being accepted by their white male colleagues as equals in top-management positions. My study concurs with other similar findings in that the promotion rates of ethnic minority women are negatively related to feeling accepted by white males (Bell \& Nkomo, 1994). 
There are challenges with the redress Governments' policies as solutions to uplift indigenous women to access top-management roles. This is because these policies tend to benefit a few indigenous women in top-management roles, while the majority group is stuck in lower levels of society and occupations, as shown by my study. In the Republic of South Africa/uMzansi Afrika context, a study (Murray, 2000) found that Black empowerment, meaning positive legislation redressing the wrongs against Africans in the workplace, is not effective in top business. The power structures remain white male in top-management even after the implementation of the proactive policies (Murray, 2000). My findings suggest that something else needs to happen to produce the second wave of indigenous women in top-management, or to increase their numbers entering topmanagement roles enough for effective change to happen. My findings also show that having a few indigenous women in top-management does not change the power structures of their organisations. Current solutions provided by Governments are only able to advance a few indigenous women into topmanagement roles, but are not effective in improving the status of the critical mass of indigenous women. Opportunities had opened only for this first wave of indigenous women who were the elite within the group.

Once my participants were in top-management roles executing their duties, they experienced the 'concrete-ceiling', meaning challenges of being ethnic minority women. This was because the roles of my participants as top managers were fused with those of a stereotypical image of indigenous women in their societies. Davidson (1997) attributes this in some degree to stereotyping, where an individual gets located into a particular group and is ascribed characteristics on the basis of the group membership. This is particularly so for indigenous women, because women are accorded lower status than men in society, which is reflected in organisations (Ridgeway, 2001). Some scholars argue that gender in management will remain invisible until it is acknowledged and experienced as a problem for women (Sinclair, 2000), particularly ethnic minority women who also have issues of race to address. The challenges my participants faced in topmanagement roles indicate that legislation to redress past injustices and current inequities was not able to ensure that indigenous women did not experience 'racialised-gender' in top-management. 
My participants had to have skills and abilities to succeed in order to take advantage of the Government solutions (see Chapter Five). They had to have abilities to overcome hurdles on the way up the organisational ladder. These skills and abilities included using 'strategies' that were drawing from their cultural backgrounds. Because my participants had these successful tactics to overcome hurdles on the way to the top, they continued to be in demand by being actively recruited. However, 'climbing up the ladder' is 'taxing' them (see Chapter Seven).

\section{Scope and transferability of the study}

I discuss the research scope and transferability of my findings.

My focus was on top jobs in predominately white organisations and interactions between race and gender. It did not intend to compare the politics and histories of New Zealand/Aotearoa and the Republic of South Africa/uMzansi Afrika as an objective; rather, I intended to study my participants within their local contexts. In addition, I did not intend to study indigeneity as an objective for my study or part of my theorisation for this study. However, I bring up aspects of being indigenous because of my research samples and how these issues impacted on my subjects. The study captures indigenous women's experiences in topmanagement roles according to their own understanding and my interpretation to their understanding in the context of theoretical studies focusing on women in management. My interpretation of the experiences and perceptions of my participants are limited within the boundaries of studies focusing on women in management.

This thesis links history and politics of countries in theorising women in management. The challenge with this approach is that the understanding of the experiences of indigenous women entering top-management roles may be specific to the time period in the country from which the sample is drawn. This is because the history and politics of a country tend to be specific and difficult to generalise. For example, in the case of my participants, both New Zealand/Aotearoa and the Republic of South Africa/uMzansi Afrika have 
similarities regarding the status of indigenous women in top-management. Although the histories and politics of these countries share some similarities, they are not alike. For example, in the Republic of South Africa/uMzansi Afrika, the Apartheid policies were specific to the country and created a legacy of structures that are complex to dismantle in advancing the status of African women entering top-management roles. In addition, the geography of countries may present difficulties in generalisation. New Zealand/Aotearoa is a relatively small country with less than 4.5 million individuals; while the Republic of South Africa/uMzansi Afrika has about 50 million people.

I take the position that New Zealand/Aotearoa and the Republic of South Africa/uMzansi Afrika have special conditions that facilitate access into topmanagement roles for ethnic minority women. In New Zealand/Aotearoa, there was the Treaty of Waitangi that positioned Māori as indigenous people (see Chapter Two). The Treaty gives a base from which Māori can negotiate their economic position in New Zealand/Aotearoa. On the other hand, in the Republic of South Africa/uMzansi Afrika, the mere numerical majority of indigenous people helped to improve their positions to negotiate access to resources. In addition, indigenous people are the majority in the African National Congress (ANC)-led Government having an influence in driving positive policies in the country, which may increase the chances of success for indigenous women. As this is one of the initial studies focusing on indigenous women in countries with a presence of former British rulers, it is difficult to assume that my participants were representative of the majority of women in top-management in these countries. However, my study gives strong evidence that Government interventions can assist in improving the status of indigenous women. Nevertheless, Governments' interventions were not enough to ensure the success of indigenous women once in top-management roles, as per my findings.

I prefer to use the term transferability instead of generalisability for my research. I believe that important aspects of this research are transferable to other studies. What is transferrable from my study is the usage of the historical and political approach to theorise about women in management. The wider issue of historical and political context in empirical research is often present; however, it is rarely 
acknowledged. Indigenous women in top-management only indicated some aspects of unique cultural and policy issues. The implications for women in management studies are that the debates get widen to include the impact of national policies on the experiences of women in management. My study also implies that theories in the women in management literature that are based in specific historical and cultural contexts, tell the stories of ethnic minority women beyond specific western contexts.

\section{Future research}

I recommend questions for future research. Based on my findings, questions become: are there other countries that provide also different scenarios regarding the application of the 'concrete-ceiling' theoretical metaphor? Or are my findings transferable to all indigenous women with former British colonisers, e.g. Canada, where historical wrongs are currently redressed? Are indigenous women in other countries with former British colonisers also in demand for roles that are intended to redress power injustices through governments' policies at this point in history? My conclusions are that every case and country is different, depending on government strategy to address indigeneity and the presence of political activism. Future research may apply the 'concrete-ceiling' metaphor to other indigenous women with different histories from those of New Zealand/Aotearoa and the Republic of South Africa/uMzansi Afrika to add understanding to a diverse group of ethnic minority women. Future research may also investigate other historical points for other different types of women. For example, how do my findings compare with the historical moments of other ethnic minorities, such as African-American women in the context of Affirmative Action in the USA?

Future studies could investigate whether white women in management from the Republic of South Africa/uMzansi Afrika have similar experiences as other white women from different countries. The complexities in the Republic of South Africa/uMzansi Afrika are that white women are the minority, in terms of numbers. However, they are privileged compared to African women because of the legacy of the Apartheid policies. It would also be an interesting study to examine white South African/uMzansi Afrika women's experiences as ethnic 
minority women in management based on their numbers. Also, African women from the Republic of South Africa/uMzansi Afrika could be compared to other African or Black racial groups in different countries. I argue that this could bring diverse discussions, to the concepts, definitions and debates present in the women in management literature.

Future studies in the women in management literature could also examine old topics, such as 'strategies' for success assisting ethnic minority women entering top-management roles with 'new lenses'. For example, new studies could investigate other forms of mentorship that are rarely discussed in the mentorship literature. In addition, new research could investigate the role of national policies regarding the role of women in management.

If I had more resources and time, I would have examined the 'concrete-ceiling' effect at different managerial levels. This means that I could have also interviewed those indigenous women who could not enter top or higher management levels because of 'barriers'. I could also have examined the experiences of those indigenous women who left organisations because they could not progress. The findings would have made an interesting study to understand a broader picture on what caused indigenous women to progress or get stuck at different layers in organisations.

\section{My personal reflection}

Having completed this project, I have some thoughts and lessons that I have learnt, regarding my $\mathrm{PhD}$ journey and being an ethnic minority woman in management. As a personal reflection, I come back to my original practical problem of facing difficulties in advancing to higher levels of management. I ask myself the question: what would I do differently when returning to the corporate sector, after having conducted this research? My primary focus would be on rebuilding networks and relationships that I did not nurture when conducting my $\mathrm{PhD}$ studies. I will have to 'pay my dues' to my friends and social community for being absent. Hopefully, by being in contact with other professionals, indigenous women, friends, family and different groups, opportunities may emerge through these networks. As this study emphasises, these networks are 
helpful for indigenous women entering initial top-management roles through Government policies. Once I obtain the opportunity to join an organisation, I will support myself through my networks with individuals who define a part of me - professional specialisation, professionals, indigenous, women, and a similar vision of promoting social progress and change. I also hope to support another indigenous woman wishing to further her studies. Key to my lesson from this project is that leaving an organisation because of 'barriers' such as negative attitudes towards ethnic minority women is not a reason to resign. This is because personal prejudice towards ethnic minority women in management seems to happen in most organisations. I plan to create my space in the work environment and learn to develop personal 'strategies'.

This research was interesting to me for several reasons. Firstly, I am excited to have researched the first generation of indigenous women who benefitted from the EEO / similar legislation / policies to penetrate top-management roles. This group of indigenous women is the first group in top-management to have been involved in changing the economic, political and social situations of both New Zealand/Aotearoa and the Republic of South Africa/uMzansi Afrika. They were the first group of indigenous women to transcend stereotypes and 'barriers' in top-management roles in predominantly white organisations. I feel that I am also part of the changes in having had the privilege of interviewing them. I am also honoured to share the change process in writing about their experiences, as I believe that I am creating history with them through my $\mathrm{PhD}$ thesis. I believe that my study adds not only to the theoretical knowledge, but also the practical knowledge to improve the status of indigenous women in both these countries.

Secondly, this $\mathrm{PhD}$ has been a different kind of 'race' for me. I have grown at a personal level. Most of all, my $\mathrm{PhD}$ process has taught me to be patient. Throughout the project, I learnt to be patient by looking at my study from different angles with inputs from my supervisors. I learnt to understand and write my study with the eyes of my participants, my potential examiners, and $\mathrm{PhD}$ requirements, while also being true to myself as an individual. This requires patience in producing a document that meets the requirements for all the above individuals. I had to be patient to be 'true to myself' and my participants 
within the research space by reflecting on my project throughout the research process. My break-through moments for my project manifested 'at their own time'. In so doing, I had to 'let go', trust the process, and be patient to receive the 'break-through moments' when I was ready.

Lastly, my thinking changed during this $\mathrm{PhD}$ process. Coming from a strong culture of political resistance and trade unionism in the workplace in the Republic of South Africa/uMzansi Afrika, prior to this project, I had strong views about how change in a society could happen. I challenged everything that was different and outside my frame of knowledge and understanding, as this was a part of my socialisation and upbringing as a Black woman in the Republic of South Africa/uMzansi Afrika. As I was interacting with my participants, conducting interviews with them and analysing my results, my thinking started to change. Through personal reflection, I started questioning my views and allowing room for different ideas. I started to become aware of 'my issues' and the experiences of my participants. Through personal reflection and the $\mathrm{PhD}$ process, I underwent changes, moving from what I thought I knew what indigenous women in management experience to understanding the experiences of my participants as ethnic minorities in top-management. I also understood the maturity, sensibility and justification for their 'strategies' from their angles. Through this project, I was able to learn, comprehend issues from different angles and understand that sometimes solutions are not always obvious.

Minority women have both gender and racial disadvantages in the workplace, which are based on history and politics. They do not have the same access to the scarce resources of their societies because of their membership of female and ethnic minority categories. Challenges faced by ethnic minority women in topmanagement roles rest in changing the broader societal structures rather than just fixing 'policies, systems and processes' in organisations. Systems in western societies are largely categorised by 'white male norms' with their associations with patriarchy and 'white norms', and are based on history and access to economic resources, as suggested by my study. Negative attitudes towards ethnic minority women that are reflected in organisations are a symptom of a broader societal problem of power and economic access. To change these 
attitudes, the work of the collective (government, business, and interest groups) is important, in my view. My proposition is the need for collective efforts rather than placing the solution on the individual woman to 'strategise' when achieving in top-management roles, as presently stated by the women in management literature.

Also, it is still not sufficient to place the responsibility of historical redress solely on governments' EEO related policies without changing the economic and social structures that created inequalities. As per my research findings, in the context of New Zealand/Aotearoa and the Republic of South Africa/uMzansi Afrika, solutions by these countries kept the power structures within the select few (white males) and gave access to top-management roles only to an elite group of ethnic minority women. As I was informing my personal mentor, who is an African National Congress (ANC) freedom fighter, the status of my $\mathrm{PhD}$ Degree, she said to me, "Zanele, remember, our enemies are the economic and social structures that created legacies of oppression for indigenous women. We (Black women) cannot exhaust our energies on women's issues without fighting these structures that created those inequalities". 


\section{REFERENCES}

Acker, J. (1990). Hierarchies, jobs, bodies: A theory of gendered organizations. Gender and Society, 4(2), 138-158.

Acker, J. (1998). The future of 'Gender and Organizations': Connections and boundaries. Gender, Work and Organization, 5(4), 195-206.

Acker, J. (2006). Inequality regimes: Gender, class and race in organizations. Gender and Society, 20(4), 441-464.

Acker, J. (2009). From glass ceiling to inequality regimes. Sociologie du travail, 51(2009), 199-217.

Adler, N. (1983). Cross-cultural management research: The ostrich and the trend. Academy of Management Review, 8(2), 226-232.

Adler, N. (1993). "Competitive frontiers: Women managers in the triad". International Studies of Management and Organization, 23(1), 3-23.

Adler, N., \& Izraeli, D. (1994). Competitive frontiers: Women in a global economy. Cambridge: Blackwell.

Adler, P., \& Adler, P. (1994). Observational techniques. In N. Denzin \& Y. Lincoln (Eds.), Handbook of qualitative research. London: Sage.

Alexander, V., \& Thoits, P. (1985). Token achievement: An examination of proportional representation and performance outcomes. Social Forces, 64(2), 332-340.

Alkebulan, A. (2007). Defending the paradigm. Journal of Black Studies, 37(3), 410-427.

Allen, T., \& Eby, L. (2004). Factors related to mentor reports of mentoring functions provided: Gender and relational characteristics. Sex Roles, 50(1-2), 129-139.

Allen, T., Lentz, E., \& Day, R. (2006). Career success outcomes associated with mentoring others: A comparison of mentors and non-mentors. Journal of Career Development, 32(3), 272-285.

Allen, T., Russell, J., \& Maetzke, S. (1997). Formal peer mentoring: Factors related to proteges satisfaction and willingness to mentor others. Group and Organization Management, 22(4), 488-507. 
Alvesson, M. (1998). Gender relations and identity work: A case study of masculinities and femininities in the advertising industry. Human Relations, 51(8), 969-1005.

Anastas, J. (2004). Quality in qualitative evaluation: Issues and possible answers. Research on Social Work Practice, 14(1), 56-65.

ANC. (2011). African National Congress: South Africa's National Liberation Movement. Retrieved January 17, 2012, 2012, from http://www.anc.org.za/show.php?id=207

Andersen, M. (2005). Thinking about women: A quarter century's views. Gender and Society, 19(4), 437-455.

Andrade, A. (2009). Interpretive research aiming at theory building: Adopting and adapting the case study design. The Qualitative Report, 14(1), 42-60.

Andrews, P. (2001). From gender apartheid to non-sexism: The pursuit of women's rights in South Africa. North Carolina Journal of International Law and Commercial Regulation, 26(3), 694-722.

April, K., Dreyer, S., \& Blass, E. (2007). Gender impediments in the South African executive boardroom. South African Journal of Labour Relations, 31(2), 51-67.

Arber, S. (Ed.). (1993). The research process. London: Sage.

Bachi, C. (2000). The seesaw effect: Down goes affirmative action, up comes managing diversity. Journal of Interdisciplinary Gender Studies, 5(2), 64-83.

Bailey, K. (1994). Methods of Social Research. New York: Free Press.

Baldwin, N. (2000). Early promotion of women and minorities in the United States Air Force. Journal of Political and Military Sociology, 28(1), 109130.

Barnes, H. (2000). Kaupapa Māori: Explaining the ordinary. In W. R. Group: (Ed.), Alcohol and Public Health Unit. Auckland: University of Auckland.

Bartol, K., Martin, D., \& Kromkowski, J. (2003). Leadership and the glass ceiling: Gender and ethnic group influences on leader behaviors at middle and executive managerial levels. Journal of Leadership and Organizational Studies, 9(3), 8-20. 
Baugh, G., \& Sullivan, S. (2005). Mentoring and career development. Career Development Journal, 10(6/7), 425-428.

BBC News. (2012). Timeline: New Zealand. BBC News. Retrieved from http://www.bbc.co.uk/news/world-asia-pacific-15370160

Beal, F. (1969). Double jeopardy: To be black and female. New Generations, 5(38), 40-42.

Bell, E. (1990). The bicultural life experience of career-oriented black women. Journal of Organizational Behavior, 11(6), 459-477.

Bell, E., Denton, T., \& Nkomo, S. (Eds.). (1993). Women of colour in management: Towards and inclusive analysis. Newbury Park: Sage.

Bell, E., \& Nkomo, S. (1994). Barriers to workplace advancement experienced by African-Americans. Cambridge: MIT Press.

Bell, E., \& Nkomo, S. (2001). Our separate ways: Black and white women and the struggle for professional identity. Boston: Harvard University Press.

Berger, P., \& Luckmann, T. (1967). The social construction of reality. Garden City: Anchor.

Berthoin Antal, A., \& Izraeli, D. (1993). A global comparison of women in management: Women managers in their homelands and expatriates. In E. Fagenson (Ed.), Women in management: Trends, issues and challenges in managerial diversity (pp. 52-96). Newbury Park: Sage.

Bess, R. (2010). New Zealand 's Treaty of Waitangi and the doctrine of discovery: Implications for the foreshore and seabed. Marine Policy, 35(1), 85-94.

Bezuidenhout, A., Bischoff, C., Buhlungu, S., \& Lewins, K. (2008). Tracking progress on the implementation and impact of the Employment Equity Act since its inception. Johannesburg: Department of Labour.

Bhatta, G., \& Washington, S. (2003). 'Hands up': Mentoring in the New Zealand public service. Public Personnel Management 32(2), 211-227.

Bhavnani, R., \& Coyle, A. (2000). Black and ethnic minority women managers in the UK: Continuity or change? In M. J. Davidson \& R. Burke (Eds.), Women in Management: Current research issues. London: Sage.

Big Media South Africa. (2008). Gauteng launches BEE strategy. Johannesburg: Brand South Africa. 
Bishop, R. (1996). Collaborative research stories. Whakawhanaungatanga: Dunmore Press.

Bishop, R. (1999). Māori and psychology: Research and practice. In N. Robertson (Ed.), The proceedings of a symposium sponsored by the Māori and Psychology Research Unit. Hamilton: Māori and Psychology Unit.

Blake-Beard, S. (1999). The cost of living as an outsider within: An analysis of the mentoring relationships and career success of black and white women in the corporate sector. Journal of Career Development, 26(1), 21-36.

Blake-Beard, S. (2001). Taking a hard look at formal mentoring programs: A consideration of potential challenges facing women. Journal of Management Development, 20(4), 331-345.

Blake-Beard, S. (2009). Mentoring as a bridge to understanding cultural difference. Adult Learning, Winter, 20(1/2), 14-24.

Blake, S. (1999). At the crossroads of race and gender: Lessons from the mentoring experiences of professional black women. In A. Murrell, F. Crosby \& R. Ely (Eds.), Mentoring dilemmas: Developmental relationships within multicultural organizations (pp. 83-104). Mahwah: Lawrence Erlbaum Publishers.

Bligh, M., \& Kohles, J. (2008). Negotiating gender role expectations: Rhetorical leadership and women in the US Senate. Leadership, 4(4), 381-402.

Booysen, L. (1999). A review of challenges facing black and white women managers in South Africa. South African Business Review, 13(2), 15-26.

Booysen, L. (2001). The duality of South African leadership: Afrocentric or eurocentric. South African Journal of Labour Relations, 23(2), 36-63.

Booysen, L., \& Nkomo, S. (2010). Gender role stereotypes and requisite management characteristics. Gender in Management: An International Journal, 25(4), 285-300.

Bozionelos, N. (2004). Mentoring provided: Relation to mentor's career success, personality, and mentoring received. Journal of Vocational Behavior, 64(1), 24-46.

Brett, J. (1992). All the Right Stuff: A comparison of female and male manager's career progression. Journal of Applied Psychology, 77(3), 251-260.

Brigham, J. (1971). Ethnic stereotypes. Psychological Bulletin, 76(1), 15-38. 
Brown, R. (1965). Social psychology. New York: Free Press.

Browne, I., \& Misra, J. (2003). The intersection of gender and race in the labour market. Annual Review of Sociology, 29(2003), 487-513.

Bryans, P., \& Mavin, S. (2003). Women learning to become managers: Learning to fit in or to play a different game? Managerial Learning, 34(1), 111134.

Bryman, A. (2006). The researcher interview: A reflective perspective. Qualitative Research in Organizations and Management: An International Journal 1(1), 41-55.

Burgess, R. G. (1991). In the Field: An introduction to field research. New York: Routledge.

Burke, J. (2010). Workplace stress and well-being across cultures. CrossCultural Management: An International Journal, 17(1), 5-9.

Burke, R. (1984). Mentors in organizations. Group and Organization Management, 9(3), 353-372.

Burke, R., \& McKeen, C. (1994). Career development among management and professional women. In M. J. Davidson \& R. J. Burke (Eds.), Women in management: Current Research Issues. London: Paul Chapman.

Burns, J. (2001). EEO Trust diversity index 2001, November. Auckland: Equal Employment Opportunities Trust.

Burrell, G., \& Morgan, G. (1979). Sociological paradigms and organizational analysis. London: Heinemann.

Businesswomen's Association of South Africa. (2011). South African women in leadership census 2011. Johannesburg: Business Women Association of South Africa.

Carli, L., \& Eagly, A. (2001). Sex, hierarchy, and leadership: An introduction. Journal of Social Issues, 57(4), 629-636.

Carr, M., \& Human, P. (1989). Race as a limiting factor in organizational life: A South African study. OMEGA International Journal of Science, 17(4), 355-362.

Casale, D., Muller, C., \& Posel, D. (2004). Two million net new jobs? A reconsideration of the rise in employment in South Africa, 1995-2003. South African Journal of Economics, 72(5), 978-1002. 
Cassell, C. (1997). The business case for equal opportunities: Implications for women in management. Women in Management Review, 12(1), 11-16.

Cassell, C., Bishop, V., Symon, G., Johnson, P., \& Buehring, A. (2009). Learning to be a qualitative management researcher. Managerial Learning, 40(5), 513-533.

Catalyst. (1999). Women of colour in corporate management: Opportunities and barriers. New York: Catalyst.

Catalyst. (2000). Women and the MBA: Gateway to opportunity. New York: Catalyst.

Catalyst. (2003). Women in leadership: Comparing European and US women executives. New York: Catalyst.

Catalyst. (2007). The double-bind dilemma for women in leadership: Damned if you do, doomed if you don't. New York: Catalyst.

Cater, C. (1995). Creating equal opportunity. Optima, September, 19-22.

Chandler, D., \& Kram, K. (2005). Applying an adult development perspective to developmental networks. Career Development International, 10(67), 548-566.

Chao, G. (1997). Mentoring phases and outcomes. Journal of Vocational Behavior, 51(1), 15-28.

Chao, G., Watz, P., \& Gardner, P. (1992). Formal and informal mentorships: A comparison on mentoring functions and contrast with non-mentored counterparts. Personnel Psychology, 45(3), 619-636.

Charmaz, K. (1990). Discovering chronic illness: Using ground theory. Social Science and Medicine, 30(11), 1161-1172.

Charmaz, K. (2006). Constructing grounded theory: A practical guide through qualitative analysis. London: Sage.

Chernesky, R. (2003). Examining the glass ceiling. Administration in Social Work, 27(2), 13-18.

Clark, E. (2000). University administrative careers in family and consumer sciences. Journal of Family and Consumer Science, 92(1), 89-94.

Cleveland, J., Stockdale, M., \& Murphy, K. (2000). Women and men in organizations: Sex and gender issue at work. Hillsdale: Laurence Erlbaum Associates. 
Clutterbuck, D. (2004). Everyone needs a Mentor: Fostering talent in your organisation (4th ed.). London: Charted Institute of Personnel Development.

Coates, G. (1998). Integration or separation: Women and the appliance of organisational culture. Women in Management Review, 13(3), 114-124.

Cock, J., \& Bernstein, A. (2001). Gender differences: Struggles around "Needs and Rights" in South Africa. NWSA Journal, 13(3), 138-152.

Cockburn, C. (1989). "Equal opportunities: The short and the long agenda". Industrial Relations Journal, 20(3), 213-225.

Coll, C., Cook-Nobles, R., \& Surrey, J. (1997). Building connection through diversity. In J. V. Jordan (Ed.), Women's growth in diversity: More writings from the Stone Center (pp. 176-198). New York: Guilford Press.

Collins, P. (1986). Learning from the outsider within: The sociological significance of black feminist thought. Social Problems, 33(6), S14-S32.

Collins, P. (1989). The social construction of black feminist thought. Signs: Journal of Women in Culture and Society, 14(4), 745-773.

Collins, P. (1990). Black feminist thought: Knowledge, consciousness, and the politics of empowerment. New York: Routledge.

Collins, P. (1998). Fighting words: Black women and the search for justice. Minneapolis: University of Minnesota Press.

Combs, G. (2003). The duality of race and gender for managerial AfricanAmerican women: Implications of informal social networks on career advancement. Human Resources Development Review, 2(4), 385-405.

Commission for Employment Equity. (2001). Equity statistics. Pretoria: Commission for Employment Equity Republic of South Africa.

Commission on Gender Equality. (1999). Gender and the private sector. Braamfontein: Commission on Gender Equality.

Connell, R. (1987). Gender and power: Society, the person and sexual politics. Sydney: Allen \& Unwin.

Constas, M. (1992). Qualitative analysis as a public event: The documentation of category development procedures. American Educational Research Journal, 29(2), 253-266.

Cotter, D., Hermesen, J., Ovadia, S., \& Vanneman, R. (2001). The glass ceiling effect. Social Forces, 80(2), 655-682. 
Cox, T. (1994). Cultural diversity in organizations: Theory and practice. San Francisco: Berrett-Koehler Publishers.

Cox, T. (2004). Problems with research by organizational scholars on issues of race and ethnicity. Journal of Behavioral Science, 40(1), 124-145.

Cram, F. (2001). Rangahau Māori: tona tika, tona pono: The validity and integrity of Māori research. In M. Tolich (Ed.), Research Ethics in Aotearoa/New Zealand. Auckland: Longman.

Crampton, S., \& Mishra, J. (1999). Women in management. Public Personnel Management, 28(1), 87-106.

Crawford, K., \& Smith, D. (2005). The we and the us: Mentoring AfricanAmerican women. Journal of Black Studies, 36(2/3), 52-63.

Creswell, J. (1998). Qualitative inquiry and research design: Choosing from among five traditions. Thousand Oaks: Sage.

Creswell, J. (2007). Qualitative inquiry and research design: Choosing among five approaches (2 ed.). Thousand Oaks: Sage Publications.

Cross, C. (2006). Barriers to advancing female careers in the high-tech sector: Empirical evidence from Ireland. Women in Management Review, 21(1), 28-39.

Cross, E. (1992). Making the invisible visible. The Healthcare Forum Journal, 35(1), 28-32.

Crotty, M. (1998). The foundations of social research: Meaning and perspective in the research process. London: Sage.

Curtin, J. (2008). Women, political leadership and substantive representation: The case of New Zealand. Parliamentary Affairs, 61(3), 490-504.

Davids, G., \& Watson, G. (1982). Black life in corporate America. Garden City: Anchor Press.

Davidson, M. (1997). The black and ethnic minority woman manager: Cracking the concrete ceiling. London: Paul Chapman.

De Fries, J., Webb, C., \& Eveline, J. (2006). Mentoring for gender equality and organisational change. Employee Relations, 28(6), 573-587.

Denscombe, M. (2002). The good research guide: For small-scale social research projects. Buckingham: Open University Press. 
Denton, M., \& Vloeberghs, D. (2002). Leadership challenges for organisations in the new South Africa. Leadership and Organizational Development Journal, 24(2), 84-95.

Denzin, N., \& Lincoln, Y. (Eds.). (2000). Introduction: The discipline and practice of qualitative research (2 ed.). Thousand Oaks: Sage.

Department of Labour Republic of South Africa. (1998). Employment Equity Act No 55 of 1998 (Vol. 19370). Pretoria: Government Gazette Republic of South Africa.

Dey, I. (1999). Grounding grounded theory: Guidelines for qualitative inquiry. London: Academic Press.

Doherty, L., \& Manfredi, S. (2010). Improving women's representation in senior positions in universities. Employee Relations, 32(2), 138-155.

Dovidio, J. (1993). The subtlety of racism. Training and Development, 47(4), 5157.

Dovidio, J. (2001). On the nature of contemporary prejudice: The third wave. Journal of Social Issues, 57(4), 829-849.

Dreher, G., \& Ash, R. (1990). A comparative study of mentoring among men and women in managerial, professional, and technical positions. Journal of Applied Psychology, 75(5), 539-546.

Dubno, P. (1985). Attitudes towards women executives: A longitudinal approach. Academy of Management Journal, 28(1), 235-239.

Dubois, W. (1961). The soul of black folks: Essays and sketches. New York: Fawcett.

Duehr, E., \& Bono, J. (2006). Men, women, and management: Are stereotypes finally changing. Personnel Psychology, 59(4), 815-846.

Durie, M. (2008). Bioethics in research: The ethics of indigeneity. Auckland: Ninth Global Forum on Bioethics in Research (GFBR9).

Eagly, A., \& Johnson, B. (1990). Gender and leadership style: A meta-analysis. Psychological Bulletin, 108(2), 233-256.

Eagly, A., \& Karau, S. (2002). Role congruity theory of prejudice toward female leaders. Psychological Review, 109(3), 573-598.

Edgar, F. (2001). Equal Employment Opportunity: Outcomes in the New Zealand Public Sector. New Zealand Journal of Industrial Relations, 26(2), 217-226. 
EEO Trust. (2001). Diversity index, 2001. Auckland: Equal Employment Opportunities Trust.

EEO Trust. (2007). Diversity survey report 2007. Auckland: Equal Employment Opportunities Trust.

Ehrich, L. (2008). Mentoring and women managers: Another look at the field. Gender in Management: An International Journal, 23(7), 469-483.

Ely, R., \& Meyerson, D. (2000). Theories of gender in organizations. In B. Staw \& R. Sutton (Eds.), Research in organizational behaviour. New York: JAI.

Enomoto, E. K., Gardiner, M. E., \& Grogan, M. (2000). Notes to Athene: Mentoring relationships for women of colour. Urban Education, 35(December 2000), 566-583.

Ensher, E., Thomas, C., \& Murphy, S. (2001). Comparison of traditional, stepahead, and peer mentoring on proteges' support, satisfaction, and perceptions of career success: A social exchange perspective. Journal of Business and Psychology, 15(3), 419-438.

Enslin, P. (2001). Multicultural education, gender and social justice: Liberal feminist misgivings. International Journal of Educational Research, 35(chapter 3), 281-292.

Erasmus, B. (1998). Women power: Aspects of working life in the late 1990s. Management Today, June, 25-28.

Essed, P. (1991). Understanding everyday racism: An interdisciplinary theory. Newbury Park: Sage.

Essed, P. (2000). Dilemmas in leadership: Colour in the academy. Ethnic and Racial Studies, 23(5), 888-904.

Fagenson, E. (1990). At the heart of women in management research: Theoretical and methodological approaches and their biases. Journal of Business Ethics, 9(4/5), 267-274.

Fairhurst, G., \& Snavely, B. (1983). Majority and token minority group relationships: Power acquisition and communication. Academy of Management Review, 8(000002), 292-300.

Fawcett, R., \& Pringle, J. (2000). Women CEOs in New Zealand: Where are you? Women in Management Review, 15(5/6), 253-260. 
Fearfull, A., \& Kamenou, N. (2006). How do you account for it? A critical exploration of career opportunities for and experiences of ethnic minority women. Critical Perspectives on Accounting, 17(7), 883-901.

Feeney, M. (2006). Mentoring women in the public sector: Expectations and realities. International Journal of Learning and Change, 1(4), 381-406.

Fischer, S. (1995). "Placing women on the affirmative action agenda". People Dynamics, 13(5), 23-25.

Fischer, S. (1996). Affirming equal opportunities for white males. People Dynamics, April, 30-34.

Fitt, L., \& Newton, D. (1981). When the mentor is a man and the protege is a woman. Harvard Business Review, 59(2), 56-60.

Fitzgerald, T. (2003). Changing the deafening silence of indigenous women's voices in educational leadership. Journal of Educational Administration, 41(1), 9-23.

Fitzgerald, T. (2004). Powerful voices and powerful stories: Reflections on the challenges and dynamics of intercultural research. Journal of Intercultural Studies, 25(3), 233-245.

Fitzgerald, T. (2006). Walking between two worlds: Indigenous women and educational leadership. Educational Management Administration \& Leadership, 34(2), 201-213.

Fontana, A., \& Frey, J. (2005). The interview: From neutral stance to political involvement. In N. Denzin \& Y. Lincoln (Eds.), The sage handbook of qualitative research. Thousand Oaks: Sage.

Forbat, L., \& Henderson, J. (2005). Theoretical and practical reflections on sharing transcripts with participants. Qualitative Health Research, 15(8), 1114-1128.

Forson, C. (2006). The strategic framework for women's enterprise: BME women at the margins. Equal Opportunities International, 25(6), 418432.

Fossey, E., Harvey, C., McDermott, F., \& Davidson, L. (2002). Understanding and evaluating qualitative research. Australian and New Zealand Journal of Psychiatry, 36(6), 717-732.

Freire, P. (1970). Pedagogy of the oppressed. New York: Continuum International. 
French, E. (2001). Approaches to equity management and their relationship to women in management. British Journal of Management, 12(4), 267-285.

Gaertner, S., \& McLaughin, J. (1983). Racial stereotypes, associations and ascriptions of positive and negative characteristics. Social Psychology Quartely, 46(1), 23-30.

Gatrell, C., \& Swan, E. (2008). Gender and diversity in management: A concise introduction. London: Sage.

Geisler, G., Mokgope, K., \& Svanemyr, J. (2009). South Africa:The National Gender Machinery, gender mainstreaming and the fight against gender based violence: African Development Bank.

Gibbs, M. (2005). The right to development and indigenous peoples: Lessons from New Zealand. World Development, 33(8), 1365-1378.

Gibson, D. (2004). Role models in career development: New directions for theory and research. Journal of Vocational Behavior, 65(1), 134-156.

Giscombe, K., \& Mattis, M. (2002). Leveling the playing field for women of color in corporate management: Is the business case enough? Journal of Business Ethics, 37(1), 103-119.

Giscombe, K., \& Sims, A. (1998). Breaking the color barrier. HR Focus, 75(7), S9-S10.

Glaser, B. (1978). Theoretical sensitivity. Mill Valley: The Sociology Press.

Goetz, A. (1998). Women in politics and gender equity in policy: South Africa and Uganda. Review of African Political Economy, 25(76), 241-262.

Govender, P., \& Bayat, S. (1993). Leadership styles: The gender issues. Journal of Industrial and Social Relations, 13(314), 139-144.

Government Communications and Information Republic of South Africa. (2008). Economy. In Government Communications and Information System (Ed.), South Africa Yearbook 2007/08. Pretoria: Government Communication and Information System Republic of South Africa.

Green, S., \& Bauer, T. (1995). Supervisory mentoring by advisors: Relationships with doctoral students potential, productivity, and commitment. Personnel Psychology, 48(3), 537-561.

Greenbaum, T. (1998). The handbook for focus group research. Thousand Oaks: Sage. 
Greenhaus, J., \& Parasuraman, S. (1993). Job performance attributions and career advancement prospects: An examination of gender and race effects. Organizational Behavior and Human Decision Processes, 55(2), 273-297.

Guba, E. (1990). The alternative paradigm dialog. In E. G. Guba (Ed.), The paradigm dialog. Newbury Park: Sage.

Guenther, M. (2006). The concept of indigeneity. Social Anthropology, 14(1), $17-32$.

Gutek, B. (1985). Sex and the workplace. San Francisco: Jossey Bass.

Guy, J. (1971). A note on firearms in the Zulu Kingdom with special reference to the Anglo-Zulu war, 1879. The Journal of African History, 12(4), 557570.

Hackett, G., \& Byars, A. (1996). Social cognitive theory and the career development of African-American women. The Career Development Quartely, 44(4), 322-340.

Hart, K., \& Padayachee, V. (2000). Indian business in South Africa after apartheid: Old and new trajectories. Comparative Studies in Society and History, 42(4), 683-712.

Heilman, M. (2001). Description and prescription: How gender stereotypes prevent women's ascent up the organizational ladder. Journal of Social Issues, 57(4), 657-674.

Heilman, M., Block, C., Martell, R., \& Simon, M. (1989). Has anything changed? Current characterizations of men, women, and managers. Journal of Applied Psychology, 74(6), 935-942.

Hendrix, K. (2001). "Mama told me...": Exploring childhood lessons that laid a foundation for my "Endarkened" epistemology. Qualitative Inquiry, 7(5), 559-577.

Henry, E., \& Pene, H. (2001). Kaupapa Māori: Locating indigenous ontology, epistemology and methodology in academy. Organization, 8(2), 234-242.

Henry, E., \& Pringle, J. (1996). Making voices, being heard in Aotearoa/New Zealand. Organization, 3(4), 534-540.

Hewitt, J. (2007). Ethical components of researcher-researched relationships in qualitative interviewing. Qualitative Health Research, 17(8), 1148-1159. 
Hite, L. (1996). Black women managers and administrators: Experiences and implications. Women in Management Review, 11(6), 11-17.

Hite, L. (2004). Black and white women managers: Access to opportunity. Human Resource Development Quarterly, 15(2), 131-146.

Hite, L. (2005). Perceptions of racism and illusions of equity. Women in Management Review, 21(3), 211-223.

Hite, L. (2007). Hispanic women managers and professionals: Reflections on life and work. Gender, Work and Organizations, 14(1), 20-36.

Hofstede, G. (1980). Culture's consequences: International differences in workrelated values. Newbury Park: Sage Publications.

Hofstede, G. (2006). What did GLOBE really measure? Researchers' minds versus respondents' minds. Journal of International Business, 37(7), 882896.

Holmes, J., Burns, L., Marra, M., Stubbe, M., \& Vine, B. (2003). Women managing discourse in the workplace. Women in Management Review, $18(8), 414-424$.

Holvino, E. (2010). Intersections: The simultaneity of race, gender and class in organization studies. Gender, Work and Organizations, 17(3), 248-277.

Hook, G., Waaka, T., \& Raumati, L. (2007). Mentoring Māori within a Pakeha framework. MAI Review 3, Target Article 2.

Hooks, B. (1989). Talking back: Thinking feminism, thinking black. Boston: South End Press.

Horner, M. (1972). Toward an understanding of achievement related conflicts in women. Journal of Social Issues, 28(1), 157-178.

House, R., Hanges, P., Javidan, M., Dorfman, P., \& Gupta, V. (2004). Culture, Leadership and Organizations. Thousand Oaks: Sage.

Human, L. (1996). Managing workforce diversity: A critique and example of South Africa. International Journal of Manpower, 17(4/5), 46-66.

Human, L., \& Allie, F. (1989). Attitudes of white English-speaking male managers to the advancement of women in business. Institute of Personnel Management Journal, 22-24.

Human, P., \& Hofmeyr, K. (1987). Attitudes of South African managers to the advancement of black in business. South African Journal of Labour Relations, 11(3), 5-19. 
Hurley, A., \& Fagenson-Eland, E. (1996). Challenges in cross-gender mentoring relationships: Psychological intimacy, myths, rumours, innuendoes and sexual harassment. Leadership and Organization Development Journal, 17(3), 42-49.

Husserl, E. (1962). Ideas: General introduction to pure phenomenology (W. R. B. Gibson, Trans.). London: Collier Macmillan.

Ibarra, H. (1993). Personal networks of women and minorities in management. Academy of Management Review, 18(1), 56-87.

International Finance Corporation. (2006). Access to financial services for women entrepreneurs in South Africa. Johannesburg: Department of Trade and Industry Republic of South Africa.

Isa, M. (2008). South Africa: Country cannot grow faster than 3.5 percent. Business Day - US Group.

Itzin, R., \& Newman, J. (1995). Gender, culture and organizational change. London: Routledge.

Jack, G., \& Westwood, R. (2009). International and cross-cultural management studies: A postcolonial reading. Palgrave: Macmillan.

Jackson, J. (2001). Women middle managers' perception of the glass ceiling. Women in Management Review, 16(1), 30-47.

Jahnke, H., \& Taiapa, J. (1999). Māori research. In C. Davidson \& M. Tolich (Eds.), Social science research in New Zealand. Auckland: Longman.

James, C. (1994). The paradox of power and privilege. Race, gender and occupational position. Canadian Women's Studies, 14(2), 47-51.

Jewkes, Y., \& Letherby, G. (2001). Insiders and outsiders: Complex issues of identification, difference and distance in social research. Auto/Biography Studies, 16(2), 41-50.

Jogulu, U., \& Wood, G. (2008). A cross-cultural study into peer evaluations of women's leadership effectiveness. Leadership and Organization Development Journal, 29(7), 600-616.

Johnson, J. (2008). Indigeneity's challenges to the white settler-state: Creating a thirdspace for dynamic citizenship. Alternatives, 33(2008), 29-52.

Johnstone, G. (2005). Women's participation in the labour force: New Zealand Treasury working paper 05/06: New Zealand Treasury. 
Jones, G. (2006). Management: The Aotearoa/New Zealand context. Singapore: John Wiley \& Sons.

Jones Jr, E. (1986). Black managers: The dream deferred. Harvard Business Review, 64(3), 84-93.

Jorgens, S. (2005). How do we justify knowledge produced within interpretive approaches? Organization of Research Methods, 8(1), 41-68.

Kalbfleisch, P., \& Davies, A. (1993). An interpersonal model for participation in mentoring relationships. Western Journal of Communication, 57(4), 399415.

Kamenou, N., \& Fearfull, A. (2006). Ethnic minority women. Human Resources Management Journal, 16(2), 154-172.

Kanter, M. (1977a). Men and women of the corporation. New York: Basic Books.

Kanter, M. (1977b). Some effects of proportion on group life: Skewed sex ratios and responses to token women. American Journal of Sociology, 82(5), 965-990.

Karenga, M. (1988). Black studies and the problematic of a paradigm: The philosophical dimension. Journal of Black Studies, 18(4), 395-414.

Kerfoot, D., \& Knights, D. (1998). Managing masculinity in contemporary organizational life: A managerial project. Organization, 5(1), 7-26.

Kershaw, T. (1992). Afrocentrism and Afrocentric methods. Western Journal of Black Studies, 16(3), 497.

King, D. (1989). "Multiple jeopardy, multiple consciousness": The context of a black feminist idealogy. Signs, 14(1), 42-72.

King, T., \& Ferguson, A. (2001). Charting ourselves: Leadership development with black professional women. NWSA Journal, 13(2), 123-139.

Kingdon, G., \& Knight, J. (2007). Unemployment in South Africa 1995-2003: Causes, problems and policies. Journal of African Economics, 16(5), 813848.

Klenke, K. (1996). Women and leadership: A contextual perspective. New York: Springer.

Koberg, C., Boss, R., \& Goodman, E. (1998). Factors and outcomes associated with mentoring among health-care professionals. Journal of Vocational Behavior, 53(1), 58-72. 
Kogler, H., \& Gant, G. (2000). Mentoring by minorities: The organizational communication support program. Review of Business 21(1/2), 53-57.

Korac-Kakabadse, N., \& Kouzmin, A. (1997). Maintaining the rage: From "glass and concrete ceilings" and metaphorical sex changes to psychological audits and renegotiating organizational scripts - Part 2. Women in Management Review, 12(5), 207-230.

Kossek, E., \& Zonia, S. (1994). The effects of race and ethnicity on perceptions of human resource policies and climate regarding diversity. Journal of Business and Technical Communication, 8(3), 319-334.

Kottke, J., \& Agars, M. (2005). Understanding the processes that facilitate and hinder efforts to advance women in organizations. Career Development International, 10(5), 190-261.

Kram, K. (1985). Mentoring at work: Developmental relationships in organizational life. Glenview: Scott Foresman.

Kram, K., \& Isabella, L. (1985). Mentoring alternatives: The role of peer relationships in career development. Academy of Management Journal, 28(1), 110-132.

Kuper, A. (2003). The return of the Native. Current Anthropology, 44(3), 389395.

Leonard, R., \& Locke, D. (1988). Communication stereotypes in the 1980s: How do blacks and whites see themselves and each other? Educational and Psychological Research, 8(2), 73-82.

Liamputtong, P. (2008). Doing research in a cross-cultural context: Methodological and ethical challenges. In P. Liamputtong (Ed.), Doing cross-cultural research. Victoria: Springer Science and Business Media.

Liff, S., \& Cameron, I. (1999). Changing equality cultures to move beyond 'women's problems'. Gender, Work and Organization, 4(1), 35-46.

Liff, S., \& Dale, K. (1994). Formal opportunity, informal barriers: Black women managers within a local authority. Work, Employment and Society, 8(2), 177-198.

Lincoln, Y., \& Guba, E. (1985). Naturalistic inquiry. Beverly Hills: Sage.

Littrell, R., \& Nkomo, S. (2005). Gender and race differences in leader and behaviour preferences in South Africa. Women in Management Review, 20(8), 562-580. 
Lyness, K., \& Heilman, M. (2006). When fit is fundamental: Performance evaluations and promotions of upper-level female and male managers. Journal of Applied Psychology, 91(4), 777-785.

Lyotard, J. (1991). Phenomenology (B. Beakley, Trans.). New York: State University of New York Press.

Macke, A. (1881). Token men and women: A note on the salience of sex and occupation among professionals and semi-professionals. Sociology of Work and occupations, 8(1), 25-38.

Maniero, L. (1994). Getting anointed for advancement: The case of executive women. Academy of Management Executive, 8(2), 53-63.

Marshall, J. (1984). Women managers: Travellers in a male world. Toronto: Wiley.

Marshall, J. (1995). Women managers moving on: Exploring career and life choices. London: Routledge.

Mathur-Helm, B. (2002). Expatriate women managers: At crossroads of success, challenge and career goals. Women in Management Review, 17(1), 18-28.

Mathur-Helm, B. (2005). Equal opportunity and affirmative action for South African woman: A benefit or barrier? Women in Management Review, 20(1), 56-71.

Mathur-Helm, B. (2006). Women and the glass ceiling in South African banks: An illusion or reality? Women in Management Review, 21(4), 311-347.

Mattis, M. (1995). Corporate Initiatives for advancing women. Women in Management Review, 10(7), 5-14.

Maume, D. (1999). Glass ceiling and glass escalators. Work and Occupations 26(4), 483-509.

Maume, D. (2004). Is the glass ceiling a unique form of inequality? Evidence from a random effects model of managerial attainment. Work and Occupations, 31(2), 250-274.

Mazama, A. (2001). The Afrocentric paradigm: Contours and definitions. Journal of Black Studies, 31(4), 387-405.

McCauley, C. (1980). Stereotyping: From prejudice to prediction. Psychological Bulletin, 87(1), 195-208.

McClelland, D. (1965). The achievement motive. New York: Appleton-CenturyCrofts. 
McCourt, W. (1999). Paradigms and their development: The psychometric paradigm of personnel selection as a case study of paradigm diversity and consensus. Organization Studies, 20(6), 1011-1033.

McGlowan-Fellows, B., \& Thomas, C. (2005). Changing Roles: Corporate mentoring of black women. International Journal of Mental Health, 33(4), 3-18.

McGregor, J. (2002). Rhetoric versus reality? A progress on the rise of women's power in New Zealand. New Zealand Centre for women and leadership working paper, 02(1).

McGregor, J. (2010). NZ Human Rights Commission: Human rights and women. Wellington: New Zealand Human Rights Commission.

McGregor, J., Still, L., \& Dewe, P. (1996). The earnings gap and managerial woman in transition. Equal Opportunities International, 15(2), 25-35.

McLeod, J. (1995). Ain't no makin' it: Aspirations and attainment in a lowincome neighborhood (2nd ed.). Boulder: Westview.

Mehmetoglu, M., \& Levent, A. (2006). Examination of grounded theory analysis with an application to hospitality research. Hospitality Management, 25(1), 12-33.

Meintjes, S. (1996). The Women's struggle for equality during South Africa's transition to democracy. Transformation, 30, 47-64.

Meintjes, S. (2005). Women in parliament: Beyond numbers (A revised edition ed.). Stockholm: International IDEA publications.

Metge, J. (1990). Te Rito o Te Harakeke: Conceptions of the whaanau. Journal of the Polynesian Society, 99(1), 55-92.

Middleton, S. (2007). Mentoring and teaching in academic settings: Professional and cultural identities from one Pakeha perspective. AMI Review 3, 1-6.

Mingers, J., \& Brocklesby, J. (1997). Multimethodology: Towards a framework for mixing methodologies. International Journal of Management Science, 25(5), 489-509.

Ministry of Māori Affairs. (1994). Māori women statistics 1994. Wellington: Ministry of Māori Affairs New Zealand.

Ministry of Māori Development. (2007). Māori women in the workforce:

Factsheet 20. Wellington: Ministry of Māori Development New Zealand. 
Ministry of Māori Development. (2008). The Māori asset base. Wellington:

Ministry of Māori Development New Zealand.

Ministry of Women's Affairs. (2008). Timeline: A brief history of women in New

Zealand arranged by date. Wellington: Ministry of Women's Affairs

New Zealand.

Ministry of Women's Affairs. (2009). Quickfacts: Population. Wellington:

Ministry of Women's Affairs New Zealand.

Mintrom, M., \& True, J. (2004). Framework for the future: Equal opportunities employment in New Zealand. Auckland: University of Auckland.

Monserrat, S., Dufffy, J., Olivas-Lujan, M., Miller, J., Gregory, A., Fox, S., et al. (2009). Mentoring experiences of successful women across the Americas. Gender in Management, 24(6), 455-476.

Morrison, A., White, R., \& Van Velsor, E. (1988). Breaking the glass ceiling: Can women reach the top of America's largest corporations? Reading: Addison-Wesley.

Morse, J., \& Field, P. (Eds.). (1995). Considering theory from qualitative research. Thousand Oaks: Sage.

Moss, L. (2005). Biculturalism and cultural diversity. International Journal of Cultural Policy, 11(2), 187-197.

Mukherjee, A., Mukherjee, A., \& Godard, B. (2006). Translating minoritized cultures: Issues of caste, class and gender. Postcolonial Text, 2(3), 1-23.

Muller, H. (1998). American-Indian women managers: Living in two worlds. Journal of Management Inquiry, 7(1), 4-28.

Murray, G. (2000). Black empowerment in South Africa: "Patriotic capitalism" or a corporate black wash? Critical Sociology, 26(3), 183-204.

Muwanga-Zake, J. (2009). Building bridges across knowledge systems: Ubuntu and participative research paradigms in Bantu communities. Discourse: Studies in the Cultural Politics of Education, 30(4), 413-426.

Myakayaka-Manzini, M. (1998). Women empowered - Women in Parliament in South Africa. In International IDEA (Ed.), Women in Parliament: Beyond numbers. Stockholm: International IDEA.

Naidoo, G. (1997). Women must assert themselves in organizatons that disregard them in formal structure. People Dynamics, 15(2), 20-27. 
Nair, M. (2006). Defining indigeneity: Situating transnational knowledge. Zurich: World Society Foundation.

New Zealand Parliament Library. (2008). Immigration chronology: selected events 1840-2008. Retrieved from http://www.parliament.nz/enNZ/AboutParl/HstBldgs/History/QkHistory/9/e/e/9ee7f032ce27459f815f a87660a8f98d.htm.

Nicolson, P. (1996). Gender, power, and organizations. London: Routledge.

Noe, R. (1988). Women and mentoring: A review and research agenda. Academy of Management Review, 13(1), 65-79.

Noy, C. (2008). Sampling knowledge: The hermeneutics of snowball sampling in qualitative research. International Journal of Social Methodology, 11(4), 327-344.

Nunkoosing, K. (2005). The problems with interviews. Qualitative Health Research, 15(5), 698-706.

O'Leary, Z. (2004). The essential guide to doing research. London: Sage.

Oakley, J. (2000). Gender-based barriers to senior management positions: Understanding the scarcity of female CEOs. Journal of Business Ethics, 27(2), 321-335.

Office on the Status of Women. (2006). South African's Report to the AU Secretariat on the Implementation of the AU Heads of States' Solemn Declaration on Gender Equality in Africa. Pretoria: The Presidency Republic of South Africa.

Okurame, D. (2008). Mentoring and preferences: A diagnostic survey for equal mentoring opportunity. Equal Opportunities International, 27(6), 519536.

Olian, J. D., Carroll, S. J., \& Giannantonio, C. M. (1993). Mentor reactions to protege: An experiment with managers. Journal of Vocational Behavior, 43(3), 266-278.

Oliver, D., Serovich, J., \& Mason, T. (2005). Constraints and opportunities with interview transcription: Towards reflection in qualitative research. Social Forces, 84(2), 1273-1289.

Olsson, S., \& Pringle, J. (2004). Women executives: Public and private sectors as sites of advancement? Women in Management Review, 19(1/2), 29-39. 
Olsson, S., \& Walker, R. (2003). Through a gendered lens? Male and female executives' representations of one another. Leadership and Organizational Development Journal, 24(7), 387-396.

Olsson, S., \& Walker, R. (2004). "The wo-men and the boys": Patterns of identification and differentiation in senior women executives' representation of career identity. Women in Management Review, 19(5/6), 244-252.

Padgett, D. (1998). Qualitative methods in social work research: Challenges and rewards. Thousand Oaks: Sage.

Parker, M., \& McHugh, G. (1991). Five texts in search of an author: A response of John Hassard's multiple paradigms and organizational analysis. Organization Studies, 12(3), 451-457.

Parker, V., \& Kram, K. (1993). Women mentoring women: Creating conditions for connection. Business Horizon, March/April, 42-51.

Pfeffer, J. (1993). Barriers to the advance of organizational science, paradigm development as a dependent variable. Academy of Management Review, 18(4), 599-620.

Phillips, D., \& Burbules, N. (2000). Postpositivism and educational psychology. Oxford: Rowman \& Littlefield Publishers.

Piper, H., \& Piper, J. (2000). Disaffected young people as the problem: Mentoring as the solution. Education and work as a goal. Journal of Education and Work, 13(1), 77-94.

Polkinghorne, D. (2005). Language and meaning: Data collection in qualitative research. Journal of Counselling Psychology, 52(2), 137-145.

Pomper, D. (2011). Fifty years later: Mid-career women of colour against the glass ceiling in communications organizations. Journal of Organizational Change Management, 24(4), 464-486.

Powell, G. (1988). Women and men in organisations. Newbury Park: Sage Publications.

Powell, G. (1993). Women and men in management (2nd ed.). Newbury Park: Sage.

Powell, G., \& Butterfield, D. (2002). Exploring the influence of decision makers' race and gender on actual promotions to top management. Personnel Psychology, 55(2), 397-428. 
Powell, G., Butterfield, D., \& Parent, J. (2002). Gender and managerial stereotypes: Have the times changed? Journal of Management, 28(2), 177-193.

Prasad, A. (2001). Understanding workplace empowerment as inclusion: A historical investigation of the discourse of difference in the United States. Journal of Behavioral Science, 37(1), 51-69.

Prasad, A., \& Prasad, P. (2002). The coming of age of interpretive organizational research. Organizational Research Methods, 5(4), 4-11.

Prasad, P. (2005). Crafting qualitative research: Working in the postpositivist traditions. New York: M.E. Sharpe Inc.

Prichard, C., Jones, D., \& Stablein, R. (2004). Doing research in organizational discourse: The Importance of researcher context. In D. Grant, C. Hardy, C. Oswick \& L. Putnam (Eds.), The sage handbook of organizational discourse. London: Sage.

Pringle, J. (2008). Gender in management: Theorizing gender as heterogender. British Journal of Management, 19(Mar2008 Supplement 1), S110-S119.

Pringle, J., \& Olsson, S. (2002). Sites of hope and success? A cross-perceptual study of executive women in the New Zealand public and private sectors. NZ Centre for Women and Leadership Working Paper, 02(3).

Priola, V. (2007). "Being female doing gender. Narratives of women in education management". Gender and Education, 19(1), 21-40.

Prior, D. (2006). Decolonising research: A shift toward reconciliation. Nursing Inquiry, 14(2), 162-168.

Probert, B. (2005). 'I just couldn't fit it in': Gender and unequal outcomes in academic careers. Gender, Work and Organizations, 12(1), 50-72.

Quinlan, K. (1999). Enhancing mentoring and networking of junior academic women: What, why and how? Journal of Higher Education Policy and Management, 21(1), 31-42.

Ragins, B., \& Cotton, J. (1991). Easier said than done: Gender differences in perceived barriers to gaining a mentor. Academy of Management Journal, 34(4), 939-952.

Ragins, B., \& Cotton, J. (1993). Gender and willingness to mentor in organizations. Journal of Managment, 19(1), 97-111. 
Ragins, B., \& Cotton, J. (1999). Mentor functions and outcomes: A comparison of men and women in formal and informal mentoring relationships. Journal of Applied Psychology, 84(4), 529-550.

Ragins, B., \& Mattis, M. (1998). Gender gap in the executive suite: CEO and female executives report on breaking the glass ceiling. Academy of Management Executive, 12(1), 28-42.

Ralston, C. (1993). Māori women and the politics of tradition: What roles and power did, do, and should Māori women exercise? The Contemporary Pacific, 5(1), 23-44.

Ratima, M., \& Grant, B. (2007). Thinking about difference across and within mentoring. MAI Review, 3, 1-5.

Reich, M. (1985). Executive views from both sides of mentoring. Personnel, 62(3), 42-46.

Reich, M. (1986). The mentor connection. Personnel, 63(2), 50-56.

Republic of South Africa. (2004). Broad-Based Black Economic Empowerment Act, 2003 (Vol. 25899). Pretoria: Republic of South Africa Government Gazette.

Reskin, B., \& Charles, C. (Eds.). (1999). Now you see 'em, now you don't: Race, ethnicity and gender in labour market research. New York: Russell Sage Foundation.

Reskin, B., \& Hartmann, H. (1986). Women's work, men's work: Sex segregation on the job. Washington, DC: National Academy Press.

Reviere, R. (2001). Towards an Afrocentric research methodology. Journal of Black Studies, 31(6), 709-728.

Richards, H., \& Schwartz, L. (2002). Ethics of qualitative research: Are there special issues for health services research? Family Practice, 19(2), 135139.

Richards, L., \& Morse, J. (2007). Reademe first for a user's guide to qualitative methods (2 ed.). Thousand Oaks: Sage.

Ridgeway, C. (2001). Sex, status, and leadership. Journal of Social Issues, 57(4), 637-655.

Riger, P., \& Galligan, S. (1980). Women in management: An exploration of competing paradigms. American Psychologist, 35(10), 902-910. 
Rindfleish, J. (2000). Senior management women in Australia. Women in Management Review, 15(4), 172-185.

Roach, D., \& Egan, A. (2008). The equivocal definition of indigeneity and ambivalent government policy toward self-determination in New Zealand's health and foreign policy apparatus. Junctures: The Journal of Thematic Dialogue, 11(2, December 2008), 25-41.

Robson, C. (1995). Real world research: A resource for social scientist and practitioner - researchers. Wiley: Blackwell.

Ross-Smith, A., \& Chesterman, C. (2009). 'Girl disease': Women managers' reticence and ambivalence towards organizational advancement. Journal of Management and Organization, 15(5), 582-595.

Ross-Smith, A., \& Huppatz, K. (2008). Management, women and gender capital (Vol. 2008/4). Sydney: University of Technology.

Rossman, G., \& Rallis, S. (2003). Learning in the field: An Introduction of qualitatie research. Thousand Oaks: Sage.

Royal, T. (2002). Indigenous worldviews: A comparative study. Wellington: Winston Churchill Memorial Trust.

Rubin, H. J., \& Rubin, I. S. (1995). Qualitative interviewing: The art of hearing data. Thousand Oaks: Sage.

Ruwhiu, D., \& Wolfgramm, R. (2005). Revealing the key research in indigenous organizations. Berlin: Paper presented at the 21st EGOS Colloquium.

Ryan, M., \& Haslam, A. (2005). The Glass Cliff: Evidence that women are overrepresented in precarious leadership positions. British Journal of Management, 16(2), 81-90.

Saldana, J. (2009). The coding manual for qualitative researchers. Los Angeles: Sage.

Sandberg, J. (2005). How do we justify knowledge produced within interpretive approaches? Organizational Research Methods, 8(1), 41-68.

Scandura, T. (1992). Mentorship and career mobility: An empirical investigation. Journal of Organizational Behavior, 13(2), 169-174.

Scandura, T., \& Williams, E. (2001). An investigation of the moderating effects of gender on the relationships between mentorship initiation and protege perceptions of mentoring functions. Journal of Vocational Behavior, 59(3), 342-363. 
Schein, V. (2007). Women in management: Reflections and projections. Women in Management Review, 22(1), 6-18.

Schein, V., \& Davidson, M. (1993). "Think manager, think male". Management Development Review, 6(3), 24-28.

Schein, V., Mueller, R., \& Jacobson, C. (1989). The relationship between sex role stereotypes and requisite management characteristics among college students. Sex Roles, 20(1-2), 103-110.

Schein, V., Mueller, R., Lituchy, T., \& Liu, J. (1996). Think manager- Think male: A global phenomenon. Journal of Organizational Behaviour, 17(1), 33-41.

Scheurich, J., \& Young, M. (1997). Coloring epistemologies: Are our research epistemologies racially biased? Educational Researcher, 26(4), 4-16.

Schutte, G. (2000). Being African in South Africa: The dynamics of exclusion and inclusion. Social Identities, 7(2), 130-148.

Schwandt, T. (1994). Constructivist, interpretivist approaches to human inquiry. . In N. K. Denzin \& Y. S. Lincoln (Eds.), Handbook of qualitative research (Vol. 8, pp. 105-123). Thousand Oaks: Sage.

Schwiebert, V., Bradshaw, M., Deck, M., Bradshaw, P., Scott, P., \& Harper, M. (1999). Women as mentors. Journal of Humanistic Education and Development, 37(4), 241-250.

Seale, C. (1999). Quality in qualitative research. Qualitative Inquiry, 5(December), 465-478.

Seidman, G. (1999). Gendered citizenship: South Africa's democratic transition and the construction of a gendered state. Gender and Society, 13(3), 287307.

Seuffert, N. (2002). Race-ing and engendering the nation-state in Aotearoa/New Zealand. Journal of Gender, Social Policy and the Law, 10(3), 597-618.

Silverman, D. (2000). Doing qualitative research: A practical handbook. London: Sage.

Simpson, R. (2000). Gender mix and organizational fit: How gender imbalance at different levels of the organizations impacts on women managers. Women in Management Review, 15(1), 5-19.

Sinclair, A. (2000). Teaching managers about masculinities: Are you kidding? Managerial Learning, 31(1), 83-101. 
Singh, K. (2003). Women managers: Perception vs performance analysis. Journal of Management Research, 3(1), 31-42.

Smith, L. (1999). Decolonising methodologies: Research and indigenous peoples. London: Zed Books.

Smith, L. (2000). Kaupapa Māori research. In M. Battiste (Ed.), Reclaiming indigenous voice and vision. Vancouver: University of British Columbia Press.

Smith, L. (Ed.). (2005). The sage handbook of qualitative research (3 ed.). Thousand Oaks: Sage.

Sosik, J., \& Godshalk, V. (2000). The role of gender in mentoring: Implications for diversified and homogenenous mentoring relationships. Journal of Vocal Behavior, 57(1), 102-122.

South African History Online. (2012). AZAPO. Retrieved January 17, 2012, 2012, from http://www.sahistory.org.za/topic/azanian-peoplesorganization-azapo

Spangler, E., Gordon, M., \& Pipkin, R. (1978). Token women: An empirical test of Kanter's hypothesis. American Journal of Sociology, 84(1), 160-170.

Stanley, C. (2009). Giving voice from the perspectives of African-American women leaders. Advances in Developing Human Resources, XX(X), 551561.

State Services Commission. (2003). EEO progress in the public service: Report with special focus on Māori. Wellington: State Services Commission New Zealand.

Statistics New Zealand. (2006). New Zealand Official Yearbook 2006. Auckland: Statistics New Zealand.

Statistics New Zealand. (2007). QuickStats About Māori. Wellington: Statistics New Zealand.

Statistics New Zealand. (2011a). Household labour force survey: March 2011 quarter. Wellington: Statistics New Zealand.

Statistics New Zealand. (2011b). Household labour force survey: September 2011 quarter - tables. Wellington: Statistics New Zealand.

Statistics South Africa. (2011). Mid-year population estimates. Pretoria: Statistics South Africa. 
Statistics South Africa. (June 2011). Quarterly labour force survey. Pretoria: Statistics South Africa.

Steele, C., \& Brown, J. (1999). When white men can't do math: Necessary and sufficient factors in stereotype threat. Journal of Experimental Social Psychology, 35(1), 29-46.

Still, L. (1993). Where to from here? The managerial woman in transition. Sydney: Business and Professional Publishing.

Stokes, E. (1992). The Treaty of Waitangi and the Waitangi Tribunal: Māori claims in New Zealand. Applied Geography 12(2), 176-191.

Stonewater, B., Eveslage, S., \& Dingerson, M. (1990). Gender differences in career helping relationships. The Career Development Quartely, 39(2), $72-85$.

Strachan, G., Burgess, J., \& Sullivan, A. (2004). Affirmative action or managing diversity: What is the future of equal opportunity policies in organisations? Women in Management Review, 19(4), 196-204.

Strauss, A., \& Corbin, J. (1990). Basics of qualitative research: Grounded theory procedures and techniques. Newbury Park: Sage Publications.

Stubben, J. (2001). Working with and conducting research among AmericanIndian families. American Behavioural Scientist, 44(9), 1466-1480.

Sudman, S., \& Kalton, G. (1986). New developments in the sampling of special populations. Annual Review of Sociology, 12(1986), 401-429.

Sunter, C. (1997). Scenario thinking: Anticipating future opportunities and dangers. Management Today, 13(5), June.

Taylor, M. (2002). The quest for identity: From minority groups to generation xers. Westport: Praeger Publishers.

Terpstra, D., \& Larsen, J. (1980). A note on job type and applicant race as determinants of hiring decisions. Journal of Occupational Psychology, 53(2), 117-119.

Thanacoody, P., Bartram, T., Barker, M., \& Jacobs, K. (2005). Career progression among female academics. Women in Management Review, 21(7), 536-553.

Tharanou, P. (2005). Does mentor support increase women's career advancement more than men's? The differential effects of career and psychosocial support. The Australian Journal of Management, 30(1), 77-109. 
Thomas, D. (1990). The impact of race on manager's experience of developmental relationships (mentoring and sponsorships): An intraorganizational study. Journal of Organizational Behavior, 11(6), 479492.

Thomas, D. (2001). The truth about mentoring minorities: Race matters. Harvard Business Review, 79(4), 98-112.

Thomas, D., \& Alderfer, C. (1989). The influence of race on career dynamics: Theory and research on minority career experiences. In D. Hall \& B. Lawrence (Eds.), Handbook of career theory. Cambridge: Cambridge University Press.

Thomas, D., \& Gabarro, J. (1999). Breaking through: The making of minority executives in corporate America. Boston: Harvard Business School Press.

Thomas, D., \& Higgins, M. (1996). Mentoring and the boundaryless career: Lessons from the minority experience. In M. Arthur \& D. Rousseau (Eds.), Boundaryless Careers: A new employment principle for a new organisational era. New York: Oxford University Press.

Tolich, M. (2001). Research ethics in Aotearoa/New Zealand: Concepts, practice, critique. Auckland: Longman.

Tolich, M. (2002). Pakeha "paralysis". Cultural safety for those researching the general population of Aotearoa. Social Policy Journal of New Zealand(19), 164-178.

Tolich, M., \& Davidson, C. (1999). Starting fieldwork: An introduction to qualitative research in New Zealand. Auckland: Oxford University Press.

Tomkiewicz, J., Brenner, O., \& Adeyemi-Bello, T. (1998). The impact of perceptions and stereotypes on the managerial mobility of AfricanAmericans. Journal of Social Psychology, 138(1), 88-92.

Touise, T. (2005). A critical examination of formal and informal mentoring among nurses. The Healthcare Manager, 24(1), 68-76.

Tremaine, M. (Ed.). (1991). Equal employment opportunity and the state sector reform. Auckland: Oxford University Press.

Turban, D., \& Dougherty, T. (1994). Role of protege personality in receipt of mentoring and career success. Academy of Management Journal, 37(3), 688-702. 
Turner, C. (1997). Psychosocial barriers to black women's career development. In J. V. Jordan (Ed.), Women growth in diversity: More writings from the Stone Center. New York: Gilford Press.

Turner, C., Myers, S., \& Creswell, J. (1999). Exploring underrepresentation: The case of faculty of color in Midwest. The Journal in Higher Education, 70(1), 27-59.

Turner, C., \& Shuter, R. (2004). African-American and European-American women's visions of workplace conflict: A metaphorical analysis. Journal of Communications, 15(3), 169-184.

UN. (2004). The concept of indigenous peoples. New York: Department of Eocomic and Social Affairs: Division for Social Policy and Development Secretariat of the Permanent Forum on Indigenous Issues.

Underhill, C. (2006). The effectiveness of mentoring programs in corporate settings: A meta-analytical review of literature. Journal of Vocational Behavior, 68(2), 292-307.

Wacjman, J. (1998). Managing Like a Man. Oxford: Blackwell.

Walker, R. (1984). The genesis of Māori activism. The Journal of the Polynesian Society, 93(3), 267-281.

Walker, R. (1987). Nga Tau Tohetohe: Years of anger. Auckland: Penguin Books.

Warby, V. (2008). South Africa: Public Service to meet $50 \%$ women representivity by 2009. Tshwane: BuaNews.

Warner, K. (1986). Smoking and health implications of a change in the federal cigarette excise tax. JAMA, 255(8), 1028-1032.

Wells, L. (1998). Consulting to black-white relations in predominantly white organizations. The Journal of Applied Behavioral Science, 34(4), $392-$ 396.

Wentling, R. (1992). Women in middle management: Their career development and aspirations. Business Horizons, January/February 1992, 47-54.

Weyer, B. (2007). Twenty years later: Explaining the persistence of the glass ceiling for women leaders. Women in Management Review, 22(6), 482496.

Wharton, A. (2005). The sociology of gender: An introduction to theory and research. Malden: Blackwell. 
White, B. (1995). The career development of successful women. Women in Management Review, 10(3), 4-15.

Whiteford, A. (2008). Tax cuts welcome but hardly cause for wild celebration. The Dominion Post, p. C2.

Willemsen, T. (2002). Gender typing of the successful manager- a stereotype reconsidered. Sex Roles, 46(11/12), 385-391.

Wilson, D. (2008). Should non-Māori research and write about Māori? There is a role for non-Māori nurse researchers, as long as they respect and observe Māori processes, and work collaboratively with the appropriate people. Nursing New Zealand, 14(5), 14-15.

Wing, A., \& Carvalho, E. (1995). Black South African women: Toward equal rights. Harvard Human Rights Journal, 8, 57-100.

Wirth, L. (2001). Breaking the glass ceiling: Women in management. Geneva: International Labour Office.

Wood, G. (2008). Gender stereotypical attitudes. Past, present and future influences on women's career advancement. Equal Opportunities International, 27(7), 613-628.

Wood, W., \& Eagly, A. (2002). A cross-cultural analysis of the behavior of women and men: Implications for the origins of sex differences. Psychological Bulletin, 128(5), 699-727.

Yoder, J. (1994). Looking beyond numbers: The effects of gender status, job prestige, and occupational gender-typing on token processes. Social Psychology Quartely, 57(2), 150-159. 


\section{APPENDICES}

Appendix A: $\quad$ History and labour law chronologies ii

Appendix B: Interview questions xiv

Appendix C: $\quad$ Research information sheets $\quad$ xviii

Appendix D: $\quad$ Research agreement $\quad$ xxiv

Appendix E: $\quad$ Confidentiality agreement (typist) xxvi 
Appendix A:

History and labour law chronologies of New Zealand/Aotearoa and the Republic of South Africa/uMzansi Afrika 


\section{Historical Chronology}

I compare and contrast the historical chronology of both New Zealand/Aotearoa and the Republic of South Africa/uMzansi Afrika. I outline key events in the historical and employment areas that impact on Māori and African women in top-management roles. The histories of these countries influence Government solutions for indigenous women to enhance their opportunities in the workplace. In my study, history and politics are important in theorising about ethnic minority women in top-management.

\section{New Zealand/Aotearoa}

The following is the historical chronology to understand historical background of New Zealand/Aotearoa impacting on my study. I stop the historical chronology in 1998 because it marks the beginning of the Crown to recognise the breaches of the Treaty by ordering the return of the land to Māori through the Waitangi Tribunal. This year recognises the first reconciliation process for Māori.

1300 AD Māori people as descendants of the Polynesian people arrived in New Zealand/Aotearoa and their exact date of arrival is contested in documents (New Zealand Parliament Library, 2008).

1642 Dutch explorer Abel Tasman visits New Zealand/Aotearoa for the first time.

1769 James Cook, British explorer, visits New Zealand/Aotearoa for the first time.

1806 The first Pākehā (white) woman arrives in New Zealand/Aotearoa.

1815 The first British missionaries arrive in New Zealand/Aotearoa (BBC News, 2012).

1815 Thomas Holloway King becomes the first Pākehā (white) child to be born in New Zealand/Aotearoa

1839 The first New Zealand/Aotearoa company settlers arrive in Port Nicholson.

1840 The first wave of English settlers arrived in New Zealand/Aotearoa. 
1840 The British settlers and Māori tribe chiefs at Bay of Islands, New Zealand/Aotearoa, signed the Treaty of Waitangi on 06 February 1840.

1852 The Constitution Act gave the vote to men who individually owned land, women and Māori were excluded.

18674 Māori seats were established in Parliament.

1877 The Education Act provided for a national system of free, secular, compulsory education for boys and girls (7-13) years old.

1893 The Electoral Act allowed both white and Māori women the right to vote in the general elections (first self-governing country in the world to give this right to women).

1947 New Zealand/Aotearoa gains full independence from Britain (BBC News, 2012).

1948 The British Nationality and New Zealand/Aotearoa Act of 1948 gave New Zealand citizenship to all current New Zealand residents who had been either born or naturalised as British subjects (New Zealand Parliament Library, 2008).

1919 Women became eligible for election to parliament.

1949 New Zealanders became 'British Subjects and New Zealand Citizens'.

1975 The Waitangi Tribunal was established.

1985 The Waitangi Tribunal was given power to hear grievances arising since 1840 (signing of the Treaty of Waitangi).

1986 The Constitution Act ends the right of the British Parliament to pass laws for New Zealand/Aotearoa.

1998 The Waitangi Tribunal orders the Crown to return land to its Māori owners. This is the first decision by the Waitangi Tribunal to return the land to Māori owners. After this date, more land was return to Māori.

Key to these historical events is that Māori had already occupied the land in New Zealand/Aotearoa, prior to the British colonisers. Both Māori and women were sidelined in the economy (e.g. the Constitution Act did not grant women and 
Māori the right to vote in 1852). Māori and the British Crown signed the Treaty of Waitangi, which is the founding document of New Zealand/Aotearoa.

\section{The Republic of South Africa/uMzansi Afrika}

History in the Republic of South Africa/uMzansi Afrika for indigenous people has been marked by a series of wars and policies that disadvantaged them as indigenous people. Colonisation in the Republic of South Africa/uMzansi Afrika was largely forceful and contributed to many deaths through wars. The discovery of gold contributed to the wars and further marginalisation of indigenous people. Indigenous people were sidelined from the economy through a series of legislation that I lightly touch on in this section. I end the historical chronology in 1994 because the year marks the official end of oppressive policies for Africans and starts the beginning of reconciliatory processes to compensate indigenous people.

The following is the historical chronology of the Republic of South Africa/uMzansi Afrika influencing my study.

400AD The Bantu (current Africans) migrated into South Africa.

1480 Bartholomeu Dias, Portuguese navigator, travels to the southern tip of Africa. He was the first European to travel into this part of South Africa.

1652 Jan van Riebeeck, Dutch merchant, representing the Dutch East India Company, arrived at the Cape Colony (current Cape Town city) and the Dutch settlement of South Africa began.

1795 The British forces seized the Cape Colony from the Dutch. The territory was returned to the Dutch in 1803 , and was later ceded to the British in 1806. All these changes occurred through a series of wars.

1807 British missionaries arrived in Southern Africa.

1819 The British defeated the Xhosa (African tribe) and the Xhosas were evicted from the land they occupied.

1820 There was en masse arrival of the British nationals to settle and start colonising some parts of South Africa (Eastern Cape). 
1852 Britain recognised Transvaal province as the independent State for the Afrikaans speaking people (Dutch descendants) at the Bloemfontein Convention.

1854 Britain recognised Orange Free State as the state for Afrikaans speaking people in the Bloemfontein Convention.

1867 Diamonds were discovered in Kimberly city and Orange Free State province.

1877 The British annexed the Transvaal (Greater Johannesburg).

1879 After the wars between the British and the Zulus (indigenous group), at the Battle of Ulundi, the Zulus were defeated by the British and they disintegrated the Zulu Kingdom into different kingdoms.

1880s Gold was discovered in the Transvaal and this triggered the South African gold rush, which encouraged wars and disputes over these resources.

1905 -1906 This period marks the last Zulu uprising against the British.

1910 South Africa became a semi-autonomous state under the British colonial rule.

1912 African National Congress (ANC) (then it was called the South African Native National Congress) was established to defend the rights of African people from the colonisation processes. It was formed to prevent the Land Act from being passed into law to limit land ownership to indigenous people.

1913 The Land Act was introduced to prevent Africans from purchasing and owning land.

1944 The ANC Youth league was formed largely by students from the University of Fort-Hare (University for Blacks only). The organisation encouraged cultural autonomy and included leaders such as Robert Sobukwe, Nelson Mandela, Walter Sisulu and Oliver Thambo.

1948 The Apartheid policy was adopted to separate whites and Africans.

1953 The Bantu Education Act was introduced to limit the education of Africans. This act stipulated that different racial groups such as 
Africans and whites were required by law to attend separate universities. The Universities for Bantu (Africans) were preparing them for menial jobs in the society.

1956 The Industrial Conciliation Act was passed which reserved the most skilled jobs for whites.

1961 South Africa was declared a Republic and left the Commonwealth.

1961 ANC launches a military wing Umkhonto we Sizwe (Spear of the Nation) to retaliate apartheid with non-statutory forces.

1963 The government banned the African National Congress (ANC) organisation and its military wing.

1964 The outcome of the banning of the ANC and its military wing was that their leaders were sentenced into what was called the 'Revonia Trial'. Ten leaders of the current ANC (including Nelson Mandela, and Govan Mbeki - father of former South African president Thabo Mbeki) were tried for 221 acts of sabotage designed to overthrow the apartheid system by spreading Communism and were sentenced to life imprisonment. Most of them found guilty on all counts. Denis Goldberg was the first defendant to be released from jail in 1985. By the beginning of 1990 only Nelson Mandela was in prison.

1970 The Citizenship Bill was passed and authorised withdrawal of South African citizenship from Africans.

1970s There were civil unrests across the country against the apartheid policies.

1970s The Group Areas Act allocated residential areas for different racial groups.

1976 There was the Soweto (African township in Johannesburg) uprising, more than 600 Black student protestors were killed. The students were revolting against studying in the Afrikaans language and extension of the apartheid policies into the Education sector.

1983 Parliament approved the representation of Indians and Coloureds (Mixed-race) (who came as slaves with the European colonisers), except Africans. 
1984-1989 The civil unrests and township revolts occurred in African residential areas. The state of emergency was implemented. Different countries around the world imposed trade sanctions against the Republic of South Africa/uMzansi Afrika because of the apartheid policies.

1989 The Indians and Coloureds (Mixed-race) along with whites gained the right to vote in parliament elections. Only Africans could not vote.

1989 One of the leaders of the ANC, Walter Sisulu and other activists who were part of the Rivonia Trial were released from prison after 25 years.

1990 ANC unbanned and Nelson Mandela released from prison after 27 years.

1990 South Africans who were in exiles in different countries began to return to the Republic of South Africa/uMzansi Afrika and peace negotiation amongst different political parties and government began under the Convention for a Democratic South Africa (CODESA).

1991 There was a release of political prisoners and apartheid laws such as the Land Act and the Population Registration Act were repealed and the international trade sanctions against the Republic of South Africa/uMzansi Afrika started to be lifted.

1993 The interim National Constitution of the Republic of South Africa/uMzansi Afrika came into effect.

1994 The ANC under the leadership of Nelson Mandela, won the first ever non-racial democratic elections (April 27 was the first day of the nationwide voting). Africans were granted the vote. The membership of the Republic of South Africa/uMzansi Afrika in the Commonwealth became restored. This marks the official end of the apartheid policies and beginning of reconciliatory processes to compensate indigenous people because of the historical injustices. 
In the Republic of South Africa/uMzansi Afrika, history affects the experiences of indigenous women in the workplace as they move into top-management roles. Historically, they had limited opportunities and were side-lined from the economy of the country. From the early 1990s, the reconciliation process amongst different groups occurred, which increased the opportunities for indigenous people in the workplace. History of the Republic of South Africa/uMzansi Afrika affects the experiences of my participants in the workplace. 


\section{Labour Law Chronology}

In both New Zealand/Aotearoa and the Republic of South Africa/uMzansi Afrika indigenous women in top-management roles have increased opportunities based on the changes in legislation in these countries.

\section{New Zealand/Aotearoa}

Below is the chronology of different policies and legislation impacting on indigenous women in top-management roles to improve their opportunities.

1894 The Industrial Conciliation and Arbitration Act allowed the formation of trade unions and gave women the right to negotiate legally enforceable awards and agreements. Despite this, many awards and agreements had lower rates of pay for females than for males, for the same work (Ministry of Women's Affairs, 2008).

1960 The Government Service Equal Pay Act was passed to eliminate different pay rates for men and women doing the same job in the public sector.

1972 The Equal Pay Act was passed. This legislation extended the right of women to equal pay for the same job in the private sector (McGregor, 2010).

1981 The Amendments of Factories and Commercial Premises Act repealed the prohibition of women's employment on night-shift factories (Ministry of Women's Affairs, 2008).

1983 The Minimum Wage Act was introduced entitling women over 20 years to the same minimum wage as men.

An Equal Employment Opportunities (EEO) Policy was introduced in the public service with four target groups: Māori, ethnic groups, women and people with disabilities. 
1984

1986

1988

1990

1990

Cabinet approved the establishment of the Ministry of Women's Affairs as a separate department of state to advise government on policies focusing on women (Ministry of Women's Affairs, 2008). The Ministry of Women's Affairs was established and in operation.

The State Sector Act required the public service entities to put the Equal Employment Opportunities (EEO) mechanisms in place.

The Employment Equity Act established a mechanism to assess the comparable worth of jobs. This legislation was introduced because the equal pay legislation had not been effective for women to eliminate pay disparities between men and women (McGregor, 2010). It was a process to promote EEO in both the public and private sector employers of 50 or more workers (Mintrom \& True, 2004). To support this initiative a Commission for Employment Equity was established under the Act to ensure employer compliance. The National Party repealed this legislation (Employment Equity Act) six months later.

The Bill of Rights Act 1990 set out basic rights including freedom from discrimination on the grounds of sex and marital status.

The Human Rights Commission Act was passed and amended to include protection from discrimination in the employment matters such as sex, pregnancy, childbirth, sexual orientation, marital status, job advertisement, and application process.

Jenny Shipley became the first woman Prime Minister in New Zealand.

The Employment Relations Act was passed.

The interest accrual was removed from student loans while studying. This was to facilitate obtaining a tertiary qualification for all individuals. Students who accrued interest prior to 2001 were required to pay that interest.

The Equal Opportunities Unit was established in the New Zealand/Aotearoa Human Rights Commission.

The government launched an Action Plan for New Zealand/Aotearoa Women focusing on improving the economic 
dependency of women, achieving greater work-life balance for families and improving the well-being and quality of life of New Zealand/Aotearoa women.

2007 The Employment Relations Act was passed to address flexible work.

Labour Law Chronology - the Republic of South Africa/uMzansi Afrika

The following is a chronology of labour laws in the Republic of South Africa/uMzansi Afrika.

1995

The Labour Relations Act No 66 was promulgated and later its amendments. This legislation amongst others addresses code of good practice by the employer, collective bargaining and freedom of association for employees.

1997 The Basic Conditions of Employment Act 77 of 1997 came into force. This legislation focuses on the regulation of the employment conditions and gives an employee rights as a worker to the workplace.

1998 The Employment Equity Act No 55 of 1998 was adopted. This legislation concentrates on fair and unfair discrimination. It targets Black people, women and people with disabilities as a group that it seeks to affirm in the workplace.

1998 The Skills and Development Act came into force and targets training and development in the workplace. It encourages employers to invest in training and development of individuals for tax incentive purposes and to improve the skill of employees.

2003 The BEE Act 53 of 2004 was adopted and became an umbrella legislation that guides other legislation to promote the condition of Black people, particularly Black women in the workplace. It is both a moral legislation to advance the economic status of indigenous women and as a strategy to advance growth for the country. 
Labour legislation is important because it is in the context of the history of the structure of labour politics. It shapes the context of the labour market in the Republic of South Africa/uMzansi Afrika and New Zealand/New Zealand/Aotearoa. 
Appendix B: Interview Questions 


\section{Interview questions}

\section{Background information}

○ Please explain who you are and where you are from (describe yourself in terms of identity, early life influences, community, etc).

- Please explain your current role in your organisation.

- How long have you been in this role?

- What is the composition of the demographic staff (gender and race) reporting to you?

- What is your educational background?

- How long has it taken you to reach your current level?

○ What was your previous role?

- What were your initial aspirations prior to your current position?

- Did you have a motivation to be in a top-management role? Please explain your answer.

\section{What gender and race identity issues did Black / indigenous women}

\section{experience when they moved into top-management roles?}

- Do you feel being an African / Black / indigenous person has affected your movement into top-management?

○ Do you feel being a woman has affected your movement into topmanagement?

\section{What strategies have Black / indigenous women implemented to enhance} their opportunities to advance into top-management roles?

○ Do you have a strategy to assist your career mobility?

○ On reflection, what strategies do you feel would have assisted you to reach a top-management role earlier?

- What strategies do you use to become effective as an ethnic minority woman in top-management? 
○ Can you tell me some of the influences that have helped you to move into your current top-management role.

○ Did you have any barriers to reach your current level? if so, what were they?

\section{Do Black / indigenous women have professional support?}

Do you have any of the following?

○ Do you have any professional support from any source?

○ Do you have a network?

If yes, what type of network?

If yes, describe your network structure.

○ If yes, describe your network activities and value to you.

○ Do you have a mentor?

- If yes, describe your mentor and the type of support that you receive from your mentor?

- If yes, describe your mentoring relationship / activities with your mentor?

○ Do you have a role model?

○ Are you involved in any activities that uplift other women / Black communities?

\section{How are Black / indigenous women recruited?}

- How were you recruited for this role?

○ Were you approached for this role?

○ Have you always wanted to be in this role?

○ What were your reasons to apply for your current role?

\section{How do Black / indigenous women manage their insider and/ outsider} status/es?

○ How do your values as a Black / and indigenous woman compare with those of your organisation?

- How do your values as a Black / an indigenous woman compare with those of your community?

- How do you feel about being a woman in top-management?

○ How do you feel about being Black / indigenous in top-management? 
- What is important to you as a Black / an indigenous woman in topmanagement?

○ To whom do you attribute your success?

○ Do you sometimes have to deal with competing values with yourself and your organisation because of being a Black / an indigenous woman?

\section{General questions}

○ Do you think that you had to "pay a price" by being where you are now?

○ If yes, what was "your price"?

○ How is your family life affected by your role in top-management?

- Have you ever experienced bullying at work?

- Are there any other issues you would like to discuss?

○ Do you have family support?

\section{Demographic questions}

What is your age group?

$\circ$ younger than 30 years of age

○ $(30-39)$ years of age

○ (40 - 49) years of age

○ $(50-55)$ years of age

$\circ$ (more than 55) years of age

Do you have children?

- Yes / No

If yes, how many children do you have?

If yes, when did you have your first child?

○ How does your timing of having children relate to your professional career times? 
Appendix C: Research information sheets for

a. South Africa

and

b. New Zealand 


\section{RESEARCH INFORMATION SHEET - SOUTH AFRICA}

Research Title: The experiences of Māori and African women moving into topmanagement roles.

My name is Zanele Ndaba. I am a PhD student at the Victoria Management School, Victoria University of Wellington, New Zealand. I am originally from Thokoza Township, Gauteng. I went to New Zealand to conduct PhD studies. I am interested in understanding issues that empower indigenous women. I am also interested in indigenous research collaboration amongst indigenous people. This is my motivation for going to New Zealand to conduct $\mathrm{PhD}$ research.

This research is for my $\mathrm{PhD}$ program in the Victoria Management School at Victoria University of Wellington, New Zealand. The objective of my research is to gather information on the experiences of Māori and African women moving into top-management roles. I would like your consent to participate in my $\mathrm{PhD}$ research. I would like to ask you questions regarding your experiences as an African woman moving into top-management roles. The duration of the interview will be $1 \mathrm{~h} 30 \mathrm{mins}$ to $2 \mathrm{hrs}$. The discussion is confidential, that is, your name, name of your organisation and name of your previous work organisations will not be used and stated in the research. I will not state or use the name of the industry from which your organisation is located. I will use a generic name and title, such as, top manager to describe you as a research participant. The research findings will not identify individuals or organisations. The responses of the participants will be reported in such a manner that it is not possible to identify individuals and organisations. You are free to withdraw from the research anytime before 30 December 2009, that is, the final date that I will analyse the data. From 30 December 2009 it may be difficult to withdraw from the research as I will have completed the data analysis process. 
I request to tape record our conversation or use a typist. If you allow the typist to be present, her or his only role in the interview process is to type the interview. $\mathrm{He} /$ She has signed the confidentiality agreement contract and the copy of the contract is attached to this information leaflet. The typist will not have access to the typed information after the interview. The interview information will be password protected so that only myself will able to access the information. If you choose to agree to be tape recorded, access to the recorded tape will be limited only to myself, as a researcher. The recorded tape will be kept in a locked password-secure file and will be electronically wiped after three years of the date of interview. After the interview, I will transcribe the information on the tape and password protect the transcribed information. I will store the transcribed information in a manner that is not possible to identify the individuals and organisations. I plan to transcribe the information from tapes within two weeks of the date of the interview. I will keep both the transcribed electronic information and written information for three years, after the date of the interview. After three years of the date of the interview, I will destroy all the transcribed research material or I may forward them to you by email, upon your request. The reason for keeping the written documents and the original tape for three years is that I may use the information for publication in academic journals and the publication process may take time. I may discuss the transcribed data with my $\mathrm{PhD}$ supervisors Dr Deborah Jones and Dr Todd Bridgman who are located at the Victoria Management School, Victoria University of Wellington, New Zealand. However, they will not know who said what during the interview.

After the interview, I will forward the transcribed data, that is, contents of the interview to you by email. You are free to amend or edit any part of the interview upon reflection. Then you may email back your comments / amendments / confirmation that the transcribed data is a true reflection of the interview. The results of the research will be a written thesis for the $\mathrm{PhD}$ programme in Management at Victoria University of Wellington, New Zealand. The results of this research may later be published in an academic journal or in any media. A summary report of the $\mathrm{PhD}$ thesis will be available upon request to the email address: zanele.ndaba@vuw.ac.nz or telephone number 00964 
2102497930. You are free to contact me anytime regarding any questions you may have about this research. The details of my supervisors are Dr Deborah Jones and Dr Todd Bridgman at Victoria Management School, Victoria University of Wellington, Wellington, New Zealand. Their contact details are Deborah.jones@vuw.ac.nz at telephone number $006964 \quad 4 \quad 4635731$ and todd.bridgman@vuw.ac.nz at telephone number 0096444635118.

My details are Zanele Ndaba and email address Zanele.ndaba@vuw.ac.nz and telephone number 009642102497930 (New Zealand). My contact details while I'm in South Africa are mobile number . I plan to leave South Africa on the 02 October 2009 to return to New Zealand to complete my data analysis and $\mathrm{PhD}$ studies. 


\section{RESEARCH INFORMATION SHEET - NEW ZEALAND}

Research Title: The experiences of Māori and African women moving into topmanagement roles.

This research is for the $\mathrm{PhD}$ programme at Victoria University of Wellington in the Victoria Management School. The objective of the research is to gather information on the experiences of Māori and African women moving into topmanagement roles. The discussion is confidential, that is, your name, name of your organisation and name of your previous work organisations will not be used and stated. I will not state or use the name of the industry from which your organisation is located. I will use a generic name and title, such as, top manager to describe you as a research participant. You are free to withdraw from the research anytime before 30 June 2009, that is, the final date the data will be analyzed. From 30 June 2009 it may be difficult to withdraw from the research as the data analysis will have been finalised. The duration of the interview will be $1 \mathrm{~h} 30 \mathrm{mins}$ to $2 \mathrm{hrs}$.

I request to tape record our interview. Access to the recorded tape will be limited only to myself, as a researcher. The recorded tape will be kept in a locked file with a security. The recorded tape will be electronically wiped out after three years of the date of the interview. After the interview, I will transcribe the information on the tape and store in a manner that is not possible to identify the individuals and organisations. The transcribed information will be password protected and access to the information will be limited only to myself. I plan to transcribe the information from tapes within two weeks of the date of the interview. I will keep the transcribed information for three years after the date of the interview. The reason for keeping both the written documents and original tape for three years is that I may use the information for publication in academic journals and the publication process may take time. Also, the average duration 
of full time $\mathrm{PhD}$ degree is around (3-4) years at the Victoria University of Wellington. I may discuss the transcribed data with my supervisors Dr Deborah Jones, Dr Todd Bridgman. However, they will not know who said what during the interview. After the interview, I will forward the transcribed data, that is, contents of the interview to you by email. You are free to amend or edit any part of the interview upon reflection. Then you may email back your comments / amendments / confirmation that the transcribed data is a true reflection of the interview.

The research findings will not identify individuals or organisations. The responses of the participants will be reported in such a manner that it is not possible to identify individuals and organisations. The results of the research will be a written thesis for the $\mathrm{PhD}$ programme in Management at Victoria University of Wellington. The results of this research may later be published in an academic journal or in any media. A summary report of the $\mathrm{PhD}$ thesis will be available upon request to the email address: zanele.ndaba@vuw.ac.nz or telephone number 02102497930. You are free to contact me anytime regarding any questions you may have about this research. The details of my supervisors are Dr Deborah Jones, Dr Todd Bridgman at Victoria Management School, Victoria University of Wellington, Wellington. Their contact details are Deborah.jones@vuw.ac.nz at telephone number $04 \quad 463 \quad 5731$ and todd.bridgman@vuw.ac.nz at telephone number 044635118.

My details are Zanele Ndaba, email address Zanele.ndaba@vuw.ac.nz and telephone number 00642102497930. 
Appendix D: Research agreement 


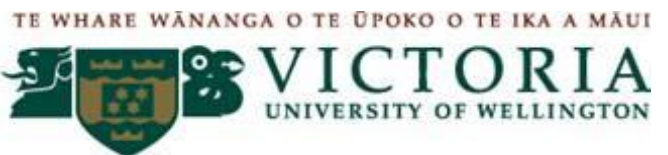

The experiences of Māori and African women moving into top-management roles

The purpose of the research agreement is to obtain evidence of consent.

\section{RESEARCH AGREEMENT}

This is a research agreement with you personally to be interviewed regarding your experiences entering top-management levels.

\section{I agree that :}

$\square$ I have read and understood the information sheet

I I understand that the interview is confidential

I agree to be interviewed and to participate in this research

I I agree to be tape recorded $\mathbf{O R}$

$\square$ I agree for the typist to be present during the interview

\section{Participant's comments}

Write in: any extra comments or conditions, if you have any?

\section{Participant:}

Name of participant:

Signature of participant:

Date :

\begin{tabular}{|l|l|}
\hline \multicolumn{2}{|c|}{ Contact Information } \\
\hline Researcher: & Supervisor: \\
Name: Zanele Ndaba & Associate Professor Deborah Jones \\
PhD Student Victoria Management & Victoria Management School \\
School & Victoria University of Wellington \\
Victoria University of Wellington & New Zealand \\
New Zealand & deborah.jones @ vuw.ac.nz \\
zanele.ndaba@ vuw.ac.nz & 64-4-9719130 \\
00 964 21 02597930 (New Zealand) & \\
or & \\
until 02 October 2009) & \\
\hline
\end{tabular}


Appendix E: Confidentiality Agreement (Typist) 


\section{TYPIST: CONFIDENTIALITY AGREEMENT, SOUTH AFRICA}

The experiences of Māori and African women moving into top-management roles

I

agree not to

divulge in any manner any information I gained during interviews or discussions where I may act as a typist for Zanele Ndaba during her $\mathrm{PhD}$ research at Victoria University of Wellington in New Zealand. I agree to keep confidential the identities of the interviewees as well as any information they may give, which I will type. I understand and agree to the contents of the agreement.

Signature of typist:

Name of typist:

Date of signature:

Contact details of typist:

\section{Contact Information}

\section{Researcher:}

Name: Zanele Ndaba

PhD Student Victoria Management

School

Victoria University of Wellington

New Zealand

zanele.ndaba@vuw.ac.nz

009642102597930 (New Zealand)

or

until 02 October 2009)

\section{Supervisor:}

Associate Professor Deborah Jones

Victoria Management School

Victoria University of Wellington

New Zealand

deborah.jones@vuw.ac.nz

64-4-9719130 